\title{
Managing financial risks: from an institutional to a macro perspective
}

Citation for published version (APA):

Dinh, T. H. T. (2014). Managing financial risks: from an institutional to a macro perspective. [Doctoral Thesis, Maastricht University]. Maastricht University. https://doi.org/10.26481/dis.20141029td

Document status and date:

Published: 01/01/2014

DOI:

10.26481/dis.20141029td

Document Version:

Publisher's PDF, also known as Version of record

\section{Please check the document version of this publication:}

- A submitted manuscript is the version of the article upon submission and before peer-review. There can be important differences between the submitted version and the official published version of record.

People interested in the research are advised to contact the author for the final version of the publication, or visit the DOI to the publisher's website.

- The final author version and the galley proof are versions of the publication after peer review.

- The final published version features the final layout of the paper including the volume, issue and page numbers.

Link to publication

\footnotetext{
General rights rights.

- You may freely distribute the URL identifying the publication in the public portal. please follow below link for the End User Agreement:

www.umlib.nl/taverne-license

Take down policy

If you believe that this document breaches copyright please contact us at:

repository@maastrichtuniversity.nl

providing details and we will investigate your claim.
}

Copyright and moral rights for the publications made accessible in the public portal are retained by the authors and/or other copyright owners and it is a condition of accessing publications that users recognise and abide by the legal requirements associated with these

- Users may download and print one copy of any publication from the public portal for the purpose of private study or research.

- You may not further distribute the material or use it for any profit-making activity or commercial gain

If the publication is distributed under the terms of Article $25 \mathrm{fa}$ of the Dutch Copyright Act, indicated by the "Taverne" license above, 


\section{Managing Financial Risks:}

From An Institutional to A Macro Perspective 


\section{(C) 2014 Dinh Thi Huyen Thanh}

All rights reserved. No part of this publication may be reproduced, stored in a retrieval system, or transmitter, in any form, or by any means, electronic, mechanical, photocopying, recording or otherwise, without the prior permission in writing from the author.

ISBN 978-90-9028517-7 


\title{
Managing Financial Risks:
}

From An Institutional to A Macro Perspective

\author{
Proefschrift \\ ter verkrijging van de graad van doctor \\ aan de Universiteit Maastricht \\ op gezag van de Rector Magnificus, \\ Prof. dr. L.L.G. Soete, \\ volgens het besluit van het College van Decanen, \\ in het openbaar te verdedigen \\ op woensdag 29 oktober 2014 om 16:00 uur \\ door
}

Dinh Thi Huyen Thanh 


\section{Promotor}

Prof. dr. P.M.A. Eichholtz

\section{Copromotors}

Dr. Stefanie Kleimeier

Dr. Stefan Straetmans

\section{Beoordelingscommissie}

Prof. dr. Dennis Bams (chair)

Prof. dr. Christian Wolff

Prof. dr. Rob Bauer

Prof. dr. Tom van Veen

Dr. Chen Zhou

Dit onderzoek werd financieel mogelijk gemaakt door Maastricht Research School of Economics of Technology and Organizations (METEOR). 


\section{Contents}

Contents

Preface $\quad v$

Chapter $1 \quad$ Introduction 1

Institutional financial risk management $\quad 2$

Macro financial risk management $\quad 3$

Chapter 2 When are Consumer Loans Collateralized in Emerging Markets? $\begin{array}{ll}\text { Evidence from Vietnam } & 7\end{array}$

$\begin{array}{ll}\text { 2.1. Introduction } & 7\end{array}$

2.2. Determinants of collateral 9

2.2.1. Collateral and borrower quality 9

2.2.2. Collateral and bank-borrower relationship $\quad 10$

2.3. The Vietnamese banking market 11

2.4. Empirical model and hypotheses 12

$\begin{array}{ll}\text { 2.5. Data and descriptive statistics } & 17\end{array}$

$\begin{array}{ll}\text { 2.6. } & \text { Regression results } \\ & 22\end{array}$

2.6.1. Empirical evidence regarding our hypotheses 22

2.6.2. Economic relevance $\quad 32$

2.6.3. Robustness of the results 34

$\begin{array}{lll}\text { 2.7. Conclusions } & 37\end{array}$

2.8. Appendix 38

Chapter 3 Bank Lending Strategy, Credit Scoring and Financial Crises 41

3.1. Introduction 41

3.2. A credit scoring methodology for retail loans 44

3.2.1. The estimation method 45

3.2.2. Variable identification 45

3.2.3. Variable categorization 48

3.2.4. Variable selection and estimation of the CSM 48

3.2.5. CSM's predictive accuracy 49

3.3. An application to the Vietnamese retail lending market 51

3.3.1. Variable identification $\quad 54$

3.3.2. Variable coding, selection and model estimation 57

3.3.3. Model calibration and out-of-sample assessment 62

$\begin{array}{lll}\text { 3.4. } & \text { Credit scoring and bank strategy } & 67\end{array}$ 
$\begin{array}{ll}\text { 3.4.1. Profitability } & 67\end{array}$

3.4.2. Efficiency in transactional versus relationship lending 68

$\begin{array}{ll}\text { 3.4.3. Risk-based pricing } & 70\end{array}$

$\begin{array}{lll}\text { 3.6. Conclusions } & 73\end{array}$

$\begin{array}{lll}\text { 3.7. Appendix } & 74\end{array}$

Chapter 4 Comparing Tail Risk and Systemic Risk Profiles for Different Types of US Financial Institutions 81

$\begin{array}{ll}\text { 4.1. Introduction } & 81\end{array}$

4.2. Tail risk and Systemic risk Indicators 85

4.2.1. Univariate tail risk indicators $\quad 85$

4.2.2. "Extreme systematic" risk indicator or Tail- $\beta$

4.3. Tail risk and systemic risk estimation 89

4.3.1. Estimating tail risk measures $\quad 89$

4.3.2. Estimating the systemic risk indicator (Tail- $\beta$ ) 90

\begin{tabular}{ll} 
4.4. & Empirical results \\
\hline
\end{tabular}

4.4.1. Tail risk and systemic risk $\quad 94$

4.4.2. Size as a potential driver of tail risk and systemic risk 102

$\begin{array}{ll}\text { 4.5. Conclusions } & 107\end{array}$

$\begin{array}{ll}\text { 4.6. Appendix } & 108\end{array}$

Chapter 5 Extreme Risks and The Business Cycle 113

$\begin{array}{lll}\text { 5.1. Introduction } & 113\end{array}$

5.2. Extreme linkages: probability theory and regime dependence 117

5.2.1. Probability theory 117

5.2.2. Mixtures of tail models 122

$\begin{array}{ll}\text { 5.3. } & \text { Estimation and hypothesis testing } \\ & 123\end{array}$

5.3.1. Semi-parametric estimation procedures $\quad 124$

5.3.2. Hypothesis testing 126

$\begin{array}{ll}\text { 5.4. Empirical results } & 126\end{array}$

5.4.1. Data description $\quad 127$

5.4.2. Extreme downside risk for different asset classes and the business cycle $\quad 127$

5.4.3. Systemic instability and the business cycle 131

5.4.4. Co-crash versus Flight-to-quality effects and the business cycle 134

5.4.5. Minimizing portfolio tail risk 137

$\begin{array}{lll}\text { 5.5. Conclusions } & 140\end{array}$ 
Chapter 6 General Concluding Remarks

$\begin{array}{lll}\text { Chapter } 7 & \text { Valorization } & 145\end{array}$

$\begin{array}{lr}\text { Nederlandse samenvatting } & 149\end{array}$

$\begin{array}{lr}\text { Biography } & 153\end{array}$

$\begin{array}{ll}\text { References } & 155\end{array}$ 



\section{Preface}

Looking back the past years as a PhD student, I realize that I have learnt a lot, both on a professional level, and on a personal level. I also realize that it would not have been possible to finish this thesis without the help and support of the kind people around me. Although it is not possible to name them all, I would like to thank some of the most important ones.

My first words of gratitude go to my supervisors Stefanie Kleimeier and Stefan Straetmans for all their help, patience and continuous support that guided me throughout the process of writing this thesis. Without their good advice, motivation and enthusiasm I would not be able to reach this stage of writing these words. Furthermore, I would like to thank my promoter Piet Eichholtz for his constructive guidance and advice through my $\mathrm{PhD}$.

My other co-author, Christa Hainz should not be forgotten. It was a pleasure to write a paper with Christa and I have enjoyed the time that we spent together for the paper in Munich very much.

I want to express my gratitude to the members of my assessment committee Dennis Bams, Christian Wolff, Tom van Veen's, Chen Zhou and Rob Bauer for their great comments and suggestions on the manuscript.

I would like to thank all my friends and colleagues at the Finance Department of Maastricht University who shared my experience and supported me throughout my thesis. Sajid, thank you for being very kind and supportive and for various insightful discussions. Sally and Andrea, thank you for accepting to serve as paranymphs on my thesis defense. A word of thanks goes to other colleagues: Anna, Erkan, Gaby, Lei, Michael, Mukul, Oana, Rogier and Simone. Many thanks to Francien, Carina, Ells and Cécile who assisted me with administrative duties whenever they could, especially in the last phase of my $\mathrm{PhD}$.

In addition, I would like to thank my Vietnamese friends in Eindhoven for making us feel always like home here in the Netherlands. Thank you Peter, Inge and their children for their continuous friendship and support and also for their personal contribution to this thesis in form of the Dutch summary. I also would like to thank my colleagues in De Lage Landen for their support and for providing me a great balance between research and practice. 
My biggest thanks go to my family. I would like to thank my parents in-law who always love and support me as if I am their own daughter. I want to thank Đức 'tồ' who personally contributed to this thesis in designing the front page and putting the thesis format in a better shape. A special thank to my Mom, my Dad, my brother and his family, without their support, their love and their trust in me I would never be able to make it this far, also geographical distance-wise ;). Finally, I would like to say my special thanks to my husband and my daughter for being the endless source of love, support and motivation through all my ups and downs, thank you for being the very bright part of my life. 


\section{Chapter 1 \\ Introduction}

Risk management began to be studied after World War II. Several sources (Crockford, 1982; Harrington and Neihaus, 2003) date the origin of modern risk management to 1955-1964. Prior to that time there were no references found in textbooks about risk management and no business schools offered courses in the subject. Risk management was first associated with the use of insurance to cover various losses associated with accidents (Harrington and Neihaus, 2003). During the 1970s derivatives were introduced as innovative risk management instruments. During the 1980s the use of derivatives expanded rapidly as companies intensified their risk management. It was also in the 1980s when companies began to pay attention to financial risk management.

Concomitantly, new statistical tools were put in place in financial institutions to facilitate the assessment of default and credit risk, to facilitate risk based pricing (e.g. credit scoring) and to manage credit risk. In 1994 and 1997 JP Morgan developed the two well-known internal risk management models - RiskMetrics for market risk and CreditMetrics for credit risk. The publication of the RiskMetrics model spread the Value-at-Risk (VaR) rapidly among practitioners and academics. These new risk management tools are important instruments to calculate banks' regulatory capital.

Regulators also started to focus on risk with the Basel I Accord of 1988 as a first key regulatory benchmark. After a series of credit risk crises - the Asian crisis, the Russian crisis and the collapse of Long Term Capital Management - in the late 1990s risk management became a corporate affair and adequate capital reserves became a major concern. Basel II introduced more rigorous rules but authorized banks to use internal models in calculating their regular capital. Financial institutions developed internal risk management models to be Basel compliant and to formulate capital calculation to hedge against unanticipated risks and reduce regulatory capital. In the wake of various scandals and bankruptcies resulting from poor risk management, the Sarbanes-Oxley regulation was introduced in the United State in 2002. Stock exchanges also added risk management governance rules for listed companies (Blanchard and Dionne, 2003).

However, these regulations, rules, and added risk management methods did not suffice to prevent the financial crisis that began in 2007. The roots of the crisis go back much further, and there are various views on the fundamental causes. In his report prepared for the members of Congress in the US, Jickling (2010) presents a number of factors that have been identified as causes of the crisis: from the credit standards in U.S. mortgage lending that were relaxed in the early 2000s to the 
long-term developments in financial markets to blame for the instability. In this dissertation, we strive to provide a better understanding on these factors: we investigate risk management both at the institutional level as well as at the macro level. To that aim, we focus our research on four factors out of those presented in Jickling (2010): "Securitization" and "Bad computer models" as institutional risk management and "No systemic risk regulator" and "Tail risk" as macro risk management. In this dissertation: (i) we show under which circumstances banks require credit support, e.g. collateral, for borrowers (Chapter 2); (ii) we demonstrate how to overcome the limitations of credit scoring models to sustain their performance over the recent financial crisis period (Chapter 3); (iii) we discuss the systemic risk and tail risk in US financial institutions (Chapter 4); (iv) we analyze the co-movements of these risk measures among different asset classes across different business cycle regimes (Chapter 5). In the next section, I outline each chapter briefly by presenting the background, the research questions, followed by discussions on the most important findings and their implications.

\section{The institutional financial risk management}

Chapter 2 studies factors that influence the decision to securitize a consumer loan with collateral. Collateral is one of the key features of a loan contract together with the loan's interest rate, maturity, size and possible covenants. Theories about the use of collateral, however, are contradicting and the empirical literature has not yet helped to settle important issues such as whether collateral signals a more risky or a safer loan, or whether relationship banking increases or decreases the use of collateral. In addition, very little is known about how macro-economic conditions affect the use of collateral. Most of the existing studies on collateral examine business loans and thus very little is known about securitization of consumer loans. Thanks to a unique data set, we are able to examine as-of-yet unexplored determinants of collateral for consumer loans and we provide a sharper test of the relation between collateral use and a borrower's credit risk. To be more specific: we consider the determinants of the incidence of collateral and the degree of collateral with specific focus on the role of the borrower's ex ante credit risk as perceived by the bank, the borrower's ability to pledge collateral and the bankborrower relationship. We find that lenders are more likely to require collateral from ex-ante riskier borrowers. At the same time, borrowers with ability to pledge collaterals prefer securitized loans in order to benefit from a reduction in their interest costs. The strength of the relationship between banks and borrowers influences the use of collateral. However, the scale and scope of the relationship have opposite impacts: while the scale increases the use of collateral due to the hold-up effect, the scope decreases the incidence of collateral due to a reduction in information asymmetry. The use of collateral also increases significantly during economic downturns. 
As aforementioned banks started to develop internal models - Credit Scoring Models (CSM) - to help select borrowers in the late 1980s. The rules newly introduced in Basel II that authorized banks to use internal CSMs in calculating regular capital have further prompted the attention of financial institutions towards CSMs. Furthermore, nowadays reversing credit rationing in a responsible manner is a vitally important step towards mitigating the tremendous impact of the global financial crisis on the corporate and retail sector. An effective credit decision system that enables sound lending decisions is a critical part of the solution. CSMs are central components of such a system. They are key to bank's survival and profitability in this new and constantly changing environment. However, the global environment has experienced a fundamental shift due to the crisis and that the existing CSMs which were built on data collected during a period of economic strength probably no longer function as they once did. In Chapter 3 we examine the impacts of the global financial crisis on CSMs and outline how those models need to be adjusted to ensure that credit providers can avoid an onset of delinquencies and bad debt. We also outlines how CSMs can be utilized to improve credit quality and consequently to increase profitability and efficiency of the lending business. To be more specific, we estimate separate CSMs for a pre-crisis, crisis and post crisis period, respectively. Firstly, we note that the predictors of default change over time. For example, post-crisis personal information appears to lose importance and is no longer predictive, whereas information about bank-borrower relationships becomes more predictive of default. Characteristics of the bankborrower relationship represent soft information that cannot be observed directly but persists over the crisis whereas the value of hard information, e.g., borrower characteristics, diminishes with fundamental economic changes triggered by the crisis. Second, we assess the performance of these different models on a post-crisis holdout sample. In this way, we put ourselves in the position of a loan officer required to assess the unknown ex-ante creditworthiness of a loan applicant in 2011. Different performance measurements are deployed such as power statistics (ROC, GINI) and accuracy rates (PCC, Sensitivity and Specificity) to assess the accuracy of different models with ex-post observed defaults. We then hypothetically replicate the bank strategies and show that an updated model can maximize a bank's profit by more accurately identifying defaults, increasing efficiency by reducing the manual assessment, and increasing its competitiveness by more precise risk-based pricing.

\section{Macro financial risk management}

In Chapters 4 and 5 we investigate alternative measures of tail risk and systemic risk for financial institutions (chapter 4) or, more generally, to assess systemic instability and risk spillovers in financial markets (chapter 5). We therefore put statistical extreme value analysis at work in order to capture the low frequency 
character of crises and crisis spillovers in financial markets. In Chapter 4 we question whether the risk of financial institutions - either the idiosyncratic tail risk or the systemic risk - depends on the type of financial institutions. In line with Acharya et al. (2010) and Brownlees and Engle (2011) we distinguished between deposit banks, insurance companies, and broker-dealers (investment banks) with an eye towards tail risk and systemic risk measurement. Given the cross-industry differences in business models, it is to be expected that the type of financial industry partly determine their risk taking behavior. We observe that the tail risk and systemic risk indeed differs quite substantially across different types of financial institutions. Moreover, tail risk and systemic risk tell fundamentally different stories if one wants to use these risk dimensions as inputs for financial regulation. More specifically, the ranking of financial institutions on the basis of tail risk vs. systemic risk is substantially different. Whereas the insurance industry seems to exhibit most tail risk, deposit banks seem to contribute most to systemic instability. The latter outcome is somewhat surprising given the popular perception that broker-dealers played a crucial role in triggering the banking crisis. We also find that rankings of financial institutions according to tail risk or systemic risk measures stay relatively stable over time. In other words, although tail risk and systemic risk can vary quite a lot over time, the positioning of institutions relative to each other is not dramatically changed over time. Finally, size proxies seem to correlate with systemic risk although the outcomes differ a lot depending on the used size proxies and considered subsamples (full sample, pre-crisis or crisis).

In Chapter 5 we investigate whether extreme risks (e.g. a single banking crisis) and risk comovements (e.g. a systemic banking crisis) are more likely to happen during recession phases of the business cycle. From a methodological point of view, we introduce regime dependence within the statistical theory of extremes (EVT). Traditionally, EVT assumes that all data come from one and the same underlying unconditional (long-term) distribution that stays invariant over time. We allow for regime changes in the parameters that govern the univariate (power law type) and multivariate (tail copula) behavior. In the empirical application, we construct recession and expansion subsamples in the financial data and perform subsample analyses for our indicators of tail risk and tail risk spillovers (systemic risk). We do not solely apply these concepts to the tails of bank equity losses but also to a variety of other financial assets. First, we find that tail risk rises during recessions for a variety of financial assets (stocks, bonds, currencies and commodities). Next, also market-based indicators of bank systemic risk rise during recessions. Third, upon comparing the likelihood of co-crashes between stocks, bonds or gold vs. the likelihood of flight-to-quality from stocks into bonds or gold, the spread between flight-to-quality and co-crash likelihoods widens during recessions. Finally, diversifying portfolio tail risk becomes more difficult during recessions because both (linear) correlations and general tail dependence across assets rises during 
periods of economic recession. In other words, diversification meltdowns do not only happen during periods of high financial market volatility but do also depend on the state of the real economy. 

Chapter 2

\section{When are Consumer Loans Collateralized in Emerging Markets? Evidence from Vietnam ${ }^{1}$}

\subsection{Introduction}

While there is a significant amount of research addressing the role as well as the determinants of collateral for commercial loans, there is little empirical work on the factors that affect decisions to pledge collateral for consumer loans. Theoreticians have argued that collateralization is a useful tool in resolving asymmetric information problems associated with both adverse selection and moral hazard and providing respite against default and bankruptcy loss. Empirical evidence based on accounting data supports these arguments for commercial loans. In contrast, evidence for consumer loans is not available due to the fact that public information about individual borrowers is almost impossible to obtain. However, in consumer lending the information asymmetry problem is especially severe and collateral is thus essential. Using a unique and confidential dataset of more than 30,000 consumer loans from one of the largest private banks in Vietnam, we are able to answer the following questions regarding the choice between collateralized and uncollateralized consumer loans: Does the bank require riskier borrowers to pledge collateral? How does the availability of pledgable assets influence the borrower's loan choice? How does the relationship between bank and borrower influence the loan choice?

Our analysis contributes to the understanding of the consumer banking market in a developing country, e.g. Vietnam, which is currently engaging in a process of economic liberalization. Prior empirical evidence on collateral almost exclusively focusses with developed economies with a few exceptions for Thailand (Menkhoff et al., 2006) and Mexico (La Porta et al., 2003). In emerging markets with potentially severely underdeveloped financial systems, information asymmetry problems between borrowers and lenders are severe and collateral is an important instrument of dealing with these information asymmetry problems. At the same time, however, collateral might only provide weak protection in case of borrower default if loan contracts cannot be fully enforced in emerging countries with weak legal systems (Menkhoff et al., 2006). Given these counteracting forces, we expect collateral to play a different role in emerging than in developed economies. As

\footnotetext{
${ }^{1}$ This chapter is based on 'When are Consumer Loans Collateralized in Emerging Markets? Evidence from Vietnam' co-authored with Stefanie Kleimeier and Christa Hainz.
} 
such, we cannot assume that existing developed-market evidence on the use of collateral is also valid in emerging markets. An investigation of the use of collateral in emerging markets is therefore essential.

Drawing on current theories, we empirically model the use of collateral as a function of borrower characteristics such as ex-ante credit quality, wealth and age of the borrower, loan characteristics such as loan amount and duration, the scale and scope of the borrower-lender relationship, credit market characteristics and regional governance conditions. We test this comprehensive model for the determinants of collateral using cross-sectional data on 32,655 consumer loans granted between 2007 and 2011 to Vietnamese borrowers. In line with the major empirical findings for commercial loans in developed markets we find, first, that the likelihood of pledging collateral is higher among borrowers who are observed by the bank as ex ante riskier borrowers. We also find that among borrowers with the same level of observed risk, wealthier borrowers are more often pledging collateral. In addition, the bank-borrower relationship matters. The scale and scope of this relationship have opposite effects on collateral: collateral increases with the duration of the relationship and number of prior loans, and decreases in its scope which is measured by the number of different services that the borrower purchases from the bank.

Our paper makes three main contributions. First, we use data on consumer loans in an emerging market. Thereby, we can obtain new insights that differ from those papers that study corporate loans mostly in developed markets. Second, this study is among a few (Elsas et al., 2000; Macheuer et al., 1998) that use an internal ex ante credit risk score, which directly reflects how the bank observes a borrower's credit profile. This allows us to better test the observed risk hypothesis than most previous studies. Indeed, our results are consistent with the idea that observationally riskier borrowers are more likely to pledge collateral. Finally, we observe information regarding the borrower's wealth. This allows us to differentiate between the bank's requirement to pledge collateral for risky borrowers and the borrowers' ability to pledge collateral.

The paper is structured as follows: Section 2 provides an overview of the relevant existing theory and empirical evidence on the determinants of collateral use focusing on the borrower quality and the bank-borrower relationship. Section 3 describes the Vietnamese banking market. Section 4 presents our empirical model and derives our hypotheses. Section 5 describes the data, variables and methodology. We present the results of our empirical analysis in section 6 . Section 7 concludes. 


\subsection{Determinants of collateral}

\subsubsection{Collateral and borrower quality}

Collateral is a defining feature of the loan contract, together with the interest rate, maturity, size, and any possible covenants. Drawing from current theories, collateral helps banks to solve two main problems. First, liquidating collateral in case of default limits a bank's losses. Second, collateral can solve the problem of asymmetric information between banks and borrowers arising when borrowers own private information that is not available to banks. Theories about collateral solving the asymmetric information problem can be divided into two main streams. First, collateral can be used as a signaling instrument providing banks with valuable information about the borrower's quality that would not be available otherwise. High-quality borrowers who have private information about their good creditworthiness know that their likelihood of loan default and consequent loss of their collateral are unlikely. Therefore, high-quality borrowers are more willing to pledge collateral in return for more favorable contract terms than low-quality borrowers (Stiglitz and Weiss, 1981; Bester, 1985; Chan and Kanatas, 1985; Besanko and Thako, 1987). Banks offer a menu of contracts to borrowers: one loan contract with high collateral and low interest rate and another loan contract with low collateral and high interest rate. Borrowers choose their preferred contract and signal their status as high-quality borrowers when selecting the collateralized loan. Second, collateral helps to solve the problem of moral hazard after the loan is granted (Booth et al., 1991). Collateral provides an incentive to borrowers to exert optimal effort, as their payoff in the case of default is lower with collateral than without collateral. The presence of collateral is therefore associated with lower ex-post default. In general, these quality-signaling theories that view collateral as a solution to the asymmetric information problem predict a negative relation between presence of collateral and the borrower's risk level, both ex-ante and ex-post.

However, collateral requires monitoring and increases legal costs that reduce the benefit of collateral for a bank. More importantly and contradictory to the arguments of the asymmetric information theories, there is a common view among bankers that collateral is associated with riskier borrowers (Berger and Udell, 1990; Jimenez and Saurina, 2004; Inderst and Mueller, 2006). The observed-risk hypothesis reflects this view and argues that banks are able to identify risky borrowers through ex-ante screening. Since collateral helps to reduce the loss given default, banks require more collateral from borrowers with higher default risk. 
Although a substantial amount of empirical work is devoted to banking issues, there are only a limited number of studies investigating the determinants of collateral in bank loans. Moreover, this scarce empirical literature has not settled whether collateral is associated with riskier or safer borrowers. On one hand, empirical studies explain the use of collateral as a consequence of adverse selection and/or moral hazard and conclude that the presence of collateral is a signal of safe borrowers. In this context, Jimenez, Salas, and Saurina (2006) find that the possibility of using collateral to signal credit quality occurs mainly among young borrowers who have no previous record of financial or commercial activities. Focusing on the associations between collateral, banking relationship and risk premium, Degryse and Van Cayseele (2000) find a negative link between the presence of collateral and the loan's interest rate (a proxy for risk premium) for a sample of 18,000 Belgian loans. On the other hand, the majority of studies find that collateral is associated with high-risk borrowers and therefore support the observed-risk hypothesis. In an early study Berger and Udell (1990) investigate the relationship between collateral and credit risk for a sample of one million loans from US banks and find that banks require more collateral from risky borrowers while at the same time charging them higher interest rates. Jimenez and Saurina (2004) analyze 3 million loans provided by Spanish banks and find a positive relation between the ex post credit risk and the presence of collateral. Booth and Booth (2006) examine the relation between the borrowing cost and the presence of collateral for sample of 977 US loans raised between 1987 and 1989 and find that a number of observable risk characteristics are related to the probability that a loan is secured. Regarding emerging markets La Porta et al. (2003) and Menkhoff et al. (2006) tentatively confirm the observedrisk hypothesis for Mexico and Thailand and we thus consider ex ante risk as one of the core determinants of collateralization in our sample of Vietnamese consumer loans.

\subsubsection{Collateral and bank-borrower relationship}

The theories and empirical studies of relationship lending are also inconclusive about the influence of bank-borrower relationships on collateral (Greenbaum et al., 1989; Sharpe, 1990; Boot et al., 1994). On the one hand, the strength of the bank-borrower relationship indicates the degree of information asymmetry between bank and borrower. Thus, the incidence of collateral should decline with the strength of the relationship, e.g. with the reduction in the information asymmetry. On the other hand, the ability of the bank to privately observe proprietary information about the borrower can generate a lock-in problem, e.g. a situation where it is costly for the borrower to switch to another lender. In this case the incidence of collateral should increase with the strength of the 
relationship (Sharpe, 1990; Rajan, 1992). Proxies for the intensity of the bankborrower relationship consist of scale proxies including the duration of the relationship (Dianmon, 1991; Petersen et al., 1994) and the number of prior loans as well as scope proxies such as the number of bank products used by the borrower.

The empirical evidence regarding the influence of bank-borrower relationships on collateral is limited to corporate lending. Using the 1987 NSSBF data, Berger and Udell (1995) find that in the US the use of collateral falls with the length of the bank-borrower relationship. Chakraborty and Hu (2006) use the 1993 NSSBF data and share the same conclusion. Moreover, they find that the use of collateral decreases with the scope of the relationship. Degryse and Cayseele's (2000) findings based on European data also indicate that collateral requirements decrease with the duration of relationship and increase with its scope. In line with the locked-in hypothesis, Elsas and Krahnen (2000), Lehmann and Neuberger (2001) and Machauer and Weber (1998) document a higher fraction of collateralized loans when borrowing from a housebank. Regarding emerging markets, La Porta et al. (2003) find that the incidence and degree of collateral are significantly lower for Mexican borrowers with a strong bank relationship. Menkhoff et al. (2006) analyze 560 credit files of Thai commercial banks. As long credit relationships do not reduce collateral requirement, they conclude that market imperfections result in a lock-up effect for housebank borrowers in Thailand. Overall, the evidence on the relationship between bank-borrower relationships and collateral is inconclusive.

\subsection{The Vietnamese banking market}

In 1987, Vietnam started its transformation to a market economy. Part of this process is the replacement of the monopoly of state-owned banks by a two-level banking system consisting of a national central bank on one level and state-owned as well as commercial banks on another level. ${ }^{2}$ Projects to modernize the interbank market, to create an international accounting system, and to allow outside audits of major Vietnamese banks are ongoing. However, the banking system continues to suffer from lack of capital, inadequate provisions for possible loan losses, low profitability, inexperience in capital markets, and the slow pace of institutional reform. With respect to risk assessment and management, there are numerous difficulties including a lack of transparency in non-performing loan

\footnotetext{
${ }^{2}$ In 2005, this second level of the Vietnamese banking system contained five state-owned commercial banks, one social policy bank, 31 foreign bank branches, 40 foreign credit institution representative offices, five joint-venture commercial banks, 36 domestic joint-stock commercial banks, seven finance companies, and the Central People's Credit Fund System with 23 branches and 888 local credit funds.
} 
disclosure. In order to improve risk management in light of Basel II, Vietnam's central bank has been reviewing its risk management regulations. As part of a broader strategy - which also addresses the banks' business strategy, assets and liability management, and internal audit - all state-owned commercial banks and joint-stock commercial banks have been asked to develop a comprehensive credit manual which takes international practices in risk management into account.

In this double-level banking system, the national central bank is not engaged any more in trading activities, nor is it directly involved in the process of acquiring or locating capital in the banking and financial market. Commercial banks and other financial companies perform these activities. These banks also provide banking services to corporations and individuals including traditional services like payment transactions, deposit taking, lending, issuing credit and debit cards and modern services like Internet banking. This second level is dominated by the state owned commercial banks, which accounts for almost of $80 \%$ of commercial bank operations in Vietnam in 2005. However, despite the inadequacy of the legal framework and transitional problems, private commercial banks have made significant progress due to their more customer-oriented approach and distinct profit motive.

Among commercial banks in Vietnam, about $60 \%$ to $70 \%$ of a bank's capital assets are employed for lending activities and profit from lending accounts for a major part of bank's total profit. Strategically these banks focus on the retail sector, i.e. lending to consumers, entrepreneurs, and SMEs. During Vietnam's recent period of high economic growth and transformation to a market economy, there has been an increasing demand of loans from the retail sector. Lending volumes have grown substantially since 1990 and although state owned enterprises are still the dominant users of credit, their share in bank credit fell from $86 \%$ in 1991-1992 to 58\% in December 2005 due to growing loan demand from retail borrowers. Within the retail credit sector, joint stock commercial banks play an important role as they account for more than $50 \%$ of outstanding loan value. Nevertheless, consumer credit continues to encounter barriers to growth due to, for example, the unreliable credit rating systems and complicated application procedures in Vietnam. However, the government and other financial institutions are expected to increase their efforts to resolve these issues in the near future.

Due to its strategic focus on retail lending, i.e. on consumer lending, the bank from which our data originates has developed competencies regarding the risk assessment during the initial screening of its borrowers. As a first step in the process of credit approval at the bank, borrowers have to complete a loan application form which requires personal information (age, address, occupation, 
marital status, relation with any other bank, income, home ownership, etc.) as well as information about the desired loan (amount, purpose, etc). Secondly, all information provided by the borrowers is certified by the bank regarding its correctness. Thirdly, a set of quantitative rules is used by credit officers as a benchmark for their lending decision. Generally, if the requested loan amount is less than 100 million Vietnamese dong (VND, approximately 3,000 euro) and all the criteria are met at the minimum required level then the loan application will be approved without requiring collateral. If the loan amount is more than 100 million VND then all criteria will be assessed at a more critical level and a collateral requirement becomes more likely. The criteria that the bank uses to assess their borrowers include the borrower's monthly income, her occupation, years with the current employer, the industry of occupation, etc. These criteria are combined into a simple ex ante risk score. For more detailed information about how this score is computed, please refer to Table 2.A1 in the appendix. Recently, the bank has implemented a sophisticated credit scoring system in some of its branches to replace the existing set of rules. We also consider this new risk score generated when testing the robustness of the impact of the ex ante risk score measure on the collateral use.

\subsection{Empirical model and hypotheses}

We model collateral as determined by borrower characteristics, the bank-borrower relationship, economic conditions and controls for loan characteristics, bank branch operational characteristics and regional governance characteristics. We use a Probit regression model to estimate the probability of a loan being secured by collateral. Our dependent variable is a binary variable Collateral $_{D}$, which takes the value of one if a loan is collateralized and zero otherwise. The probability of a loan being secured is thus given by equation (1) where $\Phi$ is the standard normal distribution function.

$\operatorname{Prob}\left(\right.$ Collateral $\left._{\mathrm{D}}=1\right)=\Phi\left(\alpha+\sum_{i} \beta_{i}\right.$ Borrower $_{\text {characteristics }}+$ $\sum_{j} \gamma_{j}$ Bank Borrower Relationship Characteristics ${ }_{j}+$

$\sum_{k} \delta_{k}$ Economic Conditions $_{k}+\sum_{l} \mu_{l}$ Controls $_{l}+\sum_{m} \rho_{m}$ Time Dummies $\left._{m}+\varepsilon\right)$

Borrower characteristics include the borrower's Ex ante risk score as described in Table 2.A1 in the appendix, a dummy Home owner ${ }_{D}$ indicating whether the borrower owns rather than rents her place of residence and the borrower's Age. The scale of the bank-borrower relationship is measured by the number of Years with bank and the Number of prior loans that the borrower obtained from the bank. The scope of the bank-borrower relationship is indicated by the Number of bank products that the customer purchases from the bank, a dummy indicating if the 
borrower has a business relationship with another bank (Other bank $k_{D}$ ) and a dummy indicating whether the borrower is from the neighborhood where the bank branch is located (Local borrower $_{D}$ ). The proxy for economic conditions in Vietnam is the Base rate, a policy tool used by Vietnam State Bank.

We include three sets of control variables to measure loan, bank branch and regional characteristics. Loan characteristics include proxies for Loan duration and Loan size. We include bank branch controls as our data consists of loans from one bank with a large number of branches spread over the country. We specifically control for the operational characteristics of branches by the distance from their the headquarter (Distance to headquarter) and by a dummy to indicate whether the branch is a main branch in the province $\left(\right.$ Main branch $\left._{D}\right){ }^{3}$ We consider two regional control variables. First, the Provincial legal index measures how transparent and supportive the provincial legal framework is toward enterprises. A higher value indicates a more supportive legal framework. Second, a dummy

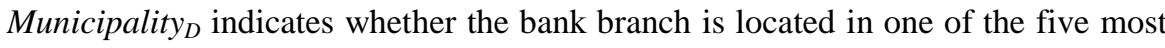
economically developed municipalities in Vietnam. Finally, we include year dummies indicating the time of loan signing. Details on the definitions of all variables can be found in Table 2.A2 in the appendix.

Next to the incidence of collateral modeled in equation (2.1), we also analyze the degree of collateral using a Tobit model. We construct an index, which is based on the collateral value to loan value ratio and ranges from zero to five with higher values indicating a higher degree of collateral. Since this collateral index contains a cluster of zeros, OLS would result in biased and inconsistent coefficients and the Tobit model as an extension of a censored regression model is an appropriate choice (Elsas et al., 2000; Lehmann et al., 2001; La Porta et al., 2003). In order to reduce the impact of outliers, i.e. loans with very high collateral to loan ratio, we use a Collateral index instead.

Predictions regarding the independent variables are derived from the previous theoretical and empirical research on the determinants of collateral. We focus our testable hypotheses on three main determinants: borrower quality, the bankborrower relationship and economic conditions. First, for consumer loans in an emerging market, the information asymmetry problem can be quite severe and a lender might therefore heavily rely on collateral to overcome the information asymmetry problem and to reduce loss given default. It is therefore particularly

\footnotetext{
${ }^{3}$ In each city or province, the bank operates several branches and generally considers one of them - or two in big cities or provinces - as a main branch. These main branches have more authority regarding loan decisions e.g. authority to approve larger loans or to approve higher interest rate reduction.
} 
important in our paper to test hypotheses between collateral and borrower quality. Second, in emerging markets the bank-borrower relationship plays a very important role. Thus, it is critical to understand how the bank-borrower relationship influences the use of collateral. Third, the recent financial crisis has dramatically changed the economic conditions and we want to study how this influences the use of collateral.

First, we hypothesize that borrowers that the bank observed as more risky are more likely to pledge collateral. This hypothesis is directly based on the observed risk argument and in line with empirical findings (Boot et al., 1991; Berger and Udell, 1990; Jimenez and Saurina, 2004). In contrast to these studies that use proxies for ex ante default risk, we can directly observe the Ex ante risk score of each borrower and thus directly measure the credit quality as perceived by the bank. The higher the score the lower the borrower's credit risk. A positive coefficient for this proxy indicates that the observed risk hypothesis holds.

Second, we hypothesize that given the same observed credit quality, wealthier borrowers are more likely to pledge collateral in order to benefit from a lower borrowing rate. This hypothesis is based on the quality signaling argument and the menu of loan contracts that is offered (Bester, 1985; Chan and Kanatas, 1985; Besanko and Thakor, 1987a). Knowing that secured loans will be charged a lower interest rate, borrowers who are able to pledge collateral have a strong incentive to do so. Collateral in Vietnam is typically provided in form of real estate. Thus, we proxy the ability to pledge collateral by a dummy variable that indicates whether the borrower owns his place of residence. In addition, Age of borrower is also included as a simple proxy for wealth.

Third, we hypothesize that the likelihood of pledging collateral decreases with the length of the borrower-lender relationship if the benefits of relationship lending dominate and increases with the length of the relationship if the costs of the "holdup" problem dominate. This hypothesis is based on studies about the effect of relationship lending on the likelihood of collateral (Boot, 2000; Berger and Udell, 2002, Jimenez et al, 2006). In addition, Boot et al. (1991) find that collateral can be a solution to problems of moral hazard and Boot and Thakor (1994) show that relationship lending can be viewed as a substitute for collateral in terms of reducing moral hazard as the repeated interaction between borrowers and lenders helps to build trust. In this case, Years with bank or Number of prior loans should carry a negative coefficient. In contrast, bank borrower relationships can result in a higher likelihood of collateral use if severe hold-up problems exist (Greenbaum et al, 1989; Sharpe, 1990; Rajan, 1992, Farinha and Santos, 2002). If so, the coefficient of Years with bank or Number of prior loans should be positive. 
Moreover, as another aspect of the borrower-lender relationship, we include Other $\operatorname{bank}_{D}$ indicating whether or not the borrower has a relation with other banks. When there is competition among lenders or when there are various sources of lending, there is a smaller hold-up effect. One last characteristic of the borrowerlender relationship that can influence the hold-up effect is the dummy Local borrower $_{D}$ which indicates whether the borrower comes from the area where the branch locates as the bank can easily value and monitor the collateral and the borrower.

Fourth, we hypothesize that the likelihood of collateral decreases with the number of different financial services that a borrower purchases from the bank. We base this hypothesis on a number of studies that differentiate between the scale and scope of the lending relationship and the use of collateral (Degryse and Cayseele, 2000; Petersen and Rajan, 1994; Chakraborty and $\mathrm{Hu}$, 2000). We focus on the scale of a lending relationship in hypothesis three. Regarding the scope of the lending relationship we consider that lenders have better access to private information when borrowers use non-loan financial services (such as checking accounts, saving accounts, or other financial services). This information can easily be quantified, transmitted, and combined with other available information to effectively assess different aspects of the borrower's profile. An increased scope should therefore reduce the need for collateral. We measure the scope with the Number of bank products used by the borrower, which can consist of a saving account, a current debit account and a credit card. We predict a negative coefficient for this explanatory variable.

Fifth, we hypothesize that the use of collateral increases during economic downturns. It is commonly believed that uncertainty increases during economic downturns and that banks would require more collateral to overcome the increase in adverse selection and moral hazard problems as well as reduce loss given default. To the best of our knowledge, Jiminez (2006) is the only study that investigates the relation between the use of collateral and economic conditions using GDP and interest rates to proxy for economic conditions. Our data allows us to test this hypothesis in two ways: First, since our sample period includes the 2007/08 banking crisis, we can use time dummies to identify when the crisis hit the Vietnamese banking market. Second, we use the Base rate as a proxy for economic conditions. The Base rate has been employed by the State Bank of Vietnam as a powerful monetary instrument in order to control lending rates in Vietnam. Specifically, commercial banks are only allowed to charge their borrowers a maximum lending rate equal to 150 times the Base rate. During crisis times government raises the Base rate to control inflation and to create more room for 
commercial banks to increase their lending interest rate. We predict a positive coefficient for the Base rate.

In assigning control variables we include some loan characteristics such as Loan duration and Loan size. Though all bank branches belong to one single bank their operation can differ from each other and the differences in operation can influence the use of collateral. We argue that the way one branch operates depends on its authority hierarchy and therefore include in the left hand side of equation (2.1) the dummy variable Main branch $_{D}$ indicating whether the loan is granted by a main bank branch with higher authority or not. Additionally, we control for the Distance to headquarter from each branch. We believe this distance also plays a role in defining the way each branch operates. Finally, we control for the regional characteristics by including the Provincial legal index that shows enterprises in different provinces have different view on how transparent and supportive the provincial legal framework and Municipality ${ }_{D}$, taking value of 1 if the branch is located in one of the five municipalities ${ }^{4}$ and 0 otherwise.

\subsection{Data and descriptive statistics}

Our sample represents consumer loans granted between January 2007 and June 2011 by all 163 branches of a commercial bank in Vietnam. In total 32,655 loans were raised by retail borrowers mainly to pay for living expenses but also to finance weddings or to pay university tuition fees. Table 2.1 provides a snapshot of this part of the bank's outstanding loan portfolio. 52\% of the bank's consumer loans are collateralized and on average, the collateral value is more than five times as large as the loan value. In a survey of collateral usage in different countries, Menkhoff et al. (2006) find that in mature markets, the percentage of collateralized loans varies between $13 \%$ and $88 \%$ and the collateral to loan ratio ranges from 0.32 to above 1. For Mexico and Thailand, La Porta et al. (2003) and Menkhoff et al. (2006) document $53 \%$ to $84 \%$ collateralized loans and collateral to loan ratios from 5.3 to 29. In comparison our values for Vietnam are at the lower end of this scale $^{5}$. Hainz (2003) indicate that collateral plays an especially important role in transition economies leading to high levels of collateral. As such our Vietnamese data appear to be reasonable.

\footnotetext{
${ }^{4}$ The five municipalities in Vietnam include Ha Noi, Ho Chi Minh city, Hai Phong, Da Nang, and Can Tho. These municipalities are the highest ranked-cities and form the most developed urban areas in the country. They are centrally controlled by the government and serve as the core development areas.

5 To compare the data above with the data in developed markets: The data presented by Berger and Udell (1995) for the U.S., and by Harhoff and Korting (1998) for Germany, bearing in mind that these two papers deal only with credit line data show that in the U.S. sample, 53\% of the loans have collateral while in the German sample this figure is $62 \%$.
} 
Table 2.1 Characteristics of the bank's loan portfolio

This table presents the fraction of collateralized loans and the average of collateral value for the whole loan sample and for different loan types

\begin{tabular}{lrrrrr}
\hline & All loans & $\begin{array}{r}\text { Small } \\
\text { loans }\end{array}$ & $\begin{array}{r}\text { Large } \\
\text { loans }\end{array}$ & $\begin{array}{r}\text { Short-term } \\
\text { loans }\end{array}$ & $\begin{array}{r}\text { Long-term } \\
\text { loans }\end{array}$ \\
\hline Number of loans signed 2007-2011 & 32,655 & 21,244 & 11,411 & 21,408 & 11,247 \\
Fraction of collateralized loans average & $51.7 \%$ & $37.1 \%$ & $79.0 \%$ & $36.8 \%$ & $80.1 \%$ \\
Value of collateral in collateralized loans & & & & & \\
$\quad$ Collateral value (ml VND) & 1,461 & 885 & 1,959 & 1,516 & 1,412 \\
$\quad$ Collateral to loan value ratio & 5.1 & 4.9 & 5.6 & 4.3 & 6.7 \\
Average interest rate & & & & & $24.2 \%$ \\
$\quad$ Uncollateralized loans & $24.1 \%$ & $24.5 \%$ & $22.3 \%$ & $23.5 \%$ \\
$\quad$ Collateralized loans & $18.8 \%$ & $18.6 \%$ & $19.1 \%$ & $17.9 \%$ & $19.7 \%$ \\
\hline
\end{tabular}

Table 2.2 presents summary statistics for the explanatory variables of the model for the whole sample in Panel A and separately for collateralized versus uncollateralized loans in Panel B. The Ex-ante risk score reveals that our bank focuses on relatively safe borrowers: The average score is 41 out of a maximum of 50. Collateralized loans are associated with on average riskier borrowers with a score of 40.60 compared to 41.37 for uncollateralized loans. This provides initial support for the observed-risk hypothesis. The percentage of home owners among borrowers is $63 \%$ but the differences between uncollateralized versus collateralized loans are substantial: $38 \%$ versus $86 \%$. This supports the idea that borrowers provide collateral if they are able to do so - possibly in order to benefit from the lower interest rates for collateralized loans as documented in Table 2.1. Regarding the bank-borrower relationship, borrowers with collateralized loans have a longer relationship and more prior loans but use fewer bank products and are less likely to have another banking relationship. Surprisingly, more uncollateralized loans seem to be granted when the Base rate is higher. Furthermore, collateralized loans have longer maturities, are larger in size and are more likely to be made by a branch further away from the bank's headquarter.

In Panel C of Table 2.2 we present separate statistics for four sub-samples. First we differentiate small from large loans. Loans of less than 100 million VND, which account for almost $65 \%$ of the sample, are classified as small loans. Loans of more than 100 million VND are classified as large loans. As discussed above, the bank is more likely to require collateral for loans above 100 million VND. This is confirmed by table 2.1 that shows the frequency of collateralization of the small and the large loans are $37.1 \%$ and $79.0 \%$, respectively. Large loans are associated with better borrowers as shown be the Ex-ante risk score of 42.2 compared to 40.3 for small loans. Large loans are also granted to wealthier borrowers: $78 \%$ of borrowers who are granted a large loan own a house while only $55 \%$ of borrowers who are granted small loans own a house. Finally, large loans are associated with longer and stronger relationships with the bank. The differences we find between 
the terms and characteristics of loans of different size suggest that to preserve homogeneity, we should estimate the model separately for each size. Second, we differentiate between short-term loans with a maturity of less than 36 months and long-term loans. This separation follows Jimenez et al. (2006) who claim that loan terms differ substantially across loans of different maturities. In our sample collateralization rates do indeed differ with $36.8 \%$ for short-term loans compared to and $80.1 \%$ for long-term loans. Furthermore, long-term loans are $50 \%$ larger on average than short-term loans. Long-terms loans are granted to ex ante safer borrowers, to wealthier borrowers, and by branches further away from the headquarter. 


\section{Table 2.2 Descriptive statistics}

This table presents descriptive statistics for all loans (Panel A), for collateralized versus uncollateralized loans (Panel B) and for four sub-samples (Panel C). The exact definitions and sources of our variables are listed in Table A2.2 of the appendix.

\begin{tabular}{|c|c|c|c|c|c|}
\hline \multicolumn{6}{|l|}{ Panel A: All loans } \\
\hline Variable & Mean & Minimum & Maximum & $\begin{array}{l}\text { Standard } \\
\text { deviation }\end{array}$ & Observations \\
\hline \multicolumn{6}{|l|}{ Borrower characteristics } \\
\hline Ex-ante risk score & 40.97 & 15.00 & 50.00 & 6.85 & 32,655 \\
\hline Home owner ${ }_{D}$ & 0.63 & 0.00 & 1.00 & 0.48 & 32,655 \\
\hline Age & 39.10 & 19.00 & 88.00 & 10.11 & 32,655 \\
\hline \multicolumn{6}{|l|}{ Bank-borrower relationship } \\
\hline Years with bank & 2.26 & 0.00 & 10.00 & 2.65 & 32,655 \\
\hline Number of prior loans & 4.96 & 0.00 & 519.00 & 12.87 & 32,655 \\
\hline Number of bank products & 1.14 & 0.00 & 3.00 & 0.85 & 32,655 \\
\hline Other bank $\mathrm{D}_{\mathrm{D}}$ & 0.06 & 0.00 & 1.00 & 0.24 & 32,655 \\
\hline Local borrower ${ }_{D}$ & 0.94 & 0.00 & 1.00 & 0.24 & 32,655 \\
\hline \multicolumn{6}{|l|}{ Economics conditions } \\
\hline Base rate & 7.30 & 0.00 & 14.00 & 3.10 & 32,655 \\
\hline \multicolumn{6}{|l|}{ Control variables } \\
\hline \multicolumn{6}{|l|}{ Loan characteristics } \\
\hline Loan duration & 39.10 & 1.00 & 360.00 & 21.21 & 32,655 \\
\hline Loan size (ml VND) & 134.31 & 10.00 & $6,000.00$ & 167.71 & 32,655 \\
\hline \multicolumn{6}{|c|}{ Branch operation characteristics } \\
\hline Distance to head-quarter & 46.80 & 0.00 & $1,047.38$ & 139.45 & 32,655 \\
\hline Main branch ${ }_{D}$ & 0.60 & 0.00 & 1.00 & 0.49 & 32,655 \\
\hline \multicolumn{6}{|l|}{ Regional characteristics } \\
\hline Provincial legal index & 4.14 & 2.79 & 6.70 & 0.74 & 32,655 \\
\hline Municipality $_{D}$ & 0.94 & 0.00 & 1.00 & 0.25 & 32,655 \\
\hline
\end{tabular}

Panel B: Collateralized versus Uncollateralized loans

\begin{tabular}{|c|c|c|c|c|c|c|}
\hline \multirow[b]{2}{*}{ Variable } & \multicolumn{3}{|c|}{ Collateralized loans } & \multicolumn{3}{|c|}{ Un-Collateralized loans } \\
\hline & Mean & $\begin{array}{r}\text { Standard } \\
\text { deviation }\end{array}$ & $\begin{array}{c}\text { Obser- } \\
\text { vations }\end{array}$ & Mean & $\begin{array}{r}\text { Standard } \\
\text { deviation }\end{array}$ & $\begin{array}{r}\text { Obser- } \\
\text { vations }\end{array}$ \\
\hline \multicolumn{7}{|l|}{ Borrower characteristics } \\
\hline Ex-ante risk score & 40.60 & 6.54 & 16,883 & 41.37 & 7.15 & 15,772 \\
\hline Home owner ${ }_{D}$ & 0.86 & 0.34 & 16,883 & 0.38 & 0.48 & 15,772 \\
\hline Age & 43.87 & 9.93 & 16,883 & 33.99 & 7.46 & 15,772 \\
\hline \multicolumn{7}{|l|}{ Bank-borrower relationship } \\
\hline Years with bank & 2.87 & 2.82 & 16,883 & 1.60 & 2.29 & 15,772 \\
\hline Number of prior loans & 8.07 & 16.42 & 16,883 & 1.63 & 5.73 & 15,772 \\
\hline Number of bank products & 1.01 & 0.94 & 16,883 & 1.28 & 0.70 & 15,772 \\
\hline Other bank $\mathrm{D}_{\mathrm{D}}$ & 0.05 & 0.21 & 16,883 & 0.08 & 0.28 & 15,772 \\
\hline Local borrower ${ }_{D}$ & 0.96 & 0.20 & 16,883 & 0.92 & 0.27 & 15,772 \\
\hline \multicolumn{7}{|l|}{ Economics conditions } \\
\hline Base rate & 7.06 & 3.41 & 16,883 & 7.55 & 2.70 & 15,772 \\
\hline \multicolumn{7}{|l|}{ Control variables } \\
\hline \multicolumn{7}{|l|}{ Loan characteristics } \\
\hline Loan duration & 46.16 & 25.09 & 16,883 & 31.54 & 12.12 & 15,772 \\
\hline Loan size (ml VND) & 199.19 & 207.26 & 16,883 & 64.85 & 54.09 & 15,772 \\
\hline \multicolumn{7}{|c|}{ Branch operation characteristics } \\
\hline Distance to head-quarter & 63.49 & 167.88 & 16,883 & 28.94 & 97.36 & 15,772 \\
\hline Main branch ${ }_{D}$ & 0.64 & 0.48 & 16,883 & 0.57 & 0.50 & 15,772 \\
\hline \multicolumn{7}{|l|}{ Regional characteristics } \\
\hline Provincial legal index & 4.26 & 0.76 & 16,883 & 4.00 & 0.69 & 15,772 \\
\hline Municipality & 0.92 & 0.26 & 16,883 & 0.95 & 0.22 & 15,772 \\
\hline
\end{tabular}




\subsection{Regression results}

\subsubsection{Empirical evidence regarding our hypotheses}

Table 2.4 presents the Probit model's estimations for the whole sample of consumer loans). Since the coefficients of Probit models cannot be interpreted directly, the marginal effect of each variable is additionally calculated and also presented in Table 2.4. The coefficient and marginal effect of the Ex-ante risk score are negative and significant therefore confirming our first hypothesis: In line with the observed risk hypothesis, borrowers with lower credit quality are more likely to pledge collateral. The marginal coefficient of the Ex-ante risk score indicates that, ceteris paribus, one point increase in Ex-ante risk score is likely to reduce the collateral requirement by $1.6 \%$. This magnitude corresponds to those obtained for the emerging market of Mexico (La Porta, et al., 2003) and for developed markets (Degrayse and Van Cayseele, 2000; Harhoff and Korting, 1998; Lehmann and Neuberger, 2001). However, these studies need to approximate the borrower's ex ante credit risk while we directly measure the Ex-ante risk score. Hence, we are able to provide direct evidence for the observed-risk hypothesis in an emerging market like Vietnam.

Home owner ${ }_{D}$ has a positive and significant coefficient and the corresponding marginal effect indicates that, ceteris paribus, being a home owner is likely to increase the use of collateral by $31 \%$ compared to a borrower who does not own the house he lives in. We thus can confirm our second hypothesis and our results are in line with Booth and Booth (2006) who show that collateral pledging decisions are generally consistent with borrowing cost minimization. Existing studies are unable to distinguish between the borrowers' willingness to pledge collateral and their ability to do so. However, our proxy allows us to directly measure the ability to pledge collateral and we can thus test the hypothesis more accurately. Given the same level of observed credit risk and thus the same requirement from the bank's side to collateralize, borrowers with the ability to pledge collateral are more likely to do. So in return, they pay a lower interest rate as documented in Table 2.1. Similarly, the coefficient of Age is positive and significant and also indicates that - if age is a proxy for wealth - wealthy borrowers are more likely to pledge collateral. 


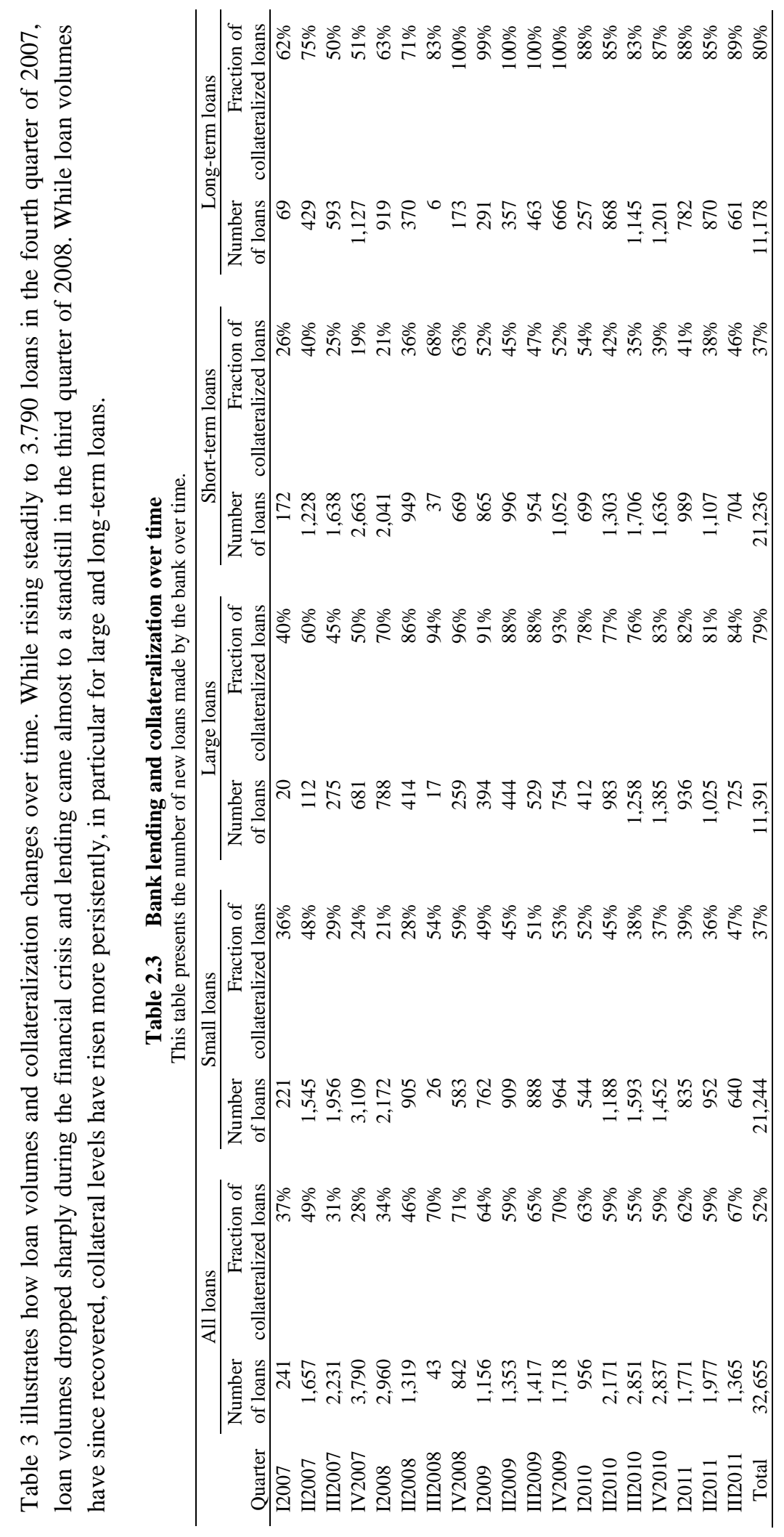




\section{Table 2.4 Determinants of the incidence of collateral}

This table presents coefficients and marginal coefficients of the Probit regression for all loans. For each independent variable, the coefficient and the $\mathrm{z}$-statistic are shown in the coefficient column and the marginal coefficient at the mean is shown in the marginal column. Standard errors are heteroskedasticity robust and clustered by borrower. ***, **, and * indicate statistical significance at the $1 \%, 5 \%$, and $10 \%$ level, respectively.

\begin{tabular}{|c|c|c|}
\hline & \multicolumn{2}{|c|}{ Incidence of collateral } \\
\hline & Coefficient & Marginal effect \\
\hline Intercept & $\begin{array}{l}-6.78 * * * \\
-33.84\end{array}$ & \\
\hline \multicolumn{3}{|l|}{ Borrower characteristics } \\
\hline Ex-ante risk score & $\begin{array}{l}-0.04 * * * \\
-23.80\end{array}$ & -0.016 \\
\hline Home owner ${ }_{D}$ & $\begin{array}{l}0.81^{* * *} \\
33.93\end{array}$ & 0.312 \\
\hline Age & $\begin{array}{l}0.04 * * * \\
32.19\end{array}$ & 0.016 \\
\hline \multicolumn{3}{|l|}{ Bank-borrower relationship } \\
\hline Years with bank & $\begin{array}{l}0.08 \text { *** } \\
15.62\end{array}$ & 0.031 \\
\hline Number of prior loans & $\begin{array}{l}0.05^{* * *} \\
17.54\end{array}$ & 0.019 \\
\hline Number of bank products & $\begin{array}{l}-0.63 * * * \\
-38.94\end{array}$ & -0.247 \\
\hline Other bank $k_{D}$ & $\begin{array}{l}-0.23 * * * \\
-5.36\end{array}$ & -0.091 \\
\hline Local borrower $_{\mathrm{D}}$ & $\begin{array}{l}0.01 \\
0.21\end{array}$ & 0.004 \\
\hline \multicolumn{3}{|l|}{ Economics conditions } \\
\hline $\begin{array}{l}\text { Base rate } \\
\text { Control variables }\end{array}$ & Control variables & 0.027 \\
\hline Loan characteristics & & \\
\hline Loan duration & $\begin{array}{l}0.03 * * * \\
41.45\end{array}$ & 0.010 \\
\hline Loan size & $\begin{array}{l}1.03 * * * \\
62.79\end{array}$ & 0.403 \\
\hline Branch operation characteristics & & \\
\hline Distance to head-quarter & $\begin{array}{l}-0.02 * * \\
-1.98\end{array}$ & -0.010 \\
\hline Main branch ${ }_{D}$ & $\begin{array}{l}0.17 * * * \\
7.67\end{array}$ & 0.067 \\
\hline $\begin{array}{l}\text { Regional characteristics } \\
\text { Provincial legal index }\end{array}$ & $\begin{array}{l}0.31 \text { *** } \\
15.82\end{array}$ & 0.120 \\
\hline Municipality $_{D}$ & $\begin{array}{l}-0.41 * * * \\
-8.11 \\
2.97\end{array}$ & -0.152 \\
\hline
\end{tabular}

(Continued) 


\begin{tabular}{|c|c|c|}
\hline \multicolumn{3}{|l|}{ Quarterly dummies } \\
\hline \multirow[t]{2}{*}{ II-2007 } & $0.08 * *$ & 0.030 \\
\hline & 2.36 & \\
\hline \multirow[t]{2}{*}{ III-2007 } & -0.04 & -0.014 \\
\hline & -1.40 & \\
\hline \multirow[t]{2}{*}{ IV-2007 } & $-0.05 * *$ & -0.021 \\
\hline & -2.48 & \\
\hline \multirow[t]{2}{*}{ I-2008 } & $-0.03 *$ & -0.012 \\
\hline & -1.70 & \\
\hline \multirow[t]{2}{*}{ II-2008 } & 0.02 & 0.007 \\
\hline & 1.14 & \\
\hline \multirow[t]{2}{*}{ III-2008 } & $0.09 * *$ & 0.036 \\
\hline & 2.83 & \\
\hline \multirow[t]{2}{*}{ IV-2008 } & $0.12 * * *$ & 0.046 \\
\hline & 8.24 & \\
\hline \multirow[t]{2}{*}{ I-2009 } & $0.07 * * *$ & 0.028 \\
\hline & 5.40 & \\
\hline \multirow[t]{2}{*}{ II-2009 } & $0.06 * * *$ & 0.022 \\
\hline & 4.43 & \\
\hline \multirow[t]{2}{*}{ III-2009 } & $0.06^{* * *} *$ & 0.023 \\
\hline & 5.03 & \\
\hline \multirow[t]{2}{*}{ IV-2009 } & $0.06 * * *$ & 0.023 \\
\hline & 5.61 & \\
\hline \multirow{2}{*}{ I-2010 } & 0.01 & 0.005 \\
\hline & 1.34 & \\
\hline \multirow[t]{2}{*}{ II-2010 } & 0.01 & 0.002 \\
\hline & 0.67 & \\
\hline \multirow[t]{2}{*}{ III-2010 } & 0.00 & 0.000 \\
\hline & -0.01 & \\
\hline \multirow[t]{2}{*}{ IV-2010 } & 0.01 & 0.003 \\
\hline & 1.18 & \\
\hline \multirow[t]{2}{*}{ I-2011 } & 0.01 & 0.002 \\
\hline & 0.69 & \\
\hline \multirow[t]{2}{*}{ II-2011 } & 0.00 & 0.001 \\
\hline & 0.53 & \\
\hline \multirow[t]{2}{*}{ III-2011 } & $0.01 *$ & 0.005 \\
\hline & 1.87 & \\
\hline Log likelihood & $-8,825$ & \\
\hline Pseudo $\mathrm{R}^{2}$ & 0.610 & \\
\hline Number of observations & 32,655 & \\
\hline
\end{tabular}

How do the effects of the Ex-ante risk score and Home owner ${ }_{D}$ relate to each other? We believe that the relation between collateralization and Ex-ante risk score reflects the bank's policy to demand more collateral from risky borrowers, whereas Home owner ${ }_{D}$ reflects the choice of the borrower. This can be seen as a simple demand-supply system of collateral. Figure 2.1 presents predicted probability of collateral relative to the level of the Ex-ante risk score for home owners and nonhome owners. The predicted probability of pledging collateral for home owners lies persistently above the predicted probability of pledging collateral for nonhome owners. This indicates that at each level of risk borrowers more frequently choose to pledge collateral if they are able to do so. This finding again confirms our second hypothesis on the supply side of collateral. In addition, from the 
demand side the downward slopping lines confirm that the bank requires less collateral from safer borrowers, both home owners and non-home owners. The interaction between Ex-ante risk score and Home owner ${ }_{D}$ regarding the collateral decision becomes visible when we compare the slope of the two lines. The slightly more negative slope for non-home owners indicates that for the same decrease in credit risk, the decrease in the collateralization requirement is larger for non-home owners than for home owners. Thus, non-home owners' collateral decision is slightly more sensitive to credit risk.

Figure 2.1 Interaction between Home owner $_{D}$ and Ex-ante risk score

This figure presents the interaction between two factors, Home owner ${ }_{D}$ and Ex-ante risk score, on the use of collateral.

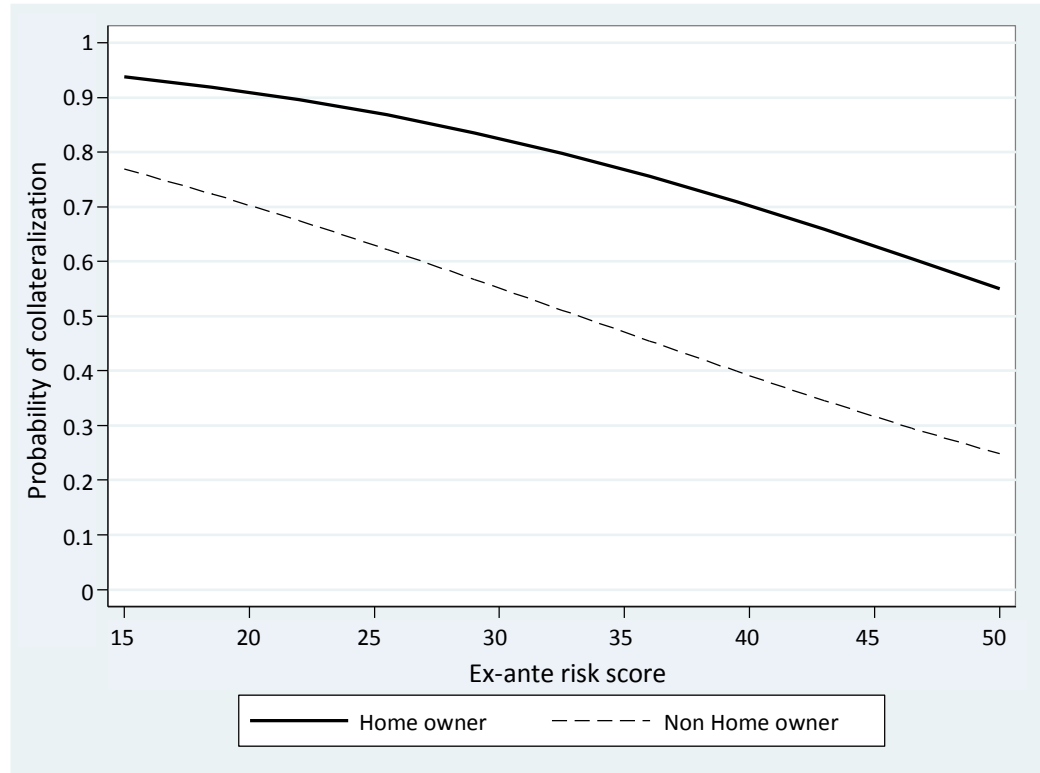

Regarding our third hypothesis, our results for Vietnam are in line with existing findings for developed markets: Collateralization depends on scale of the bankborrower relationship. The likelihood of collateralization increases with Years with bank and Number of prior loans by $3.1 \%$ and $1.9 \%$, respectively. This indicates that one more year with the bank with one more prior loan in the past would increase the use of collateral by $5 \%$ in total. This finding confirms that the "holdup" effect dominates the benefits of the lending relationship. In Vietnam it is not possible to pledge the same asset as collateral with different banks at the same time. Thus, the borrower tends to stay with the same bank that holds the pledged asset. Due to these institutional circumstances the hold-up effect is very persistent 
in Vietnam. This provides a support for the conclusion made in previous studies (Greenbaum et al., 1989; Sharpe, 1990; Rajan, 1992, Farinha and Santos, 2002) that a frequent borrower can be associated with higher likelihood of collateral use. In addition, a relationship with an Other $\operatorname{bank}_{D}$ has a negative coefficient indicating that the existence of an alternative lending source reduces the hold-up problem and consequently reduces the likelihood of collateralization. Local borrower $_{D}$ is not significant.

The proxy for the scope of the lending relationship, Number of bank products, has a negative and significant coefficient for all loans. The corresponding marginal effect implies that, ceteris paribus, using one more service at the bank would reduce the likelihood of being asked for collateral by approximately $25 \%$. Compared to the average fraction of collateralized loans of $51.7 \%$, this effect is substantial. This result strongly confirms our fourth hypothesis and is furthermore consistent with the results found in the previous studies about the effect of the scope of the lending relationship on collateral use (Degryse and Cayseele, 2000; Petersen and Rajan, 1994; Chakraborty and Hu, 2000). Thus, while the scale of the lending relationship increases the likelihood of using collateral, its scope, e.g. the number of different services that the borrower uses from the same bank, actually reduces the incidence of using collateral. The information the bank acquires about the borrowers through different kinds of services, for example different types of account such saving account, or debit account, is important for a consumer loan because it is harder to access private information than business information. This convenient source of information helps the bank to reduce both adverse selection and moral hazard and therefore the bank requires less collateral.

In line with our fifth hypothesis about the relationship between economic conditions and the use of collateral, we find that the incidence of using collateral significantly increases during the crisis period. In particular, the time dummies from the third quarter of 2008 until the fourth quarter of 2009 have positive and significant coefficients and the collateral requirement peaks in the fourth quarter of 2008 corresponding to the time when the bank's lending volume is at its lowest (see Table 2.3). In addition, we find a significant and positive coefficient for the Base rate. It implies that during the economic downturns when the State Bank increases its Base rate (Figure 2.2), commercial banks require more collateral. The marginal coefficient shows that every $1 \%$ increase in the Base rate increases the likelihood of being asked for collateral by $2.7 \%$. We conclude that over crisis periods when uncertainty increases and adverse selection and moral hazard become more severe, banks require more collateral as a solution to these asymmetric information problems and reduce their loss in case of default. 


\section{Figure 2.2 Change of the Base rate over time}

This figure presents the Base rate over time. This base rate is deployed by the State Bank as a monetary instrument and commercial banks in Vietnam are allowed to charge a maximum lending rate of $150 \%$ of this Base rate.

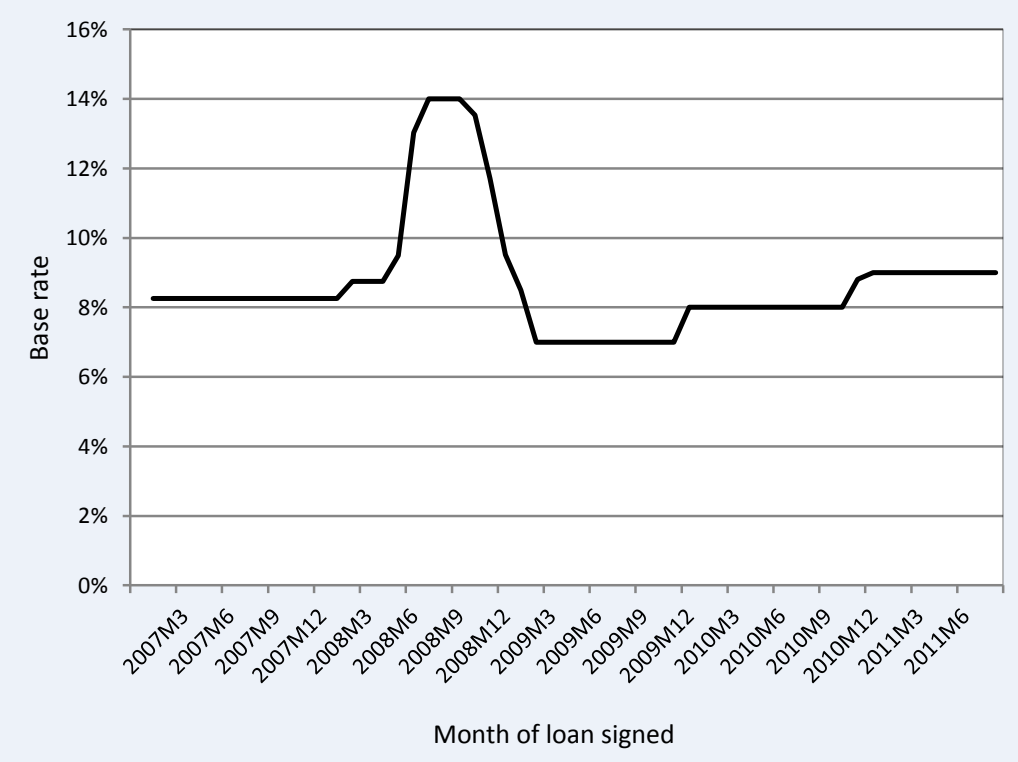

Regarding control variables, Loan size and Loan maturity both increase the likelihood of collateralization. Branch characteristics also matter as Distance to headquarter has a negative and only marginally significant coefficient while Main branch $_{D}$ has a positive and significant coefficient. Collateralisation is also a regional issue. The coefficient of the Provincial legal index is significantly positive. This result suggests that a better legal environment increases the use of collateral. This can be explained by the lower cost of collateralization in a good legal environment than in a bad one and therefore enhances the use of collateral The negative coefficient of Municipality $_{D}$ can be understood in the context of the difference in economic development between the first-class cities and the rest of Vietnam. Municipality ${ }_{D}$ - which is set equal to 1 for loans to borrowers in firstclass cities - then implies that economic development reduces information asymmetries and thus reduces the likelihood of collateral.

For the four sub-samples of small versus large and short-term versus long-term loans ${ }^{6}$, Panel A of Table 2.5 indicates many similarities but also some differences regarding the determinations of collateral incidence. In general, the results for the

\footnotetext{
${ }^{6}$ Jimenez et al (2006) made similar disentangling loan size and maturity but with different thresholds.
} 
four sub-samples provide robust results for our five hypotheses. Some differences, however, emerge. The coefficient of Home owner ${ }_{D}$ is smaller for small loans than for large loans and is smaller for short-term loans than for long-term loans. We interpret this as evidence that for large loans and long-term loans the collateralization is being more influenced by the demand side, e.g. the bank, while for small loans and short-term loans the decision to pledge collateral lies more in the hands of borrowers and therefore the ability to pledge collateral has more influence. Years with bank is negative but not significant for large loans and positive but less significant for long-term loans. This implies that the hold-up effect might only be important for small and short-term loans. Finally, large loans seem to be most vulnerable to the economic conditions as only large loans have a positive and significant coefficient for the Base rate. Large loans are also the first one that responds to the impact of the crisis as its coefficients for the quarterly dummy variables start to be positive and significant from the first quarter of 2008 . The impact of the crisis also seems to be most persisted for this sub-sample as its coefficients for these time dummies stay positive and significant until the last quarter in our sample which is the third quarter of 2011 although their magnitude reduces from the beginning of 2009.

Panel B of Table 2.5 presents the results of the Tobit model regarding the determinants of the degree of collateral use. The model is estimated for the whole sample and for the four sub-samples. The model has the same explanatory variables as the model for collateral incidence. Overall, we can observe that the factors that determine whether or not collateral is provided also affect the amount of collateral in the same direction. Interestingly, the Base rate is now positive and significant for all four sub-samples. This result is consistent with the prediction by Boot et al. (1991) and Jimenez (2006) that the amount of collateral pledged in a particular loan will increase if the loan is granted in a period of higher interest rates. 


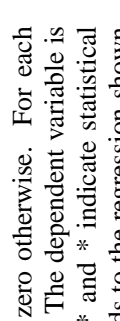

的絭

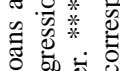

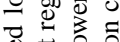

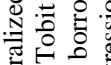

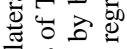

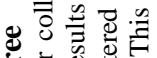

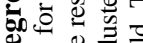

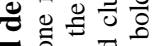

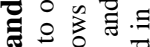

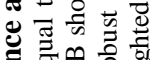

형

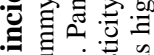

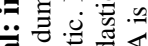

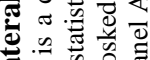

는

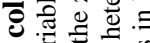

항

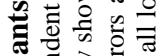

告

这它

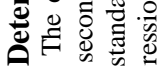

我号的总

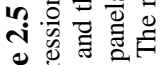

능

氙㝴

20 ن

t。

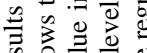

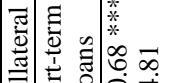

은 은

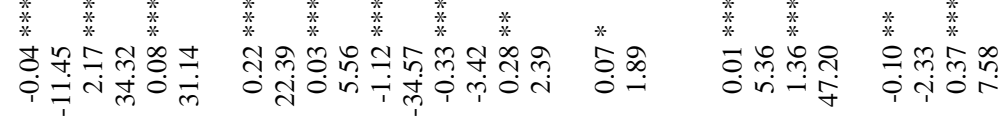

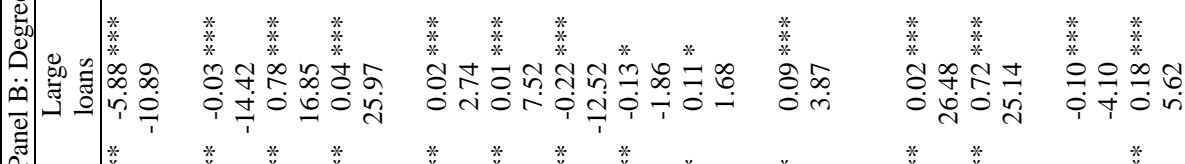

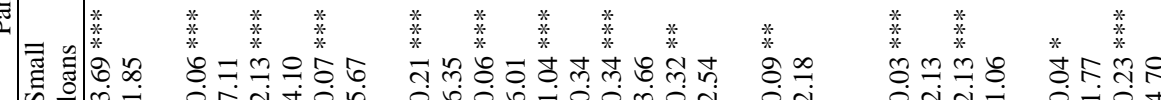
की

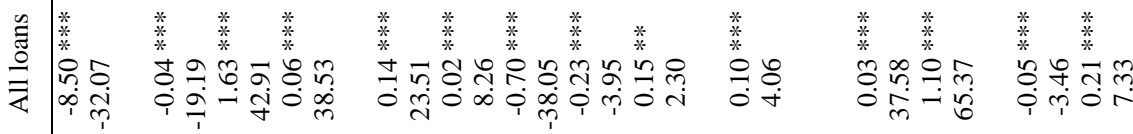

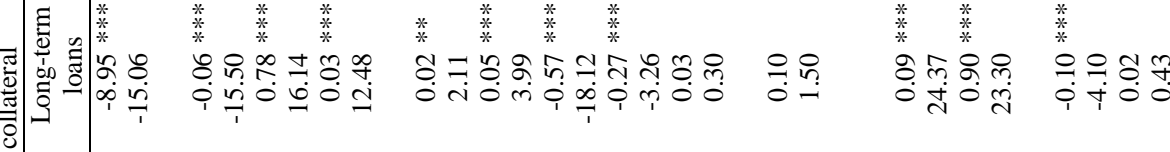

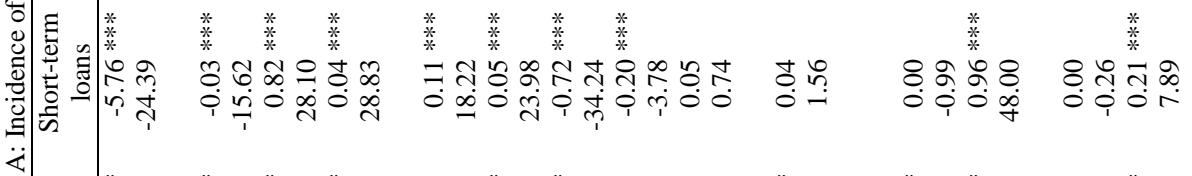

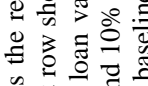

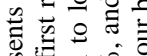

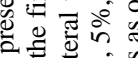
을

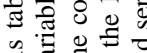
놀

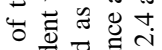

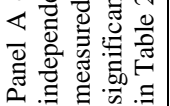

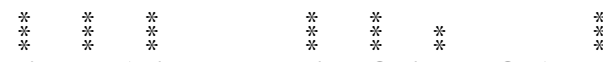

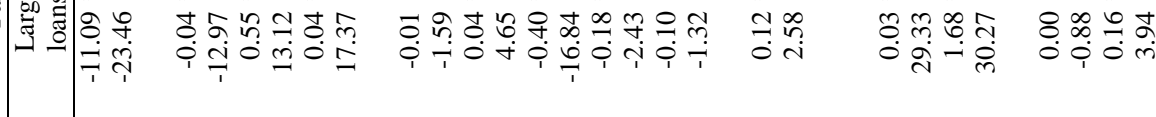

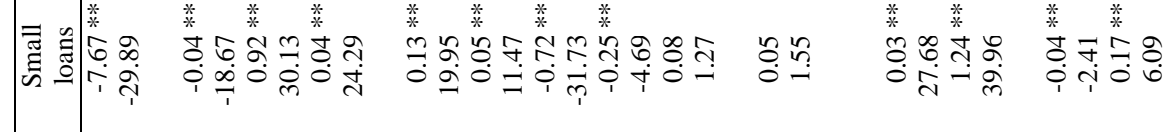




\section{* * * * * * * * * * *}

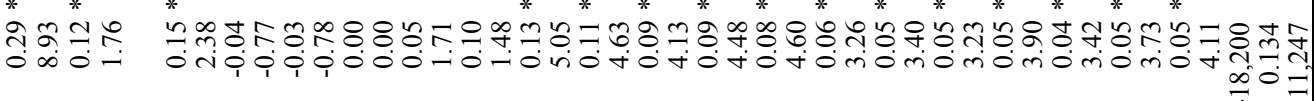

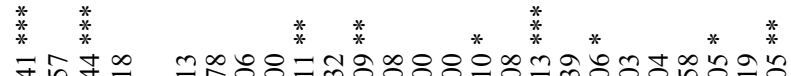

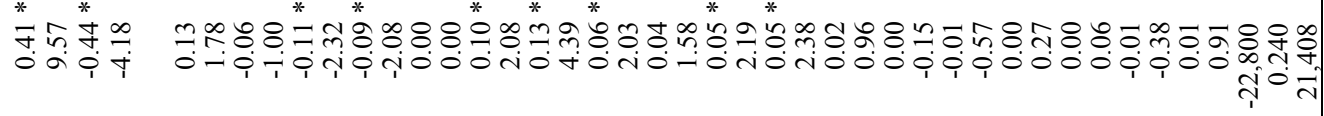

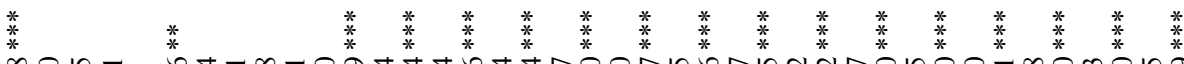

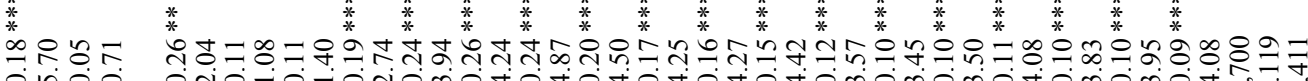

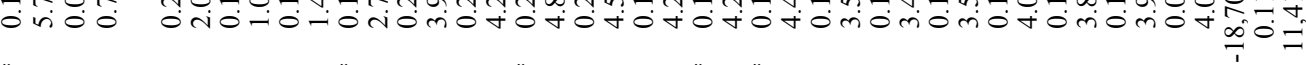

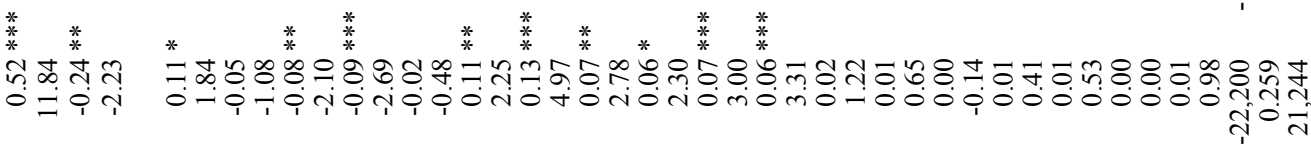

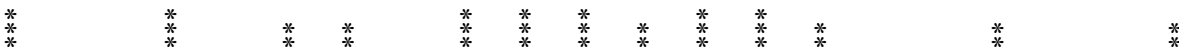

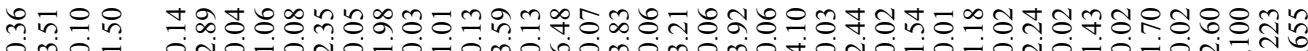

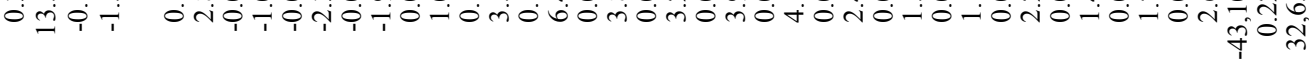

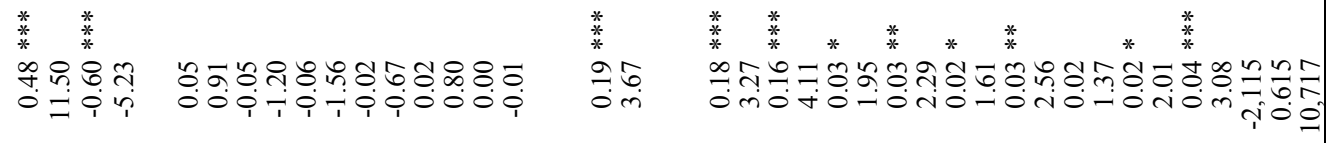

* * * * * * * * * * * * * * * * * * * * * *

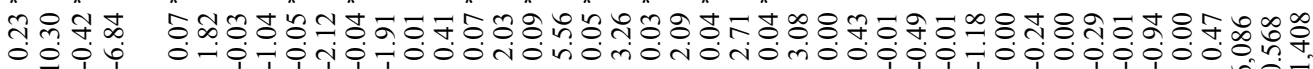

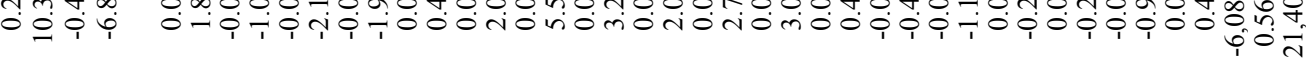

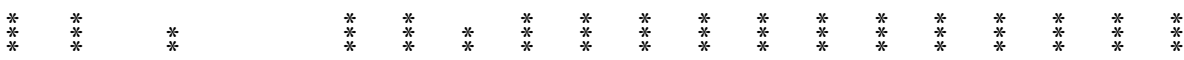

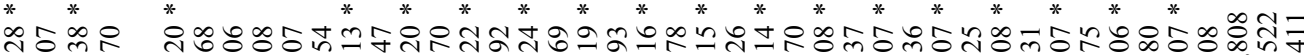

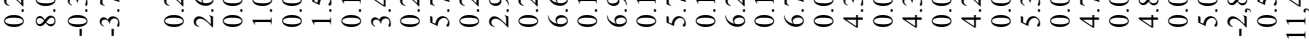

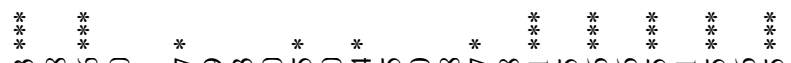

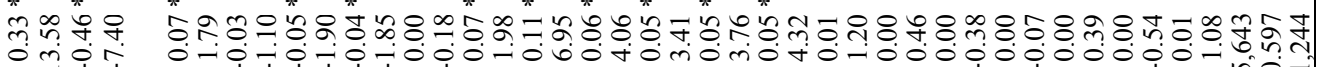

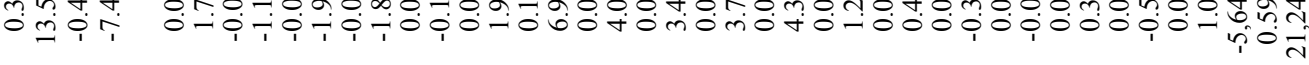

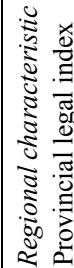

产

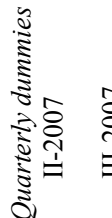

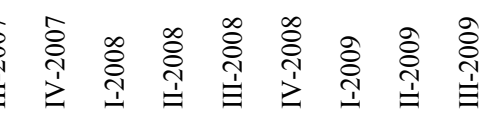

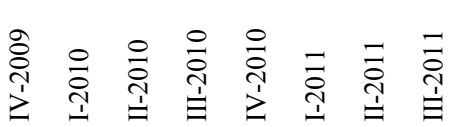

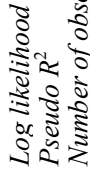




\subsubsection{Economic relevance}

Table 2.6 illustrates the change in the predicted probability of collateralization for a one-standard deviation change in each independent continuous variable or for a change from 0 to 1 for each independent dummy variable. The results are reported for our main regression shown in Table 2.4. Overall, the model predicts that $57.6 \%$ of loans are collateralized which is fairly close to the sample frequency of $51.7 \%$. The largest impact on collateralization can be observed for Loan size $(+38.6 \%)$ followed by Home owner $(+31.2 \%)$. The effect of the Ex-ante risk score is only moderate with $-1.6 \%$. This can however be explained with the relatively low variability of the score as reported in Panel A of Table 2.2 and the similarity of the average scores for collateralized and uncollateralized loans as reported in Panel B of Table 2.2. The effect of the crisis shows a clear trend: From the second quarter of 2008 till the end of the sample period which is the third quarter of 2011 the likelihood of collateralization increases by $4.6 \%$ compared to the first quarter of 2007. In conclusion, the estimated coefficients of our Probit model reported in Table 2.4 generally imply an economically substantial impact of the significant borrower characteristics, bank-borrower relationships and economic conditions on the use of collateral.

In addition, Table A2.3 in the appendix shows the marginal effects of changes in values of the explanatory variables on the likelihood of collateralization for the whole sample and for four sub-samples. This result is obtained from the Probit estimation of table of Table 2.5. The marginal effects help to calibrate the economic significance of explanatory variables. For all the significant variables, the magnitude of these effects is much larger for small loans and short-term loans than for large loans and long-term loans. For example, a 10 points increase in the ex-ante risk score would increase the likelihood of collateralization by $13 \%$ and $11 \%$ for a small loan and a short-term loan, respectively, while it increases the likelihood of collateralization by only $5 \%$ and $3 \%$ for a large loan and a long-term loan, respectively. The explanation lies in our sample where large loans and longterm loans have by far higher probability of collateralization and so the room for these effects is not as big as that of the small loans and short-term loans. The quarterly dummies, which have a statistically significant effect, also show an economically significant effect here. 


\section{Table 2.6 The determinants of collateral-Economic relevance}

This table presents the effect of a change in each independent variable from half a standard deviation below the mean to half a standard deviation above the mean on the predicted probability of collateral. If the independent variable is a dummy, a change from 0 to 1 is considered. All other independent variables are kept at their mean values. The overall predicted probability of collateral is calculated when all independent variables are at their mean.

\begin{tabular}{|c|c|c|c|}
\hline & \multicolumn{3}{|c|}{ Predicted probability of collateralization } \\
\hline & from & to & change \\
\hline \multicolumn{4}{|l|}{ Borrower characteristics } \\
\hline Ex-ante risk score & $58.4 \%$ & $56.8 \%$ & $-1.6 \%$ \\
\hline Home owner ${ }_{D}$ & $37.6 \%$ & $68.9 \%$ & $31.2 \%$ \\
\hline Age & $56.8 \%$ & $58.4 \%$ & $1.6 \%$ \\
\hline \multicolumn{4}{|l|}{ Bank-borrower relationship } \\
\hline Years with bank & $56.1 \%$ & $59.2 \%$ & $3.1 \%$ \\
\hline Number of prior loans & $56.7 \%$ & $58.6 \%$ & $2.0 \%$ \\
\hline Number of bank products & $69.4 \%$ & $45.1 \%$ & $-24.3 \%$ \\
\hline Other bank $k_{\mathrm{D}}$ & $58.2 \%$ & $49.1 \%$ & $-9.1 \%$ \\
\hline Local borrower ${ }_{D}$ & $57.3 \%$ & $57.7 \%$ & $0.4 \%$ \\
\hline \multicolumn{4}{|l|}{ Economics conditions } \\
\hline Base rate & $57.2 \%$ & $58.0 \%$ & $0.8 \%$ \\
\hline \multicolumn{4}{|l|}{ Control variables } \\
\hline \multicolumn{4}{|l|}{ Loan characteristics } \\
\hline Loan duration & $57.1 \%$ & $58.1 \%$ & $1.0 \%$ \\
\hline Loan size & $37.4 \%$ & $76.0 \%$ & $38.6 \%$ \\
\hline \multicolumn{4}{|l|}{ Branch operation characteristics } \\
\hline Distance to head-quarter & $57.6 \%$ & $57.6 \%$ & $-0.01 \%$ \\
\hline Main branch ${ }_{D}$ & $53.6 \%$ & $60.3 \%$ & $6.7 \%$ \\
\hline \multicolumn{4}{|l|}{ Regional characteristics } \\
\hline Provincial legal index & $51.6 \%$ & $63.5 \%$ & $12.0 \%$ \\
\hline Municipality $_{D}$ & $71.8 \%$ & $56.6 \%$ & $-15.2 \%$ \\
\hline \multicolumn{4}{|l|}{ Quarterly dummies } \\
\hline II-2007 & $57.0 \%$ & $60.0 \%$ & $3.0 \%$ \\
\hline III-2007 & $58.1 \%$ & $56.7 \%$ & $-1.4 \%$ \\
\hline IV-2007 & $59.1 \%$ & $57.0 \%$ & $-2.1 \%$ \\
\hline I-2008 & $58.4 \%$ & $57.2 \%$ & $-1.2 \%$ \\
\hline II-2008 & $57.4 \%$ & $58.1 \%$ & $0.7 \%$ \\
\hline III-2008 & $57.6 \%$ & $61.1 \%$ & $3.5 \%$ \\
\hline IV-2008 & $56.4 \%$ & $61.0 \%$ & $4.6 \%$ \\
\hline I-2009 & $56.5 \%$ & $59.3 \%$ & $2.8 \%$ \\
\hline II-2009 & $56.5 \%$ & $58.8 \%$ & $2.2 \%$ \\
\hline III-2009 & $56.3 \%$ & $58.6 \%$ & $2.3 \%$ \\
\hline IV-2009 & $56.0 \%$ & $58.2 \%$ & $2.3 \%$ \\
\hline I-2010 & $57.4 \%$ & $57.9 \%$ & $0.5 \%$ \\
\hline II-2010 & $57.4 \%$ & $57.6 \%$ & $0.2 \%$ \\
\hline III-2010 & $57.6 \%$ & $57.6 \%$ & $0.0 \%$ \\
\hline IV-2010 & $57.1 \%$ & $57.4 \%$ & $0.3 \%$ \\
\hline I-2011 & $57.4 \%$ & $57.6 \%$ & $0.2 \%$ \\
\hline II-2011 & $57.5 \%$ & $57.6 \%$ & $0.1 \%$ \\
\hline III-2011 & $57.2 \%$ & $57.7 \%$ & $0.5 \%$ \\
\hline $\begin{array}{l}\text { Overall predicted probability of } \\
\text { collateralization }\end{array}$ & & $57.6 \%$ & \\
\hline Fraction of collateralization loans in sample & & $51.7 \%$ & \\
\hline
\end{tabular}




\subsubsection{Robustness of the results}

Our study explores the Ex-ante risk score as one determinant of the use of collateral and its amount. As shown in Table A2.1 in the appendix, this score is generated using a list of simple rules made available by the bank to its loan officers for the loan assessing purpose. These rules have been employed at the bank for the whole sample period and our results so far show a solid relationship between this score and the incidence and degree of collateral. However, the bank has recently implemented a more sophisticated credit scoring system in some of its branches. We therefore perform a robustness test by replacing the Ex-ante credit score by with this New ex-ante risk score. Table 2.7 shows the results of our Probit (Regression 1 and 2) and Tobit (Regression 3 and 4) models. The New ex-ante risk score includes of several explanatory variables that are included in our model and a mutlicollinearity problem might thus exist. To avoid this problem, we include the New ex-ante risk score as well as its residual. The coefficients and the marginal effects are shown for Regression 1 and 2 where the New ex-ante risk score and the residual of the New ex-ante risk score are included, respectively. The coefficients are shown for Regression 3 and 4 with the New ex-ante risk score and the residual of the New ex-ante risk score, respectively. Except for the fact that the New Exante risk score and its residual are not significant in the Tobit model, new model estimations leave the main result unchanged and the goodness fit of the model remains stable. 


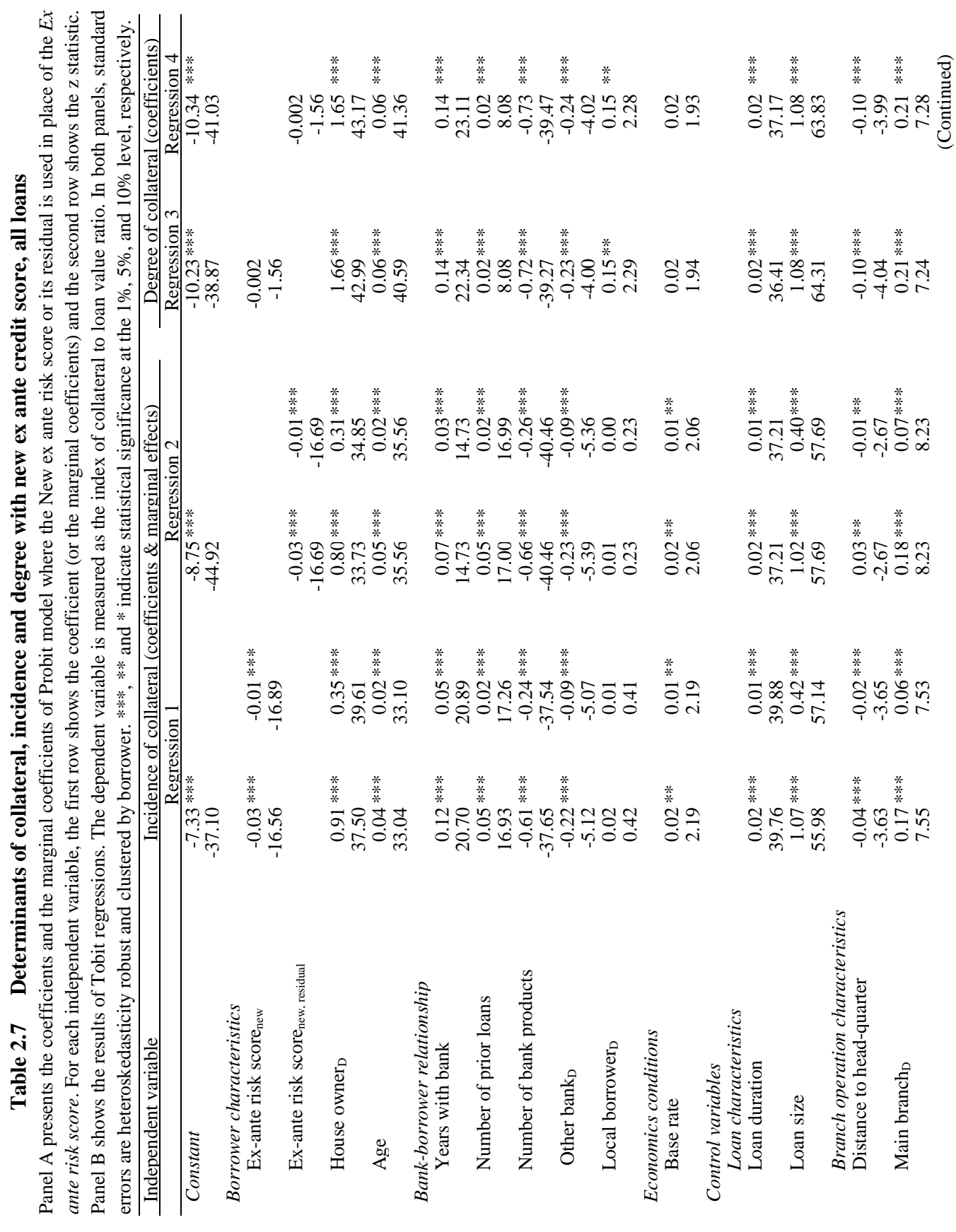




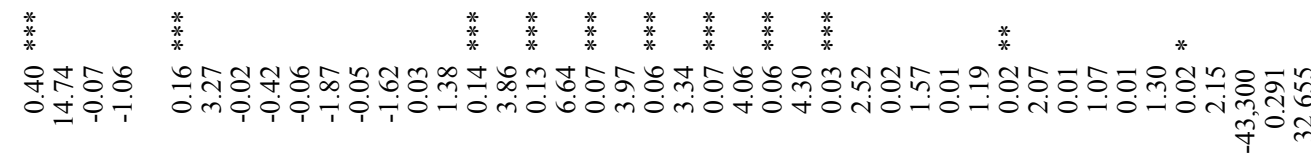

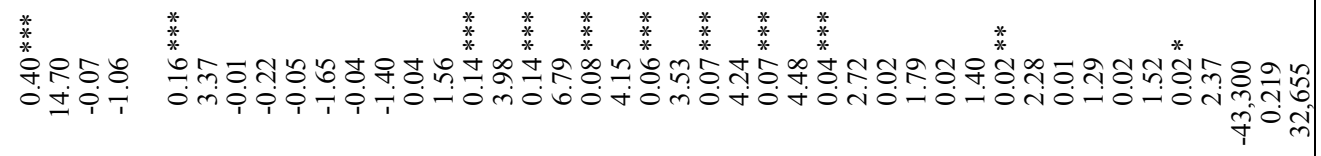

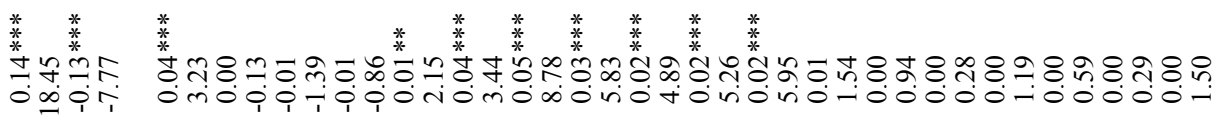

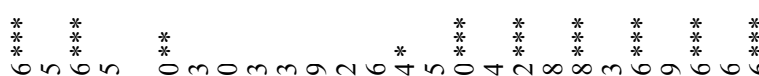

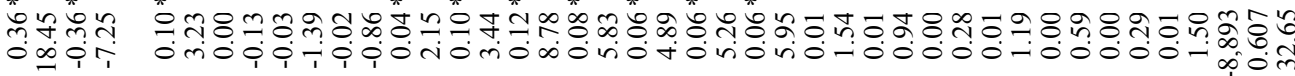

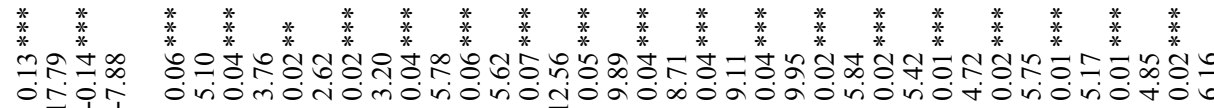

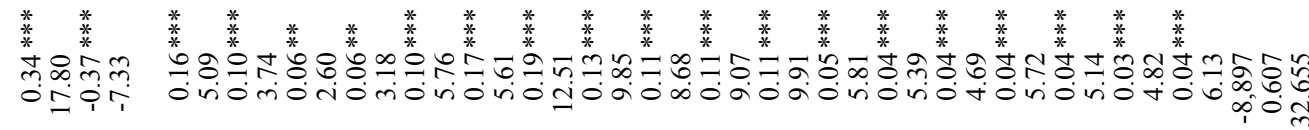

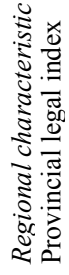

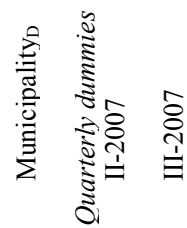

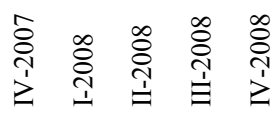

In

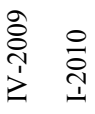

을

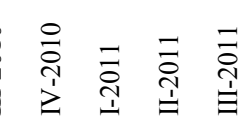

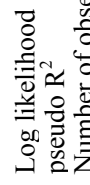




\subsection{Conclusions}

In this study we identify the factors that influence the decision to secure a consumer loan in Vietnam. We focus our analysis on five main hypotheses regarding borrower quality, bank-borrower relationship and economic conditions. We test these hypotheses using a unique data set of loans originated by a large commercial bank in Vietnam between 2007 and 2011. Previous empirical research focuses on commercial loans in developed markets and shows that for these loans lenders require collateral for loans granted to borrowers with lower credit quality. The results in our study are based on a direct measure of credit risk as observed by the bank and confirm that the observed credit quality of the borrower is an important determinant of the use of collateral for consumer loans as well. In addition, we find that wealthier borrowers who are able to pledge collateral do so to benefit from low borrowing rates. We also find that the hold-up effect dominates the benefit of relationship lending in terms of a higher likelihood of collateral in new loans, especially for relatively small loans. However, the scope rather than scale of the borrower-lender relationship actually improves the terms of the loan contract as the usage of collateral decrease. Finally, we find that during crisis periods when uncertainty increases and lending resources are limited, collateralization also increases.

Overall, we find that both incidence and degree of collateralization are higher for consumer loans in Vietnam as a developing banking market compared to developed markets. Regarding determinants of collateral, our findings are in parts consistent with existing evidence from developed markets and for commercial loans. As a typical fact in developing markets the hold-up effect is particularly strong, especially for the small loans for which collateral value is much higher than the loan amount. If property rights can be improved the borrower can make more flexible choices of pledging their asset, for instance to pledge one asset at several banks with clearly identified seniority, and thus reduce the hold-up problem. 


\subsection{Appendix}

\section{Table A2.1 Borrower characteristics included in the bank's ex-ante credit score}

To calculate the ex ante risk score, all points are added up. A higher score indicates lower risk.

\begin{tabular}{lll}
\hline Characteristic & Subdivision & Points \\
\hline Years in current & Unemployed or 0 years & 0 \\
employment/business & Less than 2 years but more than 0 years & 5 \\
& More than 2 years & 10 \\
Industry where the loan & Transportation, Tourism, Store/Office renting, & 0 \\
will be invested in & Service sector & 5 \\
& Agriculture, Construction & 10 \\
& Other or consumer loan & 0 \\
Years of education & Less than 14 years or missing & 5 \\
& More than 14 and less than 16 years & 10 \\
Industry in which & More than 16 years & 0 \\
borrower is engaged & Unemployed & 5 \\
& Service sector & 10 \\
Monthly Income & No income & 0 \\
& Less than 7.000.000 VND (in Hanoi or HCM city) & \\
& or less than 5.000.000 VND (in other provinces) & 5 \\
& More than 7.000.000 VND (in Hanoi or HCM city) & \\
& or more than 5.000.000 VND (in other provinces) & 10 \\
\hline
\end{tabular}

\section{Table A2.2 Variable sources and definitions}

Unless otherwise indicated the variables are obtained from the Vietnamese bank which makes the loan. Subscript D indicates dummy variables.

\begin{tabular}{|c|c|c|}
\hline Category & Variable & Definition \\
\hline \multicolumn{3}{|c|}{$\begin{array}{l}\text { Dependent } \\
\text { variable }\end{array}$} \\
\hline & Collateral $_{\mathrm{D}}$ & Dummy equal to 1 for collateralized loans, 0 otherwise. \\
\hline & Collateral index & $\begin{array}{l}\text { Index based on collateral to loan value ratio (CLR): } 0 \text { if unsecured; } \\
\text { index }=1 \text { if } 0<C L R<1 \text {; index }=2 \text { if } 1<=C L R<1.5 \text {; index }=3 \text { if } 1.5< \\
=C L R<5 \text {; and index }=4 \text { if } C L R>=5 \text {. }\end{array}$ \\
\hline \multicolumn{3}{|c|}{ Borrower characteristics } \\
\hline & Ex-ante risk score & $\begin{array}{l}\text { Score assigned to borrower during initial screening process. Range from } \\
0 \text { to } 50 \text { with higher value indicating lower risk. }\end{array}$ \\
\hline & Home owner ${ }_{D}$ & $\begin{array}{l}\text { Dummy equal to } 1 \text { if the borrower is the owner of his current resident, } 0 \\
\text { otherwise. }\end{array}$ \\
\hline & Age & Age of borrower in years. \\
\hline \multicolumn{3}{|c|}{ Bank-borrower relationship } \\
\hline & Years with bank & $\begin{array}{l}\text { Number of years since the first business contact (e.g. first loan or } \\
\text { account) with the bank. }\end{array}$ \\
\hline & $\begin{array}{l}\text { Number of prior } \\
\text { loans }\end{array}$ & Number of prior loans that the customer has had with the bank. \\
\hline & $\begin{array}{l}\text { Number of bank } \\
\text { products }\end{array}$ & $\begin{array}{l}\text { Number of different bank products that the customer uses with the bank. } \\
\text { This includes saving accounts, debit accounts, prepaid cards and credit } \\
\text { cards. }\end{array}$ \\
\hline & Other bank $\mathrm{D}_{\mathrm{D}}$ & $\begin{array}{l}\text { Dummy equal to } 1 \text { if the borrower indicated to the lender that she is } \\
\text { holding accounts with another bank, } 0 \text { otherwise. }\end{array}$ \\
\hline & Local borrower $r_{D}$ & $\begin{array}{l}\text { Dummy equal to } 1 \text { if the borrower comes from the province where the } \\
\text { branch locates, } 0 \text { otherwise. }\end{array}$ \\
\hline
\end{tabular}




\section{Economics condition}

Base rate

Control variables

Loan

characteristics

Loan duration

Loan size
Regulatory interest rate set by the Vietnamese central bank. Commercial banks are only allowed to lend at interest rates of $150 \%$ or less of this base rate. This base rate is adjusted over time, and being used by the State Bank of Vietnam as a monetary policy instrument. Source: This rate over time can be obtained at the official website of the State Bank of Vietnam: http://www.sbv.gov.vn/wps/portal/vn

Branch operation characteristics

Distance to

headquarter

Main branch ${ }_{D}$

Regional

characteristics

Provincial legal index

Municipality $_{D}$
Loan duration in years.

Natural Logarism of the size of the loan in million Vietnamese dong (VND).

Distance in $\mathrm{km}$ between branch and bank headquarters.

Dummy equal to 1 if the bank classifies the branch, which makes the loan as one of the main branches in the province, 0 otherwise.

An index measuring how transparent and supportive the provincial legal framework it towards enterprises. The original scale of the index ranges from 0 to 10 with higher values indicating better legal framework. Source: Provincial Competitiveness Index. PIC Survey instruments and methodology can be obtained at http://www.pcivietnam.org.

Dummy equal to 1 if the branch is located in one of the 5 first class cities (or centrally governed municipalities) as defined by the Vietnamese government, 0 otherwise. Source: This information can be obtained at the official website of the Vietnamese government: http://www.chinhphu.vn

\section{Table A2.3 Determinants of collateral: marginal coefficient}

This table replicates the Probit regressions of Panel A in Table 5 but reports marginal coefficients in stead of coefficients. The dependent variable is a dummy equal to one for collateralized loans and zero otherwise. For each independent variable, the marginal effect at the mean is reported. Standard errors are heteroskedasticity robust and clustered by borrower. $* * *, * *$ and $*$ indicate statistical significance at the $1 \%, 5 \%$, and $10 \%$ level, respectively.

\begin{tabular}{|c|c|c|c|c|c|}
\hline & All loans & Small loans & Large loans & Short-term & Long-term \\
\hline \multicolumn{6}{|l|}{ Borrower characteristics } \\
\hline Ex-ante risk score & $-0.016 * * *$ & $-0.013 * * *$ & $-0.005 * * *$ & $-0.011 * * *$ & $-0.003 * * *$ \\
\hline Home owner ${ }_{D}$ & $0.312 * * *$ & $0.293 * * *$ & $0.077 * * *$ & $0.267 * * *$ & $0.057 * * *$ \\
\hline Age & $0.016 * * *$ & $0.013 * * *$ & $0.005 * * *$ & $0.014 * * *$ & $0.002 * * *$ \\
\hline \multicolumn{6}{|l|}{ Bank-borrower relationship } \\
\hline Years with bank & $0.031 * * *$ & $0.043 * * *$ & -0.002 & $0.036 * * *$ & $0.001 * * *$ \\
\hline Number of prior loans & $0.019 * * *$ & $0.018 * * *$ & $0.004 * * *$ & $0.016 * * *$ & $0.002 * * *$ \\
\hline Number of bank products & $-0.247 * * *$ & $-0.241 * * *$ & $-0.044 * * *$ & $-0.244 * * *$ & $-0.027 * *$ \\
\hline Other bank $\mathrm{D}_{\mathrm{D}}$ & $-0.091 * * *$ & $-0.079 * * *$ & $-0.023 * *$ & $-0.064 * * *$ & $-0.016 * * *$ \\
\hline Local borrower $_{\mathrm{D}}$ & 0.004 & 0.027 & -0.010 & 0.015 & $0.001 * *$ \\
\hline \multicolumn{6}{|l|}{ Economics conditions } \\
\hline Base rate & $0.027 * * *$ & 0.016 & $0.013 * * *$ & 0.014 & 0.005 \\
\hline \multicolumn{6}{|l|}{ Control variables } \\
\hline \multicolumn{6}{|l|}{ Loan characteristics } \\
\hline Loan duration & $0.010 * * *$ & $0.009 * * *$ & $0.003 * * *$ & 0.000 & $0.004 * * *$ \\
\hline Loan size & $0.403 * * *$ & $0.412 * * *$ & $0.183 * * *$ & $0.327 * * *$ & $0.042 * * *$ \\
\hline Branch operation characteristics & & & & & \\
\hline Distance to head-quarter & $0.000 * *$ & $0.000 * *$ & 0.000 & 0.000 & 0.000 \\
\hline Main branch ${ }_{D}$ & $0.067 * * *$ & $0.056 * * *$ & $0.017 * * *$ & $0.071 * * *$ & $0.001 * * *$ \\
\hline
\end{tabular}


Regional characteristics

Provincial legal index

Municipality

Quarterly dummies

II-2007

III-2007

IV-2007

I-2008

II-2008

III-2008

IV-2008

I-2009

II-2009

III-2009

IV-2009

I-2010

II-2010

III-2010

IV-2010

I-2011

II-2011

III-2011

0.120 ***
-0.152 ***
$0.030 * *$
-0.014
$-0.021 * *$
$-0.012 *$
0.007
$0.036 * *$
$0.046 * * *$
$0.028 * * *$
$0.022 * * *$
$0.023 * * *$
$0.023 * * *$
0.005
0.002
0.000
0.003
0.002
0.001
0.005

$0.111 * * *$

$0.031 * * *$

$0.079 * * *$

$0.022 * * *$

$-0.166 * * * \quad-0.032 * * *$

$-0.156 * * *$

$-0.017$

Log likelihood

Pseudo $\mathrm{R}^{2}$

$-8825.451$

$0.022 *$

$0.023 *$

0.002

$-0.011$

$0.021 * *$

$-0.010$

$-0.002$

$-0.015 * \quad 0.007$

$-0.013 *$

$-0.001$

$0.014 * *$

-0.017 **

$-0.003$

$0.023 *$

$0.021 * * *$

$-0.001$

$0.021 * * 0.001$

$\begin{array}{llll}* & 0.024 * * & 0.024 * * & 0.000\end{array}$

$0.037 * * * \quad 0.026 * * * \quad 0.030 * * *$

$0.021 * * * \quad 0.021 * * * \quad 0.016 * * *$

$0.017 * * * \quad 0.017 * * * \quad 0.010 * *$

$0.017 * * * \quad 0.017 * * * \quad 0.012 * *$

$0.017 * * *$

0.004

$0.016 * * * \quad 0.012 * *$

0.001

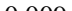

$0.012 * *$

$0.008 * * * \quad-0.002$

$-0.001$

0.000

$0.007 * * * \quad-0.003$

$0.008 * * * \quad-0.001$

0.001

$0.007 * * * \quad-0.001$

$-0.001$

$0.007 * * * \quad-0.002$

0.000

$0.009 * * *$

0.003

$0.007 * * *$

0.001

$0.008 * * *$

$0.007 * * *$

$0.002 *$

$0.001 * *$

$0.001 *$

$0.001 * *$

0.001

$0.001 *$

$0.002 * * *$

Number of observations

60.98

$-5643.298$

$-2807.7$

$-6085.6$

$-2115.1$

32655

59.71

52.18

56.78

61.46

21408

10717


Chapter 3

\section{Bank Lending Strategy, Credit Scoring and Financial Crises $^{7}$}

\subsection{Introduction}

Economic and financial crises are commonly accompanied by reductions in bank lending. During the financial crisis of 2007/08, banks substantially reduced credit to both domestic borrowers (Ivashina and Scharfstein, 2010) and international borrowers (Cetorelli and Goldberg, 2010 and 2012; Herrmann and Mihaljek, 2010; Milesi-Ferretti and Tille, 2010; Peek and Rosengren, 1997; Popov and Udell, 2012; Takats, 2010). ${ }^{8}$ According to Ivashina and Scharfstein (2010), new loans to large US borrowers fell by $47 \%$ during the peak of the financial crisis (fourth quarter of 2008) relative to the preceding quarter and by $79 \%$ relative to the peak of the credit boom (second quarter of 2007). The observed reduction in bank lending is driven by shifts in supply, e.g., credit rationing, as well as by shifts in demand (Bernanke and Gertler, 1995). While a reduction in loan demand can be attributed to the deterioration of economic conditions, i.e., fewer profitable investment opportunities for corporations or increased unemployment risk for consumers, the reduction of loan supply can be understood as the result of an increase in uncertainty and asymmetric information and an accompanying increase in adverse selection.

Lending is characterized by information asymmetry between banks and borrowers. Borrowers have an informational advantage over lenders because they know more than lenders do about the investment projects they wish to undertake. This informational advantage results in adverse selection and the classic "lemons" problem (Akerlof, 1970) that occurs because banks cannot differentiate "good" borrowers (low default risk) from "bad" ones (high default risk). Banks will therefore only make loans at interest rates reflecting average borrower quality, with high-quality borrowers paying an interest rate that is too high and low-quality borrowers paying an interest rate that is too low. Consequently, some high-quality borrowers may decide to drop out of the market. Adverse selection can also be described as a problem that occurs because potential bad borrowers are the ones that most actively seek loans which increases the chance that a loan might be made

\footnotetext{
${ }^{7}$ This chapter is based on 'Bank lending Strategy, Credit Scoring and Financial Crises' co-authored with Stefanie Kleimeier and Stefan Straetmans.

${ }^{8}$ The collapse of corporate borrowing and lending should be distinguished from the liquidity crunch in short-term interbank borrowing and lending during the 2007/2008 banking crisis. Although the causes are comparable, i.e., increased asymmetric information and adverse selection, this paper focuses rather on the collapse of corporate borrowing and lending.
} 
to a bad borrower. Stiglitz and Weiss (1981) analyze adverse selection and incentive effects in the loan market and show that a bank that raises its interest rate may suffer because only risky borrowers will be willing to borrow at higher rates. Thus, banks might choose not to raise their interest rates to eliminate credit demand, resulting in possible credit rationing.

During an economic and financial crisis, the adverse selection problem typically intensifies on two fronts. First, the degree of information asymmetry increases as banks find it more difficult to distinguish good from bad borrowers. The behavior and performance of borrowers are expected to change significantly during a crisis, but banks have difficulties in correctly anticipating these changes and incorporating them into their credit decision-making process (AD\&B, 2009). Second, increased default risk translates into a higher risk premium. These higher borrowing costs in turn cause more good borrowers to drop out of the market (Kirabaeva, 2011).

Banks have limited options to deal with adverse selection. On the one hand, they can ration credit. However, there are limits to how much banks can reduce credit supply in times of crises because a bank's business model and profitability still depend to an important extent on the size of its loan portfolio. In other words, they can also ration themselves into bankruptcy. On the other hand, banks can try to better control the adverse selection problem by incentivizing borrowers to behave well (e.g., by giving them "skin in the game" by requiring collateral) or by improving their ex-ante screening of potential clients. Through such measures, banks rely mainly on "relationship" banking by having frequent contacts with their clients or using quantitative tools, such as credit scoring models (CSMs). However, CSMs are expected to quickly become unreliable when an economic and financial crisis strikes and when the economic environment, and thus borrowers' true default risk, deteriorates. For example, Jankowitsch et al. (2007) show that enhancing the statistical power of a rating system decreases the potential effects of adverse selection. We argue that re-estimating CSMs by using more recent data constitutes one way of improving the performance of rating systems such as CSMs.

Our study contributes to the existing literature on the relationship between rating system performance and macro-economic performance; see, e.g., Avery et al. (2004), Bonfim (2009), Lucas and Klaassen (2006) or Carling et al. (2007). The existing literature claims that the failure to consider general economic circumstances in a continuous way can diminish the performance of rating models. Our approach, however, is more specific in that we explicitly focus on the impact of financial crises on credit rating systems. To our knowledge, this approach is novel to the literature concerned with performance evaluation of dynamic credit rating systems such as CSMs. We estimate CSMs over different sample periods to 
show how a CSM's performance can be improved through re-estimation. More specifically, we hypothesize that updating a CSM using post-crisis data can improve the bank's screening ability and thus reduce adverse selection. ${ }^{9} \mathrm{We}$ estimate a CSM for the Vietnamese retail banking market for the period around the 2007/2008 financial crisis. Our focus on Vietnam as an emerging country has two advantages. First, although developing markets were not directly affected by the crisis, they were nevertheless indirectly exposed through export and foreign investment channels. For example, credit grew in Vietnam between 2000 and 2011 at the substantial average annual rate of $31.45 \%$. However, the global crisis affected the Vietnamese banking market in 2008, as credit growth dropped to approximately $20 \%$. Similarly, non-performing loans rose to $3.5 \%$ in 2008 but in 2009 had dropped back to the 2007-level of approximately 2.0\% (Quach, 2011). According to an IMF survey ${ }^{10}$, developing markets are now leading the global recovery out of the financial crisis, and Vietnam is among the emerging markets that have seen growth bounce back in 2011. ${ }^{11}$ Vietnam is thus a banking market in which crisis effects are clearly present, but short-lived. This allows us to investigate not only pre-crisis and crisis periods but also a distinct post-crisis period. Last but not least, the use of emerging market data enables us to evaluate the post-crisis performance of CSMs, which may provide useful insights for bankers, policy makers or regulators in the more-developed financial systems still faced with crises and unresolved structural problems. Second, we expect that the use of emerging market data produce value-added, as adverse selection is plausibly at least as severe - if not worse - in emerging markets as in developed markets, regardless of whether crisis periods are considered. This is because in developing markets information asymmetry can be substantial, due, e.g., to weak financial disclosure laws or the absence of credit bureaus. This problem is further aggravated by an underdeveloped banking system in which CSMs are not commonly used. The lack of government regulation and the weak institutional framework within which banks must operate makes the use of appropriate screening mechanisms, such as CSMs, relatively more important for emerging market banks than for banks in more developed banking systems.

Anticipating our results, we find (i) that estimated CSM parameters differ considerably for pre-crisis, crisis or post-crisis data and (ii) that updating CSMs using post-crisis data would help banks contain the increase in adverse selection

\footnotetext{
${ }^{9}$ Adverse selection also increases the likelihood of credit rationing in which some borrowers are arbitrarily denied loans. Consequently, profitable investment projects are not undertaken, which is bad for the economy as a whole and might prolong the effects of a crisis (Stiglitz and Weiss, 1981).

${ }^{10} \mathrm{See} \mathrm{http://www.imf.org/external/pubs/ft/survey/so/2010/new120910a.htm} \mathrm{for} \mathrm{details.}$

${ }^{11}$ Developing East Asia, excluding China, is performing better with growth projected to be $5.6 \%$ in 2012 , higher than the $4.4 \%$ recorded in 2011 . Vietnam's recovery from the global economic crisis has been rapid. The growth rates of key economic indicators, including real GDP, industrial production, investment, and exports, are expected to recover to near their pre-crisis trend growth rates.
} 
problems occasioned by the crisis. In fact, post-crisis CSM can provide banks with several benefits. First, banks can substantially improve profitability. Second, banks can reduce their adverse selection problems because they can price loans more accurately. Third, an updated CSM more effectively identifies good and bad loans and thus reduces the number of loans that must be reviewed in detail by the loan officer. Thus, banks can conduct their relationship lending more efficiently.

The remainder of the paper is structured as follows: Section 2 presents a general CSM as currently applied to retail credit and illustrates the modeling steps and decisions that must be taken in formulating a CSM. In section 3, credit scoring models are estimated using different samples of period-specific input data. Specific applications of different models regarding bank profitability, risk-based loan pricing, and relationship lending are explored in section 4 . Section 5 concludes.

\subsection{A credit scoring methodology for retail loans}

CSMs are commonly structured along the lines of Altman's (1968) Z-score model in which variables are selected based on their predictive power. ${ }^{12}$ Typically, a CSM is estimated using historical loan and borrower data to identify which borrower characteristics are most strongly associated with defaulted and nondefaulted loans. Based on a CSM estimated with historical data, a credit score can now be calculated for each new loan applicant, where a higher score indicates a better-expected performance of the borrower and thus a lower probability of default (PD). This score must be compared with the CSM's cut-off rate to determine whether the loan application is accepted, rejected or requires further assessment. Thus, as part of the CSM developmental stage, calibration is also necessary so that an optimal cut-off rate, in line with the lender's objectives, can be determined.

The 2007/2008 financial crisis caused a fundamental change in the global economic environment. This change entails that existing assessment systems, including CSMs, based on historical pre-crisis data, are likely to have poor defaultpredicting power for post-crisis applicants. The crisis changed borrowers' payment behavior; therefore, adjustments will be required at all stages of CSM development, from variable selection to variable coding and from probability of default (PD) calibration to cut-off setting.

\footnotetext{
${ }^{12}$ For an overview of the bankruptcy prediction literature since Altman's original study, see Byström et al. (2005) or Philosophov and Philosophov (2002). The former paper is also the only one to investigate the issue for a developing country. See Laitinen (1999) for a discussion of the related literature on the prediction of credit risk ratings.
} 


\subsubsection{The estimation method}

The development of a CSM starts with a decision about the specification of the model, i.e., one must choose among decision trees, linear probability models, Logit or Probit regression models or multiple discriminant analyses. Following most of the existing literature, we opt for the logistic regression method. We start with a retail loan sample containing information on borrower characteristics and ex-post default status. A borrower's ex-ante PD is unobservable, but the logistic regression technique enables us to estimate it. This technique assumes the existence of a continuous latent variable $\mathrm{Z}_{\mathrm{j}}$ that is linear in the loan characteristics $\mathrm{x}$ of the bank's retail clients:

$$
Z_{j}=W^{\prime} x=W_{1} x_{j 1}+W_{2} x_{j 2}+\cdots+W_{k} x_{j k}+\varepsilon
$$

where $\mathrm{w}_{\mathrm{k}}$ is the coefficient of the $\mathrm{k}^{\text {th }}$ variable $\mathrm{x}_{\mathrm{jk}}$ is the value of variable $\mathrm{k}$ for applicant $\mathrm{j}$. $\mathrm{Z}_{\mathrm{j}}$ is known as the $\mathrm{j}^{\text {th }}$ applicant's $\mathrm{Z}$-Score. $\mathrm{Z}_{\mathrm{j}}$ is ex-ante unobservable, and default can only be defined ex-post as a dummy variable (with default corresponding to a value of 1 and 0 otherwise). Equation (3.2) relates the default probability $\pi$ to the latent variable $Z$ by assuming that they are linked via a logistic distribution model. We estimate the parameters using iterative maximum likelihood estimation. Larger values of $\pi$ reflect a higher PD.

$$
\pi_{j}=\frac{1}{1+e^{-\left(W^{\prime} x\right)}}
$$

\subsubsection{Variable identification}

A choice must be made about which variables to initially consider for equations (3.1) and (3.2). There is no overall consensus regarding the number or types of initial variables to try. Some models start with as many as 50 variables. Table 3.1 presents a list of the more commonly used variables for retail CSMs. In CSMs for corporate loans, the variables are relatively similar across countries and are limited to financial statement data (Allen et al., 2004). For retail loans, direct measures of the financial strength of the borrower, such as income or the value of one's home, are included. Given the limited availability of such proxies for individuals, proxies that measure the financial strength of a borrower indirectly (e.g., education, household size, years at employer or postal code) must also be used. There appear to be only a few variables that are typical for developing countries, such as gender, religion, branch and loan officer. This finding can be explained by the fact that banks in most developed countries are prohibited by law from using variables such as gender, whereas banks in developing countries are not. Branch and loan officer variables can reflect branch policy, bonuses, experience or training levels. Their inclusion in the CSM for Bolivia might indicate that differences across branches 
and loan officers are more pronounced in less-developed banking markets. Except for these few variables, however, it appears that retail CSM for a developing country can generally start with the same set of variables as a retail CSM for a developed country.

Note that not all variables are fully available. Values may be structurally missing (e.g., questions that are asked conditionally on the responses to previous questions). Alternatively, missing values might be due to a deficient information system in some branches or to customers who are unwilling to completely fill out application forms. Excluding all variables with missing values might substantially reduce sample size and lead to a loss of valuable information, whereas including variables with only a few valid observations might lead to unreliable results. To balance these two disadvantages, we first identify those variables that show a substantial number of missing values. Second, we rely on loan officers' expert knowledge and feeling for the data and borrower characteristics to identify which of these variables can or cannot be excluded from the model (Henley and Hand, 1997). 


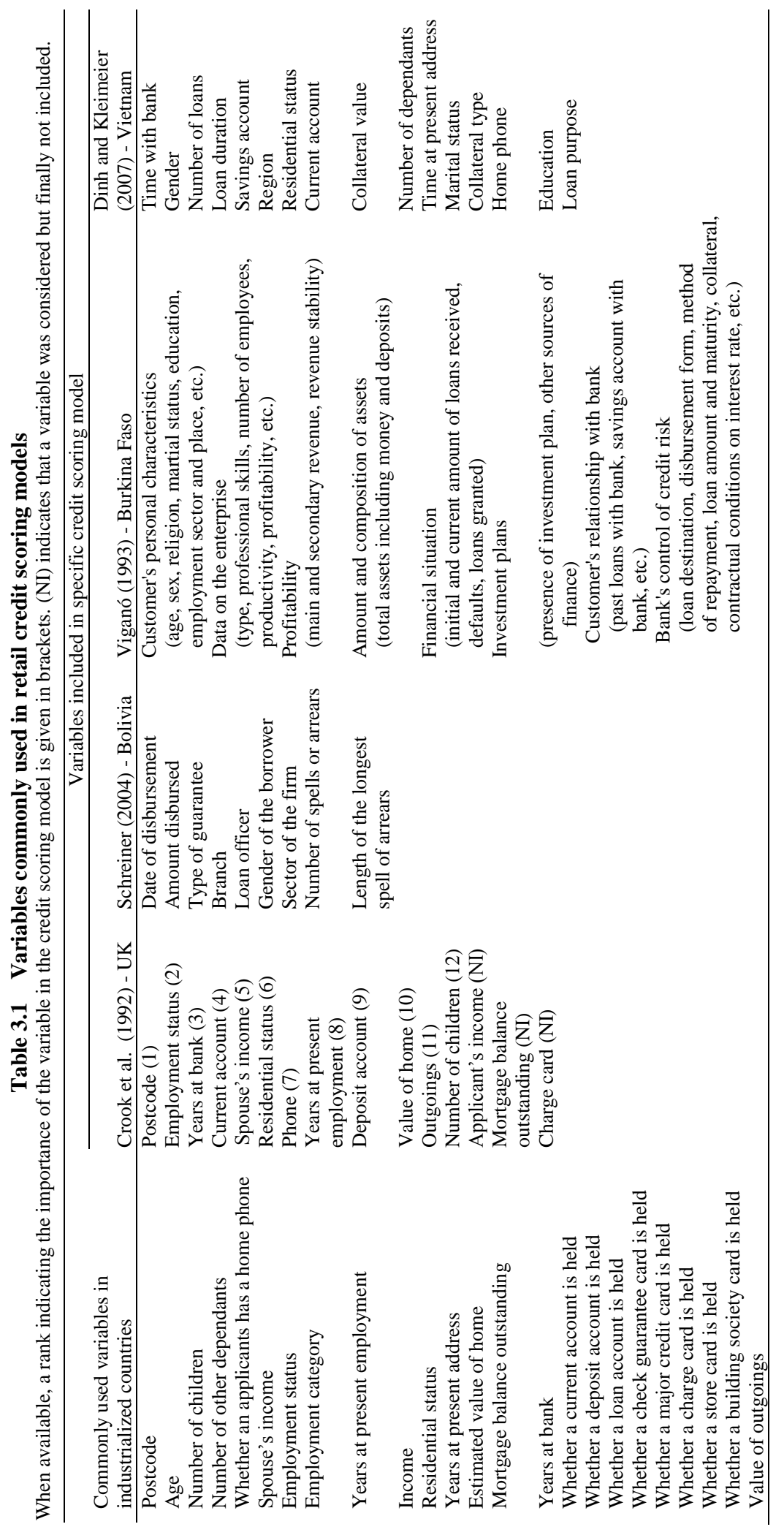




\subsubsection{Variable categorization}

After the choice of the initial set of independent variables has been made, qualitative as well as quantitative variables must be coded. Coding of a quantitative variable is required when the relationship between the variable and default probability is nonlinear. As Thomas (2000) argues, instead of trying to map such a relationship as a straight line, borrowers can be grouped into various categories, thus generating a categorical variable. The latter approach is more commonly used in credit scoring, mainly because it can also be applied to qualitative variables. Thus, we adopt this approach for all our variables. To complete the coding of the variables, a value must be attached to each category. Boyle et al. (1992) show that variables can be coded based on the distribution of defaulted and non-defaulted loans in the sample. If a variable has $m$ categories, let $g_{i}$ be the number of good (non-defaulted) loans belonging to the $\mathrm{i}^{\text {th }}$ category and $\mathrm{b}_{\mathrm{i}}$ the number of bad (defaulted) loans belonging to the $\mathrm{i}^{\text {th }}$ category. $\mathrm{G}$ and $\mathrm{B}$ are the total number of good and bad loans, respectively, in the whole sample, such that

$$
\mathrm{G}=\sum_{\mathrm{i}=1}^{\mathrm{m}} \mathrm{g}_{\mathrm{i}} \quad \text { and } \quad \mathrm{B}=\sum_{\mathrm{i}=1}^{\mathrm{m}} \mathrm{b}_{\mathrm{i}}
$$

Instead of using a simple coding rule ${ }^{13}$, estimates of the odd of good and bad loans in the $\mathrm{i}^{\text {th }}$ category are commonly used. We follow Crook and Shumway (1992) and code our variables as ${ }^{14}$

$$
\ln \left(\mathrm{g}_{\mathrm{i}} / \mathrm{b}_{\mathrm{i}}\right)+\ln (\mathrm{B} / \mathrm{G})
$$

For qualitative variables, for which the number of possible categories is very large, coding all categories becomes infeasible. For such cases, we follow Thomas (2000) and Boyle et al. (1992) recommendation and aggregate values of similar PD measured as $b_{i} /\left(g_{i}+b_{i}\right)$.

\subsubsection{Variable selection and estimation of the CSM}

Once the variables have been coded, equation (3.2) can be estimated. As is evident from retail CSMs in developed countries, the model can initially contain a large number of variables. While this might be statistically feasible for large samples, there are practical restrictions. Too many questions in an application form deter loan applicants, who may not answer all questions or decide to apply for a loan elsewhere. Efficiency and applicability thus require that the number of variables be reduced. We therefore apply a forward as well as a backward stepwise method that

\footnotetext{
${ }^{13}$ A simple rule assigns, for example, a value of 1 to the category with the lowest PD, a value of 2 to the category with the second highest PD, etc.

${ }^{14}$ In each sub-sample, $\ln (\mathrm{B} / \mathrm{G})$ is constant. In practice, when banks are updating their CSM at regular intervals, this value will change with every update.
} 
sequentially adds or withdraws variables to maximize the model's predictive accuracy (Henley and Hand, 1997). At this point, the final version of the CSM can be determined and the coefficients $w_{j}$ of equation (3.2) can be estimated.

\subsubsection{CSM's predictive accuracy}

The CSM should be tested for its predictive accuracy out-of-sample. The PD it produces is then compared to a cut-off value to establish whether a loan applicant will be a good (non-defaulting) or bad (defaulting) borrower. Initially, a cut-off value of $50 \%$ can be chosen so that an applicant whose estimated PD is greater (smaller) than $50 \%$ will be classified as a bad (good) borrower. This classification is then compared with the observed incidence of default to establish the accuracy of the model. A classification table, as shown in Table 3.2, is commonly employed at this stage. $G_{\mathrm{g}}$ represents the number of correctly classified good loans, whereas $\mathrm{G}_{\mathrm{b}}$ represents the number of good loans that are incorrectly classified as bad loans. Similarly, $\mathrm{B}_{\mathrm{b}}$ represents the number of correctly classified bad loans, whereas $\mathrm{B}_{\mathrm{g}}$ represents the number of bad loans that are incorrectly classified as good loans. The percentage of correctly classified (PCC) loans serves as an accuracy measure. The percentage of correctly classified good loans $\left(\mathrm{PCC}_{\mathrm{good}}\right)$ is defined as the proportion of correctly classified good loans to the total number of observed good loans. Correspondingly, the percentage of correctly classified bad loans $\left(\mathrm{PCC}_{\mathrm{bad}}\right)$ is defined as the proportion of correctly classified bad loans to the total number of observed bad loans. Finally, the percentage of correctly classified total loans $\left(\mathrm{PCC}_{\text {total }}\right)$ is defined as the number of correctly classified loans relative to the total number of loans. Though simple to use, PCC may not always be an appropriate accuracy measure, as it implicitly assumes that the costs of misclassification of bad and good loans are equal. For banks, however, one classification error may be much more costly than another. To address this issue, Baesens et al. (2003) use two additional accuracy measures called sensitivity (SENS) and specificity (SPEC). In contrast to $\mathrm{PCC}_{\mathrm{bad}}$, which relates the predicted bad loans to the total number of observed bad loans, SPEC is defined as the ratio of the number of correctly classified bad loans to the total number of classified bad loans. Correspondingly, SENS is defined as the ratio of the number of correctly classified good loans to the total number of classified good loans. Banks may wish to minimize both $B_{g}$ and $G_{b}$ simultaneously. However, reducing $B_{g}$ comes at the expense of increasing $G_{b}$, and vice versa. Thus, banks should take into account differences in cost arising from misclassified good versus misclassified bad loans. 


\section{Table 3.2 Predictive accuracy of credit scoring models}

For the abbreviations $G_{g}, G_{b}, B_{b}$ and $B_{g}$ the capital letter indicates the actual nature of the loan whereas the subscript indicates the predicted nature. Based on these four measures, the accuracy of a credit scoring model can be assessed by the percentage of correctly classified loans (PCC), sensitivity (SENS) and specificity (SPEC).

\begin{tabular}{|c|c|c|c|}
\hline \multirow[b]{2}{*}{ Observation } & \multicolumn{2}{|c|}{ Prediction } & \multirow[b]{2}{*}{ PCC } \\
\hline & Non-default & Default & \\
\hline Non-default & $\mathrm{G}_{\mathrm{g}}$ & $\mathrm{G}_{\mathrm{b}}$ & $\mathrm{PCC}_{\text {good }}=\mathrm{G}_{\mathrm{g}} /\left(\mathrm{G}_{\mathrm{g}}+\mathrm{G}_{\mathrm{b}}\right)$ \\
\hline Default & $\mathrm{B}_{\mathrm{g}}$ & $\mathrm{B}_{\mathrm{b}}$ & $\begin{array}{c}\mathrm{PCC}_{\text {bad }}=\mathrm{B}_{\mathrm{b}} /\left(\mathrm{B}_{\mathrm{b}}+\mathrm{B}_{\mathrm{g}}\right) \\
\mathrm{PCC}_{\text {total }}=\left(\mathrm{G}_{\mathrm{g}}+\mathrm{B}_{\mathrm{b}}\right) / \\
\left(\mathrm{G}_{\mathrm{g}}+\mathrm{G}_{\mathrm{b}}+\mathrm{B}_{\mathrm{b}}+\mathrm{B}_{\mathrm{g}}\right)\end{array}$ \\
\hline SENS & $\mathrm{G}_{\mathrm{g}} /\left(\mathrm{G}_{\mathrm{g}}+\mathrm{B}_{\mathrm{g}}\right)$ & & \\
\hline SPEC & & ${ }_{b} /\left(B_{b}+G_{b}\right.$ & \\
\hline
\end{tabular}

One major drawback of the aforementioned assessment measures is that they depend on the selected cut-offs and default percentage of the sample. Therefore, these measures are not appropriate for comparing the performances of models constructed from different data sets. CSMs are therefore usually evaluated using a power curve such as the Cumulative Accuracy Profile (CAP) ${ }^{15}$ or the Receiver Operating Characteristic (ROC) curve (Kraznowski and Hand, 2009). Unlike the CAP curve and the aforementioned measures, a ROC curve represents the CSM's performance for all possible cut-off values and is independent of the composition of the loan portfolio. A ROC curve is the most popular graphic representation of CSM performance. Therefore, in this paper, we focus on the ROC curve and its summary index, known as the Area Under the Curve (AUC), to compare the performance of our different models.

The ROC curve is represented by the non-diagonal plot of the true positive rate (SENS) on the vertical axis and the false positive rate (1-SPEC) on the horizontal axis, for all possible cut-off points. In Figure 3.1, a hypothetical ROC curve is plotted. A perfect model would correctly classify all defaults, and be represented by the horizontal line at the unit true positive rate. On the other side, a model with zero predictive power is represented by a 45 -degree line. Any other model with some predictive power would be represented by a concave curve positioned between the two extreme cases.

\footnotetext{
${ }^{15}$ The CAP curve depends on the composition of the portfolio (Basel Committee on Banking Supervision, 2005). Hence, the CAP curve cannot be used to monitor scoring models over time when the composition of the portfolio changes or to compare classifier performances of rating models across two different portfolios (Sobehart and Keenan, 2001).
} 


\section{Figure 3.1 ROC curve}

This figure shows an example of a ROC curve and its interpretation.

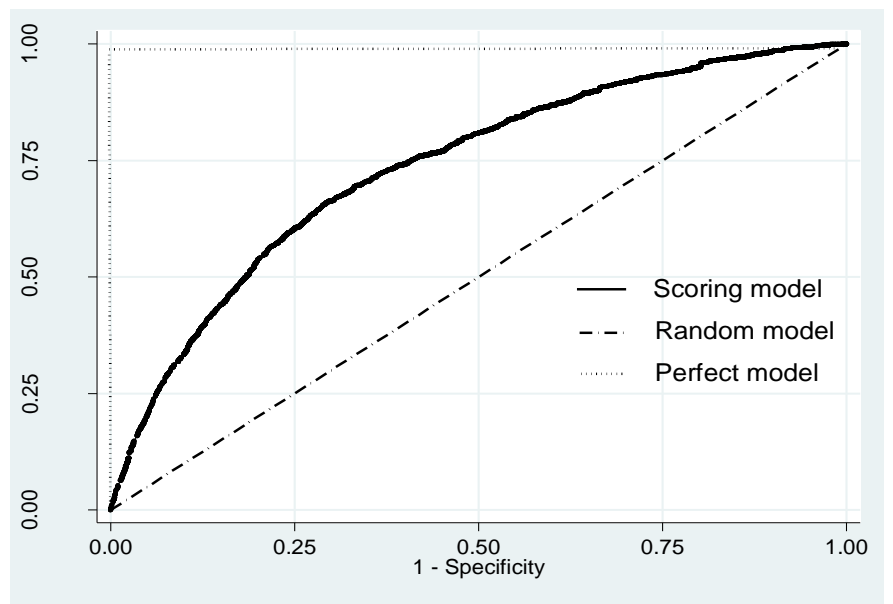

In Figure 3.1, the area between the axis of the abscissa and the ROC curve (AUC) is a measure of discriminatory power. It takes values in the $[0.5,1]$ interval, where the two bounds correspond to models with zero and full discriminatory power, respectively. By normalizing the AUC index (AUC-0.5)/0.5=G, the Gini index $\mathrm{G}$ is obtained. This index, which can be considered as a general power statistic, is widely used in banking practice. The rule of thumb is that a CSM should be updated if $\mathrm{G}$ falls below approximately $20 \%$.

Neither AUC nor G depends on the proportion of defaulted loans in the bank's portfolio. Therefore, they can be used to monitor the performance of a CSM over time. However, similarly to measures such as PCC, SENS and SPEC, the main drawback of the ROC and AUC curves is the assumption of equal misclassification error costs. For most banks, the cost of $B_{g}$ will be much higher than the cost of $G_{b}$. In section 3.4.1, we therefore introduce a more advanced method that explicitly takes these two costs into account.

\subsection{An application to the Vietnamese retail lending market}

From 1987 onward, Vietnamese economic reforms put the economy on a path from a centrally planned economy to a market economy. To date, however, Vietnamese banks have suffered from insufficient capital buffers, inadequate provisions for possible loan losses or defaults, low profitability and the slow pace of institutional reform. With respect to risk assessment and management, there are numerous difficulties, including a lack of transparency in non-performing loan disclosure. As part of a broader strategy, all banks have been asked by the State Bank of Vietnam 
(SBV) to develop a comprehensive "credit manual" that accounts for generally accepted international risk management practices and standards. The development of a proper CSM is an integral part of this initiative. By 2006, a number of large banks had implemented their CSM to meet the SBV's requirements.

Like many other open developing economies, Vietnam was affected by the $2007 / 2008$ global financial crisis, which revealed structural weaknesses in Vietnam's economy. ${ }^{16}$ The direct impact on the Vietnamese economy remained small due to Vietnam's limited linkages with international financial markets and the fact that more than $50 \%$ of the banking sector remains state-owned. Nonetheless, Vietnam was affected indirectly through trade FDI and financial capital movements. In addition, Vietnamese employment and economic growth were both negatively affected by the global financial crisis. According to reports from 41 of the 63 provinces and cities of Vietnam ${ }^{17}, 66,700$ workers (of a total 45 million) lost their jobs in 2008, raising the national unemployment rate to $4.65 \%$. The situation deteriorated further in 2009 , with unemployment rising to $5 \%$ and economic growth slowing to a $6.5 \%$ annual rate. The rise in unemployment adversely affected domestic demand and consumer sentiment in Vietnam. In 2008, investment volumes slumped as investor concern about the long-term prospects of the Vietnamese economy grew. Credit growth declined to $20 \%$ compared with $54 \%$ in 2007 . The stock market experienced its worst performance since it was established. As a result, the government started easing monetary policy beginning in July 2008 by decreasing its benchmark interest rate six consecutive times.

Thus, like many other countries, Vietnam has experienced unprecedented and rapid changes resulting from the global financial crisis. Because lower economic growth and higher unemployment adversely affected loan performance, credit managers were obliged to reassess the accuracy of their credit assessment processes.

To better understand the potentially changing borrower credit risk faced by banks in developing countries affected by the global financial crisis, we estimate our credit scoring models based on the retail loan portfolio of a single privately owned Vietnamese commercial bank. We consider 66,226 retail loans signed between July 2006 and August 2010 and observe their performance, e.g., defaults versus non-defaults, through August 2011. The crisis affected Vietnam's banking market only in 2008, and our bank is representative of the Vietnamese banking market in terms of loan volume. Figure 3.2 shows the monthly number of new loans supplied

\footnotetext{
${ }^{16}$ An example is the low efficiency of investment, especially public investment. The incremental capital output ratio (ICOR) is significantly higher in Vietnam than in other Asian countries, suggesting the lower efficiency of capital usage in Vietnam.

${ }^{17}$ There are large differences in the reported Vietnamese unemployment rate, depending on the data source. We use the unemployment data announced by the Vietnamese labor and employment ministry.
} 
by our bank from 2006 to 2010 . The number of loans rose steadily and steeply in 2006 and 2007 and reached a maximum of more than 3,000 new loans in January 2008. During 2008, however, the number of new loans dropped sharply to almost zero in August 2008. Since then, the number of new loans has steadily increased again and by late 2010 had almost reached pre-crisis levels. Motivated by these observations, we split the bank's loan portfolio into the following sub-samples: a pre-crisis sample, which contains 25,302 loans signed between July 2006 and February 2008; a crisis sample, which includes 7,432 loans signed between March 2008 and December 2008; and a post-crisis sample, which includes 18,704 loans signed between January 2009 and December 2009. Finally, our out-of sample contains 14,788 loans signed, following the post-crisis period, between January 2010 and August 2010. We estimate four models based on different combinations of the three samples. Model 1 uses the full-period sample, combining pre-crisis, crisis and post crisis samples. Model 2 covers periods of stability, combining the pre-crisis and post-crisis samples. Model 3 uses the pre-crisis sample. Finally, model 4 uses the post-crisis sample. We then assess the performance of these different models based on the post-crisis out-of sample. In this way, we put ourselves in the position of a loan officer required to assess the unknown ex-ante creditworthiness of a loan applicant in 2011. The accuracy of a model can be evaluated by comparing its predictions with ex-post observed credit risks.

Figure 3.2 Number of new loans before, during and after the crisis This figure present the number of new loans funded by our bank from 2006 to 2010. The dotted part of the line indicates those months that we consider as our crisis period.

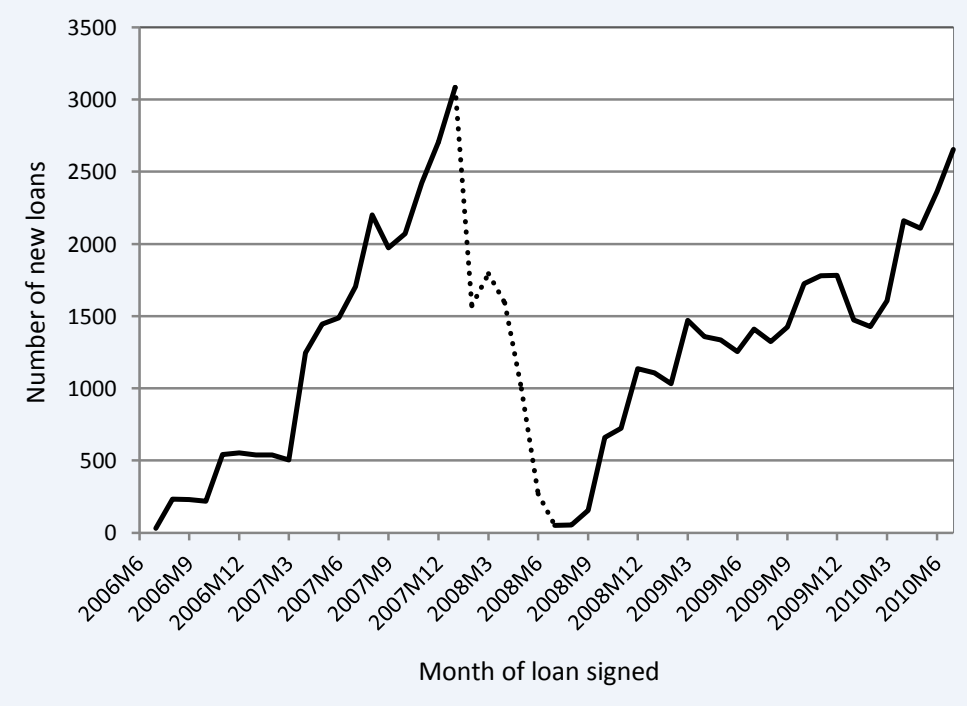




\subsubsection{Variable identification}

As Panel A of Table 3.3 shows, the bank distinguishes four borrower groups based on loan purpose: borrowers raising money to finance their business (commercial); borrowers raising money for living expenses or consumption (consumer); borrowers raising money for the purchase or maintenance of a home (real estate); and borrowers raising money via the bank's credit card facility or the bank's employees borrowing money for unknown purposes (other). Thus, our sample includes both consumer and business loans. In Vietnam in general and in our bank in particular, business loans typically finance relatively small private businesses. Due to a lack of reliable up-to-date financial data on these corporate borrowers and due to the boundary between the private and business property of an entrepreneur often being vague, the bank assesses these loans based on the personal information of the entrepreneur. Real estate and consumer loans are the most frequent loans, accounting for $37 \%$ and $26 \%$ of the bank's loan portfolio, respectively. The remaining loan types account for only $16 \%$ to $20 \%$ of the bank's loan portfolio. Over the pre-crisis sample, the bank appears to grant more loans for commercial and other purposes than for consumer purposes: the bank grants $24 \%$ of its loans for other purposes, $21 \%$ for business purposes and only $14 \%$ for consumer purposes. In terms of loan size, loans granted post-crisis are much larger than loans granted pre-crisis. This can be partly explained by the high inflation rates in Vietnam, which usually run at 7-9\% annually but sharply increased in 2008 to $23.1 \%$. It is also possible that since the crisis, the bank has focused on larger loans for more effective scanning and monitoring. However, the variations in loan size between the crisis and pre-crisis samples are substantially smaller than in the postcrisis samples. Thus, the pre-crisis and crisis loans are more homogeneous with respect to size than the post-crisis loans.

As Figure 3.2 shows, our bank's loan portfolio represents the development of the overall Vietnamese banking market very well. The crisis is reflected in a sharp but short-lived reduction in lending, as the number of loans in our sample drops from 25,302 in the pre-crisis period to 7,432 in the crisis period. Thus, in terms of loan volume, e.g., credit rationing, the bank appears to have recovered rapidly. The bank considers 90 days of payment delay, or at least three consecutive payment delays, as loan default. Defaulted loans account for 3.8\% of the 66,226 loans in our sample, which is slightly lower than the $4.9 \%$ of defaulted loans in the bank's total loan portfolio. ${ }^{18}$ Over time, default rates vary, ranging from as little as $2.6 \%$ for

\footnotetext{
${ }^{18}$ The population PD of $4.9 \%$ is in line with the PD reported on banks' financial statements but is far below the alternative figures of $35 \%$ to $70 \%$ reported by the World Bank. For the purposes of this study, we assume that the data provided to us by the bank are an accurate record of all defaults. As long as any potential misreporting is not structurally related to borrower characteristics (i.e., the variables included in our CSM), this assumption is acceptable, as it does not affect the estimation of the model but would lead only to an overstatement of the predictive accuracy of the model.
} 
post-crisis loans to $5.1 \%$ for pre-crisis loans. The low default rate for post-crisis loans may be attributable to the bank reserving loans for its best customers at this stage and to the fact that the most severe impact of the financial crisis was over before these loans were signed. The high default rate on loans signed before the crisis is understandable, as these loans suffered during the crisis period. Comparing defaulted and non-defaulted loans of different sub-samples (cf. Panel B of Table 3.3) reveals additional differences. For all samples, the defaulted borrowers are younger, have been bank customers for shorter periods of time, have fewer savings accounts at the bank and have less collateral. In contrast to the other samples, in the post-crisis sample, the defaulted borrowers have higher incomes, more past loans and more current accounts. It appears that after the crisis, the bank has given priority to high-income repeat borrowers. When discussing the coding of variables in section 3.3.2, we will investigate in greater detail the relationship between borrower characteristics and default probability. 


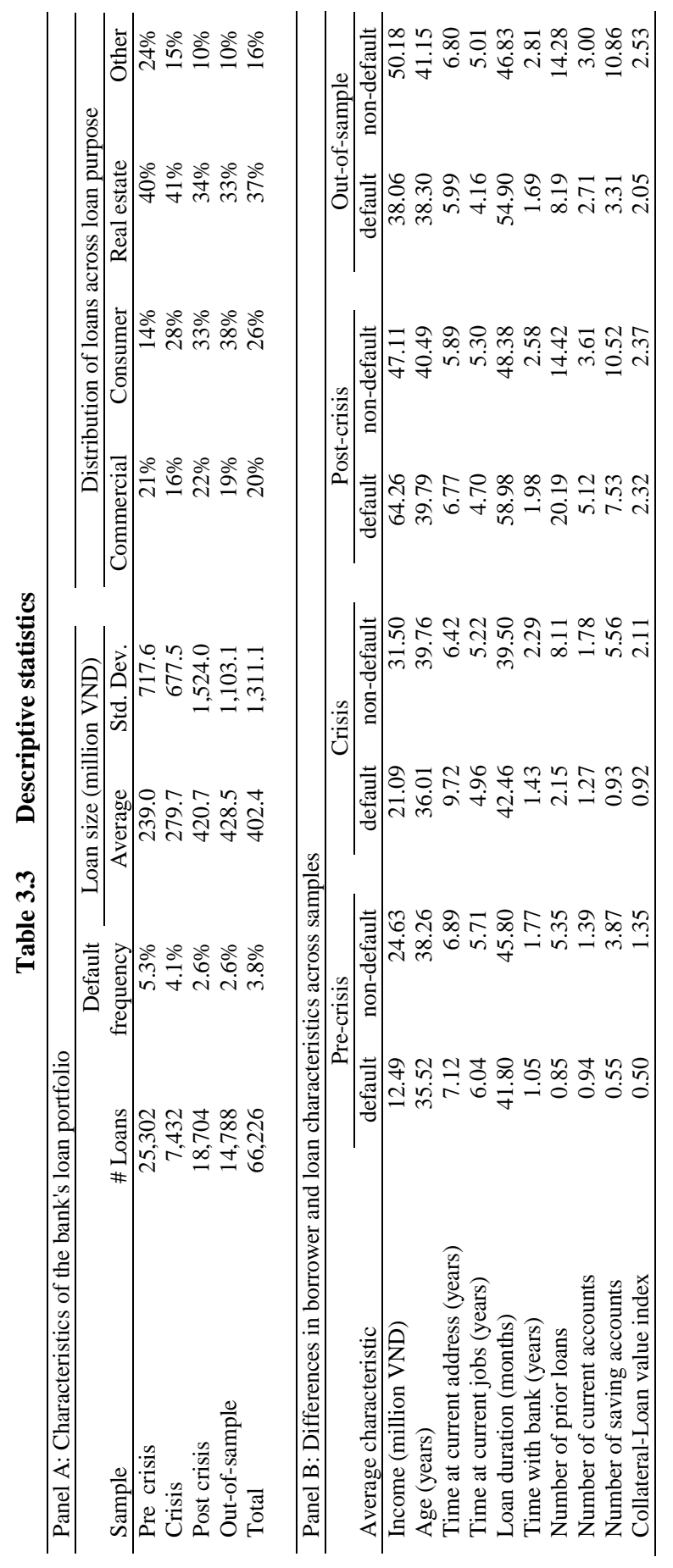




\subsubsection{Variable coding, selection and model estimation}

We can only estimate a CSM when the loan applicant provides the relevant information at the time of loan application. Currently, the bank records more than 30 variables pertaining to loan and borrower characteristics. The bank, however, grants a loan even if the applicant does not provide full information. More specifically, less than $10 \%$ of borrowers provide complete information at the time of application. The difference between samples versus population PD thus implies that a borrower who sufficiently fills in the loan application form has a lower PD than someone who does not properly complete the form. This is also consistent with one of the strategies used in practice to cope with missing values, as noted by Henley (1995): "a refusal to answer a particular question may be indicative of greater risk". Additionally, we eliminate certain variables from our CSM that almost exclusively take one value. For instance, the field 'Home phone (yes/no)' is filled with "yes" by more than $99 \%$ of borrowers. To obtain a sufficiently large sample of loans with complete and meaningful information, we rely on the expert knowledge of the loan officer and identify 17 relevant variables with relatively few missing values, as listed in Table 3.4. ${ }^{19}$ Our sample of 66,226 loans is thus based on 17 variables, and the criteria for selecting them are based on expert knowledge.

For each variable, borrowers are first grouped into categories. Categories can differ by sample. In preliminary analyses we found that the impact of our quantitative variables on default probability is rather similar in all samples except in the post-crisis sample. Thus, we use the same categories in models 1 to 3 but create slightly different categories for model 4 . The categories of models 1, 2 and 3 are shown in Table 3.4, together with the default rates estimated for each category using the total data set, which is equivalent to the data set used for model 1. Categories and their default rates in model 4 are shown in Table A3.1 of the Appendix. The values of the categories are then estimated using equation (3.4). These values differ by model, as the numbers of bad and good loans in each category differ by data set. ${ }^{20}$

\footnotetext{
${ }^{19}$ We exclude the following characteristics: credit line, living expenses, frequency of principal payment, frequency of interest payment, outstanding balance in saving account, outstanding balance in debit account, sub-income and number of days in arrears, relations with other banks, number of dependents, home phone, mobile phone, age of partner and occupation of partner.

${ }^{20}$ In line with our general discussion in section 3.2.2, we find that most of our variables are not unique to Vietnam in particular or even to developing countries in general. However, when categorizing and coding the variables, we take the specific circumstances in Vietnam into account. See Appendix B for details.
} 


\section{Table 3.4 Loan and borrower characteristics considered for the credit scoring model}

The Table presents the categories of each independent variable considered for the CSM in the top rows followed by the default probabilities in the bottom row in italics.

\begin{tabular}{|c|c|c|c|c|c|}
\hline Variable & Cat & egories and default fre & equencies & & \\
\hline Age & 18 to 35 & 36 to 50 & more than 51 & & missing \\
\hline & $6.51 \%$ & $4.68 \%$ & $2.65 \%$ & & $7.14 \%$ \\
\hline Gender & male & female & & & \\
\hline & $6.38 \%$ & $3.73 \%$ & & & \\
\hline Marital status & married & single & widowed & divorced & \\
\hline & $4.45 \%$ & $7.81 \%$ & $4.52 \%$ & $8.39 \%$ & \\
\hline Education & university graduate, & college, high school & occupational & & missing \\
\hline & post graduate & graduate & school graduate & & \\
\hline & $5.11 \%$ & $6.53 \%$ & $3.22 \%$ & & $2.66 \%$ \\
\hline Resident status & house owner & tenant & living with & & missing \\
\hline & & & parents/relatives & & \\
\hline & & & \& other & & \\
\hline & $3.23 \%$ & $8.30 \%$ & $8.04 \%$ & & $16.07 \%$ \\
\hline Time at present address & less than 1 & 2 to 15 & more than 16 & & missing \\
\hline (in years) & $5.59 \%$ & $4.61 \%$ & $5.65 \%$ & & $3.70 \%$ \\
\hline Monthly income & less than 5 & 5 to 10 & more than 10 & & missing \\
\hline (in million VND /month) & $9.07 \%$ & $5.68 \%$ & $2.87 \%$ & & $4.40 \%$ \\
\hline Occupation & management & labour work & $\begin{array}{r}\text { retired, } \\
\text { unemployed }\end{array}$ & other & missing \\
\hline & $7.16 \%$ & $4.73 \%$ & $1.07 \%$ & $5.45 \%$ & $6.78 \%$ \\
\hline Time with present & less than 1 & 1 to 9 & 10 to 20 & more than 21 & missing \\
\hline employer (in years) & $2.89 \%$ & $8.10 \%$ & $4.78 \%$ & $7.21 \%$ & $4.82 \%$ \\
\hline Loan purpose & commercial & consumer & real estate & other & \\
\hline & $2.88 \%$ & $5.81 \%$ & $3.19 \%$ & $7.69 \%$ & \\
\hline Loan duration & 1 to 12 & 13 to 48 & 49 to 120 & more than 120 & \\
\hline & $1.55 \%$ & $6.83 \%$ & $3.74 \%$ & $2.78 \%$ & \\
\hline Collateral to loan ratio & 0 & more than 0 up to 1 & more than 1 up to & more than 1.5 & more \\
\hline & & & 1.5 & up to 5 & than 5 \\
\hline & $7.50 \%$ & $2.75 \%$ & $3.07 \%$ & $2.30 \%$ & $1.59 \%$ \\
\hline Time with bank & 0 & 1 to 2 & 3 to 6 & more than 7 & \\
\hline & $7.16 \%$ & $4.33 \%$ & $2.87 \%$ & $5.62 \%$ & \\
\hline Number of prior loans & 0 & 1 to 2 & 3 to 7 & 8 to 23 & more \\
\hline & $8.19 \%$ & $3.67 \%$ & $204 \%$ & $1.28 \%$ & $\begin{array}{l}\text { than } 24 \\
0.49 \%\end{array}$ \\
\hline Number of current & 0 & 1 & 2 & more than 3 & \\
\hline & $4.08 \%$ & $8.06 \%$ & $2.57 \%$ & $1.28 \%$ & \\
\hline Number of saving & 0 & 1 to 3 & 4 to 8 & more than 9 & \\
\hline & $6.56 \%$ & $3.15 \%$ & $1.72 \%$ & $0.77 \%$ & \\
\hline Region & $\begin{array}{l}\text { central highland, } \\
\text { south central coast }\end{array}$ & south east & Red river delta & $\begin{array}{l}\text { Mekong delta } \\
\text { river, north }\end{array}$ & missing \\
\hline & & & & $\begin{array}{r}\text { central coast, } \\
\text { north east }\end{array}$ & \\
\hline & $9.09 \%$ & $5.12 \%$ & $7.39 \%$ & $9.56 \%$ & $6.78 \%$ \\
\hline
\end{tabular}

For each model, after the variables are coded the forward stepwise method is used to select among these 17 initial variables. This method starts with a model without any independent variables and sequentially adds variables. At each step, the 
variable that leads to the greatest improvement in predictive accuracy - in terms of the highest score statistic conditional upon a significance level of less than $10 \%$ is added. The process continues until no variable with a significance level of less than $10 \%$ remains. Based on the forward stepwise method, a subset of the initial 17 variables is included in the CSM. To ensure that the selected variables are the most powerful predictors, the backward stepwise method is applied as well. Here, the starting point is a model that contains all 17 initial variables. At each step, the method eliminates the weakest variable so that only the strongest predictors are retained in the final CSM. As expected, the backward stepwise method selects the same number of variables as the forward stepwise method. The remaining variables are excluded for one of two reasons: first, because they have insignificant coefficients and do not contribute to the explanation of the dependent variable's variance; second, because they are correlated with included variables. Together with adding the most predictive variables to the model, at each step of the backward stepwise regression, the tolerance $\left(1-R_{i}^{2}\right)$ of every excluded variable is calculated. Those variables with tolerances of less than $80 \%$ (i.e., with $20 \%$ or more of the variance of the variable explained by variations in the other variables) are considered for deletion. In the case of multicollinearity, the inclusion of all variables leads to inferior results in the out-of sample.

As observed in Table 3.5, models 1 to 4 have 13,11, 12, and 10 selected variables, respectively. The four models have substantial overlap in the variables selected. Fifteen variables are selected in at least one of the four models. Variables pertaining to the bank-borrower relationship (Time with bank, Number of prior loans) become more important during the post-crisis period, whereas borrower characteristics such as income, education, occupation and residential status become less important. Income appears only in model 3, which uses the pre-crisis sample only. Five of the 12 predictors in Crook et al. (1992) CSM for the UK, as shown in Table 3.1, are incorporated into our CSM: Time with bank, Number of saving accounts, Region, Residential status, and Number of current accounts. Crook's longer list of the 24 most typical variables overlaps with eight of our variables. Thus, our CSMs reflect - to some extent - the international norm of credit scoring. Such variables as Loan duration or Gender, however, are unique to developing country credit scoring and are indeed very effective predictors in our CSMs. First, Gender might be truly indicative of default or might simply reflect underlying risks. For Vietnam, we conclude that gender helps in the proper assessment of credit risk, even when other risk factors such as loan purpose or collateral value are taken into account. As shown in Table 3.4, women have a lower probability of default than men. Consequently Gender is significant and selected in all 4 models. Goetz and Gupta (1996) also find that women in 
Bangladesh have higher repayment rates than men due to their meaningful control over their investment activities. Furthermore, Gender might also be indicative of income, a fact that may explain the absence of more-traditional income proxies (Income, Occupation or Time at current employer) from most of our models. Second, Loan duration, as a measure of the borrower's intentions, risk aversion, or self-assessment of repayment ability, is unique to the Vietnamese context, which indicates that Vietnamese banks cannot rely solely on their own assessment of the borrower but must also rely on the borrower herself, who appears to honestly and accurately state her own loan capacity. In this context, Time with bank and Number of prior loans, as the first and third most important predictors, reflect the borrower's relationship with the bank and, thus, the role such relationships play in the Vietnamese loan market. The first indication of crisis effects on the CSM is observed in differences between the variables selected pre- and post-crisis and in the switching of certain variables' importance rankings. For example, post-crisis personal information appears to lose importance and is no longer predictive, whereas such variables as Time with bank and Number of prior loans ${ }^{21}$ become more predictive of default. These characteristics of the bank-borrower relationship represent soft information (repayment incentives and behavior, for instance) that cannot be observed directly. With fundamental economic changes triggered by the crisis, the value of hard information, e.g., borrower characteristics, diminishes, but the value of soft information persists. However, to properly assess the accuracy of these CSMs, they should be applied out-of-sample.

\footnotetext{
${ }^{21}$ Similarly, Vogelgesang (2003) finds that frequent borrowers face higher repayment problems during economic crises.
} 


\section{Table 3.5 The estimated credit-scoring model}

This table presents the models estimated by Probit regression. The dependent variable is a dummy equal to one for defaulted loans and zero otherwise. For each independent variable, the first row shows the coefficient and the second row shows the $\mathrm{z}$ statistic. $* * *, * *$, and * indicate statistical significance at the $1 \%, 5 \%$, and $10 \%$ level, respectively.

\begin{tabular}{|c|c|c|c|c|}
\hline & Model 1 & Model 2 & Model 3 & Model 4 \\
\hline & $\begin{array}{l}\text { pre-crisis, crisis, } \\
\text { and post-crisis } \\
\text { samples }\end{array}$ & $\begin{array}{c}\text { pre-crisis, } \\
\text { and post-crisis } \\
\text { samples }\end{array}$ & $\begin{array}{l}\text { pre-crisis } \\
\text { sample }\end{array}$ & $\begin{array}{c}\text { post-crisis } \\
\text { sample }\end{array}$ \\
\hline \multirow[t]{2}{*}{ Intercept } & $-1.66^{* * *}$ & $-1.15^{* * *} *$ & $-1.60 * * *$ & $-1.88 * * *$ \\
\hline & -100.44 & -32.45 & -112.67 & -91.88 \\
\hline \multirow[t]{2}{*}{ Gender } & $-0.31 * * *$ & $-0.28 * * *$ & $-0.34 * * *$ & $-0.31 * *$ \\
\hline & -7.37 & -5.89 & -6.52 & -2.53 \\
\hline \multirow[t]{2}{*}{ Marital status } & $-0.18 * * *$ & $-0.19 * * *$ & $-0.18 * * *$ & $-0.26 * * *$ \\
\hline & -5.39 & -5.05 & -3.50 & -3.65 \\
\hline \multirow[t]{2}{*}{ Eduation } & $-0.11 * *$ & & $-0.19 * * *$ & \\
\hline & -2.19 & & -2.90 & \\
\hline \multirow[t]{2}{*}{ Resident status } & $-0.18 * * *$ & $-0.18^{* * *}$ & $-0.14 * * *$ & \\
\hline & -7.54 & -7.44 & -4.18 & \\
\hline $\begin{array}{l}\text { Time at present } \\
\text { address }\end{array}$ & & $\begin{array}{l}-0.15^{*} \\
-1.67\end{array}$ & & $\begin{array}{l}-0.41 * * * \\
-4.67\end{array}$ \\
\hline Income & & & $\begin{array}{l}-0.11 * * * \\
-3.19\end{array}$ & \\
\hline Occupation & $\begin{array}{l}-0.43 * * * \\
-6.52\end{array}$ & $\begin{array}{l}-0.24 * * * \\
-7.90\end{array}$ & & \\
\hline $\begin{array}{l}\text { Time with } \\
\text { present employer }\end{array}$ & $\begin{array}{l}-0.19 * * * \\
-5.48\end{array}$ & $\begin{array}{l}-0.18 * * * \\
-4.78\end{array}$ & $\begin{array}{l}-0.51 * * * \\
-11.64\end{array}$ & $\begin{array}{l}-0.24 * * * \\
-3.40\end{array}$ \\
\hline Loan duration & $\begin{array}{l}-0.15 * * * \\
-6.15\end{array}$ & $\begin{array}{l}-0.11 * * * \\
-3.76\end{array}$ & & $\begin{array}{l}-0.36 * * * \\
-5.66\end{array}$ \\
\hline $\begin{array}{l}\text { Collateral to loan } \\
\text { ratio }\end{array}$ & $\begin{array}{l}-0.08 * * \\
-2.94\end{array}$ & & $\begin{array}{l}-0.06 * \\
-1.68\end{array}$ & $\begin{array}{l}-0.14 * * \\
-2.17\end{array}$ \\
\hline Time with bank & $\begin{array}{l}-0.06 * * \\
-2.21\end{array}$ & $\begin{array}{l}-0.10 * * * \\
-3.43\end{array}$ & & $\begin{array}{l}-0.26 * * * \\
-4.87\end{array}$ \\
\hline $\begin{array}{l}\text { Number of prior } \\
\text { loans }\end{array}$ & $\begin{array}{l}-0.14 * * * \\
-5.61\end{array}$ & $\begin{array}{l}-0.14 * * * \\
-5.22\end{array}$ & $\begin{array}{l}-0.20 * * * \\
-6.49\end{array}$ & $\begin{array}{l}-0.22 * * * \\
-4.37\end{array}$ \\
\hline $\begin{array}{l}\text { Number of } \\
\text { current accounts }\end{array}$ & $\begin{array}{l}-0.12 * * * \\
-4.57\end{array}$ & $\begin{array}{l}-0.11 * * * \\
-4.10\end{array}$ & $\begin{array}{l}-0.16 * * * \\
-5.08\end{array}$ & \\
\hline $\begin{array}{l}\text { Number of } \\
\text { saving account }\end{array}$ & $\begin{array}{l}-0.23 * * * \\
-9.27\end{array}$ & $\begin{array}{l}-0.21 * * * \\
-8.07\end{array}$ & $\begin{array}{l}-0.24 * * * \\
-7.52\end{array}$ & $\begin{array}{l}-0.21 * * * \\
-3.67\end{array}$ \\
\hline Region & $\begin{array}{l}-0.30 * * * \\
-4.64\end{array}$ & $\begin{array}{l}-0.31 * * * \\
-4.25\end{array}$ & $\begin{array}{l}-0.21 * * \\
-2.03\end{array}$ & $\begin{array}{l}-0.26 * * * \\
-2.92\end{array}$ \\
\hline Log likelihood & $-8,128$ & $-6,980$ & $-4,767$ & $-2,108$ \\
\hline Pseudo $\mathrm{R}^{2}$ & 0.085 & 0.833 & 0.0915 & 0.689 \\
\hline $\begin{array}{l}\text { Number of } \\
\text { observations }\end{array}$ & 51,438 & 44,006 & 25,302 & 18,704 \\
\hline
\end{tabular}




\subsubsection{Model calibration and out-of-sample assessment}

Table 3.6 shows AUC and Gini measures in-sample and out-of-sample for our four estimated models, and ROC curves are shown in Figure 3.3. The in-sample performance measures of the four models are very close, whereas the out-of sample measures are quite distinct. Because we are most interested in the performance of these models with respect to the out-of sample, we now focus on the out-of sample performance measures. Model 3, estimated using the pre-crisis sample, performs worst, with a Gini coefficient of $12 \%$ and an AUC of 56\%. In contrast, model 4 , estimated using the post-crisis sample, performs best, with a Gini coefficient of $26.22 \%$ and an AUC of $63.11 \%$. Models 1 and 2 perform at intermediate levels between the other two. This preliminarily assessment indicates that the borrower population has changed over time and that the CSM constructed based on pre-crisis data is out of date following the crisis. This result answers the banks' question of whether to reformulate their CSMs following the crisis: Yes, they should adjust their CSMs, if not redevelop them entirely. Additionally, banks in general do not want to waste any data and, hence, may want to include loans signed before and during the crisis in their updated CSMs. They should, however, consider this step very carefully, as it could significantly reduce the performance of their new model, as we show in the cases of models 1 and 2. To emphasize the improvement in the performance of model 4, we continue to look more closely into the calibration of this model compared with those of the others, particularly model 3.

\section{Table 3.6 Model predictive performances}

The table presents two predictive statistics that are commonly used to assess CSM performance by banks. The higher these statistics the more predictive the CSM is.

\begin{tabular}{|c|c|c|c|c|c|}
\hline \multirow[b]{3}{*}{ Model 1} & \multirow[b]{2}{*}{ Estimation sample } & \multicolumn{2}{|c|}{ Predictive statistic GINI } & \multicolumn{2}{|c|}{ Predictive statistic AUC } \\
\hline & & $\begin{array}{c}\text { In } \\
\text { sample }\end{array}$ & $\begin{array}{l}\text { Out-of } \\
\text { sample }\end{array}$ & $\begin{array}{c}\text { In } \\
\text { sample }\end{array}$ & $\begin{array}{l}\text { Out-of } \\
\text { sample }\end{array}$ \\
\hline & pre-crisis, crisis, post-crisis & $47.60 \%$ & $20.80 \%$ & $73.80 \%$ & $60.40 \%$ \\
\hline Model 2 & pre-crisis, post-crisis & $47.00 \%$ & $22.08 \%$ & $73.50 \%$ & $61.04 \%$ \\
\hline Model 3 & pre-crisis & $47.80 \%$ & $12.00 \%$ & $73.90 \%$ & $56.00 \%$ \\
\hline Model 4 & post-crisis & $44.56 \%$ & $26.22 \%$ & $72.28 \%$ & $63.11 \%$ \\
\hline
\end{tabular}


Figure 3.3 ROC curves

The figure presents ROC curves of the four different CSMs both in and out of sample. A more concave curve (larger area under ROC curve) indicates a better predictive power of the CSM.

Panel A: In-sample ROC curves

Model 1

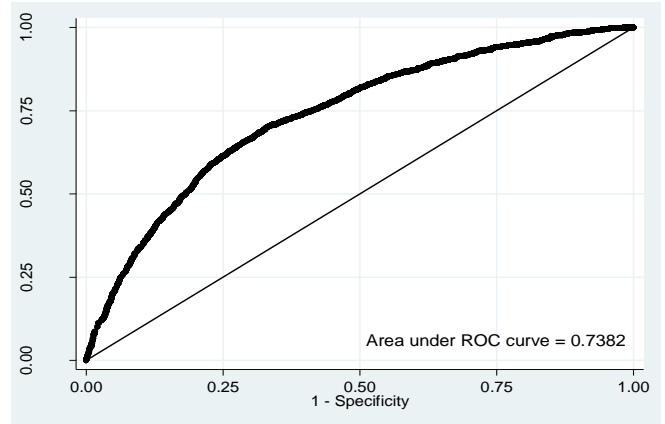

Model 2

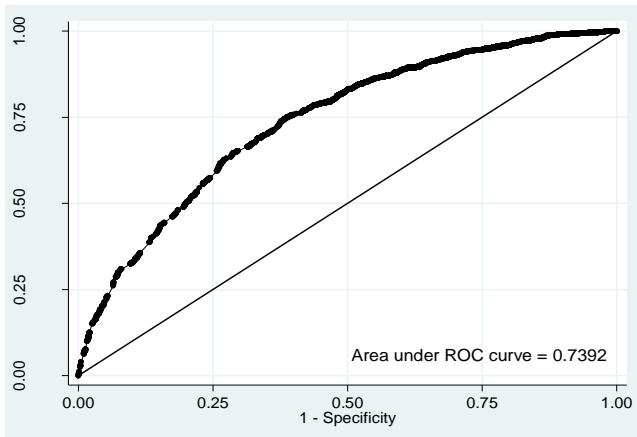

Model 3

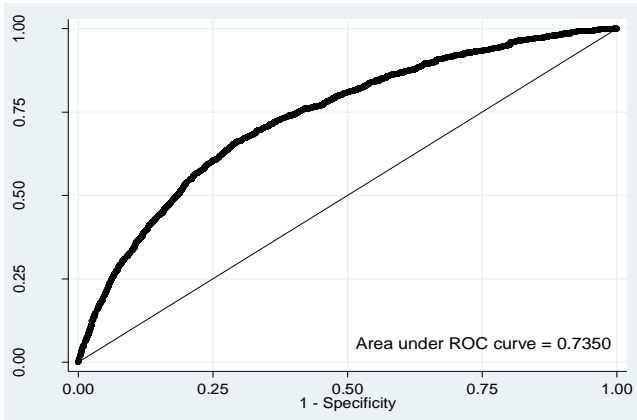

Model 4

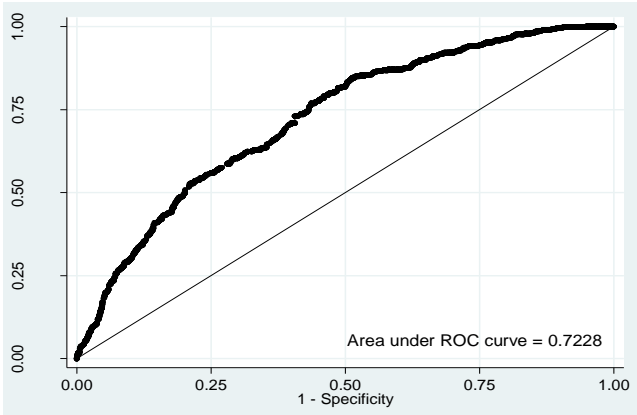

Panel B: Out-of-sample ROC curves

Model 1

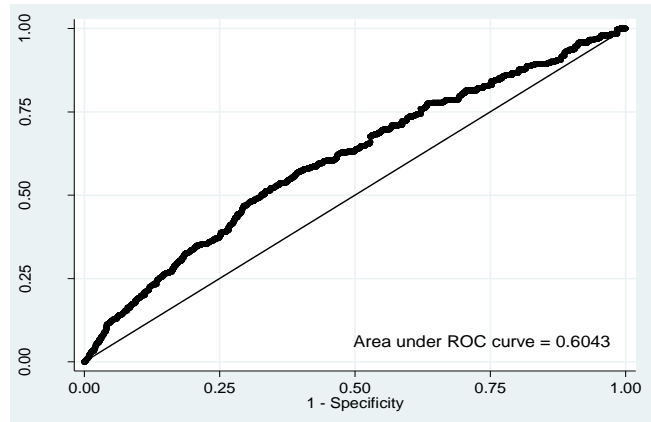

Model 2

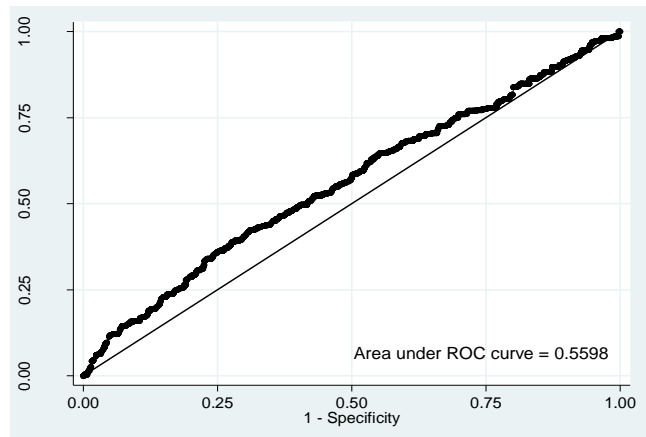

Model 3

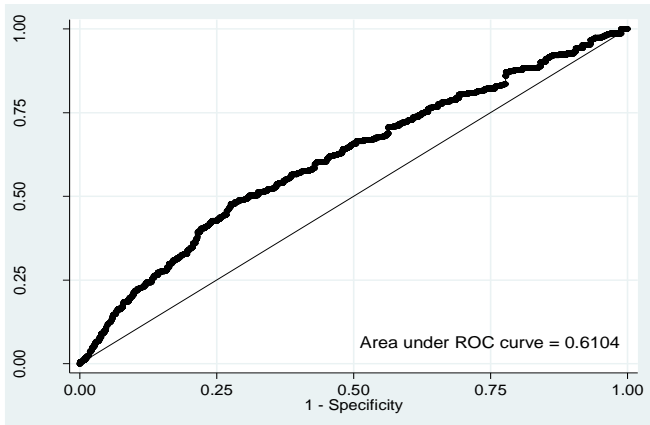

Model 4

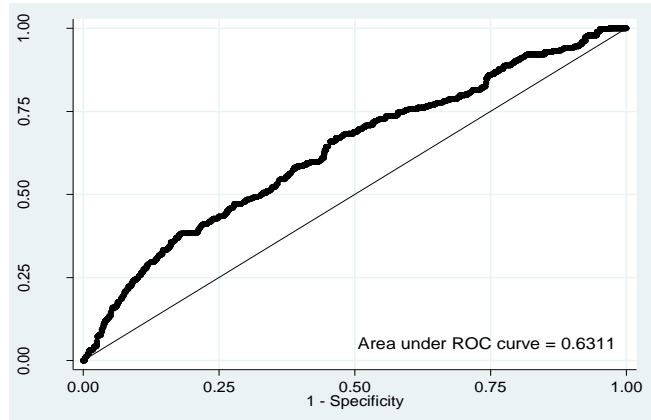


When the out-of sample is used to calibrate models 3 and 4, we find, as expected, a significant difference in the predicted PDs between observed defaulted and observed non-defaulted borrowers. Table 3.7 shows that for model 3, the average of predicted PDs is $2.53 \%$ for non-defaulted loans compared with $7.25 \%$ for defaulted loans. However, the ranges of predicted probabilities are rather large and overlap for the two loan groups. For defaulted loans, the PDs range from $0.34 \%$ to $31.53 \%$ compared with $0.03 \%$ to $21.82 \%$ for non-defaulted loans. The results are slightly better for model 4 , where the average of the predicted PDs is $2.37 \%$ for non-defaulted loans and $8.24 \%$ for defaulted loans. Defaulted loans, under model 4 , have PDs that range from $0.40 \%$ to $24.69 \%$ whereas non-defaulted loans have PDs that range from $0.00 \%$ to $23.37 \%$. Table 3.7 also reports the observed versus predicted PDs for different loan groups, generated by sorting all loans of similar predicted PDs into five groups of approximately equal size. The average estimated PD of model 3 is $2.66 \%$, compared with an observed PD of $2.58 \%$, whereas the average estimated PD of model 4 is 2.95 . Thus, model 4 overestimates default probabilities more often than model 3. However, if we more closely examine the different loan groups, we see that model 4 is better at distinguishing between the lowest and highest risk groups from the remaining groups, as shown by the larger gap between their observed PDs. A more detailed accuracy analysis using the PCC, SENS and SPEC indicators is thus warranted.

Table 3.7 Goodness of fit based on predicted versus observed probabilities of default in the out-of sample

This table presents predicted probability of default versus observed frequency of default. Loans are ranked and grouped into 5 groups according to the predicted probability of default. Average of predicted probability and observed frequency of default are calculated and shown here.

\begin{tabular}{|c|c|c|c|c|c|}
\hline \multicolumn{6}{|c|}{ Default probabilities by loan groups } \\
\hline \multirow{3}{*}{$\begin{array}{l}\text { Loan } \\
\text { Group }\end{array}$} & \multirow[b]{3}{*}{ \# Loans } & \multicolumn{4}{|c|}{ Probability of default (in \%) } \\
\hline & & \multirow[b]{2}{*}{ Observed } & \multicolumn{3}{|c|}{ Predicted } \\
\hline & & & Min & Mean & Max \\
\hline \multicolumn{6}{|c|}{ Panel A: Model 3 based on pre-crisis sample } \\
\hline 1 & 2,959 & 1.08 & 0.03 & 0.31 & 0.58 \\
\hline 2 & 2,958 & 1.52 & 0.58 & 0.91 & 1.25 \\
\hline 3 & 2,980 & 1.28 & 1.25 & 1.75 & 2.34 \\
\hline 4 & 2,934 & 2.59 & 2.34 & 3.23 & 4.31 \\
\hline 5 & 2,957 & 6.46 & 4.31 & 7.10 & 31.53 \\
\hline Total & 14,788 & 2.58 & 0.02 & 2.66 & 31.53 \\
\hline Non-default & & & 0.03 & 2.53 & 21.82 \\
\hline Default & & & 0.34 & 7.25 & 31.53 \\
\hline \multicolumn{6}{|c|}{ Panel B: Model 4 based on post-crisis sample } \\
\hline 1 & 2,958 & 0.74 & 0.00 & 0.45 & 0.91 \\
\hline 2 & 2,972 & 0.57 & 0.91 & 1.31 & 1.75 \\
\hline 3 & 2,944 & 1.29 & 1.75 & 2.28 & 2.86 \\
\hline 4 & 2,957 & 1.29 & 2.86 & 3.61 & 4.51 \\
\hline 5 & 2,957 & 9.03 & 4.52 & 7.13 & 24.69 \\
\hline Total & 14,788 & 2.58 & 0.00 & 2.95 & 24.69 \\
\hline Non-default & & & 0.00 & 2.37 & 23.37 \\
\hline Default & & & 0.40 & 8.24 & 24.69 \\
\hline
\end{tabular}


The determination of the optimal cut-off point for a CSM depends on the preferences of the bank. Our bank - though it does not have a CSM in place, relying instead on subjective credit assessment - has set a target for nonperforming loans. Assuming this target is $1.5 \%$, we must set the cut-off point to achieve a SENS of $98.5 \%$ (SENS $=100 \%-1.5 \%=98.50 \%)$. At first glance, one might think that to achieve this target, banks should accept only customers who have predicted PDs of less than $1.5 \%$. A cut-off of $1.5 \%$ would, however, lead to a SENS higher than $98.50 \%$ and, thus, a lower expected PD. Panels A and B of Table 3.8 show that a cut-off of $5.3 \%$ would achieve the desired result for model 3 , and a cut-off of $7.4 \%$ would do the same for model 4 . Comparing the accuracy of these cut-offs in the two models reveals the following dynamics: assuming tolerance of a small number of bad loans (a decrease in $\mathrm{PCC}_{\mathrm{bad}}$ from $49.97 \%$ to $45.81 \%$ ), model 4 increases its number of correctly accepted good loans substantially compared with model 3 (a rise in $\mathrm{PCC}_{\text {good }}$ from $86.92 \%$ to $94.58 \%$ ). Hence, following the crisis, when credit managers would tend to be prudent in their loan approvals, a more accurate model, such as model 4, will achieve greater certainty regarding good and bad loans in the bank's portfolio. Credit managers could now be more confident that a large number of good loans can compensate for a small number of bad loans and that profit can thus be maximized. In terms of SENS and SPEC, both models have a SENS of $98.50 \%$, while the SPEC for model 3 is $9.2 \%$ and that for model 4 is $18.3 \%$. Our SENS accuracy is slightly higher than that reported in other studies, while our SPEC accuracy is average or slightly below average. For example, Baesens et al. (2003) survey reports SENS measures up to $96.36 \%$, whereas some models of UK data have a SPEC of $0 \%$. SENS and SPEC, however, depend on the default percentage of the sample, so any comparison of these can be misleading unless the models are applied to the same data as our models. Compared with model 3, model 4 can improve SPEC by $9.1 \%$ at no cost to SENS. Nevertheless, to conclude that model 4 can indeed improve the bank's economic performance, the costs of different error types must be taken into account. 


\section{Table 3.8 Predictive accuracy for credit scoring models with one cut-off}

This table presents how well the model 3 and 4 can predict probability of default and how accurate they can identify defaulted and non-defaulted loans. To calculate the economical benefit made by these models we assume that the cost per bad loan is ten times the benefit per good loan and the annual margin is $2 \%$. Given the average loan amount of VND 337 million and the average loan duration of 48 months the change in profit can be estimated using the equation: $\Delta$ profit $=$ cost per bad loan* B_b benefit per good loan*G_b.

Panel A: Predictive accuracy of model 3 with a pre-specified cut-off (5.3\%) to achieve a target PD of $1.5 \%$

\begin{tabular}{|c|c|c|c|c|}
\hline \multirow[b]{2}{*}{ Observed } & \multicolumn{2}{|l|}{ Predicted } & \multirow[b]{2}{*}{ PCC } & \\
\hline & Non-default & Default & & \\
\hline Non-default & 12521 & 1885 & $86.92 \%$ & $=$ PCCgood \\
\hline Default & 192 & 190 & $\begin{array}{l}49.74 \% \\
84.67 \%\end{array}$ & $\begin{array}{l}=\text { PCCbad } \\
=\text { PCCttal }\end{array}$ \\
\hline
\end{tabular}

SENS $98.5 \%$

SPEC $\quad 9.2 \%$

Change in Profit 404 mil VND

Panel B: Predictive accuracy of model 4 with a pre-specified cut-off $(7.4 \%)$ to achieve a target PD of $1.5 \%$

\begin{tabular}{lllll}
\hline & Predicted & & \\
\cline { 2 - 3 } Observed & Non-default & Default & & PCC \\
\hline Non-default & 13,625 & 781 & $94.58 \%$ & $=$ PCCgood \\
Default & 207 & 175 & $45.81 \%$ & $=$ PCCbad \\
& & & $93.32 \%$ & $=$ PCCttal \\
SENS & $98.5 \%$ & & & \\
SPEC & & $18.3 \%$ & \\
Change in profit & 26,124 mil VND & & & \\
\hline
\end{tabular}




\subsection{Credit scoring and bank strategy}

In the previous section, cut-off values of $5.3 \%$ and $7.4 \%$ were chosen for the bank to achieve its assumed default target of $1.5 \%$ under models 3 and 4, respectively. However, is this optimal when the bank follows other strategies such as minimizing the time spent on credit assessment or maximizing returns? To answer this question, we examine alternative ways to set the cut-off points for the CSM.

\subsubsection{Profitability}

A CSM's benefit may lie in the positive effect a new credit assessment policy has on the bank's profitability, which is especially important following a crisis. If an updated CSM leads to increased bank profits, then the loan officer has a clear incentive to increase loan approvals following periods of depressed loan supply. Schreiner (2003) suggests measuring changes in profits in terms of opportunity cost. In particular, he focuses on the ratio of good loans lost $\left(\mathrm{G}_{\mathrm{b}}\right)$ to bad loans avoided $\left(\mathrm{B}_{\mathrm{b}}\right)$.

$$
\Delta \text { profit }=\text { cost per bad loan } * \mathrm{~B}_{\mathrm{b}} \text { - benefit per good loan } * \mathrm{G}_{\mathrm{b}}
$$

Given the selected cut-offs, as shown in Panels A and B in Table 3.8, a comparison between models 3 and 4 shows that model 3 avoids 15 additional bad loans (190 minus 175) by foregoing 1,104 good loans (13,625 minus 12,521). Thus, the tradeoff factor in model 3 is quite high: it foregoes 73.6 good loans for each bad loan avoided. To assess changes in profits, we assume a relationship between the cost per bad loan and the benefit per good loan. Because data for developing countries are not available, we use data from the credit card market in industrialized countries as a benchmark. In industrialized countries, practitioners maintain that at least 10 good loans are required to cover the cost of one bad loan (Schreiner 2003). Under this assumption, a cut-off of $7.4 \%$ for model 4 leads to an increase in profits of 26.12 billion VND (approximately $€ 1,279,080$ ), whereas a cut-off of $5.3 \%$ for model 3 leads to an increase in profits of only 0.40 billion VND (approximately $€ 19,800$ ), which would indicate that our bank should prefer model 4 . Figure 3.4 shows how this change in profits varies for different cut-off points of the two models. In particular, it reveals that neither a cut-off of $5.3 \%$ for model 3 nor a cut-off of $7.4 \%$ for model 4 maximizes profits. Instead, maximum profits are obtained by model 4 at a cut-off of $9.1 \%$. This results in an expected PD of $1.62 \%$, which is slightly above target and implies that our bank has set a rather too conservative strategy. A further look at Figure 3.4 reveals that at all cutoff values model 4 always outperforms model 3 in terms of profit-maximization. A cut-off of $9.1 \%$ also maximizes profit if model 3 is used. However, this 
maximum profit is less than that achieved with model 4 . The optimal cut-off point for model 3, moreover, results in an expected PD of $1.84 \%$, which exceeds $1.62 \%$, the expected PD if the optimal cut-off is used for model 4. In summary, because model 4, which is based on post-crisis data, always leads to superior profits compared with model 3, we conclude that an updated CSM does indeed provide a bank with an incentive to lend.

Figure 3.4 Change in profit of model 3 and 4 with different cut-off values

This figure presents the change in profit when different cut-off points are applied to model 3 and 4 assuming that borrowers with a PD higher (lower) than the cut-off point will be rejected (accepted).

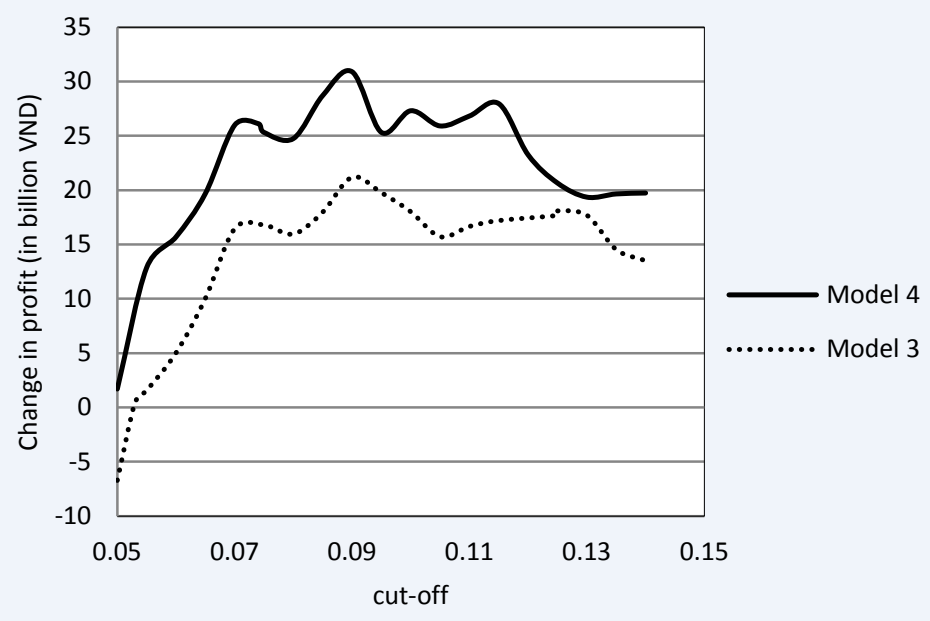

\subsubsection{Efficiency in transactional versus relationship lending}

Should banks rely exclusively on their CSM, i.e., transactional lending, or should there also be room for relationship lending? The benefits of transactional lending, e.g., credit scoring, are clear. Mester (1997), for example, reports that credit scoring has substantially reduced the length of the loan approval process, from two weeks to 12.5 hours for small-business loans in the US and from nine to three days for consumer loans in Canada. Once a CSM is in place, these benefits can be achieved at a cost of $\$ 1.50$ to $\$ 10$ per loan. Mester (1997) also reports that Banc One exclusively uses credit scores for loans of up to $\$ 35,000$ and approves a further $30 \%$ of all loans below $\$ 1$ million based solely on credit scores. The downside, however, can be substantial. Schreiner (2003) recalls the case of a Bolivian finance company that relied exclusively on its CSM and went bankrupt. The recent contraction in small business lending in the United State, where the use of CSMs is most advanced, has also cast doubt on transactional lending, which 
relies exclusively on CSMs. ${ }^{22}$ Through their relationships with borrowers, banks can discover qualitative risks that are not quantifiable in terms of "hard" variables. Thus, a combination of transactional and relationship lending can be valuable. Rio et al. (2011) suggest that transactional lenders use CSM primarily for cost-saving purposes, whereas relationship lenders combine CSM with relationship lending to reduce the asymmetric information banks face with respect to potential borrowers. During the 2007/08 crisis, transactional lenders suffered higher default rates on loans approved exclusively on the basis of borrower's credit scores, e.g., using CSMs. ${ }^{23}$ In contrast, relationship lenders suffered lower default rates on those loans approved based on borrowers' soft information in combination with credit scores. Thus, a combination of relationship, soft-information-based lending and transactional, CSM-based lending might be especially valuable during and after periods of crisis when a borrower's condition, and thus the determinants of default probability, undergo fundamental change.

To implement such a strategy in our CSM, we rely on Mester (1997), who reports that US banks have credit officers review their CSMs' decisions, particularly for loan applicants with scores close to the cut-off point. For the First National Bank of Chicago, this led to substantial changes in credit decisions regarding smallbusiness loans. Approximately $25 \%$ of the applications rejected by the CSM were later approved by the credit officer, while another $25 \%$ accepted by the CSM were later rejected by the credit officer. Based on our out-of sample, we illustrate this approach by setting two cut-offs for our CSMs, $\mathrm{C}_{1}$ and $\mathrm{C}_{2}$, with $0<\mathrm{C}_{1}<\mathrm{C}_{2}<1$. This calibration allows banks to define loans that require further examination instead of rejecting or accepting them outright. All loan applicants with an estimated $\mathrm{PD}<\mathrm{C}_{1}$ are accepted outright, whereas all applicants with an estimated $\mathrm{PD}>\mathrm{C}_{2}$ are rejected outright. The remaining loans with $\left(\mathrm{C}_{1}<\mathrm{PD}<\mathrm{C}_{2}\right)$ are classified as marginal and are thus reviewed by the credit officer. The bank's credit assessment can thus be a combination of transactional lending via CSMs and relationship lending.

Table 3.9 reports the results of this strategy for models 3 and $4 . C_{1}$ and $C_{2}$ are determined according to a somewhat ad hoc decision rule, which can be interpreted within the context of PCC. This rule specifies (1) that the proportion of incorrectly classified bad loans should be less than $20 \%$ of all bad loans, i.e., $\mathrm{B}_{\mathrm{g}} / \mathrm{B}<20 \%$, and (2) that the proportion of correctly classified bad loans should be at least $50 \%$ of all bad loans, i.e., $\mathrm{B}_{\mathrm{b}} / \mathrm{B} \geq 50 \%$. The emphasis on bad loans is justified by the relatively high penalty cost associated with overlooking bad loans. The benefit is the gain from reducing the number of good loans subjected to

\footnotetext{
${ }^{22}$ See, for instance, "When Business Credit Scores Get Murky", Wall Street Journal, March 18, 2010.

${ }^{23}$ For cost-saving motives, these lenders probably rely heavily, if not solely, on CSMs.
} 
evaluation. We apply the above decision rule to both models 3 and 4. This allows us to determine whether model 4 is more efficient than model 3: to achieve a given target of $\mathrm{B}_{\mathrm{g}} / \mathrm{B}$ and $\mathrm{B}_{\mathrm{b}} / \mathrm{B}$, according to the rule, would model 4 result in fewer applicants being reviewed manually than model 3 ? As shown in Table 3.9, the cutoff points are $C_{1}=1.65 \%$ and $C_{2}=5 \%$ for model 3 and $C_{1}=3 \%$ and $C_{2}=6.5 \%$ for model 4. Given these cut-off points, model 3 predicts 7,079 good loans, 5,168 marginal loans, and 2,159 bad loans, whereas model 4 predicts 9,135 good loans, 4,282 marginal loans, and 1,371 bad loans. Thus, if model 4 is used, the bank will need to manually review 4,282 applications compared with 5,168 applications with model 3. By applying two cut-off points to the outcome of model 4, our bank can combine its transactional lending with relationship lending to achieve a predetermined default target, yet improve its efficiency by minimizing the number of manual reviews. Thus, the updated post-crisis CSM improves not only the bank's profitability, as shown in the previous section, but also its efficiency.

Table 3.9 Predictive accuracy for credit scoring models with two cut-offs

This table presents how accurate models 3 and 4 can identify defaulted and nondefaulted loans if two cut-off points are applied and how many applications should be referred to loan officers to be assessed manually.

\begin{tabular}{|c|c|c|c|}
\hline \multicolumn{4}{|c|}{ Panel A: Model 3 with two cut-offs at 0.0165 and 0.050} \\
\hline & \multicolumn{3}{|c|}{ Predicted } \\
\hline Observed & Non-default & Marginal & Default \\
\hline Non-default & 7,079 & 5,168 & 2,159 \\
\hline Default & 79 & 112 & 191 \\
\hline $\mathrm{B}_{\mathrm{g}} / \mathrm{B}$ & $20.7 \%$ & & \\
\hline $\mathrm{B}_{\mathrm{b}} / \mathrm{B}$ & & & $50 \%$ \\
\hline \multicolumn{4}{|c|}{ Panel B: Model 4 with two cut-offs at 0.03 and 0.065} \\
\hline & & Predicted & \\
\hline Observed & Non-default & Marginal & Default \\
\hline Non-default & 9,056 & 4,170 & 1,180 \\
\hline Default & 79 & 112 & 191 \\
\hline $\mathrm{B}_{\mathrm{g}} / \mathrm{B}$ & $20.7 \%$ & & \\
\hline $\mathrm{B}_{\mathrm{b}} / \mathrm{B}$ & & & $50 \%$ \\
\hline
\end{tabular}

\subsubsection{Risk-based pricing}

In principle, a loan should be priced in accordance with the bank's cost of funds, origination costs, servicing costs, and implicit costs associated with potential default. While fixed costs do not generally vary within the same product category, expected default costs can vary across borrowers and should be calculated as PD times the loss given default (LGD). The risk-based interest rate $\mathrm{R}$ could thus be derived in a simple model as

$$
\mathrm{R}=\text { cost of funds }+ \text { overhead cost }+ \text { expected default cost }+ \text { profit margin }
$$


Because a crisis increases borrowers' default risk, a bank might respond by increasing interest rates, and because this increase in interest rates may in turn increase the bank's adverse selection problem, the overall effect might well be detrimental to the bank. An updated CSM, such as our model 4, enables the bank to better predict borrower default. A bank can thus improve the accuracy of its pricing strategy and thereby lessen the adverse selection problem. Based on our CSM, we can suggest a simple pricing strategy.

Given the cut-off point that maximizes the bank's profit - a cut-off point of $9.1 \%$ in the case of model 4 - any applicant with an estimated PD above $9.1 \%$ will be rejected. As Panel B of Table 3.10 shows, we split the bank's accepted borrowers into three risk classes containing approximately 4,750 borrowers each. The predicted PD for the low risk class ranges from $0.00 \%$ to $1.39 \%$, that for the moderate risk class from $1.40 \%$ to $3.12 \%$, and that for the high risk class from $3.13 \%$ to $9.09 \%$. Based on discussions with Vietnamese bankers, a $2.00 \%$ profit margin and an average $1.50 \%$ overhead cost appear to be reasonable and realistic assumptions. However, customers with higher risk usually generate higher costs because they tend to take up more of the credit officer's time. To be consistent with customer-specific pricing, overhead costs of $2.00 \%, 1.50 \%$, and $1.00 \%$ will be allocated to the high-, moderate-, and low-risk borrowers, respectively. The cost of funds can be approximated by the bank's deposit interest rate. In Vietnam, the annual deposit interest rate on local currency deposits between 2006 and 2010 ranged from $7.5 \%$ to $11.2 \%$, with an average of $9.3 \%$. Finally, the expected cost of default, PD*LGD, must be considered. Our CSM provides estimates for PD, but it is beyond the scope of this study to accurately estimate LGD. LGD will be at least loan-type specific, as each type of loan is associated with a different type of collateral. However, nearly $99 \%$ of the collateral used in our data comprises real estate or savings certificates, both of which have a $100 \%$ recovery rate. Thus, we assume LGD on average is $20.2 \%$, the percentage of unsecured loans. Thus, default cost can be quite significant. As a benchmark, note that in 1997 risk premia for US consumer loans ranged from as low as $0.10 \%$ to more than $2.00 \%$ for the highest-risk borrowers (Sangha, 1998). In line with this study, we assign a $2.00 \%$ default cost to the high-risk borrowers, $0.20 \%$ to the moderate-risk borrowers and $0.10 \%$ to the low-risk borrowers. As Panel B in Table 3.10 shows, the bank could charge $12.40 \%, 13.00 \%$, and $15.30 \%$ to the different risk classes, respectively. If, on the other hand, the bank decides to charge the same price to all borrowers, it could charge an average interest rate of approximately $13.57 \%$ to obtain the same profit margin. As the second set of calculations shows, these assumptions would be fairly consistent with an LGD of $20.2 \%$ and a PD based on 
the realized PD of the risk class. In practice, PD could be based on the historic PD obtained from the loan portfolio used in estimating the CSM. ${ }^{24}$

To compare models 3 and 4 in terms of risk-based pricing, we repeat the above calculations, using the outcome of model 3 with the cut-off point of $9.1 \%$, which maximizes profitability under that model. The calculations are shown in Panel A of Table 3.10. When model 3 is used, the low risk class has a higher observed PD than the low risk class classified as such by model 4; therefore, the interest rate corresponding to low risk class classified by model 3 is estimated to be higher than that for model 4. This is also the case for the moderate risk class. Thus, if the bank uses the outcome of the model constructed using pre-crisis data (model 3) to formulate its risk-based pricing policy, it will charge low-risk borrowers a relatively high interest rate while charging high-risk borrowers a relatively low interest rate compared with model 4. Thus, an updated CSM based on post-crisis data improves the bank's loan pricing ability and reduces its adverse selection problem.

Table 3.10 Risk -based loan pricing

The abbreviations are probability of default (PD) and loss given default (LGD).

\begin{tabular}{|c|c|c|c|c|}
\hline & \multicolumn{3}{|c|}{ Borrower class } & \multirow[b]{2}{*}{ All } \\
\hline & Low risk & Moderate risk & High risk & \\
\hline \multicolumn{5}{|c|}{ Panel A: Model 3 based on pre-crisis sample } \\
\hline Range of predicted PD & $0.03 \%-0.97 \%$ & $0.97 \%-3.64 \%$ & $2.64 \%-9.09 \%$ & $0.00 \%-9.09 \%$ \\
\hline Number of loans & 4,776 & 4,772 & 4,772 & 14,320 \\
\hline Overhead cost & $1.00 \%$ & $1.50 \%$ & $2.00 \%$ & $1.50 \%$ \\
\hline Cost of funds & $9.30 \%$ & $9.30 \%$ & $9.30 \%$ & $9.30 \%$ \\
\hline Profit margin & $2.00 \%$ & $2.00 \%$ & $2.00 \%$ & $2.00 \%$ \\
\hline Cost of default & $0.10 \%$ & $0.20 \%$ & $2.00 \%$ & $0.77 \%$ \\
\hline Loan interest rate & $12.40 \%$ & $13.00 \%$ & $15.30 \%$ & $13.57 \%$ \\
\hline $\mathrm{LD}=$ average observed PD & $0.92 \%$ & $1.57 \%$ & $3.02 \%$ & $1.84 \%$ \\
\hline LGD & $20.20 \%$ & $20.20 \%$ & $20.20 \%$ & $20.20 \%$ \\
\hline Cost of default $=\mathrm{LD} * \mathrm{LGD}$ & $0.19 \%$ & $0.32 \%$ & $0.61 \%$ & $0.37 \%$ \\
\hline Loan interest rate & $12.49 \%$ & $13.12 \%$ & $13.91 \%$ & $13.17 \%$ \\
\hline \multicolumn{5}{|c|}{ Panel B: Model 4 based on post-crisis sample } \\
\hline Range of predicted PD & $0.00 \%-1.39 \%$ & $1.40 \%-3.12 \%$ & $3.13 \%-9.09 \%$ & $0.00 \%-9.09 \%$ \\
\hline Number of loans & 4,759 & 4,767 & 4,747 & 14,273 \\
\hline Overhead cost & $1.00 \%$ & $1.50 \%$ & $2.00 \%$ & $1.50 \%$ \\
\hline Cost of funds & $9.30 \%$ & $9.30 \%$ & $9.30 \%$ & $9.30 \%$ \\
\hline Profit margin & $2.00 \%$ & $2.00 \%$ & $2.00 \%$ & $2.00 \%$ \\
\hline Cost of default & $0.10 \%$ & $0.20 \%$ & $2.00 \%$ & $0.77 \%$ \\
\hline Loan interest rate & $12.40 \%$ & $13.00 \%$ & $15.30 \%$ & $13.57 \%$ \\
\hline $\mathrm{LD}=$ average observed PD & $0.82 \%$ & $0.94 \%$ & $3.10 \%$ & $1.62 \%$ \\
\hline LGD & $20.20 \%$ & $20.20 \%$ & $20.20 \%$ & $20.20 \%$ \\
\hline Cost of default $=\mathrm{LD} * \mathrm{LGD}$ & $0.17 \%$ & $0.19 \%$ & $0.63 \%$ & $0.33 \%$ \\
\hline Loan interest rate & $12.47 \%$ & $12.99 \%$ & $13.93 \%$ & $13.13 \%$ \\
\hline
\end{tabular}

\footnotetext{
${ }^{24}$ For an in-depth analysis of the interactions among risk-based pricing, profit-maximizing cut-offs, and adverse selection problems, see Blöchlinger and Leippold (2006).
} 


\subsection{Conclusions}

As banking markets in developing countries mature, banks face growing competition and increasing regulatory attention toward their risk management policies. Especially in the wake of the global financial crisis, banks have increasingly considered whether and how credit scoring can help them in these new circumstances. Based on our evidence from the Vietnamese retail loan market, the answer clearly favors credit scoring. First, after the crisis banks should update their CSMs, as the old CSMs, built on pre-crisis data, are no longer accurately predictive for the post-crisis population. Second, by replacing their current CSMs with properly updated CSMs, banks can expect a decrease in their default ratio even as profits improve. In addition, banks can use CSMs to implement risk-based pricing to manage loan portfolio composition. The updated CSM enables banks to set lower interest rates for borrowers that exhibit less credit risk. Thus, banks will be more competitive in this loan market segment and, by attracting more low-risk borrowers, will lessen the problem of adverse selection. Finally, an updated CSM reduces the costs in time spent by the loan officer in loan assessment. In contrast to corporate or government loans, retail loans are small and their credit assessment is more costly per \$ or VND of loan volume. A CSM can thus be calibrated with this consideration in mind. Overall, with updated CSMs banks can benefit from reduced loan default, increased competitiveness, and reduced cost of manual loan assessment while optimally using its relationship lending tools, i.e., the loan officer's knowledge about the borrower. Thus, it is important to regularly update CSMs, especially after a crisis. 


\subsection{Appendix}

\section{Table A 3.1 Descriptive statistics of model 4}

For model estimation purpose, with each variable borrower are categorized into groups of comparable probability of default. This table shows the categories of each variable and their corresponding probability of default.

\begin{tabular}{|c|c|c|c|c|c|}
\hline \multirow{2}{*}{$\begin{array}{l}\text { Variable } \\
\text { Age }\end{array}$} & \multicolumn{5}{|c|}{ Categories and default frequency of model 4} \\
\hline & 18 to 35 & 36 to 49 & more than 50 & & missing \\
\hline & $3.63 \%$ & $2.30 \%$ & $1.69 \%$ & & $2.94 \%$ \\
\hline \multirow[t]{2}{*}{ Gender } & male & female & & & \\
\hline & $2.99 \%$ & $2.12 \%$ & & & \\
\hline \multirow[t]{2}{*}{ Marital status } & married & single & widowed & divorced & \\
\hline & $2.27 \%$ & $4.35 \%$ & $1.74 \%$ & $5.09 \%$ & \\
\hline \multirow[t]{3}{*}{ Education } & university & college, high & other & & missing \\
\hline & $\begin{array}{r}\text { graduate, post } \\
\text { graduate }\end{array}$ & $\begin{array}{r}\text { school } \\
\text { graduate }\end{array}$ & & & \\
\hline & $3.13 \%$ & $2.50 \%$ & $2.05 \%$ & & $1.82 \%$ \\
\hline \multirow[t]{3}{*}{ Resident status } & house owner & tenant & living with & & missing \\
\hline & & & parents \& other & & \\
\hline & $1.96 \%$ & $3.73 \%$ & $4.70 \%$ & & $6.40 \%$ \\
\hline Time at present & up to 5 & 6 to 16 & more than 17 & & missing \\
\hline address (in years) & $2.57 \%$ & $1.99 \%$ & $3.80 \%$ & & $12.50 \%$ \\
\hline Monthly Income & up to 10 & 10 to 30 & more than 30 & & missing \\
\hline (in million VND) & $3.20 \%$ & $2.42 \%$ & $2.61 \%$ & & $2.78 \%$ \\
\hline \multirow[t]{2}{*}{ Occupation } & management & labour work & $\begin{array}{r}\text { retired, } \\
\text { unemployed }\end{array}$ & other & missing \\
\hline & $3.30 \%$ & $4.94 \%$ & $1.67 \%$ & $2.47 \%$ & $2.65 \%$ \\
\hline Time with present & 0 & 1 to 2 & 3 to 9 & more than 10 & missing \\
\hline employer (in years) & $2.28 \%$ & $4.62 \%$ & $3.05 \%$ & $1.28 \%$ & $5.38 \%$ \\
\hline \multirow[t]{2}{*}{ Loan purpose } & commercial & consumer & real estate & other & \\
\hline & $1.90 \%$ & $3.33 \%$ & $2.54 \%$ & $2.71 \%$ & \\
\hline Loan duration & up to 6 & 7 to 12 & 13 to 120 & more than 121 & \\
\hline (in months) & $0.00 \%$ & $1.17 \%$ & $3.11 \%$ & $2.28 \%$ & \\
\hline Collateral to loan & 0 & more than 0 & more than 1 & more than 1.5 & more than \\
\hline \multirow[t]{2}{*}{ ratio } & & up to 1 & up to 1.5 & up to 5 & \\
\hline & $3.85 \%$ & $5.20 \%$ & $2.84 \%$ & $2.33 \%$ & $1.76 \%$ \\
\hline \multirow{2}{*}{$\begin{array}{l}\text { Time with bank } \\
\text { (in years) }\end{array}$} & 0 & 1 to 5 & more than 6 & & \\
\hline & $3.90 \%$ & $2.41 \%$ & $1.07 \%$ & & \\
\hline \multirow{2}{*}{$\begin{array}{l}\text { Number of prior } \\
\text { loans }\end{array}$} & 0 to 1 & 2 to 7 & 8 to 19 & more than 20 & \\
\hline & $4.46 \%$ & $2.47 \%$ & $1.57 \%$ & $1.83 \%$ & \\
\hline \multirow{2}{*}{$\begin{array}{l}\text { Number of current } \\
\text { account }\end{array}$} & 0 to 2 & 3 to 4 & 5 to 84 & more than 85 & \\
\hline & $2.95 \%$ & $1.91 \%$ & $2.88 \%$ & $0.00 \%$ & \\
\hline \multirow{2}{*}{$\begin{array}{l}\text { Number of saving } \\
\text { account }\end{array}$} & 0 & 1 to 12 & more than 13 & & \\
\hline & $3.35 \%$ & $1.62 \%$ & $1.06 \%$ & & \\
\hline \multirow[t]{5}{*}{ Region } & central & south east & Red river delta & Mekong delta & \\
\hline & highland, & & & river, north & \\
\hline & south central & & & central coast, & \\
\hline & coast & & & north east & \\
\hline & $1.66 \%$ & $2.47 \%$ & $3.57 \%$ & $6.10 \%$ & \\
\hline
\end{tabular}




\section{Appendix B}

When categorizing and coding the variables, we must take the specific circumstances of Vietnam into account. The categories, as well as the PDs associated with all 17 variables, can be found in Table 3.4. Outlined below are the details regarding these categories in the first three models, the specific circumstances of Vietnam, the ways in which the categories of model 4 differ from those of model 3, and the reasons why we expect these borrower characteristics, i.e., those captured by the variables ultimately selected, to be relevant.

Regarding Education, we expect that better educated people will have more stable, higher-income employment and thus lower PDs. We therefore distinguish borrowers by their degree of educational attainment, ranging from post-graduate to non-high school graduate. In 2002, however, less than $0.5 \%$ of the Vietnamese working population held a graduate or post-graduate degree and only $13 \%$ held an undergraduate degree (GSO, 2002). The largest share of the working population thus falls into the bottom two educational categories. Our loan sample broadly reflects these demographics but includes more highly educated borrowers: $40 \%$ of borrowers hold a post-graduate or graduate degree, 5\% hold an undergraduate degree, $35 \%$ hold a high school degree and $20 \%$ have less or other education. Contradicting our expectations, default frequencies do not appear to decline with increasing education. College and high school graduates, for example, have the highest default frequency, namely, $6.53 \%$, followed by university graduates and post-graduates, with a default frequency of $5.11 \%$.

Gender can no longer be included in CSMs in many industrialized countries, as it is deemed discriminatory. In contrast, Schreiner (2003) argues that fair discrimination - for example, based on the statistical default rates of men versus women - is acceptable, as it is based on quantifiable data. The alternative subjective scoring - discriminates equally if not more. Overall, there is ample evidence that women default less frequently than men on loans (Schreiner, 2004) but that most of this gender effect disappears when other risk factors correlated with gender are taken into account. ${ }^{25} \mathrm{We}$ thus initially include gender and rely on the variable selection procedure to determine whether gender remains in the final CSM. In Vietnam, there is, furthermore, a specific relationship between gender and income that itself might be predictive of default. Specifically, the GSO (2004) reports higher income for women than for men. For wage earners, the average

\footnotetext{
${ }^{25}$ For Bolivian microfinance, Schreiner (2004) shows that women are less risky borrowers than men, as women are more likely to be traders than manufacturers and have smaller businesses that require smaller, shorter loans.
} 
monthly income per month is 228 thousand VND, if the head of the household is a woman, and 139 thousand VND, if the head of the household is a man. The same holds in the aggregate, when all income sources are combined. However, the aggregate differences between women and men are less pronounced, with women earning 589 thousand VND and men 489 thousand VND. ${ }^{26}$ It appears that women, who have higher average incomes than men, default less than men. Overall, default frequencies are $3.73 \%$ and $6.38 \%$ for women and men, respectively.

Region represents the area of the country where the borrower lives. Because people of similar wealth tend to live in the same location (a suburb might attract richer residents and the resulting increase in housing and property prices may make such a location prohibitively expensive for poorer households), this geographic criterion can indicate a borrower's level of financial wealth. A typical proxy is an area's postal code, but in Vietnam a postal code is not part of the address. Instead, we approximate region by the branch where a loan is issued. According to bank policy, borrowers can only obtain loans from their local branches. Branch location therefore coincides with the borrower's residential area. The many bank branches are located in eight regions, defined by the government. These eight regions are then categorized into four groups based on their average frequencies of default. Note that, given this coding, region might not only proxy for borrower's wealth but might also reflect the credit assessment capabilities of the different branches. In our sample, it appears that borrowers from the southeast (branches in Ho Chi Minh City contribute the most to this region) are the best borrowers, while those from the central part of the country are the worst. This pattern can be understood in terms of per capita income, which is highest in Ho Chi Minh City, followed by the north and south, while the center is the poorest area in Vietnam (World Bank 2004).

Time at current address represents the number of years that a borrower has resided at his current address. Crook et al. (1992) find that default risk drops with increases in this variable. Thus, time at present address might be a proxy for the borrower's maturity, stability, or risk aversion. However, this relationship does not hold in Vietnam, where default rates increase with time at present address. In Vietnam, people who acquire financial wealth tend to seek better living conditions and thus often move to a new home in a better area. Thus, changing addresses might be a signal that a borrower's financial wealth is high and/or improving rapidly. Under these conditions, he is better able to repay his loan.

\footnotetext{
${ }^{26}$ For this and all other binary variables, coding the variable based on equation (3.4) leads to a more precise measure than simply assigning values of 0 and 1 .
} 
Residential status indicates whether borrowers own their home, rent, or live with their parents. Errunza et al. (1981) finds that land ownership is a significant factor in predicting default. Ex ante, the relationship between residential status and default is unclear. On the one hand, residential status can indicate financial wealth, particularly in the case of home ownership. On the other hand, residential status can indicate increased financial pressure on the borrower's income through insurance fees, taxes, or electricity costs. Crook et al. (1992) find that borrowers who are most likely to default belong to the "other" category, whereas borrowers living with their parents are least likely to default. We expect that this ranking will be different for our sample, as the reasons for having a certain residential status in Vietnam are dissimilar from those in industrialized countries. Almost $90 \%$ of all borrowers in our sample own their homes, which properly reflects the Vietnamese population as a whole, where $95 \%$ of all households own their own home. Home ownership is somewhat higher in rural areas, at $98 \%$, compared with urban areas, where it is $86 \%$ (GSO 1999). If a home is used as collateral, as is likely when the borrower is a homeowner, default rates are among the lowest, whereas default rates are highest for tenants who do not own their homes. This pattern can be attributed to the importance of owning a home in Vietnamese culture, a norm that renders many Vietnamese borrowers averse to the prospect of losing their home.

Marital status can matter if it has an effect on the responsibility, reliability, or maturity of borrowers. In our sample, the default rate is lower for married than for single and widowed borrowers. We conjecture that clients without a spouse may be considered riskier than married clients, who take responsibility for a partner and perhaps also a family. Furthermore, married clients may be considered less risky because of possible dual incomes available for loan repayment. Another linkage exists between marital status and age. The Committee for Population, Family and Children (2003) found that in 2002 Vietnamese women married mainly in their 20s. Among 20- to 24 -year old women, only $46 \%$ were married, compared with $80 \%$ to $90 \%$ of older women. Thus, the age group that shows the highest default rates (18 to 35 years) also has the most unmarried people. However, because $87 \%$ of borrowers are married, it is unclear ex ante how informative marital status will be compared with other variables such as age or income.

Loan purpose describes how borrowed funds are used. Generally speaking, pledging collateral reduces default risk. Most defaults occur in the uncollateralized or in the "other" loan purpose group. The "other" loan purpose group consists of credit card lending and loans to the bank's employees; $21.85 \%$ of these loans are collateralized with a physical asset, and $7.69 \%$ are in default. At the other end of the distribution, $98.62 \%$ of business loans are collateralized and only $2.88 \%$ are in 
default. Of the real-estate-related loans, $85.51 \%$ are collateralized and $3.19 \%$ are in default. Because a majority of pledged collateral is real estate, this fact might indicate borrower's risk aversion regarding the loss of his house and is also consistent with Vietnamese culture in which people view their homes as important aspects of their lives. Finally, there is an overlap between collateral type and residential status, as only borrowers who live in their own homes can use their homes as collateral. Note, however, that many borrowers who own more than one property use as collateral a property they do not reside in for (business) loans. This could again be a strong signal of the cultural importance of owning one's own home. As a related proxy, the collateral to loan ratio reflects the value of collateral relative to loan value. The higher this value, the greater the incentive for the borrower, who does not want to lose her collateral, to repay.

Loan duration measures the maturity of a loan in months. In preceding literature, Godquin (2004) establishes that loan duration is a significant determinant of repayment performance throughout all specifications. Usually, this feature of a loan results from negotiations between borrowers and banks and is thus excluded from CSMs. However, the Vietnamese situation is different. What we measure here is the loan duration as proposed by the borrower and not as negotiated between the bank and the borrower. This variable can thus be observed to reflect the borrower's intention, risk aversion, or self-assessment of repayment ability.

Time with bank measures the length of the banking relationship in years. Within the context of relationship lending, it can be assumed that the longer a customer stays with a bank, the more the bank knows about him and the lower the default risk becomes. However, while this relationship is confirmed for industrialized countries (Crook et al. 1992), it does not entirely hold in Vietnam. The highest default rates are found for those borrowers who have been with banks for 7 years or more, whereas for relationships of less than 7 years, the longer the relationship, the lower the default rate tends to be. This could reflect the fact that the Vietnamese banking market is in the process of reform and that credit officers still have room for preferential credit allocation. As reform progresses and CSMs are put into place, the effect of this variable is expected to change and should thus be reassessed regularly.

Number of prior loans counts the number of loans a customer was granted at the bank prior to the loan currently being considered. Many borrowers not only have a sequence of historical loans but also have taken out more than one loan at a time. Because a defaulted borrower has difficulty obtaining new loans, this proxy can be informative about default risk. As expected, default is least frequent for repeat borrowers: whereas $8.19 \%$ of first-time borrowers default, $3.67 \%$ of borrowers with one or two prior loans default, and only $0.49 \%$ of borrowers with more than 
24 prior loans do so. This variable thus clearly reflects the importance of the bankborrower relationship and a good credit record.

Number of current accounts is a variable that indicates how many bank accounts the borrower currently holds at the bank. In Vietnam, the concept of a personal bank account is still unfamiliar to most of the population, with only approximately $6 \%$ of the population possessing a bank account in 2006. This percentage, however, is substantially higher for the urban middle class, at $35 \%$, and had increased substantially from only $12 \%$ in $2001 .{ }^{27}$ In a recent conference on banking technology in Hanoi, it was reported that in 2012 approximately $20 \%$ of the population had a bank account; it is expected that this figure will increase to $35-40 \%$ by $2015 .^{28}$ Having a bank account is largely indicative of a modern lifestyle among young people and may thus suggest education or financial wealth (see also Crook et al. 1992). In our sample, $50 \%$ of borrowers have one current account and another $23 \%$ have two or more accounts at the time of the loan request - both of these percentages are higher than the population average. These borrowers have a higher default risk. The high growth in current accounts might substantially change the relationship between default and current account ownership in the future. Consequently, this variable must be reassessed regularly if it is to be included in a CSM. ${ }^{29}$

Number of saving accounts is expected to be a strong predictor of default. Because the number of savings accounts at the bank is an indicator of a borrower's wealth, a higher number of savings accounts should reduce the default rate. In our data, borrowers without a savings account have the highest default rate of $6.56 \%$, whereas the default rate falls to only $0.77 \%$ for borrowers with more than nine savings accounts at the bank.

Occupation refers to the type of job the borrower has. It is classified into five groups. Surprisingly, the management group, which counts for $10.84 \%$ of borrowers, has the highest default rate $(7.16 \%)$, whereas the labor group and the retired and unemployed group have default rates of only $4.73 \%$ and $1.07 \%$, respectively. This may be explained by the fact that individuals in the management group may involve themselves in riskier projects than members of the other groups.

\footnotetext{
${ }^{27}$ Figures are obtained from two surveys conducted in 2006: (1) one by Visa International, as reported in the Thanh Nien News on January 8, 2007, and (2) TNS's VietCycle survey, as reported in the Vietnam Investment Review No 795 on January 8, 2007.

28 Source: http://vneconomy.vn/20120320124414420P0C6/20-dan-so-viet-nam-co-tai-khoan-nganhang.htm

${ }^{29}$ We also consider income, occupation, employer type, time with employer, age, and the ownership of a mobile phone. As these variables are not part of our final CSM, they are not described here in detail. These categories and their default frequencies are, however, listed in Tables 3.4 and A 3.1 for illustrative purposes.
} 



\section{Comparing Tail Risk and Systemic Risk Profiles for Different Types of US Financial Institutions ${ }^{30}$}

\subsection{Introduction}

The Basel II framework identifies credit risk, market risk and operational risk as the key risk factors for financial institutions (Basel Committee on Banking Supervision, 2001). Prior to the crisis, the dominant opinion used to be that by appropriately managing these risks, financial institutions can maximize the probability of their continued survival while delivering appropriate profit to the capital providers. However, this financial regulatory framework is essentially micro-prudential in nature in the sense that it is designed to limit each institution's risk individually; however Basel II typically did not take into account that distressed systemically important companies can destabilize the whole financial system as well as causing negative effects on real economic activity. The recent financial crisis created a conscience that there is an urgent need to complement Basel-II with regulations that also take into account these macro-prudential concerns, i.e. the need to monitor so-called "systemic risk". Thus, in order to preserve monetary and financial stability central banks, a regulatory and supervisory framework ideally encompasses a micro-prudential layer as well as a set of tools to monitor the systemic importance of individual financial institutions in order to get a feel of the potential contribution of each financial institution to the overall financial sector instability. This is particularly challenging in a very large and complex economy with a highly developed financial system such as the United States where tremendous consolidation as well as the removal of regulatory barriers to universal banking have made the financial system's interconnectedness extremely complex, cf. the popular reference to so-called Large and Complex Banking Organisations (or LCBO's) as institutions that are "too complex to fail".

A significant body of theoretical and empirical literature on bank contagion and systemic risk emerged throughout the years and the amount of scientific contributions in this area has nearly exploded since the occurrence of the most recent systemic banking crisis. A majority of the empirical banking stability literature has proposed "market-based" indicators of systemic risk. That is because supposed driving factors of systemic instability like e.g. the financial system's interbank interconnectedness, the location of banks within the system's "network"

\footnotetext{
${ }^{30}$ This chapter is based on 'Comparing tail risk and systemic risk profiles for different types of US financial institutions' co-authored with Stefan Straetmans.
} 
or the correlations between loan or trading (investment) portfolios are often difficult to quantify. Banks' interconnectedness may be of a "direct" nature and related to money markets, the payment system, or derivatives markets and resulting counterparty risk, see e.g. Allen and Gale (2000). However, it may also be of an "indirect" nature and induced by the overlap in banks' asset portfolios (Iori et al., 2006; de Vries, 2005; Zhou, 2010). Event studies are one of the oldest tools employed to measuring bank linkages by investigating the impacts of specific bank distress or bank failures on other banks' stock prices, see e.g. Swary (1986), Wall and Peterson (1990) or Slovin et al. (1999). Other studies regressed abnormal bank stock returns on proxies for asset-side risk, like Smirlock and Kaufold (1987) or Kho et al. (2000). De Nicolo and Kwast (2002) explain increases in bank equity correlations over time by means of proxies for bank consolidation. Gropp and Moerman (2004) and Gropp and Vesala (2004) use (market-based) equity-derived distances to default to measure bank equity spillovers. More recent market-based measures of systemic risk include the Conditional Value-at-Risk (Adrian and Brunnermeier, 2011), Marginal Expected Shortfall (Acharya et al., 2010) or SRISK (Brownlees and Engle, 2012).

Most of the studies mentioned above assume that domino-type bank equity spillovers (often dubbed "bank contagion") are at the heart of systemic risk. An alternative strand in the literature assumes that banking crises are triggered by aggregate (nondiversifiable) shocks that affect all banks simultaneously. Gorton (1988) argued that business cycles have often been leading indicators of bank panics. The studies by Gonzalez-Hermosillo et al. (1997), Demirgüc-Kunt and Detragiache (1998) and Hellwig (1994) fit in the same tradition. The latter author argued that the fragility of financial institutions to large macro shocks may partly be due to the noncontingent character of deposit contracts to the state of the macro economy. The systemic risk indicator we are going to work with fits into this latter tradition.

The use of market-based indicators for systemic risk is not without controversy and potential problems. First, it allows systemic risk assessment for listed banks only. This may lead to a biased view on the true level of financial fragility. Second, bank stocks can only be truly informative about current or future systemic risk (i.e. market-based indicators as "early warning indicator") if bank stocks reflect all relevant and available information about the risks that characterize a given financial institution, i.e., if bank stocks are efficiently priced. The evolution of bank stocks prior to 2007 suggests that the markets did not foresee the banking crisis. We nevertheless believe that the most extreme spikes in bank stocks and their co-movements exhibit at least some information content about systemic risk and financial instability. 
This paper builds on the statistical extreme value (EVT) approach followed by e.g. Hartmann et al. (2006) and Straetmans and Chaudhry (2013). More specifically, we use extreme downside risk measures that assume Pareto-type tail decline to identify bank tail risk. To identify bank systemic risk, we employ the so-called tail- $\beta$ indicator of "extreme systematic risk" as a tail equivalent of the traditional regression-based CAPM- $\beta$, introduced in Straetmans et al. (2008). The tail- $\beta$ is defined as the probability of a collapse in the market value of a bank's equity capital conditional on a large adverse aggregate shock (typically an extreme negative return on a market portfolio like a banking index, overall stock market index, credit spread etc.). The tail- $\beta$ is obviously market-based because it uses stock prices of individual bank equity as well as market information about aggregate shocks as input.

Notice that the concept of Marginal Expected Shortfall (MES) and the Conditional Value-at-Risk (CoVaR) resemble the tail- $\beta$ because these indicators are also probabilistic in nature: MES is the expected loss on individual bank equity capital conditional on large market portfolio losses. CoVaR is the Value-at-Risk (VaR) of the financial system conditional on institutions being under distress and is implicitly defined using a conditional co-crash probability. Also, and in contrast to previous correlation-based approaches towards, MES, CoVaR and the tail- $\beta$ identify non-linear dependencies (if present) in the data. The crucial difference between our approach and competing approaches like MES or CoVaR lies in the way the indicators are estimated: whereas we explicitly focus on the (univariate) extreme tail of bank equity capital and the tail dependence structure between bank stock returns, empirical studies on MES or CoVaR mainly use estimation techniques like quantile regressions or non-parametric estimation (historical simulation) that cannot go as far in the tail. One may wonder whether one truly captures systemic events if these indicators are estimated with, say, quantile regressions for quantiles that correspond with $5 \%$ or $1 \%$ significance levels. The latter studies typically assume that non-extreme outcomes are representative for what happens in the tail area but we believe this may be an overly restrictive assumption. Statistical EVT focuses on events that are severe enough to basically always be of concern for regulators and supervisors caring about financial stability, which cannot be claimed about events that happen $5 \%$ of $1 \%$ of the time.

By applying techniques of univariate and multivariate EVT to the tails of bank equity returns, we want to make four contributions to the existing literature (and more specifically to papers like Hartmann et al. (2006) or Straetmans and Chaudhry (2013)). First, we want to perform a "cross-industry" comparison of tail risk and systemic importance, i.e. do traditional banks exhibit more or less tail risk and systemic risk as compared to e.g. investment banks or insurance companies? Indeed, besides deposit banks (depositories), insurance companies (including large 
re-insures) and broker-dealers (investment banks) played a crucial role in the narrative of the 2007-2009 banking and financial crisis. It is to be expected that these different segments of the financial industry also exhibit different risk profiles and risk-taking behavior (and as a result differences in tail risk and systemic risk). Deposit banks, for instance, with their traditional banking activities are expected to expose to considerably lower systemic risk as compared to investment banks who carry large trading portfolios. Previous empirical systemic risk studies were often limited to measuring tail risk and systemic risk of "banks" in the narrow sense of the word without distinguish different types of bank. Second, we assess the forward-looking characteristics of these risk measures by looking at the stability of tail risk and systemic risk rankings over time. We achieve this by calculating rank correlations between pre-crisis and crisis ranks. Third, we reconsider the corroboration that a financial institution's size is a prime factor fueling systemic risk. We also look into the relation between tail risk and institutional size. We solely focus on size as a risk determinant because previous studies identified this variable as the single most important trigger of systemic risk. Finally, we want to assess whether the tail risk and systemic risk of the same institutions are positively or negatively related to each other. Suppose that both (micro-prudential) tail risk and (macro-prudential) systemic risk exhibit common drivers, these common factors will determine whether tail risk and systemic risk are positively or negatively related. For example, if size is the single most important variable and bigger banks exhibit less tail risk (diversification effect) but more systemic risk (too big to fail effect) than it follows that tail risk and systemic risk should be negatively related to each other across financial institutions. Whether tail risk and systemic risk are positively or negatively correlated is assessed by means of cross sectional rank correlations between tail risk and systemic risk.

Turning to the data, our panel contains roughly the same banks as in Acharya et al. (2010) and Brownlees et al. (2012), i.e. the top 102 U.S financial firms with a market capitalization greater than 7 billion USD as of the end of June 2007 (just before the start of the subprime mortgage crisis). SIC codes are used to divide financial institutions into 4 buckets: deposit banks (e.g. JP Morgan, Bank of America, Citygroup), insurance companies (e.g. AIG, Berkshire Hathaway, Countrywide), broker-dealers (e.g. Goldman Sachs, Morgan Stanley), and a residual category ("others") consisting of e.g. non-depository institutions or real estate agencies. Our dataset only includes 92 firms instead of 102 firms as in the original panel (some firms disappeared from the original panel due to mergers or bankruptcies). Stock prices and relevant balance sheet data to proxy institutional size are downloaded over the sample period January 1, 1990 to September 1, 2011. 
Anticipating our results, we find that different groups of financial institutions exhibit different levels of tail risk and systemic risk. The heterogeneity in tail risks and systemic contributions across different types of financial institutions suggests that regulators should not treat different financial industries as homogeneous when regulating and supervising their risks, i.e. a broker-dealer should be treated differently from, say, a deposit bank. The most salient outcome of our crossindustry risk comparison seems to be that the insurance industry exhibits the highest tail risk but that deposit banks are characterized by the highest degree of extreme systematic risk (our indicator of systemic risk). The latter outcome is surprising given the key role investment banks (and more specifically the trading divisions) played in the narrative of the financial crisis. What is less surprising is that both tail risk and systemic risk dramatically increased during the financial crisis. However, this does not mean that EVT-based indicators of tail risk and systemic risk are of no value when making any judgment about the propensity towards future systemic crises: we actually observe that the ranking of institutions did not change dramatically when considering pre-crisis and crisis sample tail- $\beta$ 's: rank correlations between pre-crisis and crisis ranks are relatively high which implies that the riskiest institutions in terms of tail risk and systemic risk before the crisis stay the riskiest ones over the crisis sample. The ranks and corresponding cross sample correlations are nevertheless quite different across different types of financial institutions. Last but not least, financial institutions' size does not have much to say about financial institutions' tail risk; but size does seem to matter for their systemic risk. However, the size-systemic risk relationship is not very robust and varies with the considered size proxies, subsamples and types of financial institutions.

The remainder of this chapter is organized as follows. Section 4.2 introduces indicators of downside risk and systemic risk based on statistical extreme value analysis. Section 4.3 provides estimation procedures for both measures. Section 4.4 summarizes the empirical results. Finally, section 4.5 concludes.

\subsection{Tail risk and Systemic risk Indicators}

We first introduce alternative downside risk ("tail risk") measures for financial institutions Next, we discuss a systemic risk indicator that reflects individual banks' sensitivity to system-wide non-diversifiable shocks (tail- $\beta$ ).

\subsubsection{Univariate tail risk indicators}

We define extreme downside risk (tail risk) measures for financial institutions by exploiting the empirical stylized fact that equity returns of financial institutions exhibit "heavy" tails. Mandelbrot (1963) observed that sharp short-term 
fluctuations in financial markets (typically daily returns) are non-normally distributed - and bank stocks do not constitute an exception. Let $S_{t}$ stand for the dividend-corrected stock price of a financial institution. Define $X=-\ln \left(\frac{s_{t}}{s_{t-1}}\right)$ as the loss variable we are interested in. For sake of notational convenience, the left tail of equity returns (market losses on equity capital) are mapped into positive losses which implies that all downside risk measure expressions and corresponding estimation procedures are expressed for the upper tail of a loss distribution. Loosely speaking, Mandelbrot's observation of the heavy tail feature implies that the marginal tail probability for $X$ as a function of the corresponding quantile $\mathrm{x}$ can be approximately described by a power law:

$$
P\{X>x\} \sim \mathrm{a} x^{-\alpha}, \quad \text { for large } x .
$$

This contrasts with the (much faster) exponential tail decay of thin-tailed processes like the normal distribution. The so-called tail index $\alpha$ can be interpreted as the rate at which the tail decay takes place when increasing the quantile or crisis barrier $x$ : lower $\alpha$ implies a slower decay to zero and a higher probability mass for given values of the quantile $x$. The tail index has an interesting statistical interpretation in terms of the higher moments of an empirical process: fat tailness of an empirical process implies that all distributional moments higher than $\alpha$ are unbounded and thus do not exist. In contrast, for the normal distribution, all statistical moments exist. Mandelbrot's empirical observation of heavy tails implies that the normal distribution is not a good choice if one wants to make a probability assessment of extreme returns like financial crises, bank failures etc.

Given this predominance of fat tails in financial markets, why is the normality assumption still so common when applying statistical tools into social sciences? This can be partly explained by (i) its analytical tractability; but more importantly (ii) by the predominant focus on sample averages in social science, which implies that versions of the Central Limit Theorem apply, i.e., under fairly general conditions sample averages converge in distribution to a standard normal distribution. However, if one is interested in assessing the likelihood of extreme events (financial crises, bank distress etc.) away from the mean and the distributional centre, other limit laws apply like the so-called extremal types theorem, see Embrechts et al. (1997). The heavy-tailed model (4.1) is one possible outcome of this extremal types theorem.

Popular distributional models often used in the finance literature like the Student-t, the class of symmetric stable distributions or the Generalized Autoregressive Conditional Heteroscedasticity $(\mathrm{GARCH})$ model all exhibit fat tails: they are all nested in the tail model (4.1) albeit with different pairs of tail parameters $(a, \alpha)$. 
Clearly, the tail likelihood in (4.1) is defined for a given time horizon of the loss series $X$ and values of the crisis barrier or Value-at-Risk (VaR) level $x$. Alternatively, (4.1) can be inverted and solved for the tail quantile $x$ in function of p:

$$
x \sim\left(\frac{p}{a}\right)^{-1 / \alpha}
$$

Although $\mathrm{VaR}$ has become an extremely popular device for financial risk management and a cornerstone of Basel-II, financial economists also argued it is not a "coherent" risk measure; alternative risk measures have therefore been proposed like e.g. the "expected shortfall". This is the conditional expected loss on a firm's equity capital given a sharp decline in the equity capital $(X>x))$. It can be easily seen that expected shortfall is very closely related to VaR:

$$
E(X-x \mid X>x) \cong \frac{x}{\alpha-1}
$$

Thus, within an EVT framework, the expected shortfall at the $p \%$ significance level is the rescaled VaR where the scaling factor depends on the tail index $\alpha$. Notice that the expected loss beyond VaR falls below VaR provided the variance of the process exists $(\alpha>2)$. The conditional expected loss in (4.3) reflects how severe the violation of the VaR crisis level is whereas a calculate VaR quantile itself does not provide that information. For tails of bank stock losses, it provides the expected decline in equity capital once a critical threshold is exceeded.

\subsection{2. "Extreme systematic" risk indicator or tail- $\beta$}

Similar to the downside risk measures discussed in the previous section, the proposed indicator of systemic risk is also market-based in the sense that it requires the input of daily extreme stock price movements of an individual financial institution together with daily sharp fluctuations in a nondiversifiable risk factor on which to condition. The aggregate (macro) factor is supposed to act as propagation channel of adverse aggregate shocks.

Let us now define this so-called "tail- $\beta$ " in more detail. Loosely speaking, this is a co-crash probability that reflects the dependence between the loss on an individual institution's stock and a macro factor during times of market stress. Assume these two losses are represented by $X_{1}$ and $X_{M}$, respectively. As in the univariate case, we take the negative of stock returns such as to study joint losses in the upperupper data quadrant. Without loss of generality we choose the tail quantiles $Q_{1}$ and $Q_{M}$ such that the corresponding tail probabilities are the same across the two random variables, i.e. $P\left\{X_{1}>Q_{1}(p)\right\}=P\left\{X_{M}>Q_{M}(p)\right\}=p$. The crisis barriers $Q_{1}$ and $Q_{M}$ will generally differ because the marginal distribution functions for $X_{1}$ and $X_{M}$ are unequal. However, a common significance level $p$ makes the 
corresponding tail quantiles or extreme "Value-at-Risk" level of $Q_{1}$ and $Q_{M}$ better comparable across assets or portfolios. ${ }^{31}$

From elementary probability theory we can simply write down a bivariate probability measure by using the notation introduced above:

$$
\mathcal{T}_{\beta} \equiv P\left\{X_{1}>Q_{1}(p) \mid X_{M}>Q_{M}(p)\right\}=\frac{P\left\{X_{1}>Q_{1}(p), X_{M}>Q_{M}(p)\right\}}{p},
$$

and using the fact that $P\left\{X_{M}>Q_{M}(p)\right\}=p$. The probability measure $\mathcal{T}_{\beta}$ reflects the strength of the interdependence between $X_{1}$ and $X_{M}$ when both variables jointly exceed the crisis barriers $Q_{1}$ and $Q_{M}$. Under complete statistical independence $\mathcal{T}_{\beta}$ reduces to $\frac{p^{2}}{p}=p$ which acts as a lower bound for the tail- $\beta$.

This tail- $\beta$ measure is inspired by portfolio theory as it can be interpreted as a tail equivalent of the CAPM- $\beta$. Just as the CAPM- $\beta$, it relates individual stock return movements to movements in a market portfolio. However, the tail- $\beta$ is neither a regression coefficient nor is it based on the entire sample. It is a probability that we evaluate on the tail area of the joint distribution which is the area one is interested in for sake of assessing systemic stability, i.e., low frequency comovements that do not strike often. In fact, correlation-based measures like ordinary $\beta$ 's can be quite misleading dependence measures for multiple reasons. First, CAPM or more general factor models only unveal linear relations between returns and supposed triggers whereas the systemic risk spillovers we are interested in may well be characterized by non-linear behavior. Also, correlations are often used in conjunction with the normality assumption. This is a rather dangerous cocktail because correlations tend to zero when truncated on the tail area and assuming multivariate normality. Thus, if tail co-movements exist in the true data, they will not be revealed by multivariate normal models and systemic risk will be severly underestimated as a consequence. For a more extensive discussion of the flaws of correlation-based measures, see e.g. the monograph by Embrechts et al. (1997).

Tail- $\beta$ 's have been previously used. Straetmans et al. (2008) examine the intraday effects of the 9/11 terrorist attacks on US stocks before and after the attacks took place; Hartmann et al. (2006) and Straetmans and Chaudhry (2013) make a crossatlantic comparison of tail- $\beta$ 's for US and eurozone banks using slightly different techniques and time periods. De Jonghe (2010) runs cross sectional regressions of tail- $\beta$ 's on candidate-explanatory variables like size and sources of bank revenue to determine what drives banking system (in) stability. Conditional exceedance

\footnotetext{
${ }^{31}$ If $\mathrm{Q}(1)>\mathrm{Q}(2)$ for a common significance level $\mathrm{p}$, the "tail" Value-at-Risk of position 1 exceeds that of position 2 . The VaR levels become comparable by conditioning them on a common p-value. The common p-value choice is also in line with the basel-II requirements requiring banks to disclose (less extreme) 5\% and $1 \%$ VaR numbers. This makes the downside risk of banks' trading books comparable across banks. 
probabilities for higher dimensions are defined in the same manner (see Hartmann et al. (2006), Straetmans and Chaudhry (2013)). In the current paper, we select a Datastream calculated US banking market index as conditioning macro factor $X_{M}$.

\subsection{Tail risk and systemic risk estimation}

Imposing one and the same fully parametric model (marginal distribution as well as the bivariate dependence structure) for both the centre of the distribution as well as the tail observations would greatly simplify the quantification of the considered downside risk indicators and the tail- $\beta$ for it would only require Maximum Likelihood estimation of the distributional parameters. However, if one makes the wrong distributional assumptions, the tail risk and systemic risk estimates may be severely biased due to misspecification. Moreover, there is no evidence that stock returns are identically distributed - even less so for the crisis situations we are interested in. We therefore want to avoid the model risk of making too restrictive distributional assumptions for bank stock returns. To that aim, we employ semiparametric estimation procedures from statistical extreme value analysis. First, we introduce semi-parametric estimators for extreme downside risk (tail indices, tail quantiles and conditional expected shortfalls) before turning to estimation procedures for the systemic risk indicators.

\subsubsection{Estimating tail risk measures}

Univariate tail risk estimation exploits the empirical stylized fact that financial return distributions exhibit fat tails. More specifically, we are interested in a sample counterpart of (4.1)-(4.2)-(4.3). Let the "tail cut-off point" $X_{n-m, n}$ (with $X_{n, n} \geq \cdots \geq X_{n-m, n} \geq \cdots \geq X_{1, n}$ representing the descending order statistics defined on the samples of return losses $X>0$ ) represent the lower bound of the set of upper order extreme returns used to identify the tail probability (4.1) or tail quantile (4.2) with $m$ the number of extremes used in the estimation. The tail probability (4.1) could then be estimated as:

$$
P(X>x) \simeq \frac{m}{n}\left(X_{n-m, n}\right)^{\alpha} x^{-\alpha}
$$

with $\frac{m}{n}\left(X_{n-m, n}\right)^{\alpha}$ an estimate of the scaling constant $a$ in (4.1). In financial risk management the tail quantile or crisis barrier $x$ is usually referred to as the "Valueat-Risk (VaR)", although it is often used in a reversed fashion: what is the value of $x$ for a given level of the tail probability $p$ ? (alternatively called "p-value" or "marginal significance level"). Simply inverting the tail likelihood estimator (4.5) renders:

$$
\hat{x} \simeq X_{n-m, n}\left(\frac{m}{n p}\right)^{\frac{1}{\alpha}}
$$


The tail quantile estimator $\hat{x}$ extends the empirical distribution function of the return loss data outside the historical sample boundary of $X$ by means of the Pareto law parametric assumption for the tail behavior in (4.1). The quantile estimator (4.6) still requires plugging in a value for the tail index $\alpha$. In line with the bulk of empirical studies on non-normality, power laws and extreme events, we estimate the tail index by the means of the popular Hill (1975) statistic:

$$
\hat{\alpha}=\left(\frac{1}{m} \sum_{j=0}^{m-1} \ln \left(\frac{X_{n-j, n}}{X_{n-m, n}}\right)\right)^{-1},
$$

where $m$ has the same value and interpretation as in (4.6). In fair conditions, it has been shown that the tail index and tail quantile estimators above exhibit consistency and asymptotic normality (see Haeusler and Teugels, 1985; De Haan et al., 1994). Further details on these estimators are provided in Jansen and De Vries (1991) and the monograph by Embrechts et al. (1997). An estimator for the expected shortfall (4.3) easily follows by plugging in the Hill statistic and the quantile estimator in the definition of the expected shortfall (4.3):

$$
\hat{E}(X-\hat{x} \mid X>\hat{x})=\frac{\hat{x}}{\hat{\alpha}-1} .
$$

The Hill statistic and accompanying quantile and expected shortfall estimators are still conditional on picking a value of the nuisance parameter $m$. Goldie and Smith (1987) suggest to select this threshold such as to minimize the asymptotic meansquared error (AMSE) of the Hill statistic. Due to the bias-variance trade-off characteristic of the Hill estimator such a minimum should exist. This minimization criterion actually constitutes the starting point for most empirical techniques to determine $m$. We determine $m$ by both considering the curvature of so-called Hill plots $\hat{\alpha}=\hat{\alpha}(m)$ as well as implementing the Beirlant et al. (1999) algorithm which minimizes a sample equivalent of the AMSE.

\subsubsection{Estimating the systemic risk indicator (tail- $\beta$ )}

In order to estimate the tail- $\beta$ in (4.4) it suffices to calculate the joint probability in the numerator. Upon assuming a bivariate parametric distribution function for the return pair, the distributional parameters and resulting co-exceedance probability could be easily estimated using maximum likelihood optimization. However we want to avoid making very specific distributional assumptions about both the marginal return distributions as well as their (tail) dependence structure. We therefore opt for Ledford and Tawn's (1996) semi-parametric approach. The latter authors first propose to transform the marginal distributions to unit Fréchet distributions which leaves the tail dependence structure unchanged. We opt for an 
alternative marginal transformation (to unit Pareto marginals) which renders comparable results, see Draisma et al. (2004) for a comparison of the two alternative marginal transforms' performance. After such a transformation, differences in joint tail probabilities across asset return pairs should be solely attributed to differences in the tail dependence structure of the return pairs.

The unit Pareto transformation is performed in a purely nonparametric fashion by using the return's own empirical distribution:

$$
\widetilde{X}_{l}=\frac{1}{1-R_{X_{i}} /(n+1)}, i=1,2,
$$

and where $R_{X_{i}}$ stands for the (ascending) rank number of the observation $X_{i t}$ for stock return $\mathrm{i}$ in the time series dimension. ${ }^{32}$ Upon applying this unit Pareto marginal transformation, it can be easily shown that the bivariate numerator likelihood in (4.4) boils down to:

$$
P\left\{X_{1}>Q_{1}(p), X_{2}>Q_{2}(p)\right\}=P\left\{\widetilde{X_{1}}>s, \widetilde{X_{2}}>s\right\},
$$

with $s=1 / p$, see e.g. Draisma (2004) or Hartmann et al. (2006). Consequently, the common quantile $s$ enables one to reduce the estimation of the bivariate probability to a univariate probability by considering the cross-sectional minimum of the two return series:

$$
P\left\{\widetilde{X_{1}}>s, \widetilde{X_{2}}>s\right\}=P\left\{\min \left(\widetilde{X_{1}}, \widetilde{X_{2}}\right)>s\right\}=P\left\{Z_{\text {min }}>s\right\},
$$

and where the auxiliary variable $Z=\min \left(\widetilde{X_{1}}, \widetilde{X_{2}}\right)$. In order to identify the marginal tail probability at the right-hand side, we assume that the auxiliary variable's tail inherits the fat tail property of the original returns, see e.g. Draisma et al. (2004) for further motivation:

$$
P\left\{Z_{\text {min }}>s\right\} \approx a s^{-\alpha}, \alpha \geq 1
$$

for large $s$. Obviously, fatter (thinner) tails of the $Z_{\min }$ variable imply weaker (stronger) tail dependence.

Steps (4.9), (4.10), (4.11) show that the estimation of join probabilities like (4.10) can be reduced to a univariate estimation problem. By using the inverse of the previously defined quantile estimator from de Haan et al. (1994), univariate excess probabilities can be estimated:

$$
\hat{p}_{s}=\frac{m}{n}\left(Z_{n-m, n}\right)^{\alpha} s^{-\alpha},
$$

\footnotetext{
${ }^{32}$ Division by $\mathrm{n}+1$ instead of $\mathrm{n}$ is performed in order to prevent division by zero for the largest observational rank.
} 
where the 'tail cut-off point' $Z_{n-m, n}$ is the $(n-m)^{t h}$ ascending order statistic of the auxiliary variable $Z_{\text {min }}$.

An estimator of the co-exceedance probability $\mathcal{T}_{\beta}$ in (4.4) easily follows by dividing (4.12) with $\mathrm{p}$ :

$$
\mathcal{T}_{\beta}=\frac{p_{s}}{p}=\frac{m}{n}\left(Z_{n-m, n}\right)^{\alpha} s^{1-\alpha},
$$

for large but finite $s=1 / p$.

Clearly the tail index $\alpha$ plays a double role in (4.13): it both drives the tail thickness of the auxiliary variable $\mathrm{Z}$ as well as the degree of the tail dependence for the original return pair $\left(X_{1}, X_{2}\right)$. One can distinguish two polar cases in which the pair $\left(X_{1}, X_{2}\right)$ as well as the transformed pair $\left(\widetilde{X_{1}}, \widetilde{X_{2}}\right)$ either exhibit tail dependence $(\alpha=1)$ or tail independence $(\alpha>1)$. Tail dependence implies that $\alpha=1$, or alternatively:

$$
\lim _{p \rightarrow 0} P\left\{X_{1}>Q_{1}(p) \mid X_{2}>Q_{2}(p)\right\}=\lim _{s \rightarrow \infty} P\left\{\widetilde{X_{1}}>s \mid \widetilde{X_{2}}>s\right\}=\frac{m}{n} Z_{n-m, n}>0
$$

Stated otherwise, the conditional tail probability never vanishes to zero regardless how far one looks into the tail of the joint distribution. On the other hand, tail independence $(\alpha>1)$ implies that

$$
\lim _{p \rightarrow 0} P\left\{X_{1}>Q_{1}(p) \mid X_{2}>Q_{2}(p)\right\}=\lim _{s \rightarrow \infty} P\left\{\widetilde{X_{1}}>s \mid \widetilde{X_{2}}>s\right\}=0 .
$$

For obvious reasons the tail index of the auxiliary variable is also sometimes called the "tail dependence" parameter. ${ }^{33}$ The bivariate normal distribution or the bivariate Morgenstern distribution constitute popular examples of tail independent models whereas the bivariate student-t or the bivariate logistic model exhibit tail dependence, see e.g. Hartmann et al. (2006). The bivariate normal distribution is both characterized by thin tailed as well as tail independent marginal return distributions and may therefore lead to an underestimation of the true systemic risk when pairs of bank stock returns are actually tail dependent. To illustrate this, consider a pair of bank stock returns form our bank panel (Citigroup; Bank of America) and impose a bivariate normal distribution on this data pair. The estimated first and second moments (means, standard deviations and correlation) completely determine the joint distribution. Next, we employ the bivariate normal

\footnotetext{
${ }^{33}$ Lots of papers on multivariate extreme value analysis also talk about the tail dependence "coefficient" which is typically defined as the conditional asymptotic probability itself. The tail dependence parameter thus determines the tail decay of the tail dependence coefficient 
model as a simulation vehicle to draw a sample of the same size as the raw data sample $(\mathrm{n}=5659)$. The figure below shows both data clouds

Figure 4,1 Joint bank crashes: historical vs. simulated (Gaussian) return pairs
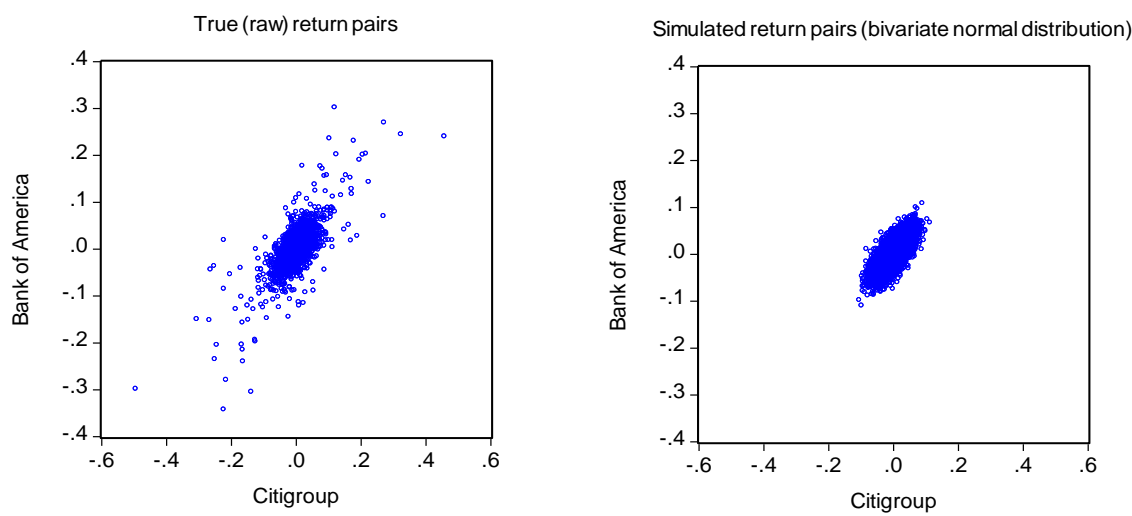

For sake of comparison, axes are identical. One observes that the RHS Gaussian data cloud does not reproduce the LHS joint downward bank stock crashes visible in the true data cloud (tail dependence). That there is so little tail dependence in the right hand side graph may seem surprising because the Pearson correlation between the two bank stock return series is found to equal $94.17 \%$. However, the bivariate normal distribution is characterized by tail independence, which implies that statistical dependence (nonzero correlation for a bivariate normal) in the centre of the distribution disappears in the tails, i.e. condition (4.10). This explains why the bivariate normal draws in the right graph are unable to replicate the joint extremes in the left graph. Thus, one either has to opt for parametric models that nest both data features of heavy tails and tail dependence or one decides to work with purely nonparametric techniques that pick up these stylized facts in the data automatically.

In this paper we do not want to make a parametric choice for either the marginal distributions or the tail dependence structure. We nevertheless decide to impose tail dependence on pairs of bank stock returns which implies the parameter restriction $\alpha=1$. The economic intuition for this restriction goes as follows: if banks have common risky exposures either at the asset side or the liability side, and these common risk drivers are heavy tailed, bank stock returns should automatically be tail dependent. De Vries (2005) provides an analytic exposition of this argument. From a statistical point of view, the restriction $\alpha=1$ is convenient because it reduces estimation risk (the Hill statistic is not needed to estimate the tail dependence parameter $\alpha$ ). Imposing tail dependence also imposes an upper bound on the systemic risk measure. From a regulatory point of view, a 
conservative assessment of systemic risk by means of an upper bound seems preferable instead of potentially underestimating indicators of systemic instability.

\subsection{Empirical results}

Our empirical analysis boils down to a cross-industry comparison of tail risk and systemic risk contributions of top US financial firms based on daily data sampled from 1st January 1990 until 1st September 2011. We consider two subsamples: January 1990 to August 2007 is the "pre-crisis sample"; and September 2007 to September 2011 is the "crisis" sample (notice the crisis sample is also partly postcrisis in nature). We would like to know to what extent our results on tail risk and systemic risk are robust across subsamples (more precisely the relative ranking of the institutions). In other words, even if the absolute values of tail risk and systemic risk change dramatically over subsamples, what about the ranking of the institutions relative to each other? And is the ranking in terms of univariate tail risk comparable to the ranking in terms of systemic risk? Also, what role does size play in the determination of tail risk and systemic risk? Finally, does the type of financial institution (deposit bank, broker-dealer etc.) matter in answering these questions?

The considered top financial institutions fall within four industry groups, see Acharya et al. (2010) and Brownlees and Engle (2012). The "deposit banks" group mainly contains standard commercial banks and constitutes the benchmark group of financial institutions. The "Broker-Dealers" group contains the top U.S. investment banks. Many of these firms were in severe distress in the crisis: Lehman Brothers declared bankruptcy, Bear Stearns was sold to J.P. Morgan, Merrill Lynch was sold to Bank of America, Goldman Sachs and Morgan Stanley became commercial banks switching to a stricter regulatory regime. The group "Other" contains real estate firms and most of them were also severely hit by the sub-prime crisis. However, compared to the "deposit group" they fall under looser financial regulations.

\subsubsection{Tail risk and systemic risk}

Disaggregated (bank level) results in tail risk and systemic risk are reported in appendix A: Table A4.1 (Depositories), A4.2 (Others), A4.3 (Insurance companies), and A4.4 (Broker- Dealers). Proxies for tail risk encompass the tail index $\alpha$, the quantile or Value-at-Risk $(\mathrm{VaR})$ and expected shortfalls. Extreme quantiles are calculated for a p-value of $0.1 \%$ which implies an expected VaR violation every 1,000 days $(=1,000 / 260 \approx 3.85$ years $)$. We calculate this extreme tail quantile using eq. (4.6). We also report extreme and nonextreme expected shortfall estimates conditioned on a crisis barrier of $50 \%$ and on $\mathrm{p}=5 \% \mathrm{VaR}$ numbers, 
respectively. The former is estimated using eq. (4.8) whereas the latter is determined via historical simulation, i.e., by conditioning the expected shortfall estimate on the $\mathrm{p}=5 \%$ downside risk quantile from the empirical return distribution. As concerns estimates of systemic risk, we report nonextreme values for the Marginal Expected Shortfall (MES) via historical simulation and extreme value estimates of the tail- $\beta$ in (4.13) using extreme value analysis. The MES is defined along the lines of Acharya et al. (2010) and Brownlees and Engle (2012) as the expected loss on the banking market index given a simultaneously sharp drop in an individual bank stock:

$$
M E S_{i}=E\left(R_{M} \mid R_{i}>Q_{i}(p=5 \%)\right)
$$

and with $\left(R_{M}, R_{i}\right)$ the pair of equity losses on the US banking market index and bank i's capital, respectively. The conditional expectation (4.16) can be interpreted as the systemic risk contribution of bank $i$ to overall systemic instability. For sake of calculating MES, we condition on (nonextreme) crisis barriers $Q_{i}(p)$ for individual bank stocks with a $p$-value of $5 \% .{ }^{34}$ The MES and the tail- $\beta$ are conditioned on the same banking market index. We estimate MES by historical simulation, i.e. by calculating the conditional average based on the joint empirical distribution of $\left(R_{M}, R_{i}\right)$. All tail risk and systemic risk indicators are estimated for full sample, pre-crisis, and crisis samples. To make certain patterns in the appendix tables more easily visible, Table 4.1 summarizes tables A4.1, A4.2, A4.3 and A4.4 by considering means, medians and standard deviations of all considered estimates per type of financial institution as well as for all financial institutions together. Table 4.1 reports mean and median estimates for each type of financial institution. We also report medians because the cross sectional distributions of bank risk might be skewed. However, mean and median estimates generally lie close to each other. Moreover, upon applying mean-median equality tests, we could nearly never reject the null hypothesis of equality. ${ }^{35}$

\footnotetext{
${ }^{34} \mathrm{We}$ only report estimates for nonextreme versions of (3.12) as the nonparametric extreme value estimation of MES is still in its infancy, see e.g. Zhou (2013).

${ }^{35}$ The testing results are not reported in the paper but they are available from the authors upon request.
} 


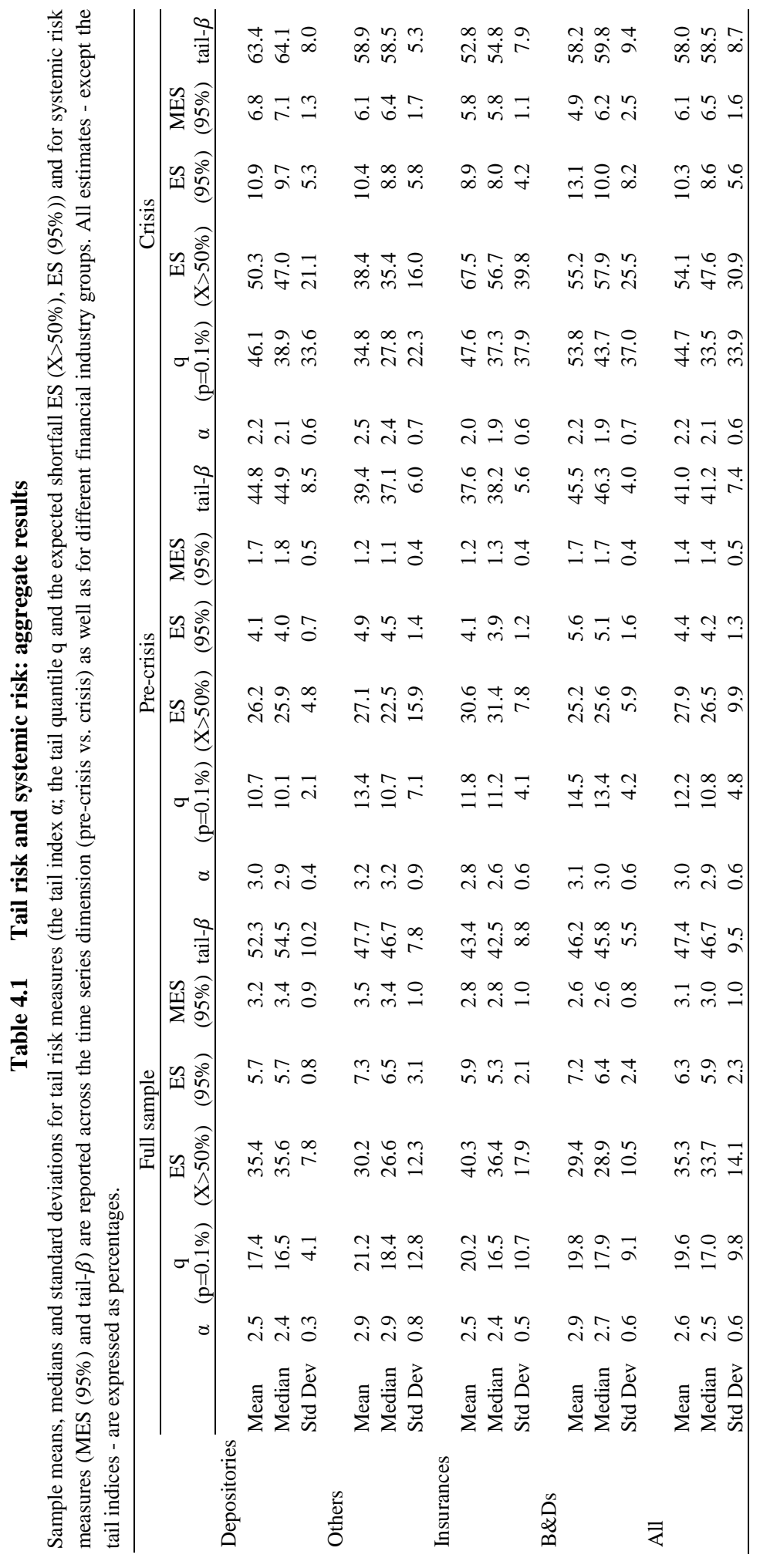


Figure 4.1 Expected Shortfall $E(X-50 \% \mid X>50 \%)$ : cross sectional averages over 1-year rolling window

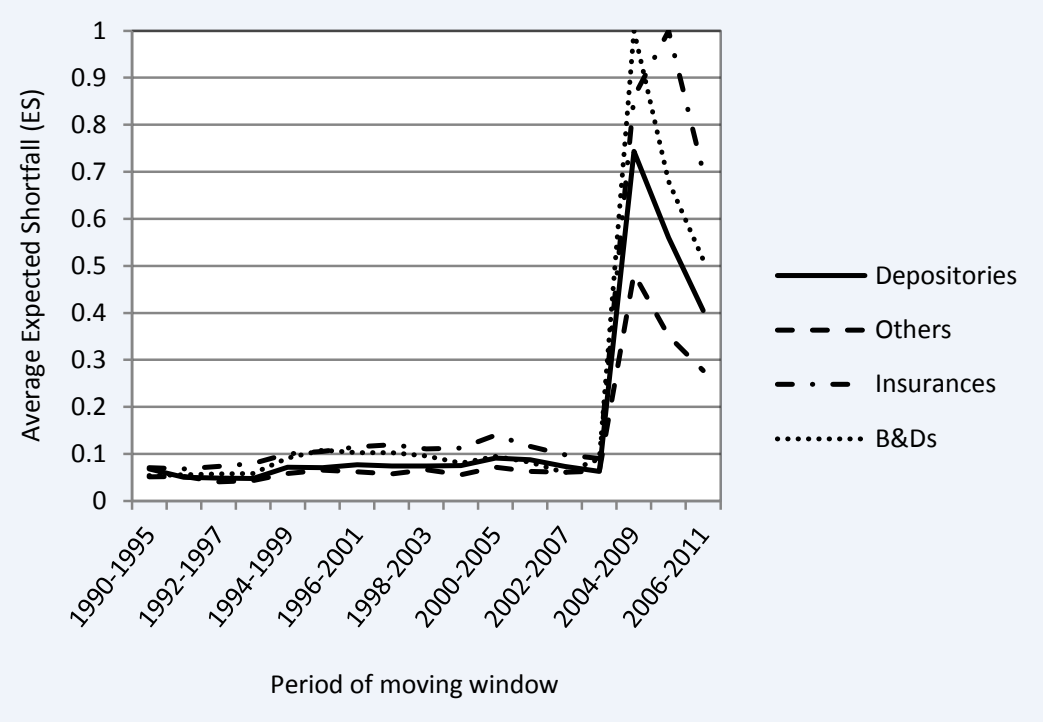

Figure 4.2 Tail- $\beta$ : cross sectional average over 1-year rolling window

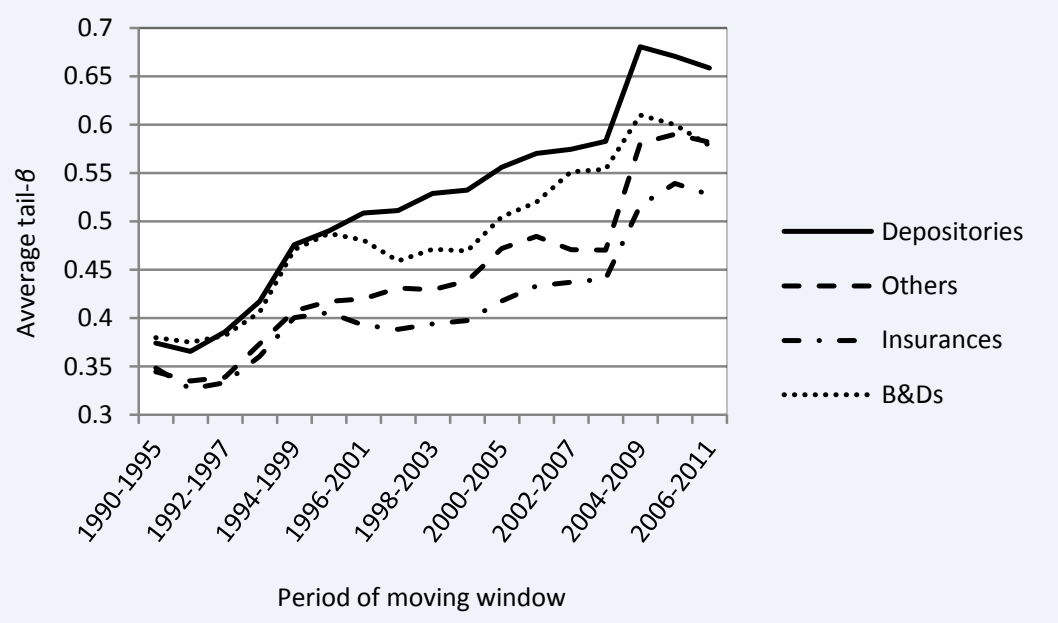

Before making any general inferences about Appendix Tables A4.1, A4.2, A4.3 and A4.4 or the condensed version in Table 4.1, it is important to grasp the economic interpretation of the risk estimates in the tables. For example, consider the subsample results for Bank of America in Table A4.1. The tail index of Bank of America dropped from 4 to 1.6 indicating that the probability mass in the tails enormously increased during the crisis period. Indeed, the crisis values of extreme 
quantiles and expected shortfalls have climbed sharply as compared to their precrisis levels. Bank of America's $0.1 \%$ tail-VaR has increased from $13.7 \%$ to $82.5 \%$ since the outbreak of the crisis whereas the tail- $\beta$ 's increase from $56.7 \%$ to $75.9 \%$; but what do all these percentages actually mean in economic terms? A precrisis Tail-VaR level of $13.7 \%$ implies that one expects a (daily) decline of $13.7 \%$ or more in the market value of Bank of America's equity capital every 3.8 years; but that crisis barrier has risen to $82.5 \%$ over the crisis period. However, a VaR crisis barrier does not tell how severe the violation of the VaR barrier may be. For that purpose it is informative to calculate so-called coherent risk measures like the expected shortfall. For example, the pre-crisis value $E(X-50 \% \mid X>50 \%)=$ $16.7 \%$ for Bank of America implies that if a VaR exceedance of $50 \%$ or more strikes, one expects an additional daily loss of $16.7 \%$. Turning to the interpretations of the extreme systematic risk estimates (tail- $\beta$ 's), a crisis value of $75.9 \%$ for Bank of America's tail- $\beta$ implies that on average a meltdown in the banking sector (proxied by a crash in the banking index) will go hand in hand with a meltdown in Bank of America's equity 3 out of 4 times! Notice that, even before the crisis, the coincidence of a banking index collapse and a Bank of America collapse in common stock is more than 1 out of 2 .

Let us now analyze the outcomes in Table 4.1 in somewhat more detail. Table 4.2 complements table 4.1 by assessing the statistical significance of the differences in average tail risk and systemic risk across the different industry groups and for the different sample periods considered. In general, there is a large cross sectional and time-series heterogeneity in bank risk. Going more systematically through Table A4.1-A4.4 and Table 4.1, one can see that: (i) all values of tail risk and systemic risk dramatically increase in the crisis period; (ii) risk estimates differ markedly across institutions but also across industry group. Tail risk is highest for insurance companies although this seems to be limited to the crisis period. For the full sample, insurance companies and the residual category "other institutions" dominate other types of financial institution in terms of tail risk. As concerns systemic risk, deposit banks seem most vulnerable during the crisis period and the full sample whereas deposit banks and broker-dealers share the first place for the pre-crisis episode. The relatively high degree of systemic risk for deposit banks is somewhat surprising given the important role investment banks supposedly played in triggering and propagating the financial crisis and resulting Great Recession. As the pre-crisis and crisis levels of bank risk in Table 4.1 also show, there is a spectacular surge in bank risk during the crisis period which is hardly surprising. This confirms earlier outcomes also based on EVT measures by Straetmans and Chaudry (2013). Table 4.2 shows that our observations above about cross industry differences in tail risk and systemic risk are indeed statistically significant. 
To illustrate bank risk dynamics even further we also consider individual risk and systemic risk exposures over moving windows of six years, the first period covering the years 1990-1995. Since the sample period spans 21 years, we obtain 17 rolling sub-samples. Rolling estimates are included in Figures 4.1 and 4.2. The figures further distinguish rolling estimates per type of financial institution. Figure 4.1 confirms that insurance companies dominate broker-dealers in terms of tail risk whereas broker-dealers in turn dominate deposit banks and the residual category "other". Figure 4.1 also reveals that this hierarchy of tail risk already seems to hold for the pre-crisis rolling samples (although tail risk lies much closer to each other over that period). Overall, tail risk for all groups exhibits a similar time series pattern which can be associated with the general level of risk in the economy. Brownlees and Engle (2012) report comparable findings for the average daily volatility within a GARCH framework but the rolling (overlapping) nature of our EVT estimates smoothens sharp peaks and troughs. The relatively higher levels of ES in the early 2000s correspond with the dot com bubble burst and resulting recession. Next follows a period of lower tail risk that lasts until mid2007. Afterwards, and similar to volatility, ES literally explodes in 2008 and peaks to the highest level measured over the considered sample. The degree of comovement between the average values of ES across banking groups differs across time. Prior to the crisis, ES clusters together for all sectors but during the financial crisis, all industry groups jump significantly and the spread between groups becomes much clearer. On average, the Insurance group takes the lead in ES, followed by the Broker \& Dealers group. This contradicts the Brownlees and Engle (2012) findings where the Insurance group stays consistently least risky in term of volatility as compared to the other industry groups.

Figure 4.2 confirms that deposit banks seem systemically the most important followed by Broker \& Dealers, the residual category "other institutions" and "insurance companies". The relative ranking of different financial industry types according to their systemic risk contribution confirms the findings in Harrington (2009) and Acharya et al. (2010). Notice also that for both figures tail risk and systemic risk both started to decline again towards the end of the sample period. 


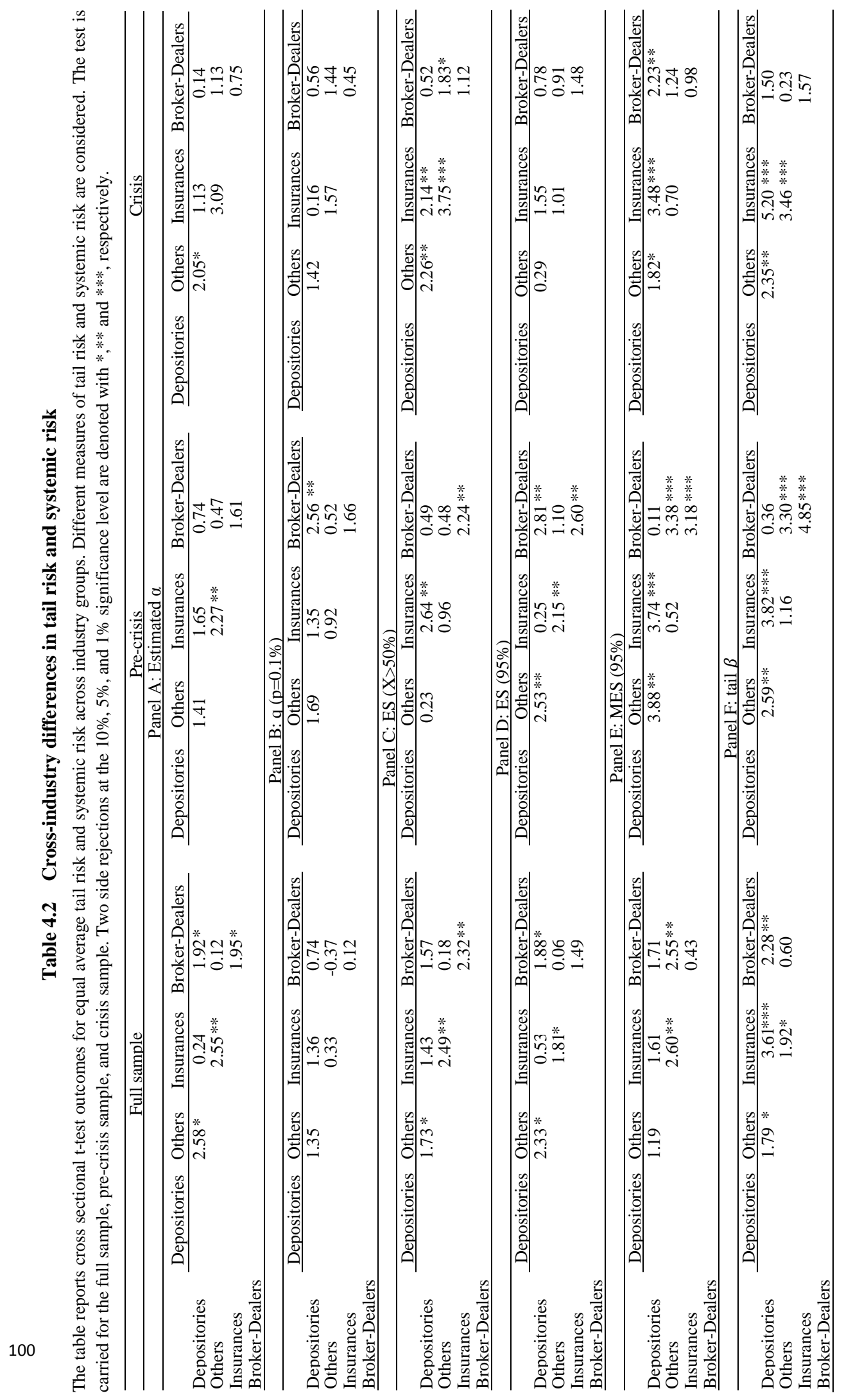


The vast increases in tail risk and systemic risk over the crisis sample - and thus apparent instability - raises the issue whether these measures have any value added towards predicting future systemic instability. If they only function as descriptive indicators that tell us what the current state of systemic risk is their value stays relatively limited. Acharya et al. (2010) and Brownlees and Engle (2012) already argued that their pre-crisis MES estimates exhibit some predictability towards adverse shocks in the banks' equity capital during the crisis. In order to judge whether the pre-crisis EVT-based measures exhibit predictive content toward their crisis counterparts, we take a slightly alternative route and scatter pre-crisis tail risk vs. crisis tail risk (Panel A) and pre-crisis tail- $\beta$ 's vs. crisis tail- $\beta$ 's (Panel B). The scatter plots are summarized in Figure 4.3. OLS regression lines are also included in the scatters. The graphs already provide some casual evidence of a positive relationship that pre-crisis values of tail risk (systemic risk) indeed have something to say about their crisis counterparts.

Figure 4.3 Tail risk (ES $(X>50 \%)$ ) and systemic risk (tail- $\beta)$ : pre-crisis versus crisis for all institutions and for separate industry groups

Panel A: ES $(X>50 \%)$
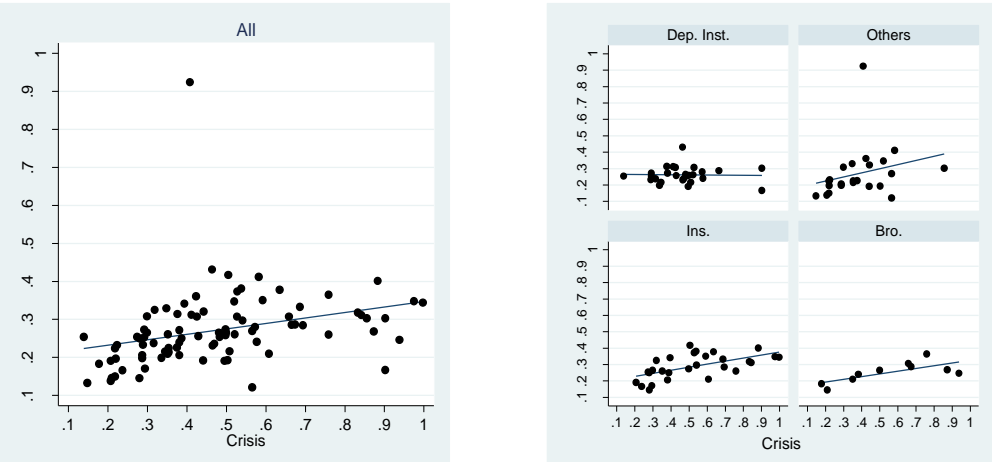

Panel B: Tail- $\beta$
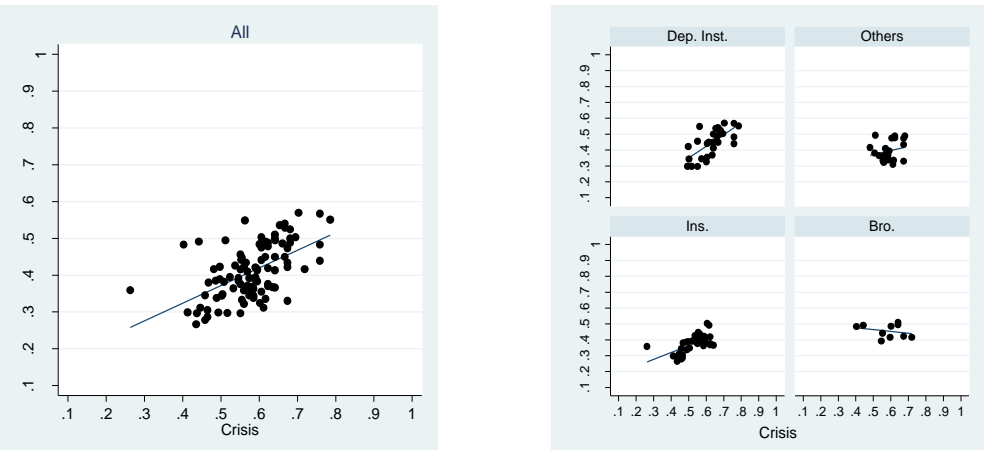
In addition to the scatter plot analysis, we also calculate (Spearman) rank correlations between pre-crisis and crisis ranks of tail risk and systemic risk proxies. These rank correlations are reported in Table 4.3.

Table 4.3 Rank correlation of tail risk and systemic risk measures (pre-crisis versus crisis)

The table presents Spearman's rank correlations (percentage) between pre-crisis and crisis for different risk measures. Statistically significant rank correlations at the $10 \%, 5 \%$, and $1 \%$ significance level are denoted with $*, * *$, and $* * *$, respectively.

\begin{tabular}{llcccc}
\hline & $\mathrm{q}(\mathrm{p}=0.1 \%)$ & $\mathrm{ES}(\mathrm{X}>50 \%)$ & $\mathrm{ES}(95 \%)$ & MES $(95 \%)$ & tail- $\beta$ \\
\cline { 2 - 6 } Depositories & -3.3 & 16.7 & -18.6 & $60.8 * * *$ & $70.2^{* * *}$ \\
Others & $43.6 * *$ & $44.6 * *$ & 19.4 & $39.1 *$ & 16.8 \\
Insurances & $35.6 * *$ & $69.2 * * *$ & 2.4 & $57.0 * * *$ & $63.0 * * *$ \\
Broker-Dealers & 53.9 & $72.1 * *$ & 24.9 & 44.8 & 0.0 \\
All & $28.5 * * *$ & $58.4 * * *$ & 5.6 & $56.0 * * *$ & $56.8 * * *$ \\
\hline
\end{tabular}

Also here, we distinguish between rank correlations for the whole cross section of institutions as well as for rank correlations per financial industry sector. It is not because the bank risk measures nearly all doubled or tripled that the riskiness of institutions relative to each other has changed. The table clearly shows that the majority of rank correlations are statistically significant and quite high in most cases. The expected shortfall measure ES (95\%), though, is very unstable over time. But those pre-crisis EVT indicators of tail risk and systemic risk that produce stable ranks over time exhibit some predictive power towards their crisis counterparts and thus still represent useful info for regulators and supervisors. Tail risk and systemic risk seem relatively persistent in that the riskiest (safest) financial institutions in the pre-crisis period seem to remain the riskiest ones (safest ones) once the crisis struck.

\subsubsection{Size as a potential driver of tail risk and systemic risk}

That there is a relation between the size of financial institutions and their systemic risk contribution seems to be taken for granted nowadays by governments or central banks. According to theory, systemic risk either arises because of "direct" channels via interbank market linkages or "indirect" channels such as similar portfolio holdings in bank balance sheets. However, bigger banks are not necessarily more interconnected with the rest of the financial system nor do they necessarily exhibit more diversified portfolio holdings. In the end, however, whether the size-systemic risk relation exists or not remains an empirical issue. Despite the consensus that seems to exist in the policy arena, the number of empirical studies that try to link some proxy of institutional size to systemic risk remains limited, see e.g. de Jonghe (2010) or Zhou (2010). The latter studies typically find a positive size-systemic risk relation but the relation is often unstable across different time periods. 
Downsizing financial institutions' balance sheets is generally considered as one of the corner stones of financial reforms nowadays but one seems to forget that institutional size almost surely also impacts the diversification properties of financial institutions, see e.g. the discussion in Slijkerman et al. (2013). In other words, it may well be that although the systemic contribution of banks is decreased by shrinking the balance sheet, the banks become less diversified and thus more unstable as an individual institution, i.e. higher individual bank risk. Whereas the empirical work on the size-systemic risk relation is already pretty scant, empirical studies on the size-univariate bank tail risk relation are nearly nonexistent. This is somewhat remarkable because the "usual suspects" that are expected to trigger systemic instability and tail risk are probably partly overlapping, i.e., a joint analysis of tail risk and systemic risk seems a natural way to proceed. We apply two types of empirical exercises on the triangle size-tail risk-systemic risk. First, we calculate rank correlations between tail risk and systemic risk. Secondly, we calculate rank correlations between tail risk and size and systemic risk and size. Rank correlations are calculated for different time series samples (full sample, pre-crisis and crisis samples) and different cross sections (all banks as well as the separate segments of the financial industry that we earlier considered). We decided to solely focus on the size variable because it is the most widely considered trigger of bank systemic risk.

Table 4.4 Rank Correlation between tail risk and tail- $\beta$

The table reports Spearman's rank correlations (percentages) between the expected shortfall and tail-beta measures. Results are reported for the full sample, pre-crisis, and crisis period. Statistically significant rank correlations at the $10 \%, 5 \%$, and $1 \%$ significance level are denoted with *** and ***, respectively.

\begin{tabular}{llcl}
\hline & Full sample & Pre-Crisis & Crisis \\
\hline & & ES $(x>50 \%)$ vs. tail- $\beta$ & \\
\cline { 2 - 4 } Depositories & $41.6^{* *}$ & -25.8 & $46.6^{* *}$ \\
Others & 34.8 & 32.3 & -5.2 \\
Insurances & $57.4^{* * *}$ & 11.0 & $42.9^{* *}$ \\
B\&Ds & 16.4 & $73.4^{* *}$ & -44.2 \\
All & $41.4^{* * *}$ & -3.7 & 7.4 \\
\hline
\end{tabular}


Figure 4.4 Tail risk $(\mathrm{ES}(\mathrm{X}>50 \%))$ versus extreme systemic risk (tail- $\beta$ ) for full-sample, pre-crisis, crisis

Panel A: Full sample
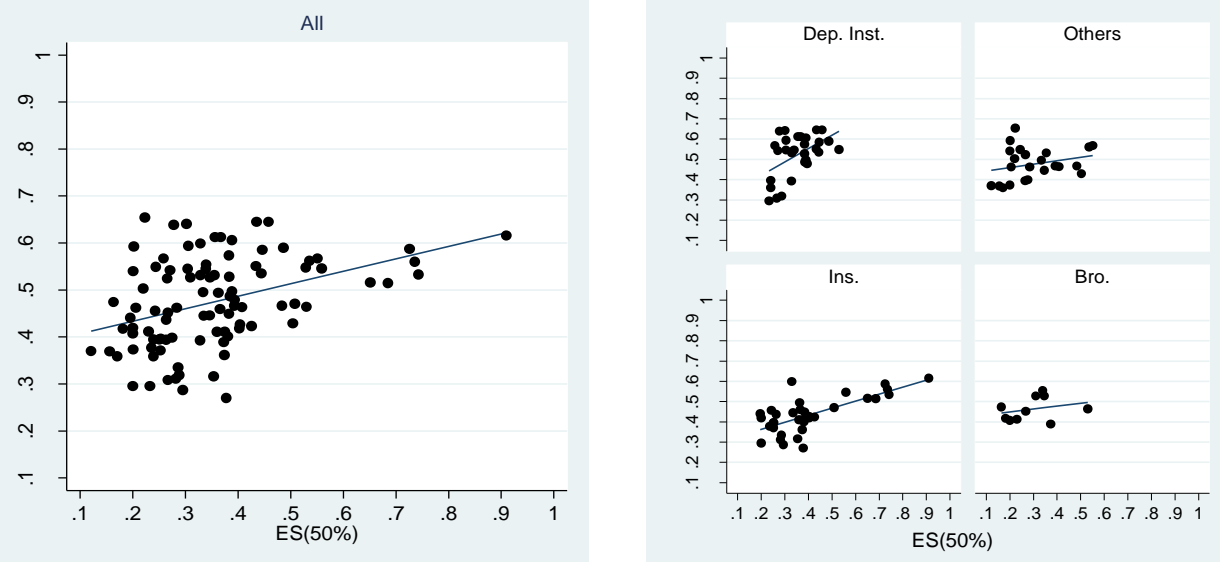

Panel B: Pre-crisis
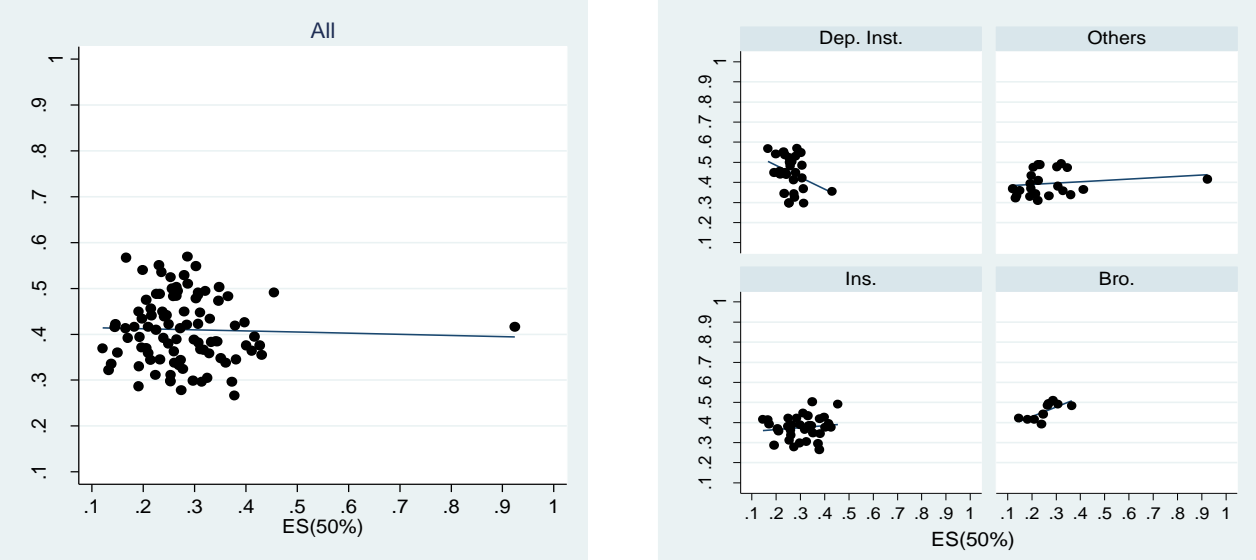

Panel C: Crisis
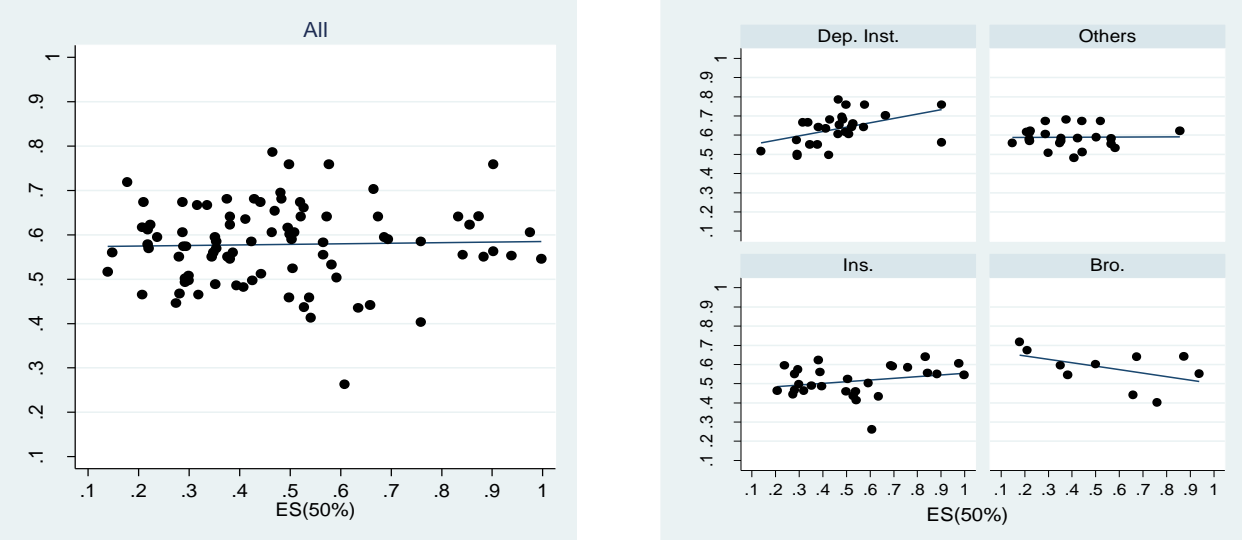
Rank correlations between individual tail risk and systemic risk are contained in Table 4.4 and Figure 4.4. Robust statistically and economically significant correlations only seem to exist for the full sample. Thus, we cannot conclude that there is a positive relationship between tail risk and systemic risk in a robust fashion because they do not seem to be related over the pre-crisis and crisis sample. Next, we correlate the ranks of tail risk and systemic risk with the size ranks of the respective institutions. Rank correlations between different size proxies, tail risk and systemic risk are contained in Table 4.5. For sake of sensitivity analysis, we distinguish four different proxies for a financial institution's size: total market capitalization, total asset, total equity and total debt (all market values). We consider two tail risk proxies and the tail- $\beta$ systemic risk measure. Conform to previous tables we distinguish different time series samples (full sample, pre-crisis and crisis outcomes) and different cross sections (results averaged across all institutions or across separate financial industry segments). Whereas size and tail risk seem rather independently evolving from each other (very few rank correlations are statistically significant), the size-systemic risk relationship appears to be significant in a majority of cases. However, notice that the significance is strongest for the full sample and the pre-crisis sample whereas the relation seems severely weakened over the crisis sample. The total asset size proxy seems most strongly correlated with systemic risk. Our results generally confirm earlier findings on the size-systemic risk relationship. 


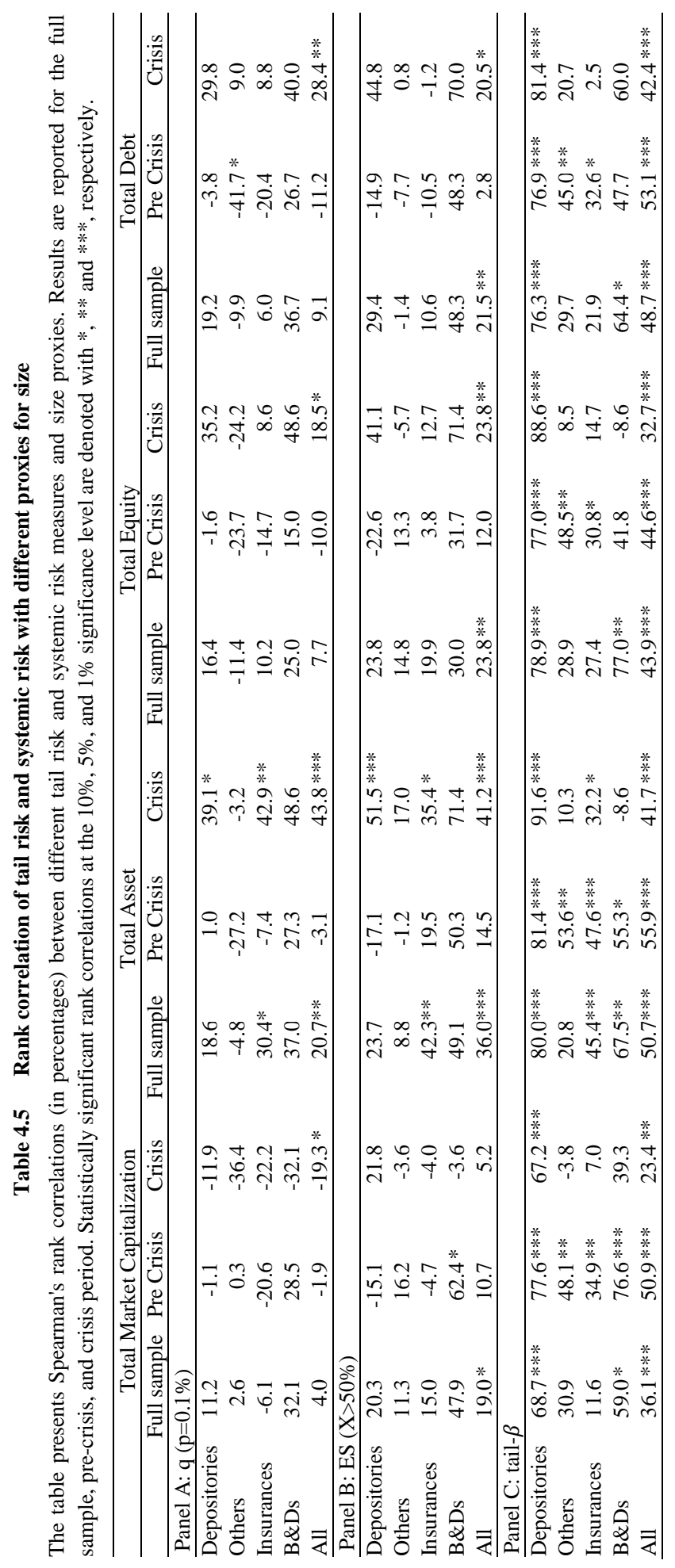




\subsection{Conclusions}

The financial sector maintains a central role in an economy to finance investment and growth in the real sector, to create money and transmit monetary policy, but also because of its involvement in the multilateral payment system. Thus, longterm financial stability, both for individual financial institutions (tail risk) as well as for the system as a whole (systemic risk) is of utmost importance. In this study, we borrow techniques from statistical extreme value analysis to estimate a downside risk measure (per individual institution) and a system-wide risk measure (systemic risk). Both are market-based indicators: they use the loss tails of the market value of equity capital as an input. The downside risk is measured using an extreme tail quantile estimator whereas the systemic risk is measured by the socalled co-crash probability of an individual bank stock conditional on a banking market index, i.e., a so-called tail- $\beta$. Tail- $\beta$ 's are estimated by the so-called Ledford and Tawn approach and by imposing the tail dependence restriction. The latter implies that asymptotic co-crash probability values always stay bounded away from zero.

We compare tail risk and systemic risk outcomes across four different industry groups containing 91 financial institutions as in Acharya et al. (2011) and Brownlees and Engle (2012): Depositors, Insurances, Brokers \& Dealers, and Others. This enables one to make cross-industry tail risk and systemic risk comparisons which constitutes the main objective of the paper. First, we find that different groups of financial institutions exhibit different levels of tail risk as well as systemic risk. Insurance companies exhibit the highest equity tail risk. Second, and somewhat surprising, deposit banks (and not broker-dealers) seem to be most strongly exposed to adverse macro shocks. Third, both tail risk and systemic risk have increased over the crisis which does not come as a surprise. However, the relative ranking of the financial institutions' riskiness is not changing dramatically over time: extreme systematic risk seems to exhibit some predictability towards future distress as the rank correlations between pre-crisis and crisis tail- $\beta$ 's are found to be relatively high. Finally, institutional size proxies are not strongly correlated with tail risk (no diversification effect for larger institutions); but size seems correlated with our systemic risk measure. However, the size and related ranking results vary considerably across industries and subsamples. 


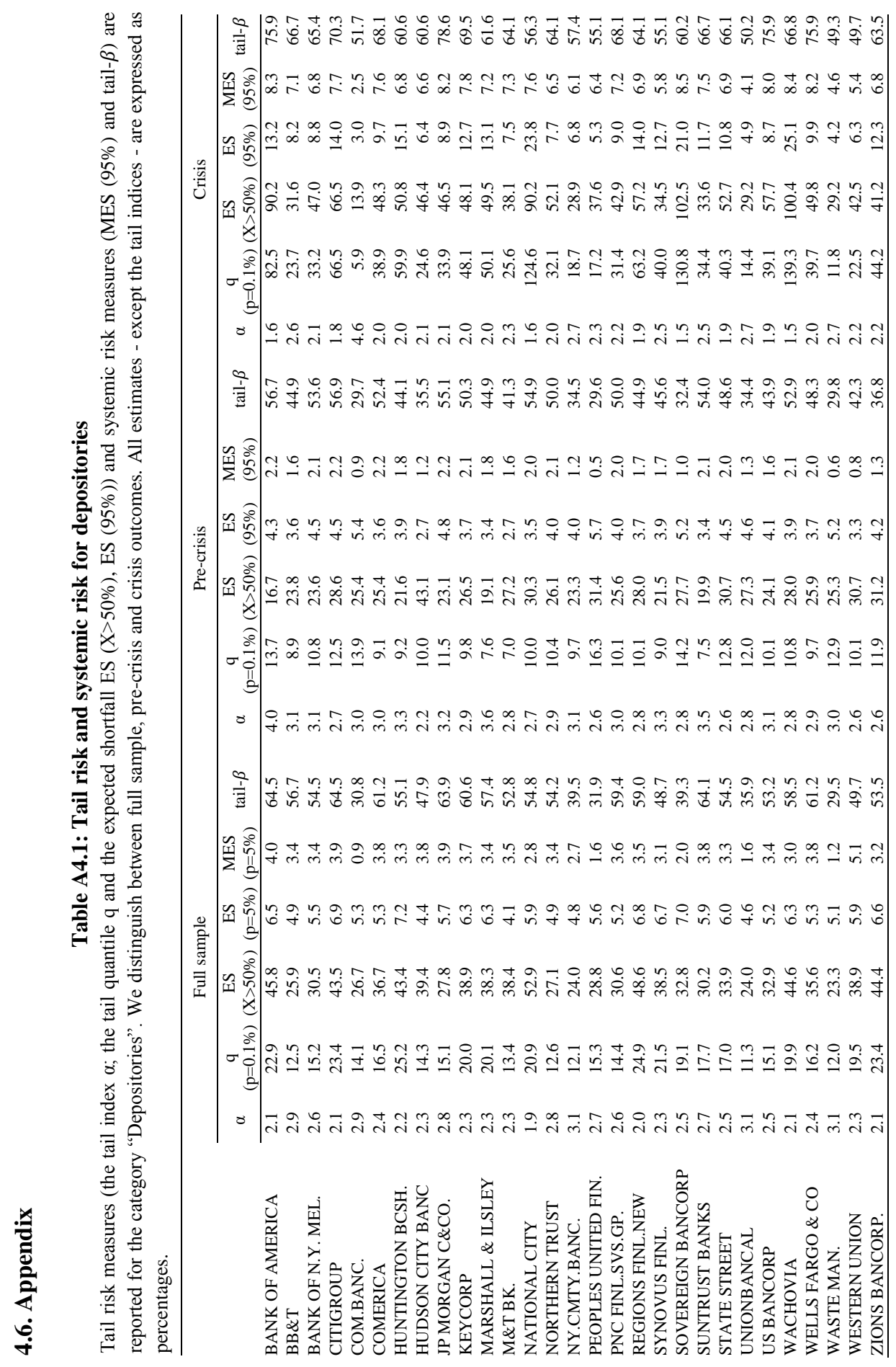




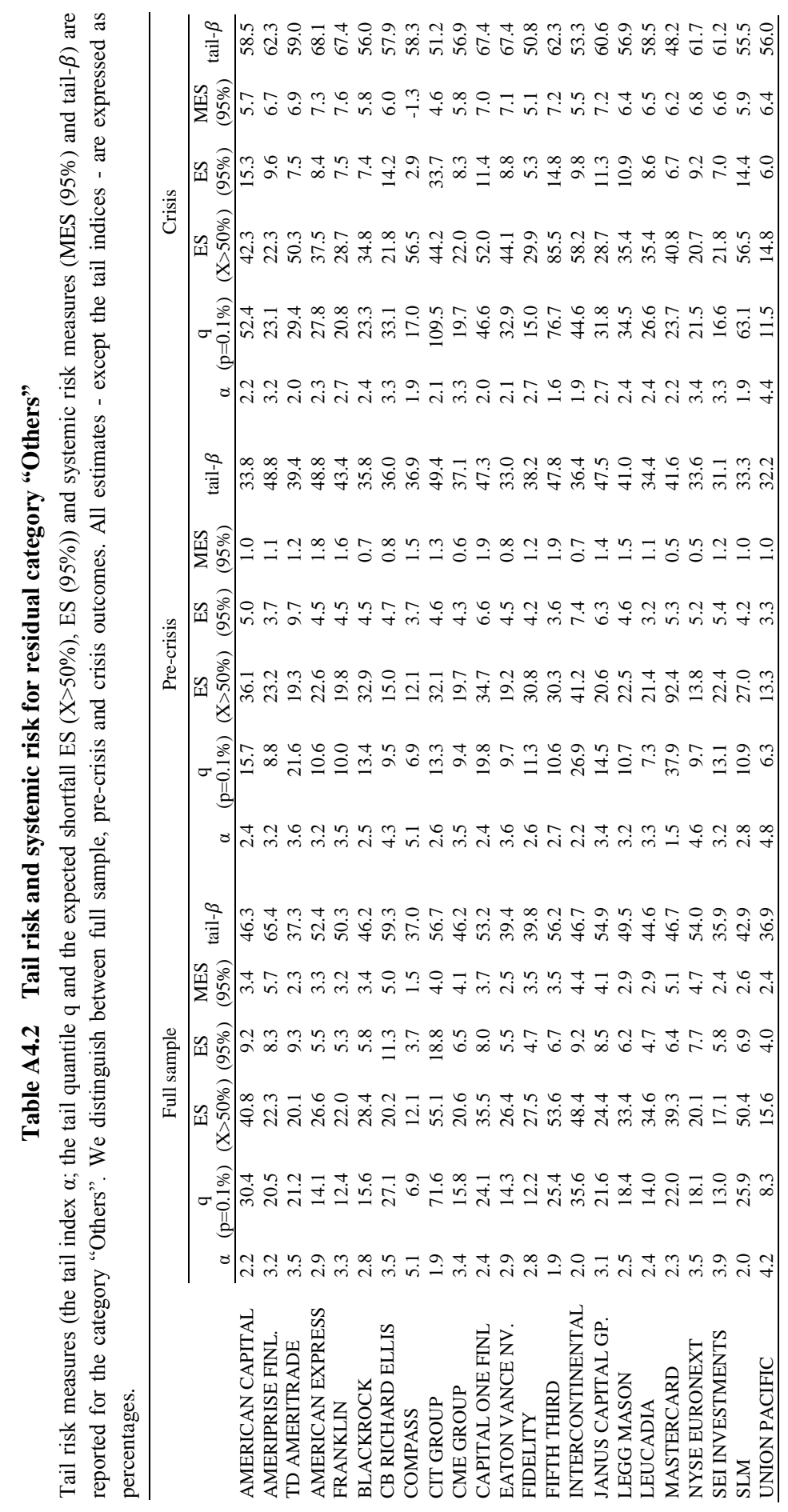




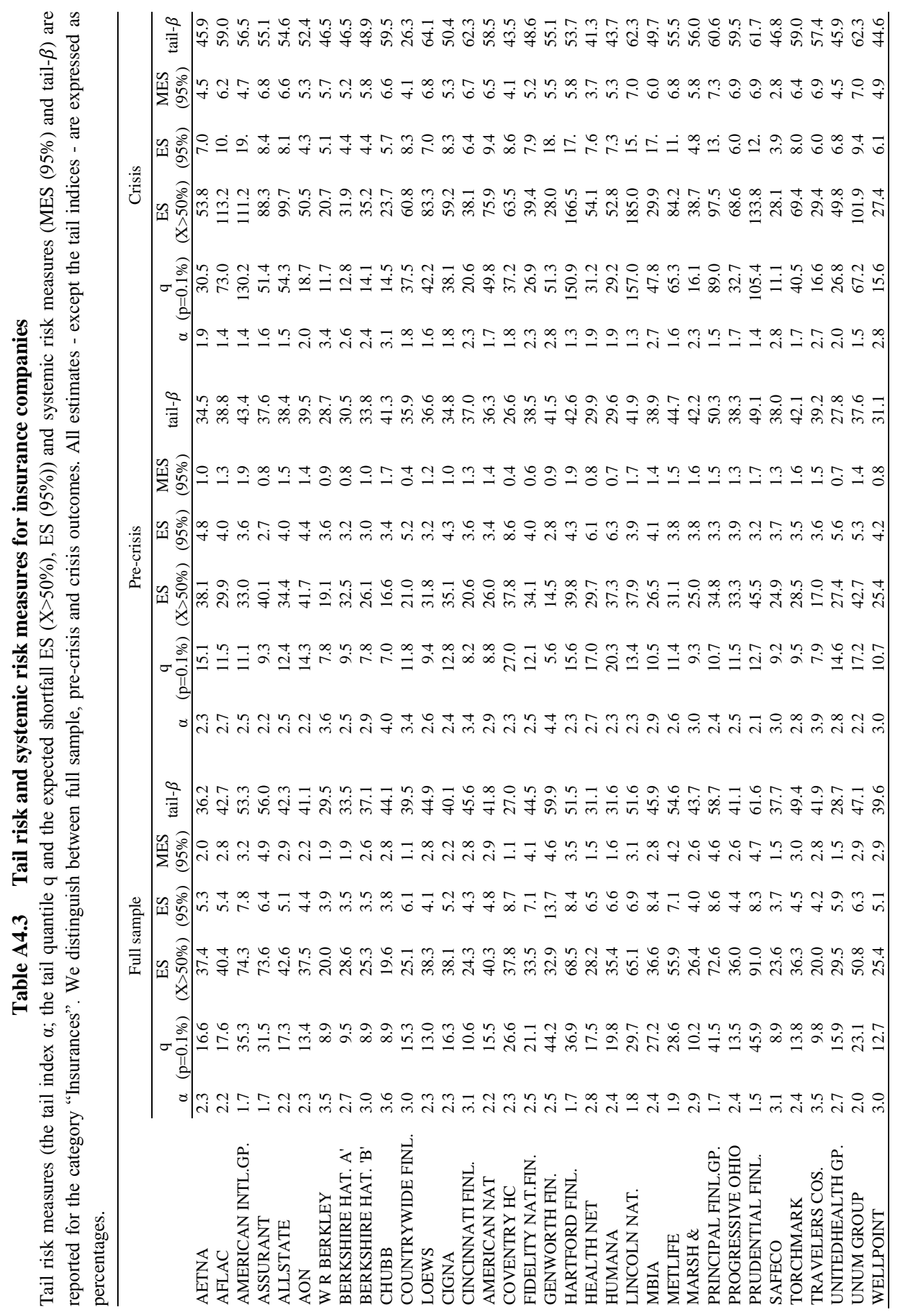




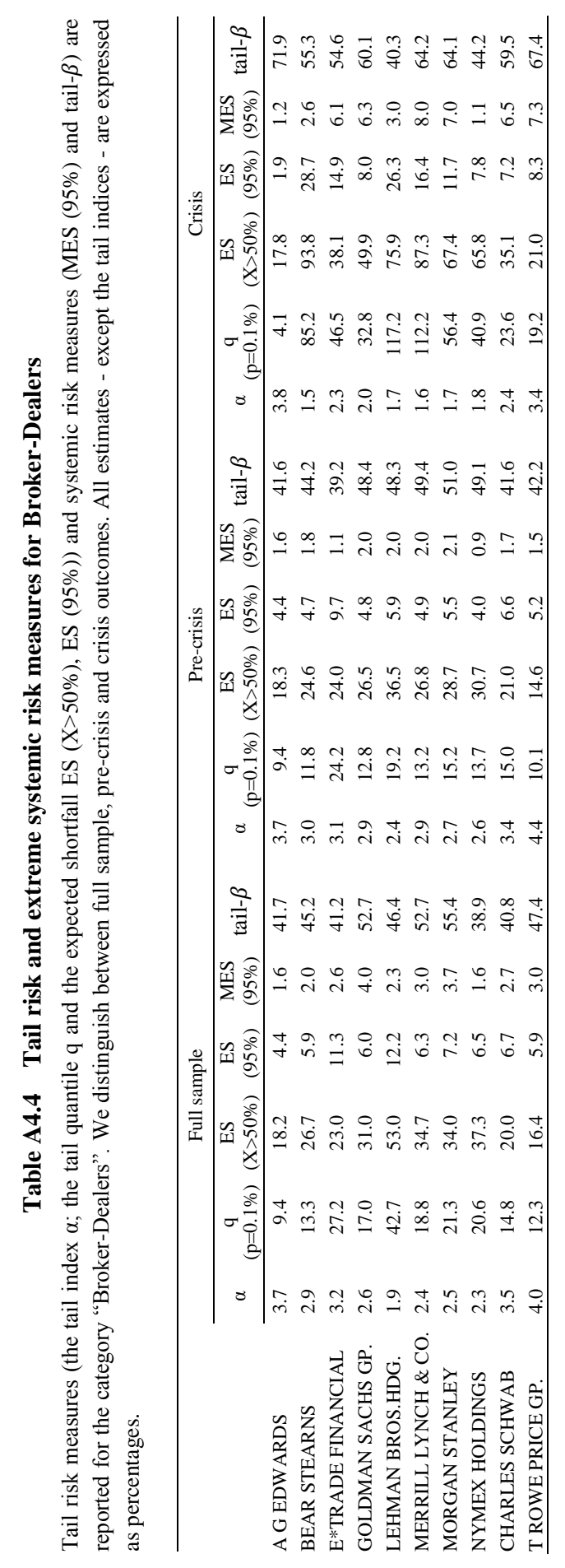



Chapter 5

Extreme Risks and the Business $\mathrm{Cycle}^{36}$

\subsection{Introduction}

Crisis episodes like the dotcom bubble burst, the 2007-2009 banking crisis or the euro area sovereign debt crisis are a reminder to academics, institutional investors and policy makers that "co-crash" linkages in financial markets or, alternatively, asset substitution phenomena like "flight-to-quality" or "flight-to-liquidity" exist and can be severe especially during periods of market stress. The severity of financial crises and crisis spillovers also potentially determines how severe the impact may be on real economic activity. Alternatively, flight-to-quality or flightto-liquidity spillovers may also enhance overall financial stability or increase the potential for diversifying the portfolio tail risk of large institutional investors like pension funds.

The vast majority of empirical studies on financial crises and crisis spillovers implemented some form of correlation analysis, see e.g. King and Wadwhani (1990); Lin et al. (1994); Susmel and Engle (1994), Bae et al. (2003), Manganelli et al. (2004), Cappiello et al. (2005) or more recently Bekaert et al. (2009, 2010, 2012) and White et al. (2013). Methodologies include, inter alia, multivariate versions of factor models, DCC-GARCH specifications, limited dependent variable models (multinomial probit and logit), multivariate quantile regressions etc. These articles typically study whether financial markets are more strongly comoving during periods of market turbulence compared to periods of low market volatility and also question the direction of international spillovers. An increasingly important subset of this "market linkages" literature focuses on whether financial crises are "contagious" (see Forbes and Rigobon (2002); Bae et al. (2003); Chan-Lau et al. (2004); Bekaert et al. (2005)). Hartmann et al. (2006) argue that the financial contagion concept is far from unambiguously defined and discuss the most frequent interpretations that co-exist nowadays. Brownlees and Engle (2012), Acharya et al. (2010) and Adrian and Brunnermeier (2011) measure bank linkages between the top US financial institutions by introducing alternative indicators of systemic risk whose estimation is based on some form of covariance analysis.

The main objection against the (bulk of the) market linkages literature is twofold in that it (i) is very correlation-oriented and (ii) often does not capture true crisis ${ }^{36}$ This chapter is based on 'Extreme Risks and the Business Cycle' co-authored with Stefan
Straetmans. 
episodes in the "systemic" sense of the word (i.e. very low frequency events) when focusing on high volatility regimes. Correlations can actually be very misleading indicators of dependence during crisis episodes.

For example, Boyer et al. (1999) and Ang and Chen (2002) show for the bivariate normal distribution that the correlation varies considerably when conditioned on subsets of the overall distributional support. The conditional correlation eventually goes to zero when truncated on the tail area. This implies that correlations in conjunction with the normality assumption to assess, say, indicators of systemic risk, almost certainly result in severe underestimation of the latter. Moreover, truncated correlations differ across different classes of multivariate distributions; also, correlations can only capture linear dependence whereas one might suspect crisis spillovers to be fundamentally nonlinear phenomena. ${ }^{37}$ For a more in-depth treatment of the pitfalls of correlation analysis, see e.g. Embrechts et al. (1999). Another problem with existing comovement approaches is that it is questionable whether they truly capture the low-incidence character of crises and crisis comovements. For example, co-quantile regressions typically focus on the $5 \%$ or $1 \%$ tail area which reflect crisis events expected to happen once in 20 days and once in 100 days, respectively. These events can hardly be considered "extreme" in the sense of large adverse shocks triggering companies into overnight insolvency. The latter types of extreme low-incidence events are the ones we are interested in.

Mainly because of the above concerns regarding the applicability of covariance analysis during periods of high market volatility, a growing body of literature applies extreme value analysis (EVT) ${ }^{38}$ Loosely speaking, EVT enables one to estimate marginal and joint probabilities of infrequent tail events like crises without the need to resort to a parametric probability law for the returns. As will be discussed in the estimation section of this paper, some mild conditions on the tail behavior of the returns suffice for the purpose of estimation and statistical inference. Also, extreme value analysis studies the tail behavior of the unconditional distribution of financial returns which constitutes a second

\footnotetext{
${ }^{37}$ The latter pitfall can nevertheless be partly remedied by integrating elements of non-linear time series analysis (e.g. jump diffusions) in multivariate comovement models based on GARCH or stochastic volatility frameworks.

${ }^{38}$ In univariate and bivariate settings EVT has been previously implemented to assess the severity of extreme market (co-) movements. For example, Koedijk et al. $(1990,1992)$ and Hols and de Vries (1991) study the (heavy) tails of foreign exchange rate returns. Jansen and de Vries (1991) and Longin (1996) analyze stock market booms and busts whereas de Haan et al. (1994) consider extreme up- and downturns in bond markets. Bivariate EVT has been employed to measure extreme stock market spillovers in either a parametric fashion (Longin and Solnik (2001)) or a semi-parametric way (see Straetmans, 2000; Poon et al., 2004). Hartmann et al. (2003, 2004) address various forms of currency and stock-bond spillovers. Finally, Hartmann et al. (2006), de Jonghe (2010), Zhou (2010) and Straetmans and Chaudhry (2013) apply EVT techniques to assess tail risk and systemic risk of financial institutions. 
methodological difference with the bulk of the comovement literature traditionally focusing on the conditional distribution of returns (all kinds of conditional $\mathrm{GARCH}$, stochastic volatility, co-quantile regressions etc.). ${ }^{39}$

In this paper we take an intermediate position between these two long-standing traditions of either modeling the multivariate distribution in a conditional fashion (time dependent and typically with a short-term focus) or in an unconditional way (time independent and typically with a long-term focus). We develop the idea that the unconditional tail of financial return distributions (despite being stationary) may exhibit time dependent "regimes" of some kind. More specifically, we assume that the parameters governing the univariate (Pareto-type) tail decline and multivariate (tail dependence structure or tail copula) tail behavior can change through time due to e.g. shifts in monetary or fiscal policy regimes, financial liberalization (e.g. liberalization of capital controls, prudential FX measures, exchange rate regimes etc.) or changes in certain macro-economic variables to name only a few possible causes.

In the aftermath of Hamilton's (1990) regime-switching paper, an "academic industry" developed on regime switching behavior in financial markets, see e.g. Engel and Hamilton (1990), Hamilton and Susmel (1994), Bekaert and Harvey (1995), Gray (1996), Ang and Bekaert (2002), Baele (2005), Guidolin and Timmermann (2008) or Ang and Timmermann (2011). In contrast, only a small number of papers tested for structural breaks in the unconditional tail behaviour of financial returns. The presence of structural breaks in univariate tail behavior (i.e. the tail index) has been investigated for different asset classes: exchange rate returns (Koedijk et al. (1990, 1992)), Bund Futures returns (Werner and Upper (2002)) and stock markets (Jansen and de Vries (1991), Pagan and Schwert (1990), Quintos et al. (2001), Galbraith and Zernov (2004) and Straetmans et al. (2008)). Straetmans and Candelon (2013) investigate the tail index constancy hypothesis for a variety of financial assets and summarize the univariate breakpoint literature. The general picture that emerges from this univariate EVT literature is that the tail index is remarkably stable over time: only emerging currency returns seem to exhibit jumps in the tail index, most probably due to

\footnotetext{
${ }^{39}$ Conditional models enable one to identify dynamic (time varying) risk measures that are widely used by risk managers and investors with short time horizons for sake of short-term volatility forecasting and portfolio rebalancing. However, for long-term investors, financial regulators and supervisors that care about e.g. assessing the likelihood of financial instability, the more relevant exercise to undertake seems the assessment of extreme risks and worst cases scenarios based on the unconditional tail of portfolio returns. The unconditional return distribution will typically render more conservative outcomes than dynamic risk measures based on the conditional return distribution. Although conservativeness in risk assessment may indeed be desirable from a regulatory or supervisory point of view $^{39}$, it may be less desirable for banks or portfolio investors themselves; financial institutions do not want to see their profitability squeezed too much and risk-averse portfolio investors may well care about tail risk events but typically also care about realizing some decent return.
} 
changes in exchange rate regimes. As for temporal changes in the multivariate tail dependence structure, the number of studies is even more limited. Straetmans (1998) found only weak evidence for structural breaks in extreme linkages between international stock markets; on the other hand, the same author established that extreme spillovers between European currencies expressed against the Dmark numeraire were seriously dampened due to the introduction of the European Monetary System (EMS). More recently, Straetmans et al. (2008) established a statistically significant " $9 / 11$ effect" in conditional co-crash probabilities between US sectoral indices and a market index. Finally, using alternative market-based (extreme value) indicators of systemic risk, Hartmann et al. (2006) and Straetmans and Chaudhry (2013) show that systemic risk has increased at both sides of the Atlantic.

The main contribution of this paper is to build further on this breakpoint literature by questioning the existence of regimes in the tail behavior of financial asset returns. More specifically, we investigate whether the tail behavior of asset returns (either single asset tail fatness or cross-asset strength of tail dependence) changes with the business cycle. Traditional applications of EVT do not take economic cycles into account and estimate tail features using as much return data as possible, i.e. the "full" sample. However, it seems natural to assume that the propensity towards financial crises or crisis spillovers is nonconstant over time and e.g. depends on the phase of the business cycle. If that is the case, full sample measures for e.g. tail-VaR or crisis spillover indicators will be biased estimates of the true state (recession-based or expansion-based estimates). If tail behavior varies with the business cycle, unbiased estimation of the tail characteristics requires splitting up the full sample into a "recession" and an "expansion" sample. ${ }^{40}$ First, we consider regime-dependent proxies of tail risk for different financial asset classes (stock indices, bond indices, bank stocks, exchange rates and commodities). Next, we calculate market-based systemic risk measures conditioned on recessions and expansions using the stock prices of US financial institutions. Third, we compare the strength of co-crashes vs. flight-to-quality between stock and sovereign bond markets across recessions and expansions. Finally, we investigate to what extent business cycle phases matter for the potential of portfolio risk diversification. To that aim we estimate and minimize both portfolio variances and tail risks across the business cycle for simple twostock portfolios selected from the Dow Jones index.

Anticipating our results, we find that extreme downside risk is significantly more severe for the recession sample as compared to the expansion sample. Second, this

\footnotetext{
${ }^{40}$ Notice, however, this also decreases estimation accuracy because recession and expansion samples are smaller than the full sample, i.e. the so-called bias-variance trade off in EVT estimation when varying the sample size. 
is also present in tail risk and systemic risk indicators of selected US financial institutions. Third, previous EVT papers like e.g. Hartmann et al. (2004) established that stock-bond co-crashes and flight-to-quality phenomena are approximately equally likely (but using weekly data from 1987-1999). In contrast, our results suggest that stock-bond co-crashes are less likely than flight-to-quality during times of market stress and that this asymmetry is largest during recessions. More specifically, flight-to-quality from stocks into bonds happens nearly twice as often as compared to stock-bond co-crashes during recessions; but the two likelihoods are much closer to each other for the expansion sample and the full sample. Finally, we establish that portfolio risk (both central risk measures like variance as well as tail risk) is much harder to diversify during recessions as compared to expansions, i.e., a diversification meltdown. The minimum tail risk portfolios are also substantially different across recessions and expansions which further confirms the rather different nature of the tail dependence structure during different phases of the business cycle.

The paper proceeds as follows. Section 5.2 summarizes theory on extreme value analysis and introduces regimes in the unconditional tails. Regimes are introduced by considering mixture models of univariate and multivariate distributional tails. Section 5.3 presents semi-parametric estimation procedures that are common in statistical EVT and that can be applied on recession-based and expansion-based subsamples. Section 5.4 contains empirical results. Conclusions are summarized in the final section 5.5 .

\subsection{Extreme linkages: probability theory and regime dependence}

We first introduce our EVT-based measures of tail risk and tail co-movement (the so-called tail- $\beta$ ) based on the unconditional distribution, i.e., without considering regime dependence. The former is identified using a Pareto-type tail decline whereas the latter is expressed in terms of the so-called tail copula or stable tail dependence function (5.2.1). Next, we show how regime dependence of our tail risk and tail comovement measures can be easily introduced by means of distributional mixtures of univariate and bivariate tail models (5.2.2).

\subsubsection{Probability theory}

Since Mandelbrot (1963), the stylized fact of fat tailed financial returns seems generally accepted within the financial economics profession. We employ it as an identification scheme for calculating tail likelihoods. Loosely speaking, it implies that the exceedance probability for a given exceedance level (or quantile) approximately evolves according to a power law of the quantile (i.e. polynomial tail decay). Assume that we are interested in the distributional tail of financial return losses. Return losses will be denoted furtheron by a positive random 
variable $X$ which implies we focus on the right tail. ${ }^{41}$ The characterizing property for distributions with a power-type tail decay is the so-called regular variation at infinity property:

$$
\lim _{s \rightarrow \infty} \frac{P\{X>s x\}}{P\{X>s\}}=x^{-\alpha}, x>0, \alpha>0
$$

From this condition it follows that distributions, like e.g. the Student-t, the class of symmetric stable distributions or the GARCH class have bounded moments up to $\alpha$, where $\alpha$ is known as the "tail index". In contrast, distributions with exponentially decaying tails or with finite endpoints have all moments finite (bounded). Another way of characterizing the class of regularly varying functions is by factorizing them into a power law part $x^{-\alpha}$ and a slowly varying function part $L(x)$ :

$$
P\{X>x\}=L(x) x^{-\alpha}
$$

with $x$ large and where $L(x)$ is a slowly varying function, i.e., $\lim _{x \rightarrow \infty} \frac{L(s x)}{L(x)}=1, x>0$. Estimation of the exceedance probability (5.2) for given quantile $x$ (or, alternatively, of $x$ for given exceedance probability $p$ ) will be discussed in the next section but basically amounts to estimating $\alpha$ and the linear (first order) part of $L(x)$.

So far the assumed power-type tail identification for sharp losses in financial returns. We now turn to the characterization of a tail dependence measure for pairs of extreme returns. Suppose one would like to know the likelihood that the market value of a bank's equity or, more generally, a financial asset or market index drops sharply if the same happens for another bank, asset or market. Alternatively, the interest may lie in identifying the joint likelihood of a crashing asset and a booming asset as reflecting substitution effects during times of market stress (flight-to-quality from risky stocks into safe heavens wit lower perceived riskiness like e.g. bonds or gold). Let $x$ and $y$ be the quantiles (or "crisis barriers") above which we speak of a financial crisis or crash (in case of a large loss) or, alternatively, a boom (in case of an exceptional gain). From elementary probability theory (starting from the standard definition of conditional probability) we know that

$$
\begin{aligned}
C P_{X Y} \equiv P\{X>x \mid Y>y\}=\frac{P\{X>x, Y>y\}}{\{P(Y>y\}} \\
=\frac{P\{X>x\}+P\{Y>y\}-P\{X>x \text { or } Y>y\}}{P\{Y>y\}} \\
\text { with } P\{X>x \text { or } Y>y\} \equiv 1-P\{X<x, Y<y\} .
\end{aligned}
$$

\footnotetext{
${ }^{41}$ This corresponds with the negative of the $(\log )$ return series calculated on the original price series of the financial asset. 
The question arises how the conditional tail probability in (5.3) should be estimated. Upon assuming e.g. multivariate normality, estimating the first and second moments is sufficient to calculate the conditional probability (5.3). However, multivariate normality and the associated correlation structure are unsuited to assess extreme linkages between asset markets, mainly because the conditional probability $C P_{X Y}$ vanishes to zero regardless the covariance levels in the distributional centre. In other words, if extremal spillover potential is present in the data, it cannot be captured by the multivariate normal distribution. Imposing parametric models with tail dependent marginal distributions like e.g. the logistic dependence model (Ledford and Tawn (1996); Longin and Solnik (2001); Poon et al. (2004)) constitutes an alternative for multivariate normality because the logistic tail dependence allows for nonzero values of $C P_{X Y}$ beyond large crisis barriers $x$ and $y$. However, within a parametric framework, one never knows what is the "true" underlying model and we therefore propose a semi-parametric estimation procedure.

We aim to estimate $C P_{X Y}$ when the conditioning quantiles $x$ and $y$ become very large. This amounts to inverting the marginal distribution functions for $X$ and $Y$ in order to work out the asymptotic equivalent of our linkage measure (5.3) in terms of the (small) probabilities of having very extreme returns. In order to do this, we first introduce the upper quantile functions for the return losses $X$ and $Y$ as

$$
\begin{aligned}
& Q_{1}(t u) \equiv\left(1-F_{1}\right)^{-1}(t u) \\
& Q_{2}(t v) \equiv\left(1-F_{2}\right)^{-1}(t v),
\end{aligned}
$$

for some small but positive values $u$ and $v$ and a scaling parameter $t$. Without loss of generality, we choose $u, v$ and $t$ such that $t u$ and $t v$ are smaller than one and thus interpretable as excess probabilities. Moreover set $Q_{1}(t u)=x$ and $Q_{2}(t v)=y$ in correspondance with the original crash levels in (5.3).

Upon substituting the above quantile functions into (5.3), one obtains the following asymptotic equivalent for (5.3):

$$
\begin{aligned}
& \lim _{t \rightarrow 0} C P_{X Y} \\
& =\frac{\lim _{t \rightarrow 0} t^{-1}\left[P\left\{X>Q_{1}(t u)\right\}+P\left\{Y>Q_{2}(t v)\right\}-P\left\{X>Q_{1}(t u) \text { or } Y>Q_{2}(t v)\right\}\right]}{\lim _{t \rightarrow 0} t^{-1} P\left\{Y>Q_{2}(t v)\right\}} \\
& =\frac{u+v-l(u, v)}{v}
\end{aligned}
$$

When the auxiliary variable $t$ converges to 0 the excess probabilities $\underline{t u}$ and $t v$ also tend to zero, and hence the corresponding quantiles $Q_{1}$ and $Q_{2}$ grow large. As for the limit function $l(u, v)$, it is defined as

$$
l(u, v)=\lim _{t \rightarrow 0} t^{-1} P\left\{X>Q_{1}(t u) \text { or } Y>Q_{2}(t v)\right\}
$$


This is the so-called Stable Tail Dependence Function (STDF) and was introduced by Huang (1992). This limit function can also be interpreted as a tail version of the statistical copula between $X$ and $Y$. Notice that the copula function that corresponds with a given joint distribution $F(x, y)$ boils down to:

$$
D(u, v) \equiv F\left(F_{1}^{-1}(u), F_{2}^{-1}(v)\right), 0 \leq u, v \leq 1,
$$

where $F_{i}^{-1}($.$) represent the general inverse functions of the marginal c.d.f. of X, Y$ $(i=1,2)$. In other words, the copula is the joint distribution function with uniformized marginals which implies that the function solely reflects cross sectional dependence information about the random pair (X,Y). Marginal information is filtered away by the marginal transforms. The STDF can now alternatively be defined as a tail version of the copula function, i.e., a "tail" copula:

$$
l(u, v)=\lim _{t \rightarrow 0} t^{-1}[1-D(1-t u, 1-t v)]
$$

see Huang (1992) for further discussion on this relation.

Multivariate extreme value theory deals with existence conditions, properties and estimators for this function, see Huang (1992) or De Haan and De Ronde (1998). More specifically, one can show that the STDF is one-to-one with the bivariate extreme value distribution of the joint extremes of $X$ and $Y$. In contrast to univariate extreme value theory, however, there is no generally applicable parametric limit law for the joint extremes. This provides an additional argument to opt for a semi-parametric estimation approach for tail dependence structures.

The curvature of $l(u, v)$ completely determines the tail dependence structure between $X$ and $Y$. Basic properties of $l(u, v)$ are its linear homogeneity, i.e., $l(\lambda u, \lambda v)=\lambda l(u, v)$ and the inequality $\max (u, v) \leq l(u, v) \leq u+v$.

Equality holds on the left hand side if $X$ and $Y$ are completely dependent in the tail area, while equality on the right hand side obtains if $X$ and $Y$ are independent in the tail area. Note that independence means that for all $Q_{1}$ and $Q_{2}$

$$
P\left\{X<Q_{1}, Y<Q_{2}\right\}=P\left\{X<Q_{1}\right\} P\left\{Y<Q_{2}\right\}
$$

while tail independence only requires this factorization to hold asymptotically (i.e. for $Q_{1}$ and $Q_{2}$ growing large). Thus it may well be that non-extreme return pairs are dependent although their extremes are asymptotically independent, e.g. the earlier example of the bivariate normal distribution with tail nonzero central correlation. 
The STDF enables one to express joint exceedance probabilities as a function of marginal exceedance probabilities. In order to show this, let, $p_{1}=P\{X>x\}, p_{2}=$ $P\{Y>y\}$ and $p_{12}=1-P\{X \leq x, Y \leq y\}$. Exploiting the homogeneity property of $l(. .$.$) one can now easily show that the bivariate excess probability p_{12}$ and the marginal probabilities $p_{1}$ and $p_{2}$ are related via the STDF. For sufficiently small $t>0$, it approximately holds that

$$
l(u, v) \approx t^{-1} P\left\{X>Q_{1}(t u) \text { or } Y>Q_{2}(t v)\right\} .
$$

We can choose $t u=p_{1}$ and $t v=p_{2}$ such that $l(u, v)=l\left(t^{-1} p_{1}, t^{-1} p_{2}\right)$. STDF's linear homogeneity now implies that $t l\left(t^{-1} p_{1}, t^{-1} p_{2}\right)=l\left(p_{1}, p_{2}\right)$. Hence, for small values of $p_{1}$ and $p_{2}$ it approximately holds that

$$
l\left(p_{1}, p_{2}\right) \approx p_{12}
$$

In other words, the joint probability $p_{12}$ only depends on the marginal probabilities $p_{1}$ and $p_{2}$ and the tail dependence structure reflected by the curvature of $l(.,$.$) . The linkage measure can thus be expressed as$

$$
C P_{X Y}=\frac{p_{1}+p_{2}-l\left(p_{1}, p_{2}\right)}{p_{2}}
$$

Referring to expressions (5.3) and (5.4) as a "tail dependence" measure is somewhat misleading because it both reflects information about the tail dependence structure as well as the marginal inequality, i.e., $p_{1} \neq p_{2}$. In financial risk management, however, it is common to calculate downside risk for common p-values of, say, $5 \%$ or $1 \%$. Conditioning on a common p-value has the advantage that it makes downside risk calculations - as reflected by the quantile or VaR level - comparable across risky positions which is not the case with unrestricted $p_{1}$ and $p_{2}$. Moreover, by setting $p_{1}=p_{2}=p$, the conditional probability in (5.7) solely reflects information on the tail dependence structure (STDF) because one controls for marginal inequalities; thus it becomes a "pure" tail dependence measure:

$$
C P_{X Y}=\frac{2 p-l(p, p)}{p} \approx 2-l(1,1)
$$

The marginal-free expression in (5.8) holds due to the approximate homogeneity of $l(.,$.$) which implies that the marginal probability can be skipped from the$ numerator and denominator of (5.8). If both returns are completely dependent in the tails, i.e. $l(1,1)=\max (1,1)=1$, then $C P_{X Y}=1$ and the pairs of assets, banks etc. co-crash with certainty. But without extreme co-movements in the two markets, $C P_{X Y}=0$ since $l(1,1) \approx 2$ (the case of full tail independence). If the second (conditioning) asset $Y$ represents a nondiversifiable risk factor like e.g. a stock market index one can call conditional probabilities like (5.3) or (5.8) "tail- $\beta$ s", see e.g. Straetmans (2008). 


\subsubsection{Mixtures of tail models}

In line with the traditional assumptions of statistical extreme value analysis, the unconditional measures of tail risk and tail comovement introduced in the previous subsection are based on stationary unconditional return distributions. Loosely speaking, stationarity in this context implies that the parameters governing the univariate and multivariate tail behavior are constant in the long-term. However, this does not exclude short-term tail parameter variation by means of e.g. regime dependence. Arguably the simplest way to introduce regime dependence in our tail risk and tail comovement measures is by means of distributional mixture models. The unconditional distributions of these mixture models still exhibit stationarity and thus constancy of the tail parameters; but the short-term parameters - and thus risk indicators - are allowed to change between regimes for a distributional mixture.

Starting with univariate tail mixtures, assume that the (long-term unconditional) univariate marginal distribution of the random variable $X$ is governed by $n$ regimes, i.e.,

$$
P\{X \leq x\}=F(x)=\sum_{i=1}^{n} \lambda_{i} F_{i}(x)
$$

where $\lambda_{i}$ is the probability that regime $i$ occurs with corresponding c.d.f. $F_{i}(x)$. Obviously $\sum_{i=1}^{n} \lambda_{i}=1$. It automatically follows that the mixture also holds for the corresponding survivor functions, i.e.,

$$
P\{X>x\}=1-F(x)=\sum_{i=1}^{n} \lambda_{i}\left(1-F_{i}(x)\right) .
$$

Upon assuming that the regime dependent tail probabilities $1-F_{i}(x)$ in (5.9) exhibit a power-type tail decay as described in (5.2), eq. (5.9) specializes to a mixture of regularly varying functions:

$$
P\{X>x\}=\sum_{i=1}^{n} \lambda_{i} L_{i}(x) x^{-\alpha_{i}} .
$$

From (5.10) it becomes clear that we allow for regime dependence in both the tail index and the slowly varying part $L($.) determining the tail probabilities. It is straightforward to show that the regular variation property (5.1) also applies to the mixture of regularly varying functions in (5.10). In order to illustrate this, we assume (without loss of generality) $n=2$ regimes and $\alpha_{1}>\alpha_{2}$. The mixture tail (5.10) can be factorized as:

$$
P\{X>x\}=L(x) x^{-\alpha_{2}},
$$

with $L(x)=\lambda L_{1}(x) x^{\alpha_{2}-\alpha_{1}}+(1-\lambda) L_{2}(x)$. Showing that $L(x)$ is also slowly varying is straightforward, i.e., $\lim _{x \rightarrow \infty} \frac{L(s x)}{L(x)}=1, x>0$. Thus, the fattest of the 
mixture tail models dominates (i.e., the tail index of the mixture equals $\alpha_{1}<\alpha_{2}$ ) and thus determines the tail decay of the unconditional (long-term) distribution.

It is equally straightforward to introduce mixtures into the tail dependence structure of asset return pairs. Analogous to the univariate case in (5.9), the joint survivor function is a mixture of survivor functions across different regimes. Consequently, the mixture automatically also holds for the corresponding stable tail dependence functions, i.e.

$$
l(u)=\sum_{i=1}^{n} \lambda_{i} l_{i}(u)
$$

with $\sum_{i=1}^{n} \lambda_{i}=1, u$ reflects a vector of uniform variables and where $l_{i}$ stands for multivariate generalizations of the STDF in (5.5).

For sake of convenience, we limit ourselves to studying the regime dependence in bivariate tail dependence measures like the conditional co-crash probability in (5.3). Moreover, as in the univariate case we only assume the existence of $n=2$ regimes but all concepts are readily generalizable to multiple regimes and multiple assets. We earlier argued that the conditional probability (5.3) can be readily expressed in terms of the stable tail dependence function, see (5.4). Suppose now that the bivariate stable tail dependence structure exhibits two regimes, i.e.

$$
l(1,1)=\lambda l_{1}(1,1)+(1-\lambda) l_{2}(1,1)
$$

This mixture automatically implies a mixture in the conditional probability (5.8) via the following chain of equalities:

$$
\begin{aligned}
C P_{X Y} & =2-l(1,1) \\
& =2-\left(\lambda l_{1}(1,1)+(1-\lambda) l_{2}(1,1)\right) \\
& =\lambda\left(\left(2-l_{1}(1,1)\right)+(1-\lambda)\left(2-l_{2}(1,1)\right)\right. \\
& =\lambda C P_{X Y}^{1}+(1-\lambda) C P_{X Y}^{2} .
\end{aligned}
$$

\subsection{Estimation and hypothesis testing}

Univariate tail index and extreme quantile estimation (reflecting downside risk) as well as an estimation procedure for the STDF are presented in Subsection 5.3.1. In Subsection 5.3.2 we introduce equality tests in order to test the equality of tail indices, tail quantiles and conditional probabilities across regimes. Rejecting the null of equal values across regimes provides further support for our approach to split up the full sample into economically meaningful subsamples. The proposed estimation and testing approaches are semi-parametric in nature and mostly follow Hartmann et al. (2004) or Straetmans et al. (2008), the only difference being that we condition EVT-based measures on regime-dependent subsamples instead of the full sample. 


\subsubsection{Semi-parametric estimation procedures}

We earlier assumed that the tails of financial returns are fat tailed, i.e. conditions (5.1)-(5.2), implying that tail likelihoods exhibit a power-type tail decay. The semi-parametric tail probability estimator from de Haan et al. (1994) is basically a first-order linear approximation of (5.2):

$$
P\{X>x\}=\hat{p}_{x}=\frac{m}{n}\left(X_{n-m, n}\right)^{\alpha} x^{-\alpha}
$$

where the "tail cut-off point" $X_{n-m, n}$ is the $(n-m)$-th ascending order statistic (or loosely speaking the $m$-th smallest return) from a sample of size $n$. The constant $\frac{m}{n}\left(X_{n-m, n}\right)^{\alpha}$ can be seen as the linear part of the slowly varying function in (5.2). For values $x>X_{n-m, n}$, the estimator basically extends the empirical distribution further into the tail. The tail quantile $x$ is usually referred to as the "Value-at-Risk" (VaR). In the empirical application, we will evaluate the regime dependence of the quantile or VaR levels for given p-values because it is the VaR for a given p-value that is so widely assessed as downside risk measure in modern-day risk management, not the exceedance probability for a given VaR. The quantile estimator is simply obtained by inverting the tail likelihood estimator (5.12):

$$
\hat{x}_{p}=X_{n-m, n}\left(\frac{m}{n p}\right)^{\frac{1}{\alpha}}
$$

Estimators (5.12)-(5.13) still require an estimator for the tail index $\alpha$. We estimate the tail index by means of the popular Hill (1975) estimator:

$$
\hat{\alpha}=\frac{1}{m} \sum_{j=0}^{m-1} \ln \left(\frac{X_{n-j, n}}{X_{n-m, n}}\right)
$$

where $m$ has the same value and interpretation as in (5.12). Further details are provided in Jansen and De Vries (1991) and the recent monograph by Embrechts et al. (1997).

The estimation of the bivariate excess probability $p_{12}$ either requires adopting a specific functional form for the STDF, like e.g. in Poon et al. (2004), or proceeding semi-parametrically. Since there does not exist a unique parametrization for the STDF, we like to pursue a semi-parametric estimation method based on the highest order statistics, see Huang (1992). An intuitive derivation of this estimator proceeds as follows. We start by setting $t=k / n>0$ in (5.6) where $n$ equals the sample size and $1 \leq k \leq n$ represents a large real number such that $k(n) \rightarrow \infty$ and $k(n) / n \rightarrow 0$. The choice of $k$ is discussed furtheron. Since the marginal probability estimates are available from the univariate step, we can also replace $(u, v)$ in $(5.6)$ by $\left(\hat{p}_{1}, \hat{p}_{2}\right)$ : 


$$
\hat{l}\left(\hat{p}_{1}, \hat{p}_{2}\right)=\lim _{n \rightarrow \infty} \frac{n}{k} P\left\{X \geq Q_{1}\left(\frac{k \hat{p}_{1}}{n}\right) \text { or } Y \geq Q_{2}\left(\frac{k \hat{p}_{2}}{n}\right)\right\}
$$

In order to turn this expression into a proper estimator, we start by replacing $P, Q_{1}$ and $Q_{2}$ by their empirical counterparts such that

$$
\hat{l}\left(\hat{p}_{1}, \hat{p}_{2}\right)=\frac{n}{k} \frac{1}{n} \sum_{i=1}^{n} 1\left\{X i>X_{n-\left[k \hat{p}_{1}\right], n} \text { or } Y i>Y_{n-\left[k \hat{p}_{2}\right], n}\right\}
$$

where 1\{.\} denotes the indicator function and where $[x]$ is the integer satisfying $x \leq[x]<x+1$. The quantiles $Q_{1}$ and $Q_{2}$ have been replaced by order statistics. So, loosely speaking the estimator of $l(. .$.$) boils down to counting the$ instances at which one or both of the markets experience an extreme return within a given sample period.

However, the empirical probability measure (5.16) is still not operational at this stage because the marginal probability arguments of the STDF are typically smaller than the inverse of the sample size $n$ which implies there are no exceedances to estimate the empirical measure. ${ }^{42}$ However, one can exploit the approximate linear homogeneity property of the STDF estimator, i.e., $\hat{l}\left(\hat{p}_{1}, \hat{p}_{2}\right) \approx$ $\lambda^{-1} \hat{l}\left(\lambda \hat{p}_{1}, \lambda \hat{p}_{2}\right)$ and choose $\lambda>1$ such as to scale up the marginal probabilities in (5.15) and to obtain excess observations. In the remainder of the article, we assume that $p_{1}=p_{2}$ and we choose the scaling factor $\lambda=p^{-1}$. The estimator $\hat{l}(1,1)$ that is required in $(5.8)$ boils down to:

$$
\begin{aligned}
\hat{l}(1,1)=\frac{\hat{l}(p, p)}{p} & =\frac{1}{p k} \sum_{i=1}^{n} 1\left\{X i>X_{n-[k p], n} \text { or } Y i>Y_{n-[k p], n}\right\} \\
& \approx \frac{1}{k} \sum_{i=1}^{n} 1\left\{X i>X_{n-k, n} \text { or } Y i>Y_{n-k, n}\right\} .
\end{aligned}
$$

This estimator evaluates $l(. .$.$) inside the tail of the joint empirical distribution.$ Notice that this counting procedure of co-exceedances is also easily applicable in higher dimensions. A more extensive discussion on this derivation is provided in Huang (1992) or Straetmans (1998).

An estimator for the conditional probability of simultaneous crashes $C P_{X Y}$ now easily follows by combining (5.8) and (5.17):

$$
\hat{P}_{X Y}=2-\hat{l}(1,1)=2-\frac{1}{k} \sum_{i=1}^{n} 1\left\{X i>X_{n-k, n} \text { or } Y i>Y_{n-k, n}\right\}
$$

Conditional on the proper choice of the nuisance parameters $m$ and $k$, the estimators of the Hill statistic and the stable tail dependence function (STDF) are asymptotically normally distributed. Goldie and Smith (1987) and Huang (1992) show that one can select $m$ and $k$ such as to minimize the respective asymptotic

\footnotetext{
${ }^{42}$ The order statistics that are supposed to estimate the quantiles $Q_{1}$ and $Q_{2}$ in that case correspond with the historical sample boundaries $X_{n, n}$ and $Y_{n, n}$, respectively.
} 
mean-squared errors (AMSE). In small samples best practice is to plot the estimators as a function of the threshold, i.e. $\hat{\alpha}=\hat{\alpha}(m)$ and $\hat{P}_{X Y}=\hat{P}_{X Y}(k)$ and to select $m$ and $k$ in the region over which the estimators tend to be constant. More advanced algorithms for selecting $m$ based on minimizing a sample equivalent of the AMSE also exist, see e.g. Beirlant et al. (1999). We use both Hill plots and the Beirlant algorithm in order to choose $\mathrm{m}$ and $\mathrm{k}$.

\subsubsection{Hypothesis testing}

We want to perform equality tests for estimates of the tail index, the tail quantile and the co-crash probability (or, alternatively, the STDF), either for single asset tails across business cycle regimes (unequal sample sizes) or across asset tails within a given regime (equal sample sizes). Asymptotic normality of the Hill statistic, the tail quantile estimator and the STDF has been established by Haeusler and Teugels (1985), de Haan et al. (1994) and Huang (1992), respectively. ${ }^{43}$ Let est stand for an estimate of either of these three magnitudes. A simple $T$-test of the equality of est across regimes (or across asset tail within a given regime) boils down to:

$$
T=\frac{e s t_{1}-e s t_{2}}{\sqrt{\sigma^{2}}\left(e s t_{1}\right)+\sigma^{2}\left(e s t_{2}\right)}
$$

which is asymptotically normal in sufficiently large samples. ${ }^{44}$ The denominator still requires the calculation of asymptotic variances. The estimable expressions for the asymptotic variance of the Hill statistic, the quantile estimator and the STDF directly follow from the asymptotic normality derivations for these estimators.

\subsection{Empirical results}

We first provide a description of our data sources in 5.4.1. Estimates of extreme downside risk (tail risk) for a variety of financial asset classes are discussed in 5.4.2. In 5.4.3 we report estimates of systemic risk for a few representative US banks. In 5.4.4 we compare extreme linkages between stocks and bonds within G5 countries. More specifically, we compare stock-bond co-crash likelihoods with flight-to-quality likelihoods from stocks into bonds. Finally, in section 5.4.5, we minimize the portfolio tail risk for a few representative stock pairs selected from the Dow Jones Index. Every EVT application distinguishes between full sample, recession-based and expansion-based estimates in order to assess whether the

\footnotetext{
${ }^{43}$ As for MES estimates, the Central Limit Theorem guarantees asymptotic normality because MES is a sample average.

${ }^{44}$ For sake of convenience, we assume that the covariance term between est 1 and est2 equals zero which is an obvious simplification. 
differences in tail behaviour across business cycle regimes are statistically and economically significant.

\subsubsection{Data description}

All considered financial data are extracted from Thomson Datastream. The financial time series consist of 7,282 daily prices for stocks, bonds, US\$ nominal bilateral exchange rates, gold, silver and oil. The sample runs from 1 February 1985 until 31 December 2012. We consider 16 (dividend-adjusted) stock price series of representative US banks. Next to individual stock prices, we also downloaded G-5 (US, UK, France, Germany and Japan) stock indices and corresponding G-5 long-term (10 year maturity) government bond indices. In order to estimate systemic risk for our set of representative US banks, we condition tail- $\beta$ 's on the Datastream US bank index. We express stock and bond prices in local currency. Prices of oil (Brent Crude), gold and silver are in US\$ per barrel or per troy ounce, respectively. Financial returns are expressed as log price differences between daily closes. ${ }^{45}$

To date US business cycles, we use the National Bureau of Economic Research (NBER) peaks and troughs in economic activity to construct a binary variable that either reflects a recession phase or an expansion phase. The turning point dates published by the NBER represent a consensus chronology of the U.S. business cycle. As for France, Germany, Japan and the UK, business cycle data were downloaded from the Economic Cycle Research Institute (ECRI). ${ }^{46}$ Comparable with what the NBER publishes on US business cycles, the ECRI reports binary (01) business cycle information without specifying either the raw data used or the dating algorithm for determining business cycle peaks and troughs. Both NBER and ECRI business cycle dummies are at the monthly frequency.

\subsubsection{Extreme downside risk for different asset classes and the business cycle}

Straetmans and Candelon (2013) recently studied the temporal stability in the tail index and accompanying quantile or "tail-VaR" for a wide variety of financial asset classes and found that structural breaks in univariate tail risk measures are relatively rare (except for emerging currency returns). This section's univariate analysis can be interpreted as an extension of this previous study because we consider a more general recession-based and expansion-based subsample partitioning instead of subsamples based on a single temporal breakpoint.

\footnotetext{
${ }^{45}$ We refer to G-5 stock and bond indices in the tables and the text using the following abbreviations: France (FR), Germany (GE), United Kingdom (UK), United States (US), Japan (JP). We consider total return indices (=dividend-adjusted and coupon-adjusted) for G-5 stock indices and 10-year benchmark government bonds.

46 The NBER and ECRI business cycle data are available at http:/www.nber.org and http://www.businesscycle.com
} 
Table 5.1 contains full sample, recession-based and expansion-based estimation and testing results for the tail index $\alpha$ and the accompanying quantile or downside (tail) risk (conditioned on a p-value of $0.1 \%$ ) and for a wide variety of asset classes. The "testing results" panel reports the equality test of the null hypothesis of equal recession-based and expansion-based tail indices and tail quantiles, respectively. Given that Straetmans and Candelon (2013) already showed that unconditional (long-term) asset tail risk may considerably differ across asset classes, we also consider a relatively large cross section of different asset types. More specifically, we distinguish between 5 different asset classes: US bank stocks (Panel A), G-5 stock indices (Panel B), G-5 bond indices (Panel C), US\$ exchange rates (Panel D), and commodities (Panel E). The downside risk for banks reflects the downside risk in the market value of bank equity capital. For sake of completeness, we also report full sample and subsample average returns and volatilities.

The table reveals that recession-based estimates of the standard deviation, the tail index and the corresponding tail quantile nearly all exceed their expansion-based counterparts for basically all considered assets. It may not come as a surprise that the asymmetry in point estimates is most pronounced for bank stocks (panel A). For some banks the differences in tail properties across the business cycle is staggering. Half of the considered banks exhibit a tail index below 2 during recessions whereas none exhibits this property in the expansion phase. Notice this moment violation $(\alpha<2)$ implies that in recession phases, financial return variances are no longer properly defined (the distributional second moment is not finite and thus does not exist). The huge discrepancy in the tail index translates into huge differences in downside risk across the business cycle. For example, Bank of America's 0.1\% Value-at-Risk equals a skyrocketing $76 \%$ during recessions but drops down to $12 \%$ during expansions. Most other banks with comparable discrepancies in the tail index also show huge discrepancies in their equity Value-at-Risk across business cycle regimes.

Business cycle asymmetries are also present in US\$ foreign exchange risk despite the fact that we solely partition using the US business cycle whereas the very nature of exchange rates implies that two business cycles exhibit potential influence. Along the lines of Danielsson and de Vries (1997) or Straetmans and Candelon (2013), the regime dependent outcomes for foreign exchange tail-VaR can be used to determine regime dependent upper limits on open positions to foreign currency dealers by the treasurers of the forex dealing room of an international bank. ${ }^{47}$ Our innovation here lies in the fact that we can make the

\footnotetext{
${ }^{47}$ See Danielsson and de Vries (1997) for a more elaborate discussion and for other applications of extreme quantile estimation for e.g. institutional investors.
} 
trading limit regime dependent (higher limits during recessions and lower limits during expansions) whereas the previous papers propose trading limits that did not distinguish between recessions and expansion phases.

Suppose a trading limit depends on the probability $p$ on a single large negative currency return that can bring the bank's solvency in jeopardy. In this example, the level $p$ is interpretable as the insolvency risk the management considers "acceptable". Suppose the management chooses a critical loss level $s<0$ which stands for the maximum loss that can be incurred without running into solvency problems. A simple way to determine the maximum allowable investment $I$ is to set $I=S / \widehat{x}_{p}$ with $\widehat{x_{p}}$ the extreme quantile estimator as defined in (5.13). Clearly, a full sample trading limit would be too conservative relative to the expansion regime and not sufficiently conservative relative to the recession regime, so a regime dependent trading limit seems desirable. Straetmans and Candelon (2013) illustrate that trading limits can hugely differ across subsamples when considering temporal breaks in the tail index; but trading limit differences remain comparable in magnitude for more complex subsample conditioning like the ones performed here. Apart from bank stocks and exchange rates, Table 5.1 clearly shows that other asset classes also exhibit tail asymmetries across business cycle regimes albeit to a lesser extent (except bond index returns that hardly show any regime dependence).

Turning to the statistical significance of the asymmetries (right panel "Testing results"), the tests reveal that the null hypothesis of equality between tail indices and tail quantiles across the business cycle is rejected in a majority of cases at the $1 \%$ significance level. Rejections are strongest for banks followed by commodities and exchange rates. Also, the equality of tail quantiles across regimes is slightly more often rejected than tail index equality. This is probably due to the fact that the quantile estimates also take account of the assets' scaling constants, i.e., even if the tail indices are invariant across regimes, tail quantiles can still be regime dependent if the scaling constants are.

Finally, notice that despite the fact that financial risk (either measured by the standard deviation or the tail quantile) is nearly always higher during recessions, this is mostly not reflected into a higher average return during recessions. On the contrary, the average recession return falls below the average expansion return in all cases. One interpretation of this outcome may be that the idiosyncratic (diversifiable) part of volatility and tail risk becomes a relatively more important component of total risk during recessions. 
Table 5.1 Extreme downside risk for different asset classes and the business cycle

The table presents estimates and equality tests for the tail index and accompanying quantile estimates (p-value of $0.1 \%$ ) for US bank stocks (Panel A), G-5 stock indices ( Panel B), G-5 bond indices (Panel C), exchange rates (Panel D), and commodities (Panel E). The threshold $\mathrm{m}=250$ is consistent with making Hill plots and applying the Beirlant et al. algorithm. The equality T-test evaluates whether expansion-based and recessionbased estimates of tail characteristics differ in a statistically significant way. All estimates reflect percentages except the tail index estimates"

\begin{tabular}{|c|c|c|c|c|c|c|c|c|c|c|c|c|c|c|}
\hline & \multicolumn{12}{|c|}{ Estimations } & \multirow{2}{*}{\multicolumn{2}{|c|}{$\begin{array}{c}\text { Testing results } \\
\text { Equality test }\end{array}$}} \\
\hline & \multicolumn{4}{|c|}{ Full sample } & \multicolumn{4}{|c|}{ Recession } & \multicolumn{4}{|c|}{ Expansion } & & \\
\hline & $\mu$ & $\sigma$ & $\alpha$ & q & $\mu_{R}$ & $\sigma_{\mathrm{R}}$ & $\alpha_{R}$ & $\mathrm{q}_{\mathrm{R}}$ & $\mu_{\mathrm{E}}$ & $\sigma_{\mathrm{E}}$ & $\alpha_{E}$ & $q_{E}$ & $\alpha_{\mathrm{R}}=\alpha_{\mathrm{E}}$ & $\mathrm{q}_{\mathrm{R}}=\mathrm{q}_{\mathrm{E}}$ \\
\hline \multicolumn{15}{|c|}{ Panel A: Bank stock returns (1/2/1985-31/12/2012) } \\
\hline BANK OF AMERICA & 0.025 & 2.6 & 2.3 & 19.1 & -0.125 & 6.0 & 1.8 & 76.1 & 0.042 & 1.9 & 2.7 & 12.3 & $-3.3 * * *$ & $2.5 * * *$ \\
\hline $\mathrm{BB} \& \mathrm{~T}$ & 0.040 & 2.0 & 2.7 & 12.8 & -0.033 & 4.0 & 2.4 & 29.8 & 0.048 & 1.7 & 3.1 & 9.2 & $-2.0 * *$ & $2.8 * * *$ \\
\hline BANK OF NEW YORK & 0.040 & 2.3 & 2.8 & 13.7 & -0.066 & 4.5 & 1.9 & 45.7 & 0.052 & 1.9 & 3.3 & 9.9 & $-3.9 * * *$ & $2.6 * * *$ \\
\hline COMERICA & 0.037 & 2.1 & 2.5 & 14.8 & -0.066 & 4.4 & 1.9 & 48.8 & 0.049 & 1.6 & 2.9 & 9.9 & $-2.9 * * *$ & $2.6 * * *$ \\
\hline HUNTINGTON BCSH. & 0.024 & 2.9 & 2.0 & 24.8 & -0.115 & 7.1 & 1.8 & 83.6 & 0.039 & 1.8 & 2.7 & 12.0 & $-2.9 * * *$ & $2.7 * * *$ \\
\hline JP MORGAN CHASE & 0.032 & 2.4 & 2.8 & 14.4 & -0.080 & 4.6 & 2.2 & 39.8 & 0.045 & 2.1 & 3.2 & 10.7 & $-3.0 * * *$ & $2.7 * * *$ \\
\hline KEYCORP & 0.021 & 2.5 & 2.3 & 18.5 & -0.164 & 5.8 & 1.8 & 69.5 & 0.042 & 1.7 & 2.8 & 11.1 & $-3.3 * * *$ & *** \\
\hline NORTHERN TRUST & 0.054 & 2.0 & 2.8 & 12.1 & -0.016 & 3.7 & 2.1 & 33.6 & 0.062 & 1.7 & 2.9 & 9.9 & $-2.4 * * *$ & $2.5 * * *$ \\
\hline PNC FINL.SVS.GP. & 0.035 & 2.2 & 2.7 & 13.2 & -0.042 & 4.7 & 2.4 & 32.2 & 0.044 & 1.7 & 3.1 & 9.4 & $-1.9 *$ & $2.9 * * *$ \\
\hline WELLS FARGO \& CO & 0.059 & 2.3 & 2.6 & 14.3 & 0.001 & 4.9 & 2.0 & 45.1 & 0.065 & 1.7 & 3.3 & 9.1 & $-3.5 * * *$ & $2.8 * * *$ \\
\hline M\&T BANK & 0.059 & 1.7 & 2.3 & 12.8 & -0.023 & 3.4 & 2.2 & 30.8 & 0.068 & 1.4 & 2.5 & 9.2 & -1.0 & $2.6 * * *$ \\
\hline REGIONS FINL.NEW & 0.014 & 2.7 & 2.1 & 21.6 & -0.169 & 6.4 & 2.1 & 58.5 & 0.035 & 1.9 & 2.8 & 11.8 & $-2.1 * *$ & $2.9 * * *$ \\
\hline SYNOVUS FINL. & 0.027 & 3.0 & 2.5 & 22.0 & -0.189 & 5.1 & 1.8 & 65.0 & 0.052 & 2.7 & 2.8 & 17.5 & $-3.1 * * *$ & $2.3 * * *$ \\
\hline STATE STREET & 0.052 & 2.6 & 2.6 & 15.2 & -0.031 & 5.8 & 2.0 & 46.2 & 0.062 & 1.9 & 3.0 & 10.9 & $-3.1 * * *$ & $2.6 * * *$ \\
\hline US BANCOR & 0.055 & 2.1 & 2.5 & 14.4 & -0.066 & 4.1 & 1.8 & 50.8 & 0.069 & 1.7 & 3.1 & 9.5 & $-3.9 * * *$ & $2.5 * * *$ \\
\hline ZIONS BANCORP. & 0.031 & 2.6 & 2.2 & 20.6 & -0.162 & 5.4 & 2.0 & 57.4 & 0.053 & 2.0 & 2.8 & 12.8 & $-2.3 * * *$ & $2.7 * * *$ \\
\hline Average & 0.038 & 2.4 & 2.5 & 16.5 & -0.084 & 5.0 & 2.0 & 50.8 & 0.052 & 1.8 & 2.9 & 10.9 & & \\
\hline \multicolumn{15}{|c|}{ Panel B: Stock index returns of G-5 countries $(1 / 2 / 1985-31 / 12 / 2012)$} \\
\hline US & 0.039 & 1.1 & 2.7 & 7.41 & -0.045 & 1.9 & 2.0 & 19.9 & 0.049 & 1.0 & 3.0 & 6.1 & $-2.8 * * *$ & $2.4 * * *$ \\
\hline GE & 0.030 & 1.2 & 2.9 & 7.61 & -0.033 & 1.4 & 2.5 & 10.2 & 0.050 & 1.1 & 2.8 & 7.4 & -0.9 & 1.5 \\
\hline UK & 0.038 & 1.1 & 2.6 & 7.15 & 0.017 & 1.3 & 2.5 & 9.9 & 0.043 & 1.0 & 2.7 & 6.3 & -0.8 & $2.0 * *$ \\
\hline FR & 0.039 & 1.2 & 2.8 & 7.79 & -0.047 & 1.7 & 2.4 & 13.0 & 0.050 & 1.2 & 2.9 & 7.0 & -1.4 & $2.0 * *$ \\
\hline JP & 0.005 & 1.3 & 2.9 & 7.72 & -0.035 & 1.5 & 2.9 & 8.9 & 0.021 & 1.1 & 2.6 & 7.7 & 0.7 & 0.9 \\
\hline Average & 0.030 & 1.2 & 2.8 & 7.53 & -0.028 & 1.6 & 2.5 & 12.4 & 0.043 & 1.1 & 2.8 & 6.9 & & \\
\hline \multicolumn{15}{|c|}{ Panel C: Bond index returns (1/2/1985-31/12/2012) } \\
\hline US & 0.029 & 0.5 & 3.3 & 2.4 & 0.028 & 0.6 & 2.7 & 4.1 & 0.029 & 0.4 & 3.4 & 2.3 & -1.6 & $2.0 * *$ \\
\hline GE & 0.026 & 0.3 & 3.1 & 1.9 & 0.036 & 0.3 & 2.3 & 2.6 & 0.023 & 0.3 & 3.2 & 1.9 & $-2.9 * * *$ & 1.4 \\
\hline UK & 0.035 & 0.4 & 3.2 & 2.2 & 0.042 & 0.4 & 3.2 & 2.3 & 0.033 & 0.4 & 3.1 & 2.3 & 0.1 & 0.1 \\
\hline FR & 0.032 & 0.4 & 3.1 & 2.0 & 0.052 & 0.4 & 2.6 & 2.4 & 0.029 & 0.4 & 3.1 & 2.0 & -1.1 & 0.7 \\
\hline JP & 0.018 & 0.3 & 2.3 & 2.5 & 0.026 & 0.3 & 2.2 & 2.6 & 0.015 & 0.3 & 2.3 & 2.6 & -0.3 & 0.1 \\
\hline Average & 0.028 & 0.4 & 3.0 & 2.2 & 0.037 & 0.4 & 2.6 & 2.8 & 0.026 & 0.4 & 3.0 & 2.2 & & \\
\hline \multicolumn{15}{|c|}{ Panel D: Exchange rate returns (1/2/1985-31/12/2012) } \\
\hline US\$/UK£ & 0.005 & 0.6 & 3.1 & 3.5 & -0.034 & 0.8 & 2.5 & 6.5 & 0.010 & 0.6 & 3.2 & 3.2 & $-1.8 *$ & $2.1 * *$ \\
\hline US\$/JPY & -0.010 & 0.8 & 3.1 & 4.5 & -0.061 & 1.2 & 2.2 & 10.9 & -0.004 & 0.7 & 3.3 & 3.9 & $-3.2 * * *$ & $2.4 * * *$ \\
\hline US\$/SFR & -0.010 & 0.6 & 3.0 & 3.4 & -0.036 & 0.8 & 2.2 & 7.5 & -0.007 & 0.5 & 3.5 & 2.8 & $-3.3 * * *$ & $2.4 * * *$ \\
\hline Average & -0.005 & 0.7 & 3.1 & 3.8 & -0.044 & 0.9 & 2.3 & 8.3 & 0.000 & 0.6 & 3.3 & 3.3 & & \\
\hline \multicolumn{15}{|c|}{ Panel E: Commodity returns (1/2/1985-31/12/2012) } \\
\hline OIL & 0.019 & 2.4 & 2.8 & 14.4 & -0.087 & 3.8 & 2.2 & 31.9 & 0.031 & 2.2 & 3.3 & 11.5 & $-2.9 * * *$ & $2.4 * * *$ \\
\hline SILVER & 0.022 & 2.1 & 2.5 & 13.7 & -0.046 & 2.4 & 2.0 & 23.8 & 0.029 & 2.0 & 2.5 & 13.2 & -1.6 & 1.5 \\
\hline GOLD & 0.023 & 1.0 & 2.7 & 6.6 & 0.018 & 1.5 & 2.4 & 12.7 & 0.024 & 0.9 & 2.9 & 5.6 & -1.4 & $2.2 * *$ \\
\hline Average & 0.021 & 1.8 & 2.7 & 11.5 & -0.038 & 2.6 & 2.2 & 22.8 & 0.028 & 1.7 & 2.9 & 10.1 & & \\
\hline
\end{tabular}




\subsubsection{Systemic instability and the business cycle}

In this section we discuss recession-based and expansion-based estimation and testing outcomes for two separate systemic risk measures: the linear correlation between a bank stock return and a banking market index, the tail- $\beta$ (see e.g. Hartmann et al. (2006) or Straetmans and Chaudhry (2013)). The latter systemic risk measure is based on the same pairs of losses on individual bank stocks and a banking market index as the correlation is. The tail- $\beta$ was defined in (5.8) and estimated according to (5.16) using the stable tail dependence function.

The two considered measures differ in the extent to which they explicitly focus on the tail behavior. The correlation is calculated for the full sample of data pairs (including the tails). The tail- $\beta$ and corresponding stable tail dependence function are evaluated "as if" one looks infinitely far into the tail: expression (5.18) does not depend on a cut off point or threshold such that it truly reflects an asymptotic value of the co-crash probability. In contrast to linear correlations, the tail- $\beta$ indicator can also detect non-linear comovements if present in the data.

The estimation results and testing results are summarized in Table 5.2. The table is organized in the same way as Table 5.1: the left and right parts of the table correspond with estimation and testing results, respectively. We further distinguish full sample, recession-based and expansion-based estimates. The testing results panel reflects outcomes for testing the null hypothesis of equal recession-based and expansion-based tail- $\beta$.

Turning to the results, recession values always exceed the corresponding expansion values although there is still a large cross sectional heterogeneity. This seems to be in line with that part of the fundamentals-based banking crisis literature that claims that banking crises and systemic instability become more likely during recessions, see e.g. Gorton (1988). The economic interpretation of the numbers in the table is straightforward. For example, the $61 \%$ full sample value for Keycorp implies that a crash of the banking sector as a whole (i.e. a banking market index) coincides with a crash in the market value of Keycorp equity in $61 \%$ of cases; whereas this number rises to $69 \%$ during recessions and drops to 54\% during expansions. In general, however, the tail- $\beta$ values are astonishingly high, even during periods of economic expansion, which is somewhat unexpected.

As concerns the magnitude of the tail- $\beta$ differences across the business cycle, they are sometimes quite spectacular (e.g. JP Morgan Chase) whereas for others they are quite small. In other words, banks seem to differ quite a lot in terms of their responsiveness to business cycle fluctuations. One possible explanation for this may be that banks that are engaged in more traditional banking activities 
generating interest-related revenues are more recession-prone than banks with a relatively important investment and trading division (non-interest related revenue sources). However, we leave the study of the determinants of this cross-regime variation for future research. It is also interesting to note that correlations between bank stock returns and the market as a whole are generally higher during recessions. We will also report "recession and expansion" correlations in the other tables still to be discussed in order to illustrate this alternative dimension of diversification meltdown. ${ }^{48}$

Turning to the testing outcomes in the right panel, it is obvious that recessionbased and expansion-based systemic risk indicators are statistically significantly different from each other (typically at the 1\% level). Upon looking at the gaps between the regime-dependent point estimates in the left panel, it is fair to say these differences are also strongly economically significant.

Finally, it is interesting to observe in Table 5.2 that the correlation-based systemic risk rankings differ from the tail- $\beta$ ranking. This may be due to the fact that tail- $\beta$ 's capture non-linear spillovers during crisis periods whereas the linear correlations do not. $^{49}$

\footnotetext{
${ }^{48}$ Traditionally, the term "diversification meltdown" characterizes a situation of rising correlations in highly volatile regimes, see e.g. Ang and Chen (2002). The question arises whether this correlation jumps are genuine changes in interdependence or induced by the rising volatilities themselves. Forbes and Rigobon (2002) constitutes the classic reference on disentangling financial contagion vs. interdependence in a context of diversification meltdown.

${ }^{49}$ This also holds when comparing rankings based on the CAPM- $\beta$ and the tail- $\beta$, see Straetmans and Chaudhry (2013). 


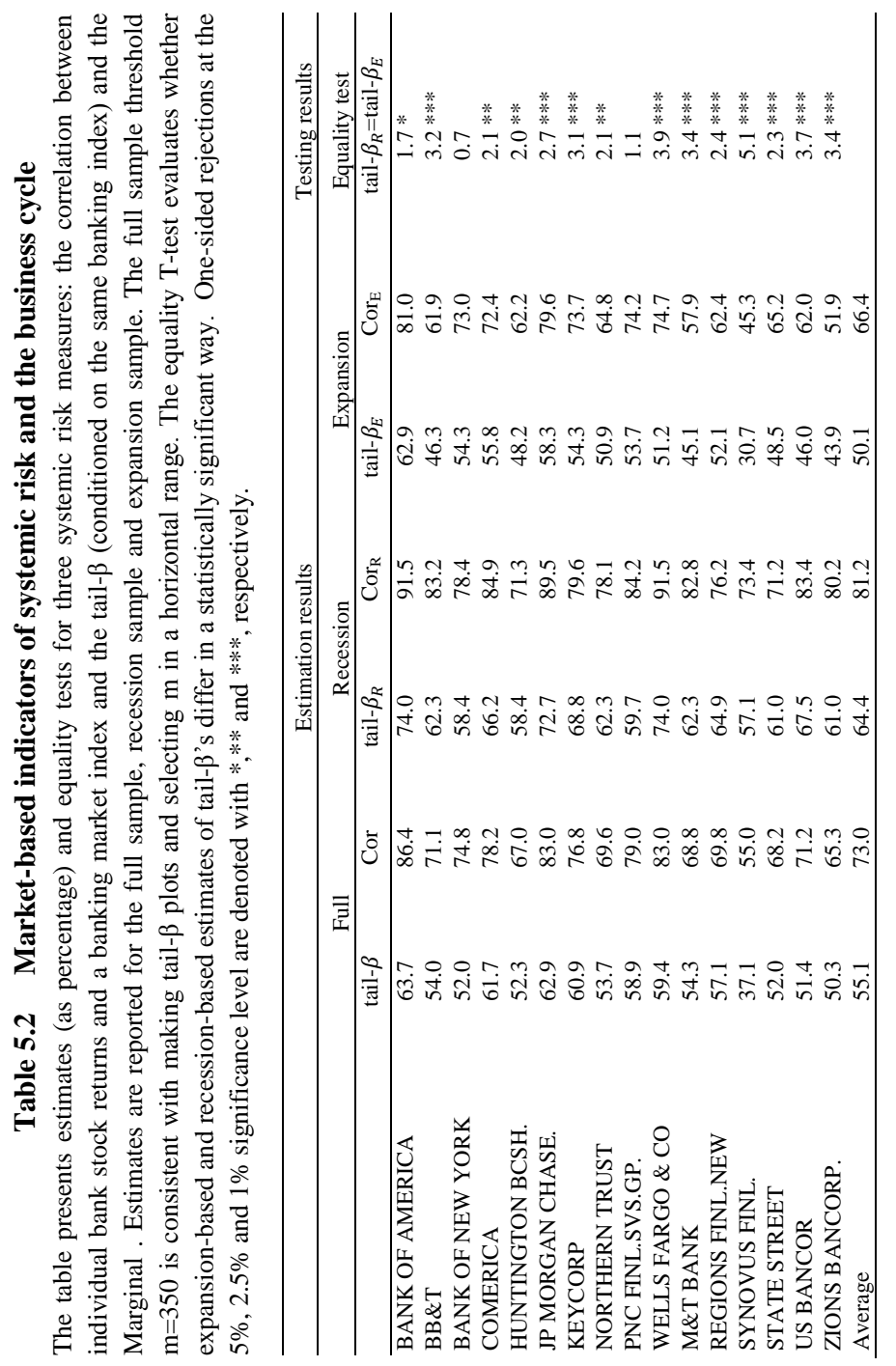




\subsubsection{Co-crash versus Flight-to-quality effects and the business cycle}

During crises, it is typically assumed that some assets that are perceived by investors as "safer" and/or more "liquid" may act as "flight to quality", "flight to liquidity" or "safe heaven" assets. ${ }^{50}$ This implies that the investors sell off the asset whom they perceive as riskier and buy the supposedly safer asset. As a result, one expects opposite return movements and negative dependence between pairs of these asset returns. The literature on these types of substitution effects is surprisingly scant. Using bivariate statistical extreme value analysis Hartmann et al. (2004) estimate the potential of co-crashes between G-5 stock indices and government bonds, both domestically and cross-border. They find that flight-toquality/liquidity effects into sovereign bonds has happened as frequently as cocrashes between stock and bond markets and hence their paper remains inconclusive as to which of both phenomena (co-crashes or flight-to-quality) dominates. Other more recent studies on whether government bonds or gold may act as safe heavens in case of stock crashes include, inter alia, Connolly et al. (2005); Baur and Lucy (2009); Brière et al. (2012); Baele et al (2013); but the evidence remains mixed and inconclusive.

We compare the likelihood of co-crashes (abbreviates as "CO") vs. flight-toquality (abbreviated as "FTQ") for three assets (stocks, bonds and gold) by measuring the probability of stock-bond co-crashes and flight-to-quality using the conditional probability estimator in (5.18). Although also based on multivariate extreme value analysis, our comovement indicator differs from the one in Hartmann et al. (2004). Moreover, the latter paper does not condition on recession and expansion subsamples.

Although initially defined for pairs of return losses, the bivariate comovement measure (5.18) can be calculated for all four data quadrants. Stock-bond (SB), stock-gold (SG) or bond-gold (BG) co-crash probability measures boil down to:

$$
\begin{aligned}
& P_{C O}^{S B}=P\left\{B<Q_{B}(1-p) \mid S<Q_{S}(1-p)\right\} \\
& P_{C O}^{S G}=P\left\{G<Q_{G}(1-p) \mid S<Q_{S}(1-p)\right\} \\
& P_{C O}^{B G}=P\left\{G<Q_{G}(1-p) \mid B<Q_{B}(1-p)\right\}
\end{aligned}
$$

Whereas flight-to-quality spillover probability expressions for the same asset pairs read:

$$
\begin{aligned}
& P_{F T Q}^{S B}=P\left\{B>Q_{B}(p) \mid S<Q_{S}(1-p)\right\} \\
& P_{F T Q}^{S G}=P\left\{G>Q_{G}(p) \mid S<Q_{S}(1-p)\right\} \\
& P_{F T Q}^{B G}=P\left\{G>Q_{G}(p) \mid B<Q_{B}(1-p)\right\}
\end{aligned}
$$

\footnotetext{
${ }^{50}$ All three concepts are often used interchangeably in the literature.
} 
In the above expressions, the abbreviations $S, B$ and $G$ refer to the returns on stocks, bonds and gold, respectively. If the marginal tail probability $p$ becomes small, the quantile function $Q(p)=(1-F)^{-1}(p)$ grows large (extreme right tail) whereas $Q(1-p)$ becomes very small (extreme left tail). Stocks are considered to be the riskiest asset and we want to assess whether the tendency of stock to co-crash with bonds or gold is stronger or weaker than selling of stocks and re-investing the proceeds into bonds or gold.

The results are summarized in Table 5.3. Just like the previous tables, the table is split into estimation results (left part) and testing results (right part). Horizontal panels distinguish between full sample outcomes (Panel A), recession outcomes (Panel B) and expansion outcomes (Panel C). The estimation results refer to all 6 conditional probabilities in (5.20)-(5.21). The probability estimates generally reveal that cross-asset co-movements (whether it be CO or FTQ) are present but highly heterogeneous (larger cross-asset pair and sample variation). Our main interest, however, lies in assessing whether FTQ probabilities exceed CO probabilities, for which type of asset pair this is the case and whether the gap between the two likelihoods is regime dependent. More specifically, one would expect that the CO-FTQ gap is widening during recessions as compared to expansions and the full sample results. The table only provides robust evidence for a dominance of FTQ over CO for pairs of stocks and bonds: FTQ probabilities exceed $\mathrm{CO}$ probabilities for the full sample and the recession sample; but the $\mathrm{CO}$ FTQ asymmetry is strikingly bigger during the recession. The dominance of stockbond FTQ is also reflected in the reported correlations: they are mostly negative and recession-based correlations are even lower. Moreover, the rise in CO-FTQ spreads during recessions is driven by a decrease in $\mathrm{CO}$ probability and an increase in FTQ probability. The testing outcomes (right panel) show that nearly all these CO-FTQ asymmetries are statistically significant for the full sample and the recession sample and to a lesser extent for the expansion sample. CO-FTQ asymmetries are also visible for other asset combinations but the testing panel shows that most of these asymmetries are not statistically significant. 


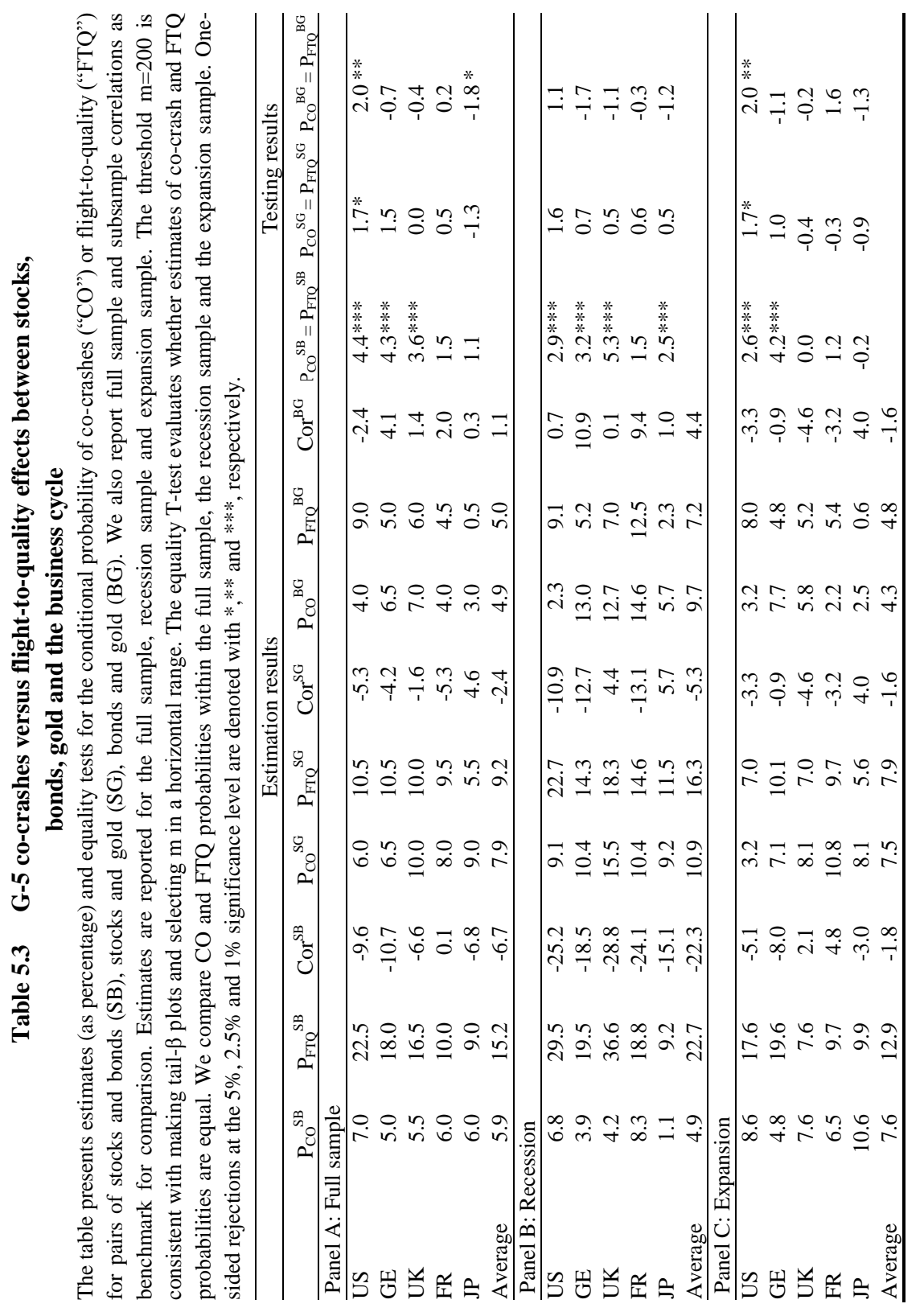




\subsubsection{Minimizing portfolio tail risk}

As a final illustration of the role regimes can play in influencing the tail behavior of returns, we consider the impact of the business cycle phase on the potential for portfolio risk diversification. The regime-dependent correlations in the previous tables already shed some light on this issue and suggest that there is also a diversification meltdown when entering a recession. However, the traditional concept of diversification meltdown refers to a situation where correlations all jump to values close to 1 during high financial market volatility regimes. This implies that the potential for diversifying portfolio risk melts away during times it is most needed, see e.g. Boyer et al. (1999), Forbes and Rigobon (2002) or Ang and Chen (2002). Here we argue that also the real state of the economy seems to matter for the diversification potential in the financial sphere (and this regardless of the state of financial market volatility). We show that this is because asset return comovements (either correlations in the distributional centre or comovements in the tail) determining the potential for risk diversification depend on the business cycle.

In order to investigate the potential impact of business cycle regimes on portfolio risk diversification we opted for the most stylized portfolio setup thinkable: two stocks and a risk averse investor that does not care about realizing return. Portfolio risk of his two-asset portfolio is either measured by the portfolio variance or with an EVT-based tail-VaR risk measure like in (5.13). Suppose the portfolio return of the two-asset equity portfolio is defined in the usual way as $R_{P}=w R_{1}+(1-$ $w) R_{2}$. Minimizing the portfolio variance $\sigma_{P}^{2}=w^{2} \sigma_{1}^{2}+(1-w)^{2} \sigma_{2}^{2}+2 w(1-$ w) $\rho \sigma_{1} \sigma_{2}$ renders the minimum variance (MV) portfolio:

$$
w_{M V}=\frac{\sigma_{2}^{2}-\rho \sigma_{1} \sigma_{2}}{\sigma_{1}^{2}+\sigma_{2}^{2}-2 \rho \sigma_{1} \sigma_{2}} .
$$

On the other hand, minimizing the Value-at-Risk of a portfolio for a given p-value (p) amounts to choosing the portfolio weight $w$ such as to minimize the portfolio quantile estimator

$$
\min _{w} \hat{x}_{p}(w)=R_{n-m, n}(w)\left(\frac{m}{p n}\right)^{1 / \alpha},
$$

and with $R_{n-m, n}$ the $(n-m)$-th ascending order statistic of the portfolio return $R_{P}$. Notice that (5.22) is equivalent to (5.13) except that the quantile estimator is made dependent on the portfolio investment weight $w$.

The empirical application consists in calculating the risk-minimizing portfolio weight $w^{*}$ as well as the corresponding minimized risk levels for the two risk measures (minimum standard deviation and minimum $\mathrm{VaR}$ ) across the phases of 
the business cycle. To that purpose we select the 8 largest companies (based on market cap) from the Dow Jones index which implies a total of 28 possible portfolios.

Table 5.4 reports the outcomes of this stylized portfolio risk minimization exercise for the full sample, the recession sample and the expansion sample. Each of these panels further contains the correlation, the minimizing risk weight $w^{*}$ as well as the corresponding minimized risk (and this for both risk measures: portfolio standard deviation and Value-at-Risk).

First, we observe that the correlations are in line with previous tables: the recession-based correlations dominate the expansion-based correlations. In line with that result, it is not surprising that the recession-based minimized risk (either measured by Value-at-Risk or standard deviation) always exceeds its expansionbased counterpart. This can be dubbed as an alternative form of diversification meltdown, i.e., portfolio risk is more difficult to diversify during recessions because correlations and tail dependencies move upward during that phase of the business cycle. It is important to realize that this outcome holds regardless the level of financial volatility. Last but not least, one observes that the risk minimizing portfolio weights strongly depend on the chosen risk measure but also on the regime.

Table 5.4 Minimum Standard Deviation and Value-at-Risk (VaR) portfolios across business cycles

The table presents the optimal weights that minimize either the 99\% Value-at-Risk (VaR) or standard deviation for 28 equity portfolios consisting of 2 stocks selected from the 28 stocks in the Dow Jones index with the largest Market Cap. 


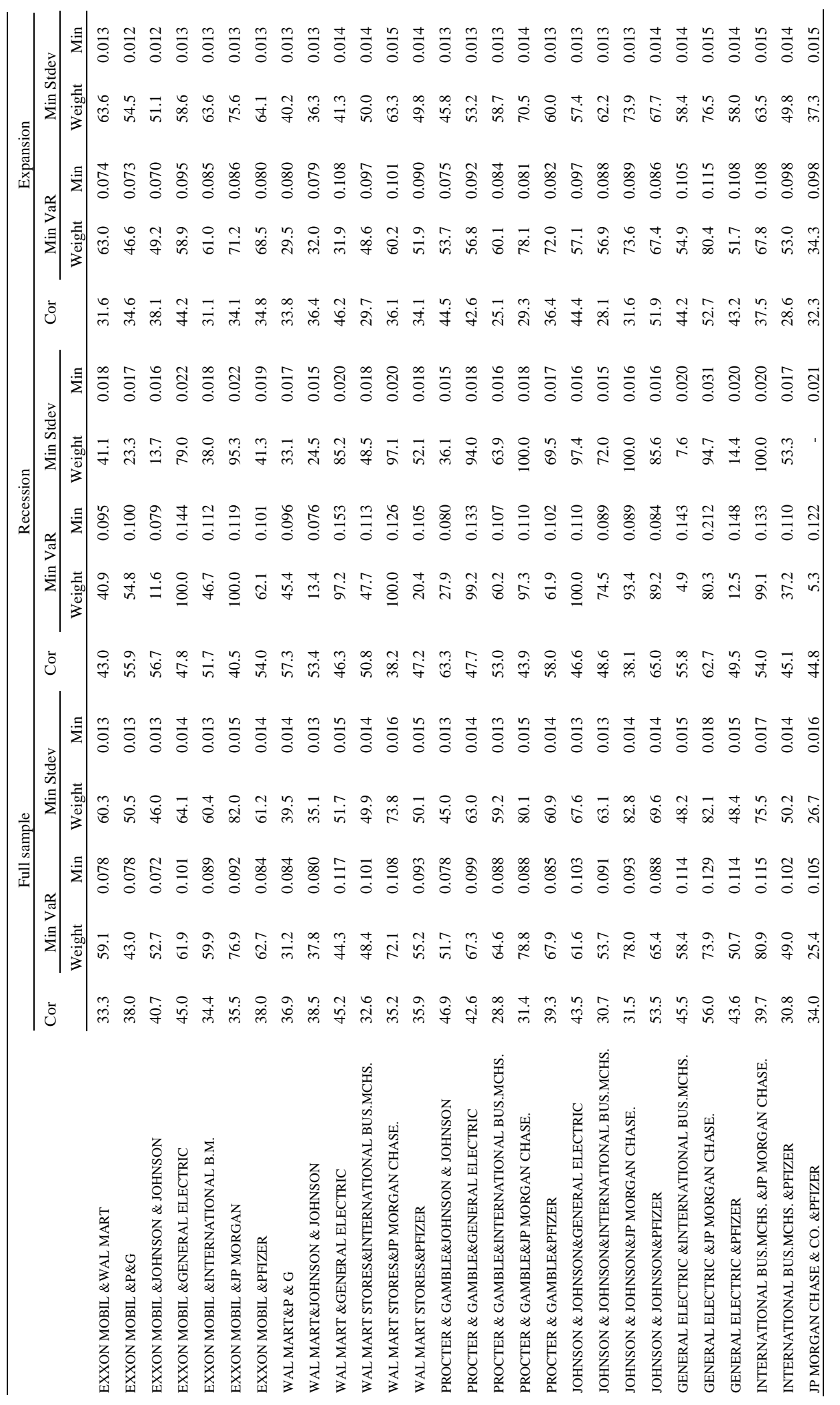




\subsection{Conclusions}

In this paper we apply statistical techniques from univariate and multivariate extreme value analysis on subsamples of financial data. Our motivation for doing this is that (univariate) tail properties like the tail index and scaling constant or multivariate tail properties like the strength of the tail dependence may depend on regimes like e.g. the business cycle. The regime dependence then determines the sample partitioning. However, we argue this regime dependence is still reconcilable with stationary unconditional long-term return distributions.

The subsamples are determined according to the business cycle "regime", i.e., recession and expansion subsamples, in order to study whether univariate extreme risk (downside tail risk) or extreme return co-movements (co-crashes or flight-toquality for stock and bond pairs, systemic risk for banks etc.) fluctuate across the business cycle. We consider different measures of tail risk and tail co-movements across the business cycle and find that regime dependence of these measures is quite general across many different types of assets or asset pairs.

In a first application, we establish that the tail indices are lower and all the corresponding tail quantiles (downside tail-VaR) are higher during recessions than during expansions. This asymmetry seems to hold for a variety of assets (US bank stocks, G-5 stock and bond indices, US\$ exchange rates and commodities). The observed regime dependence for bank stock tail risk is somewhat in line with the so-called "recession hypothesis" (see e.g. Gorton (1988) that states that recessions may trigger bank panics). ${ }^{51}$ The regime dependence in tail risk for foreign exchange rate returns may be exploited to determine regime dependent trading limits for bank traders. Previous applications of this idea only considered (fully unconditional) full sample trading limits thereby neglecting the asymmetry between tail indices and scaling constants across business cycle phases.

In a second application, we establish regime dependence for market-based indicators of systemic risk (correlation and tail- $\beta$ ) and find that systemic risk rises during recessions regardless the considered indicators. Moreover, the cross-regime differences are most of the time strongly significant, especially for the EVT-based tail- $\beta$ s. The outcomes are in line with the earlier observed "procyclicality" of market-based systemc risk indicators which is undesirable because it basically

\footnotetext{
${ }^{51}$ An important difference with papers like Gorton (1988) is that we do not study whether there is a relation between lagged states of the business cycle and extreme financial returns. We leave lead-lag relationships between extremal behavior and the business cycle for future research. In this paper we deliberately do not want to make statements about causality relations between extreme risks and the business cycle. We only focus on the coincidence of both phenomena.
} 
signals the highest systemic risk during crises and the lowest prior to crises (when risks are supposed to build up despite low volatilities and correlations). One suggestion to deal with this may simply be to re-allocate the indicators of systemic risk to the other business cycle regime in order to establish anticyclical behavior.

In a third application, we study to what extent flight to safety phenomena between stocks, bonds or gold become more or less likely depending on the state of the business cycle. We find that flight-to-quality from stocks into bonds for G-5 countries more strongly dominates stock/bond co-crashes during recession relative to expansion outcomes. The asymmetry also exists for the full sample but much smaller. But empirical evidence for flight to quality from stocks or bonds into gold is weak regardless whether one considers full samples or whether one conditions on recessions.

Finally, we establish that diversification meltdowns are not limited to periods of high financial volatility only. In fact, the potential for financial risk diversification is also reduced during recessions as compared to expansions. We illustrate this point by means of minimizing the portfolio variance vs. the portfolio Value-atRisk for the recession and expansion sample separately. Also, the optimal portfolio weights seem to vary quite substantially across the regimes for a given minimized portfolio risk indicator. 

Chapter 6

\section{General Concluding Remarks}

In order to manage risk both financial institutions and regulators have to be able to measure it accurately. This dissertation consists of four essays that strive to provide a better understanding of the different aspects of institutional risk management and macro risk management as well as to show how good measurements of risk can be utilized for management purposes.

First, lending is characterized by information asymmetry between lenders and borrowers. Borrowers have an informational advantage over lenders with respect to their own credit risk worthiness. Collateral is an important instrument to help mitigate the problem of information asymmetry. Ex-ante, collateral reduces adverse selection because it signals high quality borrowers and consequently high quality borrowers with collateral are offered lower interest rate. Ex-post, collateral reduces moral hazard as the borrower's pay-off from strategic default falls. However, if lenders are able to accurately assess borrowers' credit worthiness they will require more collateral from risky borrowers to reduce loss given default. In Chapter 2, thanks to our unique data set that contains information on both the borrowers' ex-ante credit risk and their ability to pledge collateral, we can examine these theories simultaneously. We find that the likelihood of collateralization increases for borrowers that are perceived by the bank as riskier borrowers. However at the same level of perceived risk, borrowers with ability to pledge collateral would do so in order to benefit from a lower interest rate. Moreover, the bank-borrower relationship as well as the economic conditions has strong impact on the use of collateral.

As discussed in Chapter 2, it is important for banks to have a proper risk assessment process so they can make good decisions on loan contracts including the decision to require of collateral. CSMs play a central role in that process. The development of CSMs is a statistical process that utilizes historical data to predict a future outcome. In Chapter 3 we show that the accuracy of a CSM is dependent on the quality of the data and the matching of the data elements to an appropriate forecasting horizon. It is crucial that the data utilized is timely enough to predict future behaviors and outcomes. Therefore, CSMs require ongoing evaluation and maintenance to ensure they maintain their effectiveness. This includes adjustments to respond to decreases in the value of information over time, the banks' internal strategies and external shift such as changes in the economic environment including the global financial crisis. By carrying out right adjustments credit 
rationing during economic downturns can be avoided while profitability and efficiency can still be improved.

In Chapters 4 and 5 we focus on different measures of tail risk and systemic risk for financial institution, or more generally to assess systemic instability in financial markets. To that aim we employ statistical extreme value analysis such as to capture the lower frequency character of systemic banking crises or, more generally, crisis spillovers in financial markets. In Chapter 4 we divide financial institutions into 4 sub-groups to assess to what extent tail risk and systemic risk is industry-specific. We find that there is quite some cross-industry heterogeneity in average tail risk and systemic risk that is also statistically and economically significant. More specifically, industries that exhibit a lot of tail risk (the insurance industry) are not necessarily the ones that also contribute most to overall systemic instability (deposit banks). We also find that rankings of financial institutions according to tail risk or systemic risk measures stay relatively stable over time. In other words, although tail risk and systemic risk can vary quite a lot over time, the positioning of institutions relative to each other is not dramatically changed over time. Finally, size proxies seem to correlate with systemic risk but the outcomes differ a lot depending on the used size proxies and considered subsamples (full sample, pre-crisis or crisis). Chapter 5 investigates whether there is a relation between extreme risks and phases of the business cycle. More specifically, we wonder whether and to what extent univariate tail behavior and multivariate tail comovements are dependent on the business cycle. To that aim, we partition financial data sets into recession and expansion samples and perform subsample analysis for measures of tail risk and tail comovements. First we find that tail risk is generally higher during recessions for a variety of financial assets (stocks, bonds, currencies and commodities). Next, also market-based indicators of bank systemic risk that focus on the tails indicate a higher potential of systemic instability during recessions. Third, flight-to-quality effects from stocks into either bonds or gold seem to become much more severe during recessions. Finally, portfolio diversification becomes more problematic during economic recessions because correlations and comovements in the tail increase which adds another dimension to the concept of diversification meltdown.

To sum up, my dissertation explores a number of important factors in risk management. At the institutional level, asymmetric information problems can be mitigated by securitization and by proper risk assessment processes where CSMs play a critical role. And at the macro level, tail risk and systemic risk are not necessarily substitutes and they both varies over time. It is important for regulators to understand the pattern of these risks and quantify them accurately in order to effectively maintain the stability of the financial system. 
Consumer loans have been growing remarkably in emerging markets. It has become a crucial request for both banking practitioners and regulators to better understand the behavior of borrowers and lenders with regard to contractual terms, of which collateral usage is an important one. Unfortunately, while there is a significant amount of research addressing the role as well as the determinants of collateral for commercial loans in developed markers, there is little empirical work on the factors that affect decisions to pledge collateral for consumer loans in emerging markets. Using a unique and confidential dataset of more than 30,000 consumer loans in Vietnam, we are able to answer the following questions regarding the choice between collateralized and uncollateralized consumer loans in an emerging market: Does the bank require riskier borrowers to pledge collateral? How does the availability of pledgable assets influence the borrower's loan choice? How does the relationship between bank and borrower influence the loan choice? We thereby obtain new insights that differ from those papers that study corporate loans mostly in developed markets. For instance, by answering the last question, we suggest that in an emerging market where the property right is probably not fully developed yet, the hold-up effect dominates the benefit of relationship lending and results in a higher likelihood of collateral. If property rights can be improved the borrower can make more flexible choices of pledging their asset, for instance to pledge one asset at several banks with clearly identified seniority, and thus reduce the hold-up problem.

The world has been experiencing fundamental economic changes as a results of the recent financial crisis. It is therefore very important to understand the potential impact of these changes on risk management strategies taken by banks and monitored by regulators. During and after an economic and financial crisis, banks find it more difficult to distinguish good from bad borrowers due to changes in behavior and performance of borrowers. In addition, increased default risk translated into higher risk premium and this causes more good borrowers to drop out of the market. Thus, in general after a crisis banks are struggle to set an optimal balance between business volume and the associated risk they would take while maintaining a certain level of profit. In chapter 3 of this dissertation we illustrate how banks can better overcome these difficulties to set up an optimal level of business volume. From a bank's perspective, we argue that re-estimating CSMs by using more recent data constitutes one way of improving the performance of the existing rating systems and therefore it can do a better ex-ante 
screening of potential borrowers. From regulators' perspective, our results suggest that after - or even during a crisis - banks' existing CSMs in particular and risk models in general ( developed prior crisis) should be reviewed and monitored closely as they might not function anymore as they once did. If those risk models that are not predictive anymore are still in place to determine factors used as input for calculating economic and regular capital, e.g. Probability of Default (PD), Loss Given Default (LGD), etc. this will lead to a bias estimation, and event more dangerous, an underestimation. This can have a serious impact on how banks can cover their risk and survive a worst-case scenario once the crisis unfolds. Thus, for the financial systems that are still faced with crises and unresolved structural problems it is important to take into account the performance of their risk models as soon as possible.

In chapter 4, we find that different groups of financial institutions exhibit different levels of tail risk and systemic risk. The heterogeneity in tail risks and systemic contributions across different types of financial institutions suggests that regulators should not treat different financial industries as homogeneous when regulating and supervising their risks, i.e. a broker-dealer should be treated differently from, say, a deposit bank. The most salient outcome of our crossindustry risk comparison seems to be that the insurance industry exhibits the highest tail risk but that deposit banks are characterized by the highest degree of extreme systematic risk. The latter outcome is surprising given the key role investment banks played in the narrative of the financial crisis. Furthermore, we find that these EVT-based indicators of tail risk and systemic risk are good judgment about the propensity towards future systemic crises: rank correlations between pre-crisis and crisis ranks are relatively high which implies that the riskiest institutions in terms of tail risk and systemic risk before the crisis are also often the riskiest ones over the crisis sample. Thus, it may be worthwhile for regulators to pay attention to those financial institutions that exhibit high pre-crisis systemic risk because once a crisis strikes they are expected to stay among the biggest contributors to the financial instability. Last but not least, in this chapter our results suggest that financial institutions' size does not have much to say about financial institutions' tail risk; but size does seem to matter for their systemic risk. This seems to confirm the way regulators are currently carrying out their monitoring strategies concerning systemic risk: size driven instead of exposurelinkage driven.

Our results in chapter 5 suggest that stock-bond co-crashes are less likely than flight-to-quality during times of market stress and that this asymmetry is largest during recessions. Understanding correctly the linkage across asset classes is interesting for investors who have to choose their investment portfolios according 
to their preferred risk-return combinations. On the other hand, policy makers and supervisory bodies are interested in these linkages because they potentially influence the level of systemic risk in financial markets. In addition, we establish that portfolio risk (both central risk measures like variance as well as tail risk) is much harder to diversify during recessions as compared to expansions, i.e., a diversification meltdown. 



\section{Nederlandse Samenvatting}

Bestaande regelgeving en risicobeheer kon de financiële crisis die in 2007 begon niet voorkomen. De wortels van deze crisis reiken veel verder, en er bestaan uiteenlopende meningen over de fundamentele oorzaken. Het doel van deze dissertatie is een beter inzicht te geven in een aantal van deze factoren: 'securitizering', falende computermodellen voor institutioneel risicobeheer en bestaande gebreken in regelgeving en toezicht op bancaire risico's op zowel micro-als macroprudentieel vlak. In dit proefschrift: (i) laten we zien onder welke omstandigheden banken credit-hulp behoeven, d.w.z. onderpand, voor leners (hoofdstuk 2); (ii) laten we zien hoe de beperkingen van credit scoring-modellen overwonnen kunnen worden en hun geldigheid kunnen behouden gedurende de recente financiële crisis (hoofdstuk 3); (iii) we bediscussiëren het systemisch belang ("systemic importance") en staartrisico van verschillende types van (Amerikaanse) financiële instellingen (hoofdstuk 4); (iv) we analyseren tenslotte de extreme samenhangen tussen verschillende types van financiële activa (aandelen, obligaties, goud, zilver, valuta etc.) en hoe die afhangen van de staat van de economische conjunctuur.

\section{Het institutionele financiële risico management}

Lenen wordt eerst en vooral gekarakteriseerd door het feit dat kredietverstrekkers en leners niet over dezelfde hoeveelheid informatie beschikken. Leners hebben een voordeel t.o.v. hun kredietverstrekkers omdat zij op de hoogte zijn van hun eigen kredietwaardigheid. Het eisen van een onderpand is een belangrijk instrument om de ongelijkheid in informatiebeschikking te verminderen. Een onderpand kan bijvoorbeeld voorkomen dat slechte leningen worden afgesloten en goede leners worden opgepikt zodat hen een lage rente kan worden geboden. Dit reduceert ook de kans op 'moral hazard' nadat leningen zijn toegekend. Maar als kredietverstrekkers niet in staat zijn om op accurate wijze de kredietwaardigheid van een lener in te schatten, zullen ze een hoger onderpand vragen van risicovolle leners om verlies tegen te gaan. In hoofdstuk twee, gebruikmakende van unieke data, die zowel informatie bevat over het a-priori kredietrisico van een lener en haar vermogen om een onderpand aan te dragen, kunnen we deze theorieën tegelijk bestuderen. We vinden dat de waarschijnlijkheid van 'collateralization' toeneemt bij leners die door de bank als risicovol bestempeld worden. Maar bij een gelijk waargenomen risico zullen leners met de mogelijkheid een onderpand aan te dragen, dat doen om in aanmerking te komen voor een lager rentepercentage. Bovendien hebben zowel de relatie tussen de bank en de lener alsmede de economische omstandigheden een sterke invloed op het gebruik van een onderpand. 
Zoals bediscussieerd in hoofdstuk twee, is het belangrijk voor banken de beschikking te hebben over een nauwkeurige methode om risico's mee in te schatten. Zo kunnen banken de juiste beslissingen nemen wat betreft het verstrekken van leningen, inclusief het wel of niet eisen van een onderpand. Kredietscoremodellen (Credit Scoring Models of CSMs) spelen een centrale rol in dat proces. De ontwikkeling van een CSM is een statistisch proces dat gebruik maakt van informatie uit het verleden om een voorspelling te doen over het eventueel voorkomen van een gebeurtenis in de toekomst. In hoofdstuk drie laten we zien dat de nauwkeurigheid van een CSM afhangt van de kwaliteit van de beschikbare informatie alsmede de manier waarop de informatie gebruikt wordt om uitspraken over de toekomst te doen. Het is van cruciaal belang dat de gebruikte informatie de juiste periode uit het verleden beschrijft (afdoende ver teruggaat, dan wel afdoende actueel is) om toekomstige gedragingen en gebeurtenissen te beschrijven. Daarom hoeven CSMs continu geëvalueerd te worden opdat ze hun effectiviteit behouden. CSMs moeten aangepast worden omdat informatie waarde verliest naarmate de tijd vordert maar aanpassingen zijn ook nodig om veranderingen in de interne strategie van de bank te weerspiegelen alsmede aanpassingen vanwege externe veranderingen zoals schommelingen in het economische klimaat. Door het juiste beleid te voeren tijdens perioden van economische tegenspoed kunnen banken economisch verlies voorkomen terwijl winstgevendheid en efficiëntie tegelijkertijd verbeterd kunnen worden.

\section{Macro financieel risicomanagement}

In hoofdstukken vier en vijf richten we ons op verschillende maatstaven van staartrisico en systeemrisico voor financiële instellingen, en meer in het algemeen op het meten van het potentieel tot systemische instabiliteit in financiële markten. Daartoe maken we gebruik van statistische extreme waarde analyse om onder andere vat te krijgen op de laagfrequente aard van systemische bankencrises, of in bredere zin, crisis 'spillovers' in financiële markten. In hoofdstuk vier verdelen we financiële instellingen in vier deelgroepen om vast te stellen in welke mate staartrisico en systemisch risico afhangen van de betreffende tak van industrie. We vinden dat het gemiddelde staartrisico en systeemrisico tamelijk heterogeen aanwezig is in alle takken van de industrie (maar er zijn dus belangrijke verschillen tussen industrieën onderling). Industrieën die gekenmerkt worden door een aanzienlijk staartrisico (de verzekeringsindustrie) zijn bovendien niet perse degenen die het meest bijdragen aan de algemene systemische instabiliteit (depositobanken). We vinden ook dat rangordes van financiële instellingen op basis van hun staartrisico of systemische risicomaatstaven relatief stabiel blijven over de tijd. Met andere woorden, hoewel staartrisico en systemisch risico over de tijd kan variëren, doet dit niet veel af aan de relatieve positionering van 
instellingen ten opzichte van elkaar. Tenslotte lijkt de grootte of omvang van financiële instellingen (gemeten aan de hand van verschillende proxies) te correleren met systemisch risico maar de uitkomsten verschillen naar gelang de gebruikte 'proxies' en de beschouwde deelsteekproeven (volledige steekproef, voor- of tijdens de crisis). Hoofdstuk vijf onderzoekt of extreme risico's alsmede hun samenhangen afhangen van de conjunctuurcyclus. Om dat te bewerkstelligen verdelen we onze financiële tijdreeksen in zgn. recessie- en expansiesteekproeven en analyseren we de deelsteekproeven op (univariate) staartrisico en (multivariate) samenhangen in het staartgedrag. Ten eerste concluderen we dat staartrisico hoger is gedurende recessies en dit voor een heleboel financiële activa. Daarnaast berekenen we een aantal indicatoren van systemisch risico voor banken. Deze duiden op een hogere waarschijnlijkheid van systemische instabiliteit gedurende recessies. Ten derde vinden we dat zgn. 'flight-to-quality' effecten van aandelen naar obligaties of goud lijken toe te nemen gedurende recessies. Tenslotte wordt het spreiden van risico's moeilijker gedurende economische recessies omdat de staartafhankelijkhied groter wordt tijdens recessies en het potentieel op risicodiversificatie daalt.

Samenvattend: mijn dissertatie onderzoekt een aantal belangrijke factoren in risicobeheer. Op institutioneel niveau kunnen asymmetrische informatieproblemen worden geminimaliseerd door 'securitizering' en gedegen risicobeheerprocedures waarin CSMs een cruciale rol spelen. Op macro-niveau zijn staartrisico en systeemrisico niet noodzakelijkerwijs uitwisselbaar en beiden zijn aan fluctuaties onderhevig. Voor beheerders is het belangrijk om de patronen van deze risico's te begrijpen en om ze nauwkeurig te kwantificeren en zo op effectieve wijze de stabiliteit van het financiële systeem te monitoren. 



\section{Biography}

Dinh Thi Huyen Thanh was born on August 23, 1981 in Quang Ninh, Vietnam. She studied international economics at Ngoai Thuong University, Hanoi, Vietnam. She was then an exchange student at Fontys University of Professional Education, Eindhoven, the Netherlands. She subsequently pursued a Master of Science in international business with a major in Finance at Maastricht University, the Netherlands and graduated in February 2006. After graduation, she joined De Lage Landen International B.V as a decision analytics consultant where she involved in the development of Basel compliant models such as models to predict probability of default.

In September 2008, Thanh was employed as a $\mathrm{PhD}$ student by the Department of Finance at Maastricht University. The work she has produced during her $\mathrm{PhD}$ years has been presented at various international conferences including the Financial Management Association European Conference in Istanbul (2012) and in Luxemburg (2013) and the World Finance \& Banking Symposium in Shanghai (2012).

Since April 2013, Thanh joined back to De Lage Landen International B.V as a global analytics consultant. 



\section{References}

A Dun \& Bradstreet Company (A D\&B), 2009. The Implications of the Global Credit crisis for credit scoring models. Decision Intellect Whitepaper, A Dun \& Bradstreet Company (A D\&B), available at http://www.decisionintellect.com.au

Acharya, V., Pedersen, L., Philippon, T., Richardson, M., 2010. Measuring systemic risk. New York University working paper.

Adrian, T., Brunnermeier, M. K., 2011. CoVaR. NBER Working Paper No.17454.

Akerlof, A., 1970. The Market for "lemons": Quality uncertainty and the market mechanism. The Quarterly Journal of Economics 84 (3), 488-500.

Allen, F., Gale, D., 2000. Financial contagion. Journal of Political Economy 108 (1), 1-33.

Allen, L., DeLong, G., Saunders, A., 2004. Issues in credit risk modeling of retail markets. Journal of Banking and Finance 28 (4), 727-752.

Altman, E. I., 1968. Financial ratios, discriminant analysis, and the prediction of corporate bankruptcy. Journal of Finance 23 (4), 589-609.

Altman, E. I., Narayanan, P., 1997. An international survey of business failure classification models. Financial Markets, Institutions and Instruments 6 (2), 1-57.

Altman, E. I., Saunders, A., 1998. Credit risk measurement: Developments over the last 20 years. Journal of Banking and Finance 21 (11), 1721-1742.

Ang, A., Bekaert, G., 2002. International asset allocation with regime shifts. Review of Financial Studies 15 (4), 1137-1187.

Ang, A., Chen, J., 2002. Asymmetric correlations of equity portfolios. Journal of Financial Economics 63 (3), 443-494.

Ang, A., Timmermann, A., 2012. Regime changes and financial markets. Annual Review of Financial Economics 4 (1), 313-337.

Avery, R. B. Calem, P. S., Canner, G. B., 2004. Consumer credit scoring: Do situational circumstances matter? Journal of Banking \& Finance 28 (4), 835-856

Bae, K., Karolyi, A., Stulz, R., 2003. A new approach to measuring financial contagion. Review of Financial Studies 16 (3), 717-763.

Baele, L. 2005. Volatility spillover effects in European equity markets. Journal of Financial and Quantitative Analysis 40 (2), 373-401.

Baele, L., Bekaert, G., Inghelbrecht, K., Wei, M., 2013. Flights to safety. National Bank of Belgium Working Paper No. 230.

Baesens, B., Gestel, T. V., Viaene, S., Stepanova, M., Suykens J., Vanthienen, J., 2003. Benchmarking state-of-the-art classification algorithms for credit scoring. Journal of the Operational Research Society 54 (6), 627-635.

Baur, D. G., Lucey, B. M., 2009. Flights and contagion: An empirical analysis of stock-bond correlations. Journal of Financial Stability 5 (4), 339-352.

Beirlant, J., Dierckx, G., Goegebeur, Y., Matthys, G., 1999. Tail index estimation and an exponential regression model. Extremes 2 (2), 177-200.

Bekaert, G., Harvey, C. R., 1995. Time-varying world market integration. Journal of Finance 50 (2), 403-444. 
Berger, A. N., Udell, G. F., 1990. Collateral loan quality, and bank risk. Journal of Monetary Economics 25, 21-42.

Berger, A. N., Udell, G. F., 1995. Relationship lending and lines of credit in small firm finance. Journal of Business, 68 (3), 351-381.

Berger, A. N., Udell, G. F., 2002. Small business credit availability and relationship lending: The importance of bank organization structure. Economic Journal 112 (4), 32-53.

Bernanke, B. S. and Gertler, M., 1995. Inside the black box: The credit channel of monetary policy transmission. Journal of Economic Perspectives 9 (4), 27-48.

Besanko, D., Thakor, A. V., 1987. Collateral and rationing: sorting equilibria in monopolistic and competitive credit markets. International Economic Review 28 (3), 671-689.

Bester, H., 1985. Screening vs. rationing in credit markets with imperfect information. The American Economic Review 75 (4), 850-855.

Blöchlinger, M., Leippold, M., 2006. Economic benefit of powerful credit scoring. Journal of Banking and Finance 30 (3), 851-873.

Bonfim, D., 2009. Credit risk drivers: Evaluating the contribution of firm level information and of macroeconomic dynamics. Journal of Banking \& Finance 33(2), 281-299.

Boot, A. W. Udell, G. F., 1991. Secured lending and default risk: Equilibrium analysis, policy implications and empirical results. Economic Journal 101 (406), 458-472.

Boot, A. W., 2000. Relationship banking: What do we know?. Journal of Financial Intermediation 9 (1), 7-25.

Boot, A. W., Thakor, A. V., 1994. Moral hazard and secured lending in an infinitely repeated credit market game. International Economic Review 35 (4), 899-920.

Booth, J. R., Booth, L. C., 2006. Loan collateral decisions and corporate borrowing costs. Journal of Money, Credit, and Banking 38 (1), 67-90.

Boyer, B., Gibson, M., Loretan, M., 1999. Pitfalls in tests for changes in correlation. International Finance Discussion Paper No. 5-97, Board of Governors of the Federal Reserve System, Washington (DC).

Boyle, M., Crook, J. N., Hamilton, R., Thomas, L. C., 1992. Methods for credit scoring applied to slow payers. In: Thomas, L.C., Crook, J.N., Edelman, D.B. (Eds.), Credit Scoring and Credit Control. Oxford University Press, Oxford, 75-90.

Brière, M., Chapelle, A., Szafarz, A., 2012. No contagion, only globalization and flight to quality. Journal of International Money and Finance 31 (6), 1729-744.

Brownlees, C. T., Engle, R., 2012. Volatility, correlation and tails for systemic risk measurement. SSRN Working Paper.

Byström, H., Worasinchai, L., Chongsithipol, S., 2005. Default risk, systematic risk and Thai firms before, during and after the Asian crisis. Research in International Business and Finance 19 (1), 95-110.

Cappiello, L., Gérard, B., Manganelli, S., 2005. Measuring comovements by regression quantiles. ECB Working Paper No. 0501, European Central Bank.

Carling, K., Jacobson, T., Lindé, J., Roszbach, K., 2007. Corporate credit risk modeling and the macroeconomy. Journal of Banking \& Finance 31 (3), 845-868.

Cetorelli, N., Goldberg, L., 2012. Banking globalization and monetary transmission. The Journal of Finance 67 (5), 1811-1843.

Cetorelli, N., Goldberg, L., 2011. Global banks and international shock transmission: Evidence from the crisis. IMF Economic Review 59 (1), 41-76. 
Chakraborty, A., Hu, C. X., 2006. Lending relationships in line-of-credit and nonline-of-credit loans: Evidence from collateral use in small business. Journal of Financial Intermediation 15 (1), 86-107.

Chan, Y. S., Kanatas, G., 1985. Asymmetric valuations and the role of collateral in loan agreements. Journal of Money, Credit and Banking 17 (1), 84-95.

Committee for Population, Family and Children, ORC Macro, 2003. Vietnam demographic and health survey 2002. Committee for Population, Family and Children, Hanoi. Available at http://www.measuredhs.com/aboutsurveys/search/.

Connolly, R., Stivers, C., Sun, L., 2005. Stock market uncertainty and the stock-bond return relation. Journal of Financial and Quantitative Analysis 40 (1), 161-194.

Crook, J. N., Hamilton, R., Thomas, L. C., 1992. A comparison of discriminations under alternative definitions of credit default. In: , Thomas, L.C., Crook, J.N., Edelman, D.B. (Eds.), Credit Scoring and Credit Control. Oxford University Press, Oxford, 217-245.

Danielsson J., de Vries, C. G., 1997. Tail index and quantile estimation with very high frequency data. Journal of Empirical Finance 4, 241-257. 45 .

De Haan, L. de, de Ronde, J., 1998. Sea and wind: multivariate extremes at work. Extremes 1 (1), 7 -

De Haan, L. de, Jansen, D. W., Koedijk, K., De Vries, C. G., 1994. Safety first portfolio selection, extreme value theory and long run asset risks. In J. Galambos, J. Lechner and E. Simiu (Eds.), Extreme Value Theory and Applications. Kluwer Academic Publishers, Dordrecht, 471-487.

De Jonghe, O., 2010. Back to basics in banking? A micro-analysis of banking system stability. Journal of Financial Intermediation 19 (3), 387-417.

De Nicolo, G., Kwast, M., 2002. Systemic risk and financial consolidation: Are they related? Journal of Banking and Finance 26 (5), 861-880.

De Vries, C.G., 2005. The simple economics of bank fragility. Journal of Banking and Finance 29 (4), 803-825.

Degryse, H., Van Cayseele, P., 2000. Relationship lending within a bank-based system: Evidence from European small business data. Journal of Financial Intermediation 9 (1), 90-109.

Demirgüc-Kunt, A., Detragiache, E., 1998. The determinants of banking crises in developing and developed countries. IMF Staff Papers 45 (1), 81-109.

Desai, V. S., Crook, J. N, Overstreet, G.A., 1996. A comparison of neutral networks and linear scoring models in the credit union environment. European Journal of Operational Research 95 (1), 24-37.

Desai, V. S., Crook, J. N., Overstreet, G. A., 1997. Credit scoring models in the credit union environment using neutral networks and genetic algorithms. IMA Journal of Mathematics Applied in Business and Industry 8, 323-346.

Dinh, T.H.T., Kleimeier, S., 2007. A credit scoring model for Vietnam's retail banking market, International Review of Financial Analysis 16 (5), 471-495.

Draisma, G., Drees, H., Ferreira, A., de Haan, L., 2004. Bivariate tail estimation: Dependence in asymptotic independence. Bernouilli 10 (2), 251-280.

Elsas, R., Krahnen, J. P., 2000. Collateral, default risk, and relationship lending: An empirical stusy on financial contracting. Discussion Paper No. 2540, Centre for Economic Policy Research.

Embrechts P., McNeil, A., Straumann, D., 1999. Correlation: Pitfalls and alternatives. Risk 12 (5), 6971. 
Embrechts, P., Klüppelberg, C., Mikosch, T., 1997. Modelling extremal events. Springer-Verlag, Berlin.

Engel, C., Hamilton, J. D., 1990. Long swings in the dollar: Are they in the data and do markets know It? American Economic Review 80 (4), 689-713.

Errunza, V. R., Calantone, R. J., Renforth, W. R., Strachan, H.W., 1981. Rural credit: A micro synthesis of the Salvadorean experience . Journal of Development Economics 8 (2), 227-239.

Farinha, L. A., Santos, J. A., 2002. Switching from single to multiple bank lending relationships: Determinants and implications. Journal of Financial Intermediation, 11(2), 124-151.

Forbes, K., Rigobon, R., 2002. No contagion, only interdependence: Measuring stock market comovements. Journal of Finance 57 (5), 2223-2261.

Galbraith, J. W., Zernov, S., 2004. Circuit breakers and the tail index of equity returns. Journal of Financial Econometrics 2 (1), 109-129.

Godquin, M., 2004. Microfinance repayment performance in Bangladesh: How to improve the allocation of loans by MFIs. World Development 32 (11), 1909-1926.

Goetz, A. M., Gupta, R. S., 1996. Who takes the credit? Gender, power, and control over loan use in rural credit programs in Bangladesh. World Development 24 (1), 45-63.

Goldie, C., Smith, R., 1987. Slow variation with remainder: Theory and applications. Quarterly Journal of Mathematics 38 (2), 45-71.

Gonzalez-Hermosillo, B., Pazarbasioglu, C., Billings, R., 1997. Banking system fragility: Likelihood versus timing of failure - An application to the Mexican financial crisis. IMF Staff Papers 44 (3), 295-314.

Gorton, G., 1988. Banking panics and business cycles. Oxford Economic Papers 40 (4), 751-781.

Greenbaum, S. I., Kanatas, G., Venezia, I., 1989. Equilibrium loan pricing under the bank-client relationship. Journal of Banking \& Finance, 13 (2), 221-235.

Gropp, R., Moerman, G., 2004. Measurement of contagion in banks' equity prices. In Hasan I. and Tarkka J. (Eds.), Banking, Development and Structural Change. Special Issue of the Journal of International Money and Finance 23 (3), 405-459.

Gropp, R., Vesala, J., 2004. Bank contagion in Europe. Symposium of the ECB-CFS research network on 'Capital Markets and Financial Integration in Europe', European Central Bank, Frankfurt am Main.

GSO, 1999. Population and housing census Vietnam 1999. General Statistics Office of Vietnam (GSO), Hanoi. Available at http://www.gso.gov.vn.

GSO, 2002. Establishment census of Vietnam 2002. General Statistics Office of Vietnam (GSO), Hanoi. Available at http://www.gso.gov.vn.

GSO, 2004. Living standard survey 2004. General Statistics Office of Vietnam (GSO), Hanoi. Available at http://www.gso.gov.vn.

Guidolin, M., Timmermann, A., 2008. International asset allocation under regime switching, skew, and kurtosis preferences. Review of Financial studies 21 (2), 889-935.

Haeusler, E., Teugels, J., 1985. On asymptotic normality of Hill's estimator for the exponent of regular variation. Annals of Statistics 13 (2), 743-756.

Hainz, C., 2003. Bank competition and credit markets in transition economies.” Journal of Comparative Economics 31, 223-45.

Hamilton, J. D., 1990. Analysis of time series subject to changes in regime. Journal of Econometrics 45 (1-2), 39-70. 
Hamilton, J. D., Susmel, R., 1994. Autoregressive conditional heteroskedasticity and changes in Regime. Journal of Econometrics 64, 307-333.

Dellien, H., Schreiner, M., 2005. Credit scoring, banks, and microfinance: Balancing high-tech with high-touch. Available at http://www.microfinance.com/English/Papers.

Harhoff, D., Körting, T., 1998. Lending relationships in Germany-empirical evidence from survey data. Journal of Banking \& Finance 22 (10), 1317-1353.

Harrington, S. E., 2009. The financial crisis, systemic risk, and the future of insurance regulation. Public Policy Paper, National Association of Mutual Insurance Companies.

Hartmann, P., Straetmans, S., de Vries, C. G., 2004. Asset market linkages in crisis periods. Review of Economics and Statistics 86 (1), 313-326.

Hartmann, P., Straetmans, S., de Vries, C. G., 2006. Banking system stability: A cross-atlantic perspective. In: Carey, M, Stulz R. M. (Eds.), The Risk of Financial Institutions, The University of Chicago Press , Chicago and London, 133-193.

Hellwig, M., 1994. Liquidity provision, banking, and the allocation of interest rate risk. European Economic Review 38 (7), 1363-1389.

Henley, W. E., 1995. Statistical aspects of credit scoring. Open University, Dissertation.

Henley, W. E., Hand, D. J., 1997. Statistical classification methods in consumer credit scoring: a review. Journal of the Royal Statistical Society - Series A (Statistics in Society) 160 (3), 523-541.

Herrmann, S., Mihaljek, D., 2010. The determinants of cross-border bank flows to emerging markets: new empirical evidence on the spread of financial crises. BIS Working Papers No 315.

Harhof, D., Korting, R., 1998. Lending relationships in Germany: empirical evidence from survey data. Journal of Banking and Finance 22, 1317-1353.

Huang, X., 1992. Statistics of bivariate extreme values. Tinbergen Institute Research Series, Ph.D. thesis no. 22, Erasmus University, Rotterdam.

Inderst, R., Mueller, H. M., 2007. A lender-based theory of collateral. Journal of Financial Economics 84 (3), 826-859.

Iori, G., Jafarey, S., Padilla, F., 2006. Systemic risk on the interbank market. Journal of Behaviour and Organization 61 (4), 525-542.

Ivashina, V., Scharfstein, D., 2010. Bank lending during the financial crisis of 2008. Journal of Financial Economics 97 (3), 319-338.

J.F. Slijkerman, D. Schoenmaker, and C. G. de Vries., 2013. Systemic risk and diversification across european banks and insurers. Journal of Banking and Finance 37(3), 773-785.

Jankowitsch R., Pichler S., Schwaiger W. S. A., 2007. Modelling the economic value of credit rating systems. Journal of Banking and Finance 31 (1), 181-198.

Jansen, D. W., de Vries, C. G., 1991. On the frequency of large stock returns: Putting booms and busts into perspective. Review of Economics and Statistics 73, 19-24.

Jimenez, G., Salas, V., Saurina, J., 2004. Collateral, type of lender and relationship banking as determinants of credit risk. Journal of Banking and Finance 28 (9), 2191-2212.

Jimenez, G., Salas, V., Saurina, J., 2006. Determinants of collateral. Journal of Financial Economics 81(2), 255-281.

Kho, B. C., Lee, D., Stulz, R., 2000. U.S. banks, crises, and bailouts: From Mexico to LTCM. American Economic Review Papers and Proceedings 90 (2), 28-31. 
King, M., Wadhwani, S., 1990. Transmission of volatility between stock markets. Review of Financial Studies 3 (1), 5-33.

Kirabaeva, K., 2011. Adverse selection and financial crises. Bank of Canada Review 2010-2011 (Winter), 11-19.

Koedijk, K., Schafgans, M., de Vries, C. G., 1990. The tail index of exchange rate returns. Journal of International Economics 29, 93-108.

Koedijk, K. G., Stork, P. A., de Vries, C. G., 1992. Foreign exchange rate regime differences viewed from the tails. Journal of International Money and Finance 11 (5), 462-473.

Kraznowski, W. J., Hand, D. J., 2009. ROC curves for continuous data. Taylor \& Francis, Inc. Boca Raton.

La Porta, R., Lopez-de-Silanes, F., Zamarripa, G., 2003. Related lending. Quarterly Journal of Economics 118 (1), 231-268.

Laitinen, E. K., 1999. Predicting a corporate credit analyst's risk estimate by logistic and linear models. International Review of Financial Analysis 8 (2), 97-121.

Ledford, A., Tawn, J., 1996. Statistics for near independence in multivariate extreme values. Biometrika 83 (1), 169-187.

Lehmann, E., Neuberger, D., 2001. Do lending relationships matter?: Evidence from bank survey data in Germany. Journal of Economic Behavior \& Organization 45 (4), 339-359.

Loi, H. T., 2006. Credit risk and credit access in Asia: Trends and developments in insolvency system and risk management: The experience of Vietnam. Source OECD Emerging Economies 8, 281-289.

Longin, F., Solnik, B., 2001. Extreme correlation of international equity markets. Journal of Finance 56 (2), 649-676.

Lucas, A., Klaassen, P., 2006. Discrete versus continuous state switching models for portfolio credit risk - Journal of Banking and Finance 30 (1), 23-35.

Machauer, A., Weber, M., 1998. Bank behaviour based on internal credit rating of borrower. Journal of Banking and Finance 22 (12), 1355-1383.

Mandelbrot, B., 1963. The variation of certain speculative prices. Journal of Business 36 (4), 394-419.

Manganelli, S., Cappiello, L., Gerard, B., 2004. The contagion box: Measuring co-movements in financial markets by regression quantiles. Econometric Society 2004 Latin American Meetings 77, Econometric Society.

Menkhoff, L., Neuberger, D., Suwanaporn, C., 2006, Collateral-based lending in emerging markets: Evidence from Thailand. Journal of Banking and Finance 30 (1), 1-21.

Mester, L., 1997. What's the point of credit scoring? Federal Reserve Bank of Philadelphia Business Review, September/October, 3-16.

Milesi-Ferretti, G. M., Tille, C., 2011. The great retrenchment: International capital flows during the global financial crisis. Economic Policy 26 (66), 289-346.

Miller, M., Rojas, D., 2004. Improving access to credit for SMEs: An empirical analysis of the viability of pooled data SME credit scoring models in Brazil, Colombia \& Mexico. Working paper. Available at http://siteresources.worldbank.org.

Pagan, A. R., Schwert, G. W., 1990. Testing for covariance stationarity in stock market data. Economics Letters 33 (2), 165-170.

Petersen, M. A., Rajan, R. G., 1994. The benefits of lending relationships: Evidence from small business data. The Journal of Finance 49 (1), 3-37. 
Philosophov, L. V., Philosophov, V. L., 2002, Corporate bankruptcy prognosis: An attempt at a combined prediction of the bankruptcy event and time interval of its occurrence. International Review of Financial Analysis 11 (3), 375-406.

Poon, S. H., Rockinger, M., Tawn, J., 2004. Extreme value dependence in financial markets: Diagnostics, models, and financial implications. Review of Financial Studies 17 (2), 581-610.

Popov, A., Udell, G., 2012. Cross-border banking, credit access, and the financial crisis. Journal of International Economics 87 (1), 147-161.

Provost, F., Fawcett, T., Kohavi, R., 1998. The case against accuracy estimation for comparing classifiers. Proceedings of the Fifteenth International Conference on Machine Learning, 445-553.

Quach, L. T., 2011, Banking sector report. Vietcombank Securities, Research and Analysis Department, September. Available at http://vninvestment.files.wordpress.com/2012/ 03/vietnambank2011.pdf.

Quintos, C., Fan, Z., Phillips, P., 2001. Structural change tests in tail behaviour and the Asian crisis. Review of Economic Studies 68 (3), 633-663.

Rajan, R. G., 1992. Insiders and outsiders: The choice between informed and arm's-length debt. Journal of Finance 47(4), 1367-1400.

Ryo, H., Hideaki, H., Arito, O., 2011. Differentiated use of small business credit scoring by relationship lenders and transactional lenders: Evidence from firm-bank matched data in Japan. RIETI Discussion Paper Series 11-E-070

Sangha, B. S., 1998. A systematic approach for managing credit score overrides. In: Mays, E. (Eds.), Credit Risk Modeling Design and Application. Glenlake Publishing, Chicago, 223-244.

Schreiner, M., 2003. Scoring: The next breakthrough in microcredit? CGAP Occasional Paper No.7. Available at http://www.cgap.org.

Schreiner, M., 2004. Scoring arrears at a microlender in Bolivia. Journal of Microfinance 6 (2), $65-88$.

Sharpe, S. A., 1990. Asymmetric information, bank lending, and implicit contracts: A stylized model of customer relationships. The Journal of Finance 45 (4), 1069-1087.

Slovin, M., Sushka, M., Polonchek, J., 1999. An analysis of contagion and competitive effects at commercial banks. Journal of Financial Economics 54 (2), 197-225.

Smirlock, M., Kaufold, H., 1987. Bank foreign lending, mandatory disclosure rules, and the reaction of bank stock prices to the Mexican debt crisis. Journal of Business 60 (3), 347-364.

Srinivasan, V., Kim, Y. H., 1987. The Bierman-Hausman credit granting model: A note. Management Science 33 (10), 1361-1362.

Stiglitz, J. E., and Weiss, A., 1981. Credit rationing in markets with imperfect information. American Economic Review 71 (3), 393-410.

Straetmans S., 2000. Extremal spill-overs in equity markets. In: Embrechts P (Eds.), Risk Extremes and Integrated Risk Management. Risk Books, London, 187-204.

Straetmans, S., 1998. Extreme Financial returns and their comovements, Tinbergen Institute Research Series, Ph.D. thesis no. 181, Erasmus University, Rotterdam.

Straetmans, S., Candelon, B., 2013. Long term asset tail risks in developed and emerging markets. Journal of Banking and Finance 37 (6), 1832-1844.

Straetmans, S., Chaudhry, S., 2013. Tail risk and systemic risk for U.S. and Eurozone financial institutions in the wake of the global financial crisis. Maastricht University Working Paper. 
Straetmans, S., Verschoor, W., Wolff, C., 2008. Extreme US stock market fluctuations in the wake of 9/11. Journal of Applied Econometrics 23 (1), 17-42.

Susmel, R., Engle, R. F., 1994. Hourly volatility spillovers between international equity markets. Journal of International Money and Finance 13 (1), 3-25.

Swary, I., 1986. Stock market reaction to regulatory action in the Continental Illinois crisis. Journal of Business 59 (3), 451-473.

Takats, E., 2010. Was it credit supply? Cross-border bank lending to emerging market economies during the financial crisis. BIS Quarterly Review (June), 49-56.

Thakor, A. V., 1996. Capital requirements, monetary policy, and aggregate bank lending: Theory and empirical evidence. Journal of Finance 51 (1), 279-324.

Thomas L. C., 2000. A survey of credit and behavioral scoring: Forecasting financial risk of lending to consumers. International Journal of Forecasting 16, 149-172.

Viganó, L., 1993. A credit scoring model for development banks: An African case study. Savings and Development 17 (4), 441-482.

Vogelgesang, U., 2003. Microfinance in times of crisis: The effects of competition, rising indebtedness, and economic crisis on repayment behavior. World Development 31(12), 2085-2114.

Wall, L., Peterson, D., 1990. The effect of Continental Illinois' failure on the financial performance of other banks. Journal of Monetary Economics 26, 77-79.

Werner, T., Upper, C., 2002. Time variation in the tail behaviour of Bund futures returns. ECB Working Paper.

White, H., Kim, T., Manganelli, S., 2013. VAR for VaR: Measuring tail dependence using multivariate regression quantiles. ECB Working paper.

Yobas, M. B., Crook, J. N., Ross, P., 2000. Credit scoring using neural and evolutionary techniques. IMA Journal of Mathematics Applied in Business and Industry 11, 111-125.

Zhou, C., 2010. Are banks too big to fail? Measuring Systemic Importance of Financial Institutions. International Journal of Central Banking 6 (4), 205-250. 